\title{
Crustal Structure of Wanganui Basin: Implications for back-arc basin formation
}

by

Brook Tozer

A thesis

submitted to the Victoria University of Wellington

in partial fulfilment of the

requirements for the degree of

Master of Science

in Geology.

Victoria University of Wellington

2013 



\begin{abstract}
Onshore-offshore and onshore wide-angle reflection and refraction seismic data are analysed in order to constrain the crustal P-wave velocity structure within Wanganui Basin and the southern Hikurangi margin, western North Island, New Zealand. Two, two-dimensional, P-wave velocity models are constructed using reflection and refraction phase travel-times based on fortyfour onshore-offshore receiver gathers, twelve onshore shot gathers and two marine multi-channel-seismic reflection profiles collected along two transects within Wanganui Basin. The profiles are orientated both sub-parallel and perpendicular to the strike of the Hikurangi margin.
\end{abstract}

Within Wanganui Basin, a north-south increase in Moho depth is resolved sub-parallel to the strike of the Hikurangi margin from $25 \mathrm{~km}$ depth north of Mt Ruapehu to $36.5 \mathrm{~km}$ within offshore Wanganui Basin at the latitude of Foxton. This increase is punctuated by an abrupt step in Moho depth of $7 \pm 3 \mathrm{~km}$ over a lateral distance of $<30 \mathrm{~km}$ from $25 \mathrm{~km}$ to $32 \mathrm{~km}$ depth slightly south of Mt Ruapehu. Perpendicular to the strike of the Hikurangi margin, the Moho is resolved at a depth of $35.5 \mathrm{~km}$ near the southern edge of the basin. A comparison between the Moho interpreted on multi-channelseismic reflection stacks and wide-angle reflection models suggests that the wider-angle Moho represents the highest amplitude reflector in a band of reflectivity that represents the Moho on the vertical incidence reflection stack. In this case, the Moho may be an extra $\sim 5 \mathrm{~km}$ thicker than that determined in the wide-angle models. Nonetheless, these models confirm the crust in Wanganui Basin is anomalously thick, yet may be thinner than the previously thought maximum thickness of $>42 \mathrm{~km}$ by up to $5 \mathrm{~km}$ based on 
wide-angle data.

The Australian/Pacific plate interface is imaged as a relatively smooth surface at depths of 28.15 - $35.6 \mathrm{~km}$ between the latitudes of Paekakariki and Foxton with apparent dip to the north-north-east increasing from 2.3 to $9.5^{\circ}$. Perpendicular to the strike of the Hikurangi margin, this interface increases in depth from 16 - $33 \mathrm{~km}$ with an increase in dip of $5.4^{\circ}$ beneath Featherston to $19^{\circ}$ beneath central Wanganui Basin.

P-wave velocities range between $5.8-6.5 \mathrm{kms}^{-1}$ in the upper $\sim 18 \mathrm{~km}$ of the crust within Wanganui Basin. These are interpreted to represent mid and lower-crustal rocks that have been emplaced in the upper crust by exhumation during the Miocene. In the lower crust P-wave velocities are inferred as 6.5 - $6.85 \mathrm{kms}^{-1}$ sub-parallel and $6.5-6.65 \mathrm{kms}^{-1}$ perpendicular to Hikurangi margin, suggesting a lower crustal P-wave anisotropy of up to $\sim 3 \%$ This may reflect the preferential alignment of mineral fabrics in the direction of relative transpressive plate motion during the Neogene and/or structural anisotropy parallel to the strike of the Taranaki Fault Zone and Kapiti-Manawatu Fault System.

The structure of the Pacific plate crust is resolved as two layers. The top layer is inferred as a low-velocity sediment sheet with a P-wave velocity of $5.00-5.20 \mathrm{kms}^{-1}$ and thickness of $1.5-3.5 \mathrm{~km}$. The second layer is interpreted as 9.5 - $10 \mathrm{~km}$ thick oceanic crust with $\mathrm{P}$-wave velocities between 6.7 and $7.2 \mathrm{kms}^{-1}$. This confirms that anomalously thick (up to $13.5 \mathrm{~km}$ ) Hikurangi Plateau crust has subducted at least as far east as the Tararua Ranges.

Subducted sediment appears to be pooling beneath the western side of North Island between Featherston and Kapiti Island, reaching a maximum thickness of $3.5 \mathrm{~km}$. Rock uplift driven by the relative buoyancy of this material 
is capable of explaining the average elevation of the Tararua Ranges and coupled with previous studies from the Raukumara Basin in the north, suggest accretion of subducted sediment to the overlying plate may be characteristic of the entire Hikurangi margin. 


\section{Acknowledgments}

Firstly, I thank my primary supervisor Tim Stern for providing me with the opportunity and freedom to work on a project so well suited to my personal interests. Tim and Simon Lamb, my secondary supervisor, are thanked for the great advice, ideas and insightful discussion regarding the geological interpretation of this work.

I also thank Stuart Henrys for useful discussion involving the interpretation of the seismic data. Daniel Bassett, for assistance in getting up and running and advice throughout. Adrian Benson, for very useful technical assistance. Martin Reyners, for the provision of a recently relocated GeoNet earthquake catalogue.

A special thank you to Euan Smith for always having an open door and willingness to discuss any geological issue not only with myself, but the seemingly never ending stream of students that come to see you every day.

I acknowledge the contribution of the collaborating institutions and groups that made the Seismic Array Hikurangi Experiment (SAHKE) possible GNS Science, the University of Tokyo Earthquake Research Institute, the University of South California, New Zealand Petroleum and Minerals, Victoria University of Wellington, IRIS PASSCAL and the SAHKE field team. A further thank you to those involved with SAHKE that I have personally worked with - Aaron Wech, Jesse Dimech, Anya Seward and Martha Savage. 
The New Zealand Foundation for Research Science and Technology and the Japanese Science and Technology Agency funded SAHKE.

Throughout this thesis I have received scholarships and financial support from OMV limited, the Izard Trust, Victoria University and the New Zealand Government for which I am extremely grateful.

Ingo Pecher and Euan Smith are thanked for useful comments and suggestions that helped improve an earlier version of the manuscript.

Seismic analysis was conducted using GLOBE Claritas seismic processing software and figures were generated using the Generic Mapping Tools (GMT) software package of (Wessel and Smith, 1991).

Gemma Wihare is thanked for binding the final copies of this thesis.

To my great office mates - Richard Davy, Sanne Maas, Lloyd Pledger, Laura Kehrl, Christian Arenz and Kolja Schaller thanks for creating such a enjoyable working environment and especially for the table tennis battles Christian and Kolja. A further big thank you to my friends and flatmate's, Simon Davies, Danny Rood, Des, Sam Berry-Mason, Matt Jacobs, Jackson Shanks, Kolja Schaller, Richard Davy, Christian Arenz, Tom Williams, Erin Power and Brook Keats for all of the fun times away from the office. I also acknowledge Miramar Rangers AFC for their patience and support during the final months of this work.

To my fantastic parents Kevin and Jacaleen, my sister Kelly and my special nana Patrica your continued love and encouragement has been much appreciated. Lastly, to my partner Clare, I extend an extreme amount of gratitude for your patience, support and help, especially for all the delicious dinners you cooked during the later stages of this thesis - you have been wonderful. 


\section{Contents}

1 Introduction 1

1.1 Back-arc regions within a tectonic framework . . . . . . . . 1

1.2 New Zealand plate tectonic setting and Hikurangi margin backarc evolution .................... 2

1.3 Contemporary tectonic Setting of the study region - Wanganui Basin . . . . . . . . . . . . . . 10

1.3.1 Wanganui Basin extent and crustal structure . . . . . . 10

1.3.1.1 The Taranaki-Ruapehu Line . . . . . . . . . . 11

1.3.2 Wanganui Basin deformation and seismicity . . . . . . 14

1.3.3 Wanganui Basin genesis . . . . . . . . . . . 15

1.3.4 Hikurangi margin kinematics and structure . . . . . . 24

1.4 Objective of this study . . . . . . . . . . . . . . 26

1.5 Thesis outline . . . . . . . . . . . . . . . . . . 28

2 Survey geometry and methodology 31

2.1 Introduction . . . . . . . . . . . . . . . . . . 31

2.2 SAHKE Survey Geometry . . . . . . . . . . . . . . 33

2.2.1 SAHKE I . . . . . . . . . . . . . . . . . 33

2.2 .2 SAHKE II . . . . . . . . . . . . . . 35

2.3 Data . . . . . . . . . . . . . . . 36

2.4 Seismic Surveying Methodology . . . . . . . . . . . . . 37

2.4.1 Seismic wave theory . . . . . . . . . . 37 
2.4.1.1 Onshore-Offshore seismic surveying methodology . . . . . . . . . . . . . . 39

2.4.1.2 Common receiver gather methodology . . . . 41

2.4.1.3 Receiver gather display: reduced travel-time . 44

2.5 Data processing . . . . . . . . . . . . . . . . . 46

2.6 Receiver gather interpretation and uncertainty . . . . . . . . 46

2.7 Data observations . . . . . . . . . . . . . . . . . . . . 47

2.7.1 SAHKE03 receiver gather observations . . . . . . . 48

2.7.1.1 Southern group . . . . . . . . . . . . . 48

2.7.1.2 Central group . . . . . . . . . . . . . 54

2.7.1.3 Northern group . . . . . . . . . . . . . 57

2.7.2 SAHKE02 observations . . . . . . . . . . . . . 59

2.7.3 SAHKE II observations . . . . . . . . . . . . . . . 67

3 Velocity Modelling technique $\quad 71$

3.1 Introduction . . . . . . . . . . . . . . . . . . 71

3.2 Two dimensional velocity modelling methods . . . . . . . . . . 72

3.3 Choosing a modelling technique . . . . . . . . . . . . . . 72

3.4 Adopted modelling technique used in this study . . . . . . . . 73

3.5 Two-dimensional modelling assumptions . . . . . . . . . . . . 74

3.6 Forward Modelling Strategy . . . . . . . . . . . . . . . . . 76

3.7 Pre-modelling considerations . . . . . . . . . . 76

3.7.1 Model Line Assessment . . . . . . . . . . . . . . . . 76

3.7 .2 Near surface low velocity zone . . . . . . . . . . . 78

3.8 Modelling . . . . . . . . . . . . . . . . . . . . . . . . 80

3.9 Model assessment . . . . . . . . . . . . . . . . . . . . 81

3.9 .1 Errors . . . . . . . . . . . . . . 82

4 Two Dimensional Modelling of Crustal Velocity Structure: SAHKE03 $\quad 85$

4.1 Introduction . . . . . . . . . . . . . . . . . . 85

4.2 Pre-modelling Constraints . . . . . . . . . . . . . . . 86 
4.2.1 Constraining near surface layers . . . . . . . . . 86

4.2.1.1 Bathymetry . . . . . . . . . . 86

4.2.1.2 Sedimentary section . . . . . . . . . 86

4.2.1.3 Kapiti Island static correction . . . . . . . . . 94

4.2.2 Crustal structure constraints . . . . . . . . . . . . . . 94

4.2.2.1 Plate Interface . . . . . . . . . . . . . . 96

4.2.2.2 Australian plate Moho . . . . . . . . . . . 96

4.2.2.3 Crustal and upper most mantle velocity structure .................... 97

4.3 Modelling results . . . . . . . . . . . . . . . . . . . . 101

4.3.1 Australian plate velocity structure . . . . . . . . . . 104

4.3.2 Moho structure . . . . . . . . . . . . . . . . 105

4.3.3 Plate interface structure . . . . . . . . . . . . . 105

4.3.4 Subducting oceanic crust structure . . . . . . . . . . 106

4.4 Model Assessment . . . . . . . . . . . . . . . . . . . . . . . . . 106

4.4.1 Travel-time fit and ray coverage . . . . . . . . . 107

4.4 .2 Problematic arrivals . . . . . . . . . . . . . 110

4.4.3 Resolution testing . . . . . . . . . . . . . . 110

4.5 Comparison to multi-channel-seismic data . . . . . . . . . . . 121

5 Two Dimensional Modelling of Crustal Velocity Structure: $\begin{array}{ll}\text { SAHKE02 } & 127\end{array}$

5.1 Introduction . . . . . . . . . . . . . . . . . . . . 127

5.2 Pre-modelling Constraints . . . . . . . . . . . . . . . . . . 128

5.2.1 SAHKE02-M sedimentary section . . . . . . . . . 128

5.2 .2 SAHKE II refraction modelling . . . . . . . . . . . . . 129

5.2.2.1 SAHKE II modelling limitations . . . . . . . 130

5.2.2.2 SAHKE II modelling results . . . . . . . . . . 131

5.2.3 Crustal structure constraints . . . . . . . . . . . . . . 134

5.2.3.1 Plate interface . . . . . . . . . . . . . 135

5.2.3.2 Subducting oceanic plate structure . . . . . 136

5.2.3.3 Australian plate Moho . . . . . . . . . . . . 138 
5.2.3.4 Crustal P-wave velocity structure . . . . . . 138

5.3 Modelling results . . . . . . . . . . . . . . . . . . . . . . 139

5.3.1 SAHKE02 Australian plate velocity structure . . . . 144

5.3.2 Plate interface structure . . . . . . . . . . . . 145

5.3.3 Subducting oceanic crust structure . . . . . . . . . 147

5.3.4 Moho structure . . . . . . . . . . . . . . . 147

5.4 Model Assessment . . . . . . . . . . . . . . . . . . . . . . . . . 148

5.4.1 Travel-time fit and ray coverage . . . . . . . . . . 148

5.4 .2 Problematic arrivals . . . . . . . . . . . . 153

5.4 .3 Resolution testing . . . . . . . . . . . . . . . 153

5.5 Comparison to multi-channel-seismic data . . . . . . . . . . 158

6 Synthesis 161

6.1 Introduction . . . . . . . . . . . . . . . . . . 161

6.2 Australian plate Moho structure . . . . . . . . . . . . . . . 161

6.3 Australian plate velocity structure . . . . . . . . . . . . . 166

6.4 Upper crust . . . . . . . . . . . . . . . . . . . . 166

6.5 Lower crust . . . . . . . . . . . . . . . . . . . . . . . . 168

6.6 Interpretation of High Vp values . . . . . . . . . . . . . . . . 169

6.7 Plate interface structure . . . . . . . . . . . . . . . . . 171

6.8 Pacific plate velocity structure . . . . . . . . . . . . . . . . 174

6.9 Taranaki-Ruapehu Line . . . . . . . . . . . . . . . . . . 175

6.9.1 Interpretation of seismic phase arrivals . . . . . . 176

6.9.2 Seismicity related to the Taranaki-Ruapehu Line . . . . 181

6.9.3 Geological evolution of the Taranaki-Ruapehu Line . . 183

6.10 Comparison of $\mathrm{P}$-wave velocity models and earthquake catalogues . . . . . . . . . . . . . . . 186

6.11 Application of Vp model for elastic dislocation modelling of continuous GPS data . . . . . . . . . . . . . . . . . 191

6.12 Conclusions . . . . . . . . . . . . . . . . . . . 193

6.13 Future research . . . . . . . . . . . . . . . . . 195 
A Survey parameters and data processing

A.1 Introduction . . . . . . . . . . . . . . . . . . . . . . . 219

A.2 Data . . . . . . . . . . . . . . . . 220

A.2.1 Multi-channel-seismic acquisition parameters . . . . . . 221

A.2.2 TRANSECT deployment . . . . . . . . . . . . . . . 224

A.2.2.1 Short period array . . . . . . . . . . . 225

A.2.3 WANGANUI deployment . . . . . . . . . . . . 225

A.2.4 GeoNet deployment . . . . . . . . . . . . . . 226

A.2.5 SAHKE II borehole shot sources . . . . . . . . . . . . 226

A.2.6 SAHKE II deployment . . . . . . . . . . . . . . . . . . 227

A.3 Instrumentation and data extraction . . . . . . . . . . . . 234

A.3.1 L28 sensors - Sercal L28-3D . . . . . . . . . . . . . . 234

A.3.2 L4 sensors - Sercal L4C-3D . . . . . . . . . . . . . . . 234

A.3.3 CMG sensors - Guralp CMG-3ESP . . . . . . . . . . 235

A.3.4 SNZO sensor - Geotech KS-54000 . . . . . . . . . . . 235

A.3.5 Reftek-130 data logger . . . . . . . . . . . . . . 236

A.4 Receiver gather preparation . . . . . . . . . . . . . 236

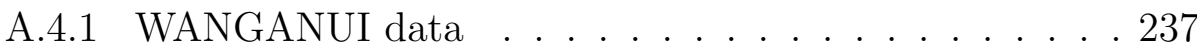

A.4.2 GeoNet data. . . . . . . . . . . . . . . 238

A.4.3 Global Seismographic Network data . . . . . . . . . . . 238

A.4.4 Constructing receiver gathers . . . . . . . . . . . 238

A.4.5 Geometry . . . . . . . . . . . . . . . . . 240

A.4.6 SAHKE II shot gather data . . . . . . . . . . . . 240

A.5 Sesimic processing . . . . . . . . . . . . . . . . . . 240

A.5.1 Debias ...................... . . 241

A.5.2 Trace balance . . . . . . . . . . . . . . . . . 241

A.5.3 Frequency filtering . . . . . . . . . . . . . . . . 241

A.5.4 Automatic gain control . . . . . . . . . . . . . 242

A.5.5 Linear moveout . . . . . . . . . . . . . . . . . 242

A.5.6 Runmix trace summing . . . . . . . . . . . . . . 242 
A.5.7 Predictive deconvolution . . . . . . . . . . . . 243

A.5.8 Visual display . . . . . . . . . . . . . . . . . . . . . 244

A.6 Interpretation . . . . . . . . . . . . . . . . . . . 244

A.7 Summary . . . . . . . . . . . . . . . . . . . . 245

A.8 Receiver and shot gather interpretations . . . . . . . . . 246

B Multi-channel-seismic shot gathers $\quad 249$

C Kapiti Island Static Correction $\quad 269$

C.1 Introduction . . . . . . . . . . . . . . . . . . . . . . . . 269

C.2 Static correction assumptions . . . . . . . . . . . . . . 270

C.2.1 Geometric ray theory . . . . . . . . . . . . . . . 270

C.2.2 Ray incidence angle . . . . . . . . . . . . . . . . . 270

C.2.3 Kapiti Island static correction . . . . . . . . . . . . 271

C.3 Correction strategy . . . . . . . . . . . . . . . . . . . . 272

C.3.1 Forward model of KIW . . . . . . . . . . . . . . . 272

C.3.2 Elevation traveltime correction . . . . . . . . . . 273

C.3.3 Medium velocity traveltime correction . . . . . . . . 274

C.3.4 Application of corrections . . . . . . . . . . 276 


\section{List of Figures}

1.1 Contemporary tectonic configuration of the New Zealand subcontinent . . . . . . . . . . . . . . 3

1.2 Tectonic evolution of New Zealand since $40 \mathrm{Ma}$. . . . . . . 5

1.3 Tectonic configuration of North Island, New Zealand . . . . . 7

1.4 Schematic cross section of western North Island . . . . . . . . 9

1.5 Onshore geology of western North Island, New Zealand . . . . 12

1.6 Map showing the basement terranes of New Zealand . . . . . . 13

1.7 Wanganui Basin seismicity . . . . . . . . . . . . . . . . 16

1.8 Isostatic/free-air gravity anomaly of North Island . . . . . . . 17

1.9 Schematic illustration of plate interface coupling . . . . . . . . 18

1.10 Cartoon illustrating the principles of a Rayleigh-Taylor instability . . . . . . . . . . . . . . . 21

1.11 Isostatic/free-air gravity anomaly of North Island . . . . . . . 24

1.12 Interseismic plate coupling of the Hikurangi Margin . . . . . . 27

2.1 Survey geometry of SAHKE I . . . . . . . . . . . . . . . . 34

2.2 Survey geometry of SAHKE II . . . . . . . . . . . . . . . 36

2.3 Snell's Law . . . . . . . . . . . . . . . . . . . 38

2.4 Explanation of the onshore-offshore surveying technique . . . . 40

2.5 Example receiver gather from station KIW . . . . . . . . . . . 43

2.6 Comparison between shot gathers and receiver gathers . . . . 44

2.7 Construction of a receiver gather . . . . . . . . . . . . . 45

2.8 Interpreted receiver gather from SAHKE03 station SNZO . . . 50 
2.9 Wide-angle reflections recorded at SAHKE03 receiver gather

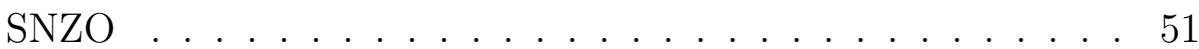

2.10 Interpreted receiver gather from SAHKE03 station KIW . . . 52

2.11 Wide-angle reflections recorded at SAHKE03 receiver gather KIW . . . . . . . . . . . . . . . 53

2.12 Interpreted receiver gather from SAHKE03 station S-RAE . . 55

2.13 Interpreted receiver gather from SAHKE03 station S-CUF . . 56

2.14 Interpreted receiver gather from SAHKE03 station TWVZ . . 58

2.15 Interpreted receiver gather from SAHKE02 station TS030 . . . 62

2.16 Interpreted receiver gather from SAHKE02 station TS013 . . . 63

2.17 Interpreted receiver gather from SAHKE02 station TS011 . . . 64

2.18 Interpreted receiver gather from SAHKE02 station TS007 . . . 65

2.19 Interpreted receiver gather from SAHKE02 station TS002 . . . 66

2.20 Interpreted shot gather from SAHKE II - shot12 . . . . . . . 68

2.21 Interpreted shot gather from SAHKE II - shot07 . . . . . . . . 69

2.22 Interpreted shot gather from SAHKE II - shot01 . . . . . . . 70

3.1 Wanganui Basin Moho wavelength . . . . . . . . . . . . 75

3.2 Schematic illustration of model coordinate construction . . . . 78

3.3 Description of the effect of near surface velocity errors . . . . . 80

4.1 Map depicting the geometry of the SAHKE03-M model . . . . 88

4.2 Depth conversion of the SAHKE03 multi-channel-seismic reflection line . . . . . . . . . . . . . . . . 89

4.3 P-wave velocity model for the SAHKE03 multi-channel-seismic reflection profile . . . . . . . . . . . . . . 90

4.4 Map displaying constraints on the thickness of sedimentary fill within Wanganui Basin . . . . . . . . . . . . . 93

4.5 Map displaying constraints on crustal structure within Wanganui Basin . . . . . . . . . . . . . . . . . . 95

4.6 Receiver function interpretation at station KIW from Ewig (2009) . . . . . . . . . . . . . . . 97 
4.7 Seismic reflection profile through the Taranaki and Wanganui Basins from Stern and Davey (1990) _ . . . . . . . . . . 98

4.8 Central conversion point receiver function stack from Salmon et al. (2011) . . . . . . . . . . . . . . . . . . . 99

4.9 P-wave velocity slice from Eberhart-Phillips et al. (2010) tomographic model coincident to the SAHKE03-M transect . . . 100

4.10 SAHKE03-M P-wave velocity model . . . . . . . . . . . . . . . 102

4.11 SAHKE03-M ray density and RMS travel-time fit . . . . . . . 109

4.12 SAHKE03-M Moho depth resolution test south of the TR-Line 112

4.13 SAHKE03-M Moho depth resolution test north of the TR-Line 114

4.14 Horizontal resolution test of the TR-Line Moho step . . . . . . 115

4.15 Plate interface depth resolution test . . . . . . . . . . . . . 116

4.16 Low velocity layer resolution test . . . . . . . . . . . . . . . 119

4.17 Oceanic crust resolution test . . . . . . . . . . . . . . . . . 120

4.18 Comparison between the Moho defined by reflections/refractions 122

4.19 SAHKE03 MCS multi-channel-seismic shot gather . . . . . . . 124

4.20 SAHKE03 multi-channel-seismic brute stack . . . . . . . . . . 125

4.21 SAHKE03 brute stack Moho reflectivity . . . . . . . . . . . 126

5.1 SAHKE02-M model geometry . . . . . . . . . . . . . . . 128

5.2 SAHKE II onshore refraction model . . . . . . . . . . . . . . 132

5.3 SAHKE II onshore refraction model travel-time fit . . . . . . . 133

5.4 SAHKE02-M model constraining datasets . . . . . . . . . . 136

5.5 Microseismicity on the SAHKE02-M transect . . . . . . . . . 137

5.6 P-wave velocity slice from Eberhart-Phillips et al. (2010) tomographic model coincident to the SAHKE02-M transect . . . 138

5.7 SAHKE02-M P-wave velocity model . . . . . . . . . . . . . . . 140

5.8 SAHKE02-M PiP ray paths . . . . . . . . . . . . . . . . . 146

5.9 SAHKE02-M ray density and RMS travel-time fit . . . . . . . 150

5.10 SAHKE02-M low velocity layer resolution test . . . . . . . . . 155

5.11 SAHKE02-M oceanic crust Vp resolution test . . . . . . . . . 157

5.12 SAHKE02 brute stack . . . . . . . . . . . . . . . . 159 
6.1 SAHKE03-M P-wave velocity model interpretation . . . . . . 164

6.2 SAHKE02-M P-wave velocity model interpretation . . . . . . 165

6.3 SAHKE02-M accreted sediment body forces . . . . . . . . . . 174

6.4 Station S-KAI amplitude analysis . . . . . . . . . . . . . . 177

6.5 Station TWVZ amplitude analysis . . . . . . . . . . . . . . 178

6.6 Cartoon illustrating diffractions from an edge . . . . . . . . . 180

6.7 Calculated travel-times for a diffraction from an edge . . . . . 181

6.8 Yield strength envelopes for different strain rates . . . . . . . 183

6.9 SAHKE02-M earthquake hypocenter correlation . . . . . . . . 188

6.10 SAHKE03-M earthquake hypocenter correlation . . . . . . . . 189

A.1 SAHKE I onshore/offshore survey geometry . . . . . . . . . . 222

A.2 SAHKE II onshore survey geometry . . . . . . . . . . . . . 223

A.3 Data processing flowchart . . . . . . . . . . . . . 246

B.1 SAHKE03 Shot gathers . . . . . . . . . . . . . . 250

C.1 Snell's Law . . . . . . . . . . . . . . . . . . . 270

C.2 KIW refraction model . . . . . . . . . . . . . . . 273 


\section{List of Tables}

4.1 SAHKE03 multi-channel-seismic reflection velocity model traveltime fit . . . . . . . . . . . . . . . . 91

4.2 Wanganui Basin exploration well locations . . . . . . . . . . 92

4.3 Previous P-wave velocity studies from Wanganui Basin and southern Hikurangi margin . . . . . . . . . . . . . . . . 100

4.4 SAHKE03-M model travel-time fit . . . . . . . . . . . . . . . . 108

4.5 SAHKE03-M Moho depth resolution test parameterisation south of the TR-Line . . . . . . . . . . . . . . . . . . 111

4.6 SAHKE03-M Moho depth resolution test parameterisation north of the TR-line . . . . . . . . . . . . . . . . . . 113

4.7 Horizontal resolution test of the TR-Line Moho step . . . . . . 115

4.8 SAHKE03-M plate interface resolution test parameterisation . 115

4.9 SAHKE03-M low velocity layer resolution test parameterisation118

4.10 SAHKE03-M Pacific plate crust resolution test parameterisation 121

5.1 SAHKEII model travel-time fit . . . . . . . . . . . . . . . 134

5.2 SAHKE02-M model travel-time fit . . . . . . . . . . . . . . 152

5.3 SAHKE02-M low velocity layer resolution test parameteristation154

5.4 SAHKE02-M Pacific plate crust resolution test parameteristation . . . . . . . . . . . . . . 156

5.5 SAHKE02-M Australian plate Moho depth resolution test results 158 
A.1 Acquisition parameters used during the multi-channel-seismic SAHKE survey . . . . . . . . . . . . . . . . . . . . . 224

A.2 TRANSECT Deployment station details . . . . . . . . . . 230

A.3 WANGANUI Deployment station details . . . . . . . . . . 231

A.4 GeoNet station details . . . . . . . . . . . . . . . . . . . . . . 232

A.5 SAHKE II onshore shot summary . . . . . . . . . . . . . . . . 233

A.6 DAS.list text file example . . . . . . . . . . . . . . . . . . 237

A.7 GSN batch request form example . . . . . . . . . . . . . . . 239 


\section{Chapter 1}

\section{Introduction}

\subsection{Back-arc regions within a tectonic frame- work}

Amongst the terrestrial planets, only Earth possesses an active plate tectonic system (Stern, 2002). Plate tectonics is responsible for the creation of the continents and ocean basins and also plays a fundamental role in the climate cycle through the development and destruction of topography and recycling of carbon (Marty and Tolstikhin, 1998). Subduction zones are the most extensive and pervasive features of the plate tectonic system and are where sediments, oceanic crust, and mantle lithosphere, in the form of subducting slabs, return to and reequilibrate with the mantle (Stern, 2002). Sinking of dense oceanic lithosphere at subduction margins is a consequence of their negative buoyancy and is thought to provide most of the force required to drive plate tectonics (Forsyth and Uyeda, 1975; Davies and Richards, 1992). As a slab subducts, it is dehydrated and fluids are released into the crust and mantle wedge of the overlying plate. In the mantle wedge, partial melts may develop, rise to the surface and erupt. In mature subduction zones known as arc-trench complexes (Stern, 2002), this process produces a linear chain of volcanoes known as a magmatic arc. The area trench-ward of the magmatic 
1. Introduction

arc is termed the forearc, while the area behind the magmatic arc is termed the back-arc. This terminology is also adopted for margins were a magmatic arc is absent.

Observations of the back-arc regions of subduction zones have shown the stress state in the overlying plate varies between two end member regimes. These are the highly extensional "Mariana-type" and highly compressional "Chilean-type" subduction zones, with some zones exhibiting little or no tectonic or magmatic activity (Uyeda and Kanamori, 1979; Jarrard, 1986). The development of a particular style of back-arc tectonics must be controlled by the forces at the plate margin (Lamb, 2006), which will be a function of the buoyancy contrast between the plates - i.e. gravitational forces due to the crustal and lithospheric density structure - and the stresses on the plate interface (controlled by rheology, temperature and pressure). These in turn may be related to many factors such as plate convergence rate, slab age, slab dip, plate interface lithology (i.e. crust, mantle or underplated sediments) and lithospheric removal (Uyeda and Kanamori, 1979; Whittaker et al., 1992; Bott et al., 1991; Scholz and Campos, 1995; Stern et al., 2006). It is therefore clear that determination of the detailed crustal and lithospheric structure within back-arc basins is fundamental for improving our understanding of how and why particular back-arc tectonic styles develop and how this relates to geodynamic plate tectonic and continental tectonic processes.

\subsection{New Zealand plate tectonic setting and Hikurangi margin back-arc evolution}

The New Zealand subcontinent straddles the Pacific-Australian plate boundary (Fig. 1.1). Oblique convergence between these plates, in addition to changes in their crustal structure, gives rise to a reversal in the polarity of subduction along their boundary (Sutherland et al., 2000). Oceanic Pacific plate lithosphere subducts westward beneath continental Australian plate 
1.2. New Zealand plate tectonic setting and Hikurangi margin back-arc evolution

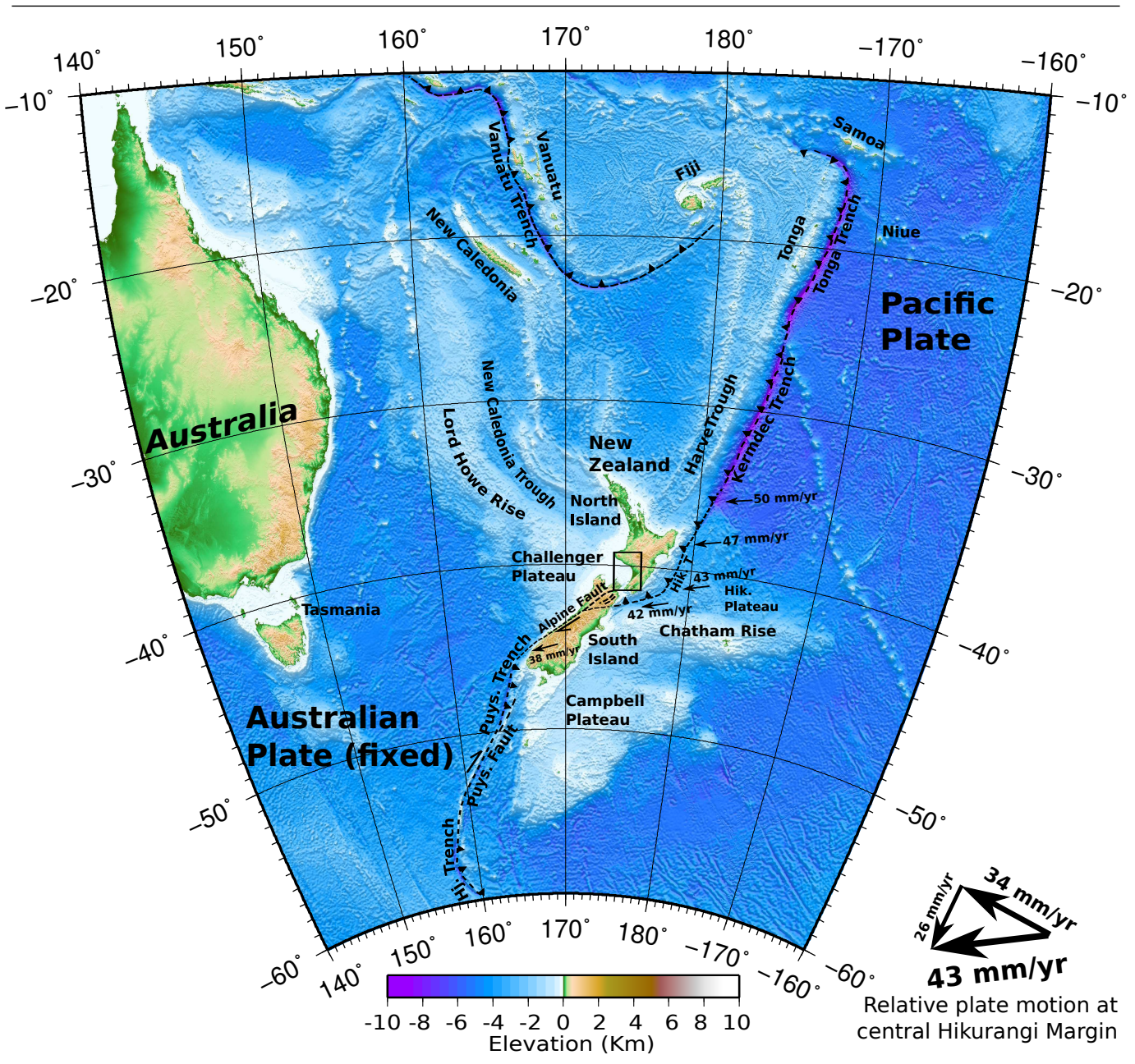

Figure 1.1: Regional elevation map of the New Zealand subcontinent and surrounding areas, displaying the major tectonic boundaries and features. Black vectors indicate the relative motion of the Pacific Plate with respect to the fixed Australian Plate (after, Beavan et al., (2002). The black rectangle illustrates the study area of this thesis, Wanganui Basin, New Zealand. Note the elevated bathymetry of the buoyant Hikurangi Plateau adjacent to the Hikurangi Margin. Hik. T = Hikurangi Trench, Hik. Plateau = Hikurangi Plateau, Puys. Trench $=$ Puysegur Trench, $\mathbf{H j}$. Trench $=$ Hjort Trench.

lithosphere within the Hikurangi Trench east of North Island. Along this margin the rate of relative plate convergence decreases southwards from $\sim$ $47 \mathrm{~mm} \mathrm{yr}^{-1}$ to $42 \mathrm{~mm} \mathrm{yr}^{-1}$ at an increasingly oblique angle of $\sim 50^{\circ}$ to the trend of the margin (Beavan, 2002; Nicol et al., 2007).

In contrast, south-west of South Island oceanic Australian plate lithosphere 
is subducting beneath continental Pacific plate along the Puysegur Trench at a relative rate of $38 \mathrm{~mm} \mathrm{yr}^{-1}$ (Fig. 1.1; Beavan, 2002). Connecting the oceanic-continental subduction zones to the north and south is the $\sim 800 \mathrm{~km}$ long Alpine Fault. This fault spans almost the entire length of South Island and represents the crustal expression of dextral transcurrent continental collision between the two plates (Walcott, 1998; Sutherland et al., 2000). The northern termination of subduction within the Hikurangi margin coincides with the increase in thickness of the Chatham Rise, while the beginning of subduction in the Puysegur trench coincides with a decrease in thickness of the Challenger Plateau (Fig. 1.1).

Figure 1.2 illustrates the tectonic evolution of the New Zealand subcontinent through the last $40 \mathrm{Ma}$ (after King, 2000). The inception of the AustralianPacific plate boundary occurred at $\sim 43 \mathrm{Ma}$ with the initiation of sea floor spreading in the Emerald Basin south of present day South Island (Weissel et al., 1977; Sutherland, 1995; King, 2000). At this time, subduction was also occurring north of New Zealand near Norfolk Ridge (King, 2000). However, structural, stratigraphic and volcanic evidence suggest that it was not until 25 - 20 Ma that subduction within the Hikurangi margin began (Lamb and Bibby, 1989; Rait et al., 1991; Issac et al., 1994). This is consistent with a rapid change from transcurrent to obliquely convergent motion suggested by southward migration of Australian/Pacific rotation pole positions during this time (Smith, 1981; Stock and Molnar, 1982; King, 2000).

Between subduction initiation and present day, plate motions require up to $90^{\circ}$ of clockwise rotation of the Hikurangi margin relative to both the Kermadec arc north of New Zealand and the Australian plate, at an average rate of $4.5^{\circ} \mathrm{Myr}^{-1}$. This is consistent with paleomagnetic data (Walcott et al., 1981; Walcott and Mumme, 1982; Mumme and Walcott, 1985; Lamb, 2011), which suggests the rotation rate has increased through time, with a rate of $\sim 6^{\circ} \mathrm{Myr}^{-1}$ estimated for the last $5 \mathrm{Ma}$. As a consequence of this 
1.2. New Zealand plate tectonic setting and Hikurangi margin back-arc evolution

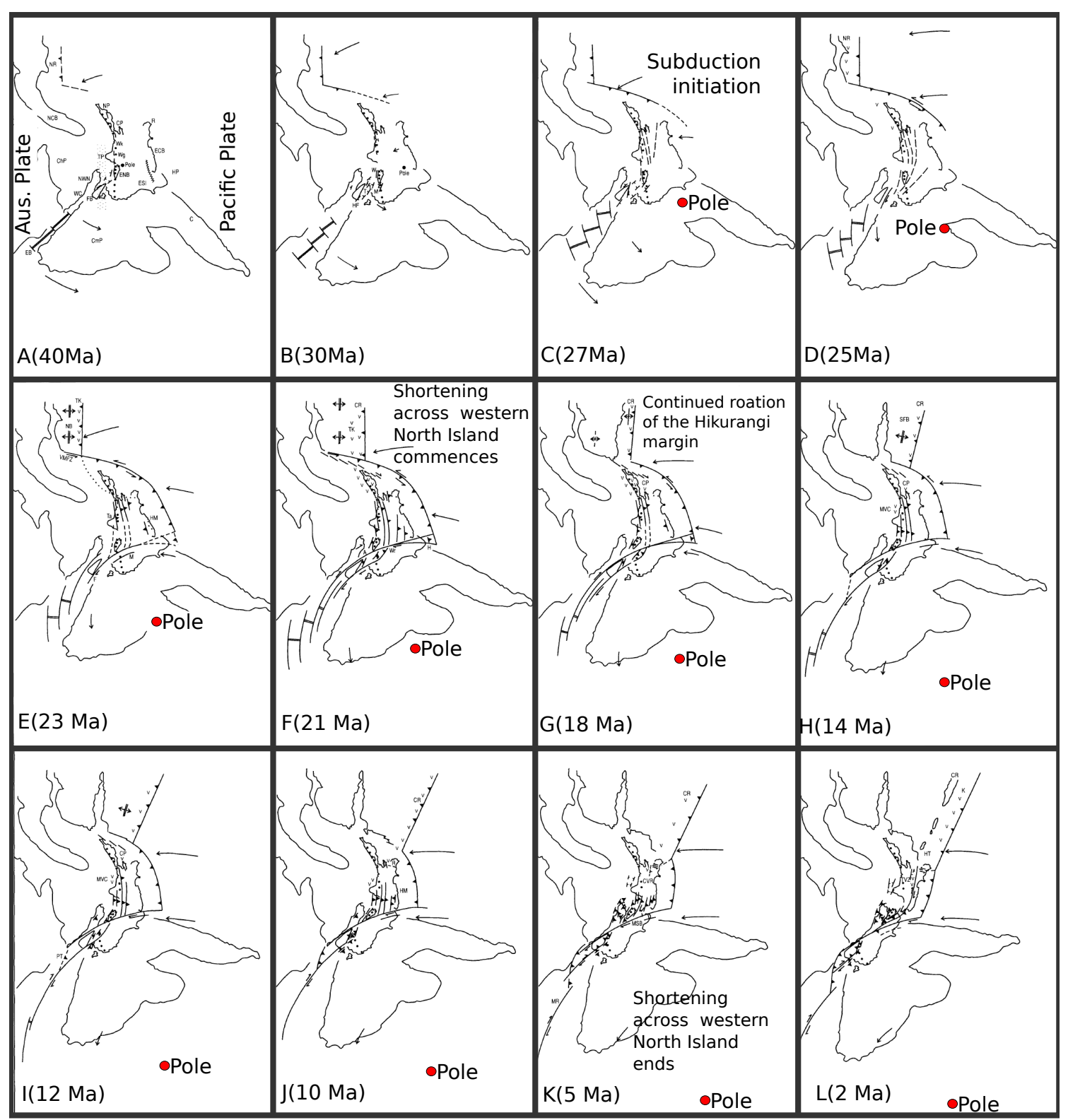

Figure 1.2: Tectonic evolution of the New Zealand subcontinent over the last 40 Ma as discussed in text (after King, 2000).

rotation, the southern end of the Hikurangi margin has migrated from near the Coromandel Peninsula to its present location near Kaikoura (Fig. 1.2). This observation is corroborated by the south and eastward migration of low- 
potash andesite volcanism during the last $20 \mathrm{Ma}$, that is interpreted to be sourced from the 70 - $100 \mathrm{~km}$ isobath of the subducting plate, hence providing a proxy of subduction zone geometry (Hatherton, 1969).

An important implication of New Zealand plate boundary reconstructions, in the context of the Hikurangi margin back-arc, is the large amount of shortening required through central North Island during the Miocene (Fig 1.2). It is thought that this shortening was accommodated in part by "thick-skinned" thrusting within the Taranaki Fault Zone. This resulted in the development of the Taranaki Basin, a $200 \mathrm{~km}$ wide $\sim 4 \mathrm{~km}$ deep foreland basin west of the fault zone (Fig 1.3; Stern and Davey, 1990; King and Thrasher, 1992; Holt and Stern, 1994). A deep seismic reflection profile shows that loading from these thrust sheets induced crustal flexure in this area with the crust thickening from $27 \mathrm{~km}$ to $>40 \mathrm{~km}$ east to west within the basin (Stern and Davey, 1990). The differential thickening of the sediment fill $(4 \mathrm{~km})$ and the crust $(>10 \mathrm{~km})$ is interpreted by Holt and Stern (1994) to indicate ductile flow of the lower crust and mantle lithosphere. In this case, shortening was accommodated by thrusting, flexure, ductile flow uplift and erosion. Following this interpretation, Stern et al. (2006) estimate $70 \pm 30 \mathrm{~km}$ of shortening occurred in this area during the Miocene.

At $\sim 5$ Ma thrusting on the Taranaki fault zone ceased and the locus of compression shifted to a fold-thrust belt in the southwest (King and Thrasher, 1996; King, 2000). Extension on north-east trending normal faults in the northern offshore area of Taranaki Basin and the Otunui Basin (Fig 1.3; formerly known as North Wanganui Basin) commenced at this time. Hence creating a reversal from extension in the north to compression in the south consistent with the ongoing clockwise rotation of the Hikurangi margin (Walcott, 1987; King, 2000).

During the Plio-Pleistocene, active back-arc spreading commenced behind 
1.2. New Zealand plate tectonic setting and Hikurangi margin back-arc evolution

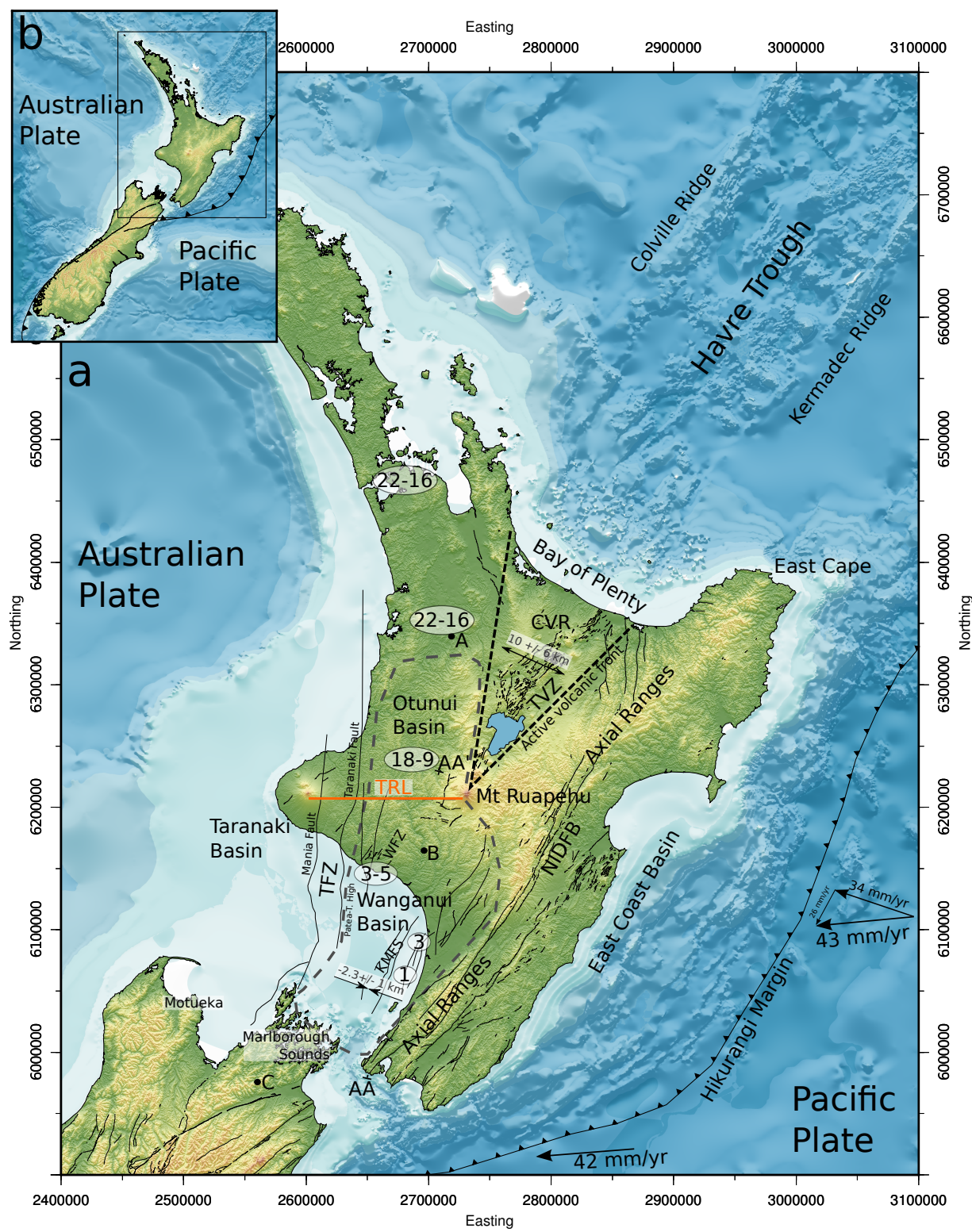

Figure 1.3: a) Region tectonic setting of North Island, New Zealand. Black vectors represent relative plate convergence of Pacific plate with respect to the Australian Plate (after, Beavan et al., 2002) Black arrows indicate Pliocene shortening (inwardly directed) and extension (outwardly directed) (after, Nicol et al., 2007). Circled numbers represent the age and location of basin depocentres in western North Island. $\mathbf{C V R}=$ Central Volcanic Region, $\mathbf{T V Z}=$ Taupo Volcanic Zone, TFZ $=$ Taranaki Fault Zone, KMFS = Kapiti-Manawatu Fault System (after Lamarche et al., 2005) WFZ = Waverley Fault Zone (after Townsend, 1998). b) Inset map showing the location of (a). 
the Tonga and Kermadec trenches North of North Island resulting in the opening of Havre Trough with 80 - $100 \mathrm{~km}$ of back arc extension (Stern, 1985, 1987; Wright, 1993, 1994). Extremely high heat output of $\sim 4 G W$, or an equivalent effective heat flow of $\sim 700-800 \mathrm{~mW} / \mathrm{m}^{2}$, and lithospheric thinning within the Central Volcanic Region (CVR) located immediately to the south (Fig 1.3), suggests this back-arc extensional regime has propagated southward into the back-arc region of the Hikurangi margin, resulting in back-arc extension of continental lithosphere (Karig, 1970; Stern, 1985). Further to the south, geological and geodetic measurements (e.g. Walcott, 1987; Wallace and Beavan, 2004; Nicol et al., 2007) show a rapid switch from classical back-arc extension within the CVR, to mild compression within Wanganui Basin occurs around the latitude of Mt Ruapehu (Fig. 1.3).

Overprinted upon the horizontal strain regimes of the CVR and Wanganui Basin are vertical motions that are intuitively paradoxical. In the central North Island, mudstone porosity analysis shows that $2.5 \mathrm{~km}$ of rock uplift, with a wavelength of $\sim 350$ - $400 \mathrm{~km}$, has occurred over the last $5 \mathrm{Ma}$, despite the overall extensional tectonic regime (Fig. 1.4; Pulford and Stern, 2004). This uplift predates the development of the TVZ by $\sim 3 \mathrm{Ma}$, an important observation given the occurrence of uplift in back-arc settings usually follows rifting and volcanism (Stern et al., 2010). In contrast, the offshore portion of Wanganui Basin, an area that has undergone compression, has been subject to $\sim 4 \mathrm{~km}$ of subsidence over the last 4 Ma (Hunt, 1980; Anderton, 1981; Proust et al., 2005; Lamarche et al., 2005). At the southern termination of this basin, Craw and Waters (2007) inferred that a reversal from uplift to subsidence occurred between 100 - 200 ka based on the timing of catchment drainage inversion. While sea level proxies within sediment cores suggest that $\sim 0.7-0.8 \mathrm{~m} / \mathrm{ka}^{-1}$ of tectonic subsidence, unrelated to discrete faulting events, has occurred over the last $6-7 \mathrm{ka}$.

These differential vertical motions are traceable through the sedimentary record of western North Island, recorded as the southward migration of basin 
1.2. New Zealand plate tectonic setting and Hikurangi margin back-arc evolution

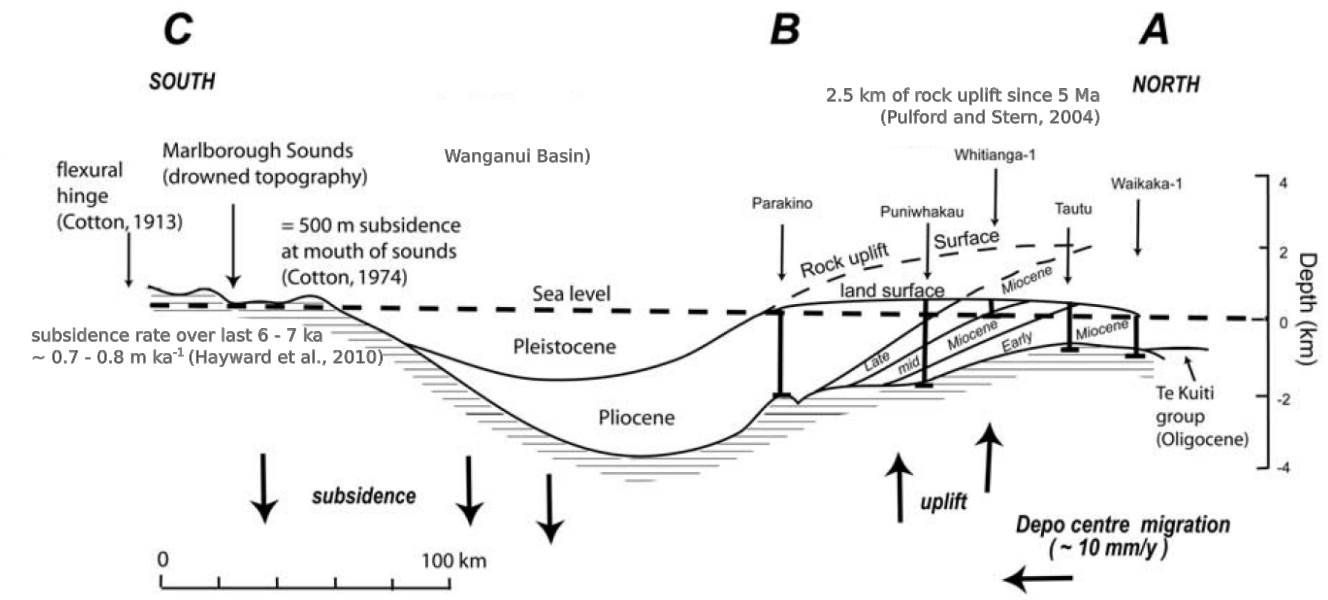

Figure 1.4: Schematic illustration showing the contrasting vertical motions of the sedimentary sequence of western North Island in space and time. The dashed black line represents a pre-erosion surface. Note the subsidence in the south and uplift in the north. locations A B C are shown on figure 1.3 (after, Stern et al., 1992).

depocentres through time (Fig 1.3; Anderton, 1981; Stern et al., 1992).

Bzased on these vertical motions in time and space, western North Island has been described as a "geological standing wave", with a wavelength of 300 km (Fig. 1.4; after Stern et al., 1992).

These relationships between extension/compression and uplift/subsidence are the opposite to which would be predicted from standard Airy isostatic compensation, and suggest a strong mantle involvement in the development of dynamic topography. Overall, in the back-arc environment of the Hikurangi Margin, it is obvious that lithospheric deformation is affected by several processes that are yet to be fully understood. It is clear however that these are affiliated with the evolution of subduction emplacement and the resulting deformation of the overriding plate's mantle lithosphere.

Hence, North Island provides a rare opportunity to study manifestations of back-arc processes in continental lithosphere where (a) subduction emplacement has occurred in recent geological time $(<25 \mathrm{Ma})$ (b) a reversal from "Mariana-type" back-arc extension to more "Chilean-type" back-arc 
1. Introduction

compression occurs over a small distance and (c) where the style of the backarc tectonics is currently evolving and is possibly driven by processes outside the paradigm of oceanic plate tectonics.

\subsection{Contemporary tectonic Setting of the study region - Wanganui Basin}

\subsubsection{Wanganui Basin extent and crustal structure}

Wanganui Basin is located on the western side of North Island, south of Mt Ruapehu and $\sim 200 \mathrm{~km}$ landward of the Hikurangi Margin subduction front (Fig. 1.3). In the past, Wanganui Basin has been subdivided into North Wanganui Basin and South Wanganui Basin, separated by stratigraphic and geophysical changes across the east-west trending Taranaki-Ruapehu Line (Fig. 1.3). Given the changes observed across this boundary, North Wanganui Basin has recently been amalgamated as part of the King Country Basin, with the section immediately north of the Taranaki-Ruapehu Line known as Otunui Basin (e.g. Kamp et al., 2002). For the remainder of this thesis Wanganui Basin refers to the Basin formerly named South Wanganui Basin.

Wanganui Basin, which began forming at $\sim 4 \mathrm{Ma}$, is rapidly subsiding at an average rate of $\sim 1 \mathrm{~km} / \mathrm{Myr}$ and is infilled by $\sim 4 \mathrm{~km}$ of mainly shallow marine Plio-Pleistocene sediments (Fig. 1.5; Hunt, 1980; Anderton, 1981; Carter and Naish, 1998; Proust et al., 2005). Oligocene sediments outcrop in small faulted outliers in the Marlborough Sounds and north of Wellington, and are the remnants of extensive Oligocene sediment cover that predates basin inception (Anderton, 1981).

The basin is elongated with a SSW-NNE trend and is bounded on its eastern and western sides by elevated Paleozoic-Mesozoic basement blocks. In the 
east, sediments onlap the Axial Ranges of North Island that have been uplifting over the last $2 \mathrm{Ma}$ and are associated with the North Island Dextral Fault Belt (NIDFB; Lamb and Vella, 1987; Katz and Leask, 1990; Wilson and McGuire, 1995). In the west, the submerged Patea-Tongaporutu High and Taranaki Fault, separate Wanganui Basin from Taranaki Basin (Lamarche et al., 2005). To the south, Wanganui Basin sediments onlap the drowned topography of Marlborough Sounds, an area that is currently subsiding (see section 1.1; Hayward et al., 2010). The northern boundary between the Wanganui Basin and Otunui Basin is poorly understood. However, it is defined geophysically by the east-west trending "Taranaki-Ruapehu Line" (TRL, Fig. $1.3)$.

Basement terranes within Wanganui Basin are shown on figure 1.6. These consist of the Eastern Province Rakaia Terrane (Older Torlesse) - a Permian to Late Triassic turbiditic sandstone-mudstone association (Mortimer, 2004), the Morrinsville Terrane - which north of Wanganui Basin is a Jurassic to Early Cretaceous lithic-volcanic-rich sandstone of zeolite to lower prehnitepumpellyite facies, however, is semi-schistose within Wanganui Basin (Adams and Mortimer, 2009) and the Caples Terrane - a Permian-Triassic weakly metamorphosed greywacke and argillite composite (Mortimer, 2004).

\subsubsection{The Taranaki-Ruapehu Line}

Running east-west between the active andesite volcanoes of Mts Taranaki and Raupehu is a distinct and deep reaching geophysical boundary, known as the Taranaki-Ruapehu Line (TR-Line) Salmon et al. (2011). This initially noted by seismologists (e.g. Mooney, 1970) who detected a strong contrast in seismic attenuation across this line. Active source seismic experiments and gravity analysis show that north of the TR-Line the crust is thin $(\sim 25 \pm$ $2 \mathrm{~km}$ ) on the western side of North Island (Stern et al., 1987). In contrast, over-thickened crust estimated as up to $\sim 42 \mathrm{~km}$ thick is observed to the south (e.g. Stern and Davey, 1990; Ewig, 2009; Salmon et al., 2011). A 
Figure 1.5: Region map displaying the simplified geology of the geology of the Wanganui Basin area (Data sourced from GNS Qmap Wairarapa, Wellington and Taranaki regional grids; Begg et al., 2000; Lee et al., 2002; Townsend et al., 2008)

common-conversion-point receiver function stack reveals that this increase in thickness is characterised by a $\sim 7 \mathrm{~km}$ step in the Moho over a lateral 


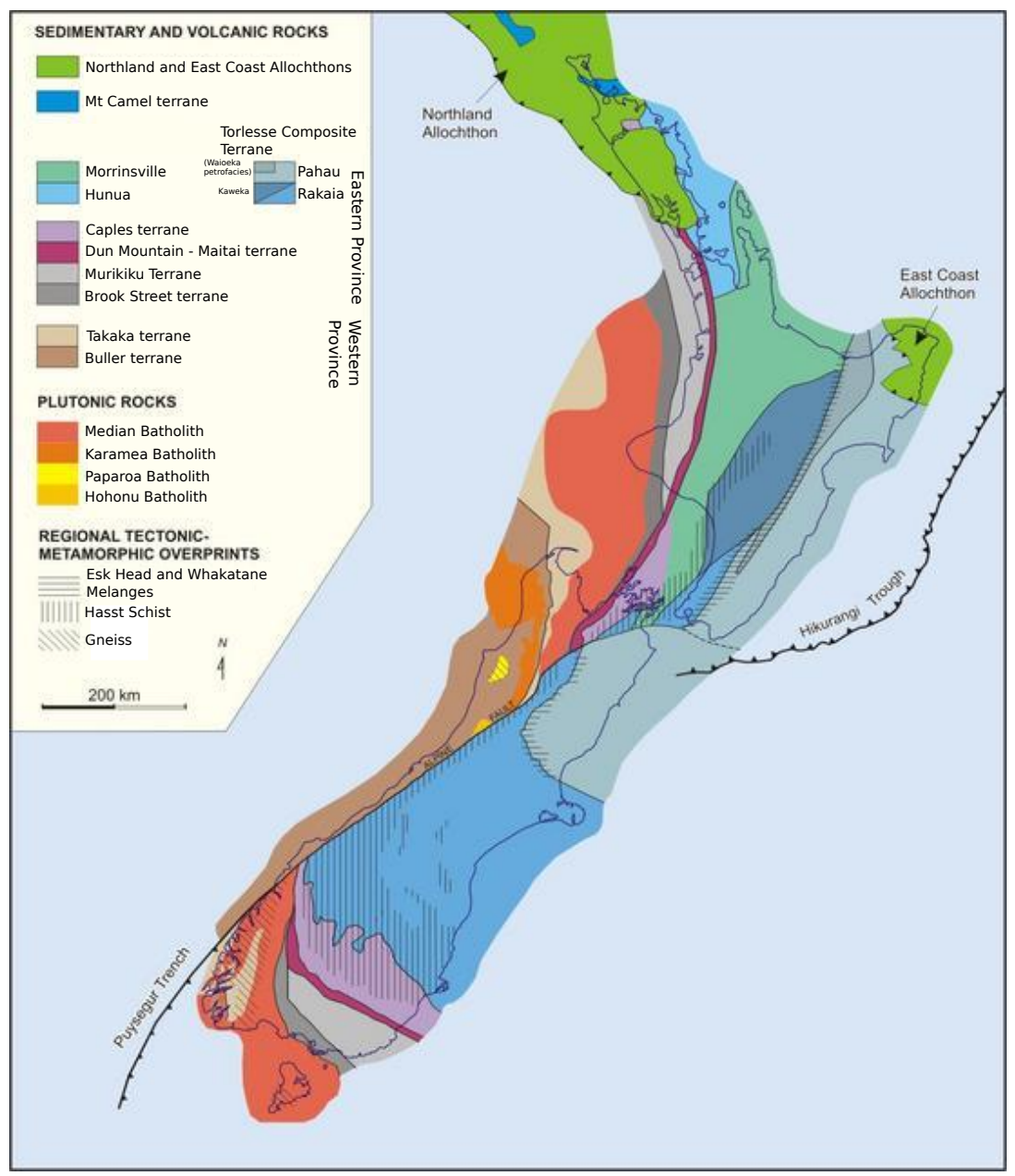

Figure 1.6: Map showing the basement terranes of New Zealand (Figure courtesy of GNS science, 2012).

distance of $\sim 8 \mathrm{~km}$ beneath the TR-Line from $\sim 24-32 \mathrm{~km}$, with further thickening to the south. Coincident with this step is a $1 \mathrm{mGal} \mathrm{km}^{-1}$ gravity gradient (Stern et al., 2010) and localised seismicity with mixed focal mechanisms at depths as great as $\sim 45 \mathrm{~km}$ (Reyners, 1989; Smith et al., 1989). Moreover, analysis of upper mantle wave speeds, receiver functions and electric resistivity across the TR-Line suggest the mantle-lid (i.e. the lithospheric portion of the mantle) is thinned or completely absent to the north (e.g. Horspool et al., 2006; Seward et al., 2009; Salmon et al., 2011). In addition, observations of mantle anisotropy reveal highly coherent, north-south 
1. Introduction

oriented fast polarisations to the south and incoherent or absent anisotropy to the north of the TRL (e.g. Audoine, 2004; Greve et al., 2008). This may indicate thick and sheared lithosphere south of the TR-Line (Salmon et al., 2011).

\subsubsection{Wanganui Basin deformation and seismicity}

Crustal deformation within Wanganui Basin is predominantly focused on the largely offshore SSW-NNE trending Kapiti-Manawatu Fault System (KMFS; Fig. 1.3; Lamarche et al., 2005). The Kapiti-Manawatu Fault System consists of mostly reverse faults and is located in the south-east section of the basin. High resolution seismic reflection surveying revealed these faults are characterised by steep dips $\left(\sim 70^{\circ}\right)$ and were probably inverted from preexisting extensional structures active sometime between the Late Cretaceous and Oligocene, when widespread extension occurred throughout New Zealand (Lamarche et al., 2005).

Lamarche et al., (2005) calculated that during the last 5 Ma $1.35 \pm 0.35$ $\mathrm{km}$ of shortening has been accommodated by this fault system, accounting for $5-15 \%$ of total shortening accumulated within the Australian plate over this time period (Nicol, 2003). Onshore, several other reverse structures have been identified on the eastern side of the basin such as the Rangitikei, Rauoterangi and Turakina faults (Anderton, 1981) and are probably onshore extensions of the Kapiti Manawatu Fault System. Additionally, actively growing anticlines in the Manawatu area have been attributed to active reverse faults within the basement rock (Te Punga, 1957; Melhuish, 1990).

In contrast, a smaller southwest-northeast trending normal fault set, the Waverly Fault Zone, is present in the north-west section of Wanganui Basin (WFZ; Fig. 1.3; Townsend, 1998). Paleoseismology reveals the inception 
of this fault zone occurred $\sim 1.63 \mathrm{Ma}$ and remains active in present time (Townsend, 1998). Furthermore, near-vertical offsets of Plio-Pleistocene sediments along normal faults have also been documented in the offshore section of the western side of the basin (Stern et al., 1992). Overall the fault offsets can only explain a minor portion of the total subsidence in Wanganui Basin (Lamarche et al., 2005), and a broad and distributed downward flexure is required to explain most of the observed subsidence (Stern et al., 1992).

In addition to the deformation observed on faults, paleomagnetic observations show that vertical axis clockwise rotation has also occurred within Wanganui Basin during the last 2.5 Ma. This rotation is shown to increase from west to east across the basin from 1.4 to $13.2^{\circ}$ (Wilson and McGuire, 1995). Modelling of contemporary geodetic measurements agrees with these rotation rates and suggest rotation continues in the present day with an estimated rate of $2.9 \pm 0.5^{\circ} \mathrm{Myr}^{-1}$ (Wallace et al., 2004).

Seismicity in Wanganui Basin is unusual in that earthquakes occur within the entire crust (Fig. 1.7). This observation suggests the crust must be relativity cold and hence strong at depth (Chen and Molnar, 1983). Reyners et al. (2006) postulate that deep earthquakes in Wanganui Basin are caused by fluid rising from the subducting plate into the overlying cold and thickened mantle lithosphere and lower crust. This is supported by swarm like earthquake activity (Garrick and Gibowicz, 1983) and receiver function analysis at the southern end of the basin, which show the presence of low S-wave velocities in the lower crust indicative of fluids (Ewig, 2009).

\subsubsection{Wanganui Basin genesis}

The most striking geophysical characteristic of Wanganui Basin is the elliptically shaped -160 mgal isostatic/free-air gravity anomaly that parallels the shape of the sedimentary basin (Fig. 1.8). Hunt (1980) calculated that the sediment fill can only account for about one third of the total anomaly, and 


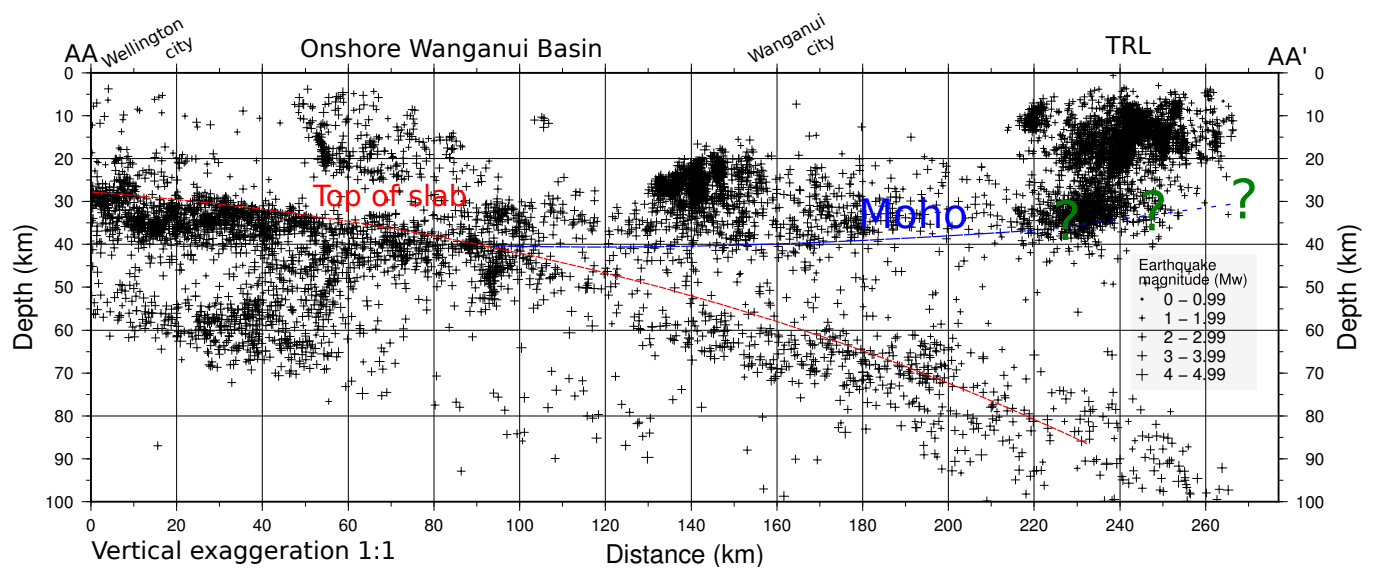

Figure 1.7: Cross section orientated SSW-NNE through the center of Wanganui Basin displaying a swath of microseismicity located within $20 \mathrm{~km}$ of the cross section (black crosses). These earthquakes were recorded by the national GeoNet seismograph network between January 2001 and March 2011, were relocated using the nationwide 3D velocity model of Eberhart-Phillips et al., (2010) and supplied for use in this study by Martin Reyners (M. Reyners, personal communication, 21 November 2011). Note this section is cut at an oblique angle with respect to the angle of plate subduction. AA - AA' displayed on figure 1.3 .

hence the remaining -100 mgal must be attributed to other sources.

If a point source is assumed as the cause of a three dimensional gravity anomaly, the depth $\mathrm{z}$ of the point source may be calculated as

$$
z=\frac{x_{1 / 2}}{\sqrt{\sqrt[3]{4}-1}}
$$

where the half width $x_{1 / 2}$ is the horizontal distance from the maximum anomaly to the point at which the anomaly has reduced to half of its maximum value (Kearey et al., 2002). In the case of Wanganui Basin, $x_{1 / 2}$ is $~$ $55 \mathrm{~km}$ and this equates to a depth of $\sim 72 \mathrm{~km}$. Although a point source is a gross oversimplification of the driving force of basin formation, the depth of $72 \mathrm{~km}$ is nevertheless suggestive of a subcrustal mechanism.

\section{Frictional coupling at the plate interface}




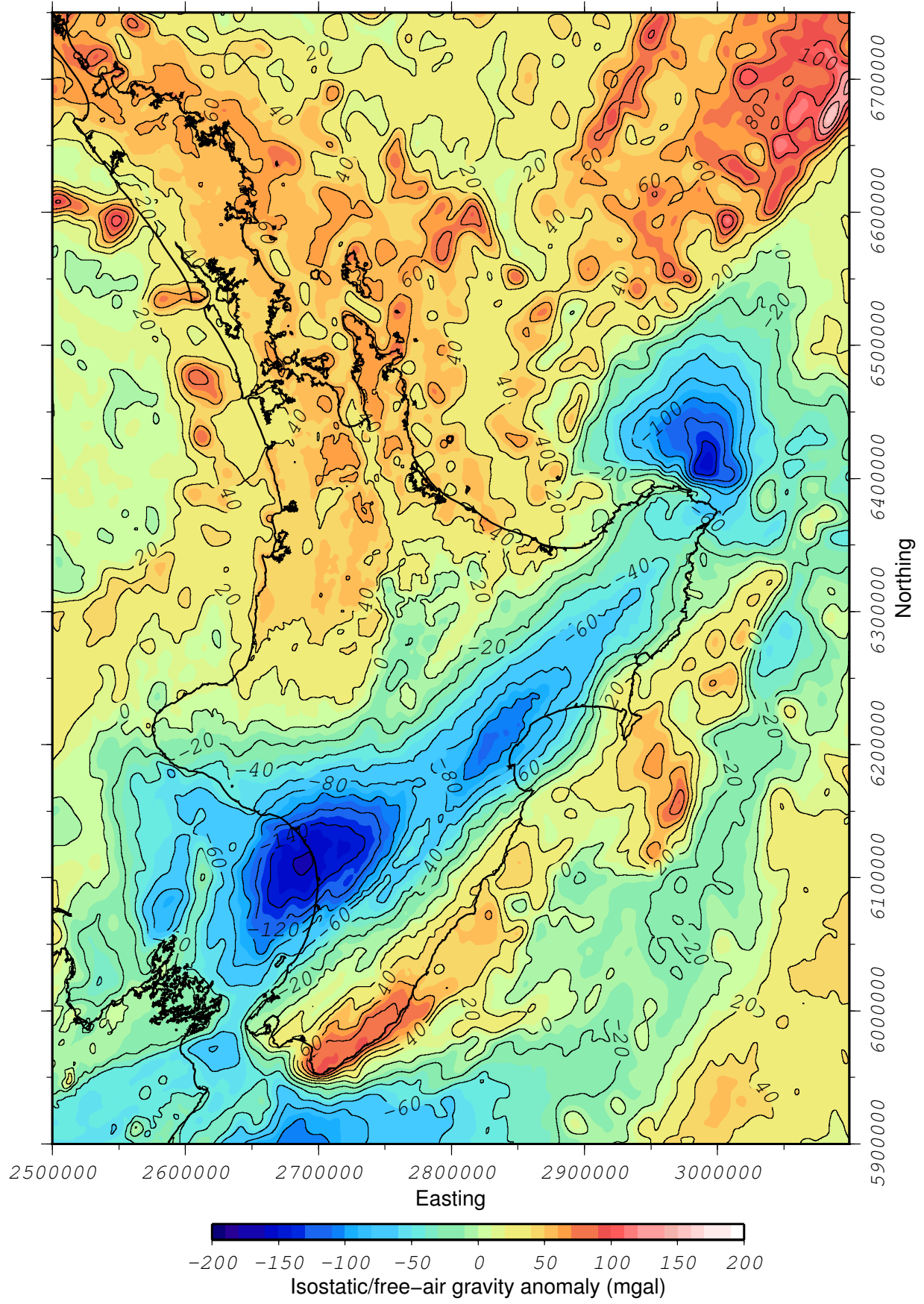

Figure 1.8: Isostatic/free-air gravity anomaly of North Island. Note the maximum 160 mgal reached in central Wagnaui Basin. Gravity grid was supplied courtesy of GNS Sccience as derived from Sandwell and Smith's (2009) marine satellite data and GNS land gravity database. 


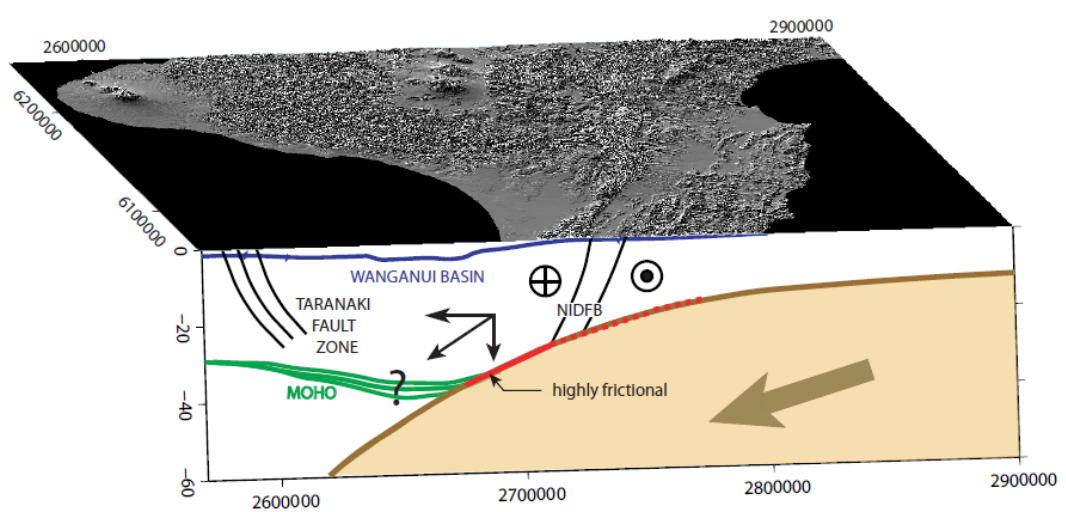

Figure 1.9: Schematic illustration of the driving force of basin formation proposed by Stern et al., (1992). The solid red line indicates the zone where the plates are proposed to be fictionally coupled, and hence shear stress is transferred across the interface (modified after Ewig, 2009).

One theory capable of explaining the subsidence observed in Wanganui Basin was formulated by Stern et al., (1992) through three dimensional flexure modelling. These authors modelled the broad flexure of Wanganui Basin using a "slab pull" force generated by the vertical component of frictional shear on the Australian-Pacific plate interface (Fig. 1.9). This model is consistent with the growth of both normal and reverse faults within the basin, as a result of the compressional and extensional stresses generated by plate flexure. The southward migration of basin depocentres, like that observed in the sedimentary record of western North Island (Fig 1.3; Anderton, 1981), is also predicted by this model as frictional coupling on the plate interface is proposed to have moved south though time, in step with the rotation of the Hikurangi margin. Furthermore, some level of frictional coupling on the plate interface may provide an explanation for the observed paleomagnetic rotations determined in Wanganui Basin (Wilson and McGuire, 1995; Taylor, 2006). This is because a southward force on the eastern side of the basin is consistent with progressively greater vertical axis rotation from west to east across the basin $\left(1.4-13.2^{\circ}\right)$.

The Stern et al. (1992) model does however imply 170 Mpa of shear stress 
at the inclined plate interface, which may be considered unrealistically high when compared to predictions of the range of shear stresses observable in major thrust zones. For example, England and Molnar (1991) suggest a range of 50 - $150 \mathrm{Mpa}$ and Lamb (2006) showed, by calculating the force balance across the Hikurangi margin that shear stress should nowhere exceed $37 \mathrm{Mpa}$. Conversely, it may be possible that high shear stresses can be sustained if the plate interface is fully locked and therefore stronger than 'regular' thrust zones (which fail in shear regularly). Additionally some portion of basin downwarp is undoubtedly maintained by sediment loading.

\section{Convective removal of the mantle lithosphere}

More recently, Stern et al., (2006; 2010) proposed a theory to explain the tectonic evolution of the entire western North Island over the last 20 Ma. These authors liken the rapid uplift, extension and magmatism currently observed in the CVR to analogous phenomenon observed in mountain ranges around the world following long periods (> $10 \mathrm{Ma}$ ) of compression, similar to that currently observed in western North Island (e.g. Houseman et al., 1981; Kay and Mahlburg Kay, 1993). Two related mechanisms capable of explaining these time-dependent vertical motions are the convective removal (e.g. Houseman and Molnar, 2001) or delamination (e.g. Bird, 1979) of the lithosphere.

In the case of western North Island, Stern et al. (2006) explain the convective removal of the lithosphere using the dynamical principles of the RayleighTaylor instability (Conrad, 2000).

This process requires uniform thickening of the lithosphere, such that over time, the mantle-lid (which is cold and denser than the underlying mantle) becomes gravitationally unstable providing it has a non-Newtonian viscosity. In this case shortening casues a decrease in lithospheric strength and perturbations to the lithospheres temperature structure. Eventually, the thickened, 
cold and dense mantle-lid will submerge into the surrounding asthenosphere and then detach and sink (e.g. Fig. 1.10).

Several surface and geological manifestations are predicted as consequences of this process. These include subsidence of surface topography during instability initiation, followed by rapid surface uplift and extension once detachment occurs (e.g. Nelson, 1992; Zandt et al., 2004), development of extensional structures in the peripheral areas a few million years after the initiation of instability development (Platt and England, 1993), the presence of high-K volcanism caused by decompressional melting of rising asthenosphere or melting of pre-emplaced pockets of K-rich meatasomatized mantle (e.g. Kay and Mahlburg Kay, 1993; Platt and England, 1993; Zandt et al., 2004; Elkins-Tanton, 2005), high P-wave speeds at asthenospheric depths due to the presence of dense mantle lid material and low shear-wave splitting delay times induced by rotation of lattice preferred orientation (e.g. West et al., 2009).

Stern et al. (2006) argue that the geological and geophysical characteristics of western North Island are manifestations of a Rayleigh-Taylor Instability that has migrated from north to south during the last 20 Ma. They postulate that the $70 \pm 30 \mathrm{~km}$ of shortening that occurred within central North Island during the Miocene, provided the initial conditions for RTI development. The uplift of the CVR, subsidence of Wanganui Basin and migration of sedimentary depocenters, are then interpreted as direct consequences of instability detachment, current growth and southward migration with time respectively.

Moreover, mid to late Micoene extension observed in western Taranaki Basin and east of Auckland (Hochstein and Ballance, 1993) following the shortening of central North Island, may be explained by peripheral forces in relation to the main foci of instability development. Further observations including the presence of high-K volcanism north of the TRL and deep $(\sim 600 \mathrm{~km})$ earth- 
(a)

Uniform thickening Surface uplift

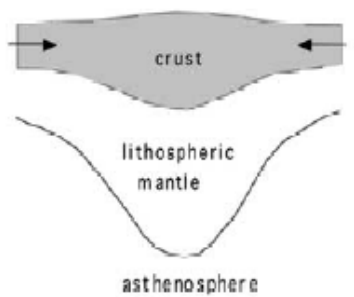

Thickening 25-5 Ma

in Taranaki Fault

Zone. Surface

uplift to above

Sea level. (b)

Instability and peripheral extension develops

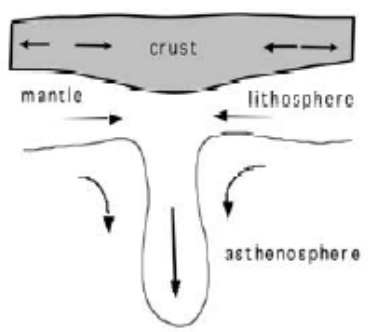

Instability develops

15. $5 \mathrm{Ma}$

Extension develops

peripheral to main

downwelling. Basin

development above

downwelling. Extensive

peripheral (offshore) igneous

activity (10-5 Ma). (c)

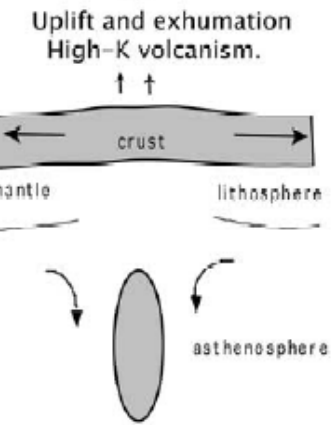

Uplift and exhumation@ @ $5 \mathrm{Ma}$

Area above instability undergoes rapid uplift. High-K volcanism above main zone of instability. Instability dewaters as it founders adding to surface volcanism and possibly deep earthquakes.

Figure 1.10: Cartoon showing the three general stages of Rayleigh-Taylor instability development through time (a) (c) proposed by Stern et al., (2006) for the western-central North Island (after Stern et al., 2006 adapted from Houseman and Molnar, 1997). Copyright Blackwell Publishing.

quakes recorded beneath western North Island (e.g. Adams and Ferris, 1976; Adams and Ware, 1977; Anderson and Webb, 1994) can both be explained in the context of a Rayleigh-Taylor Instability. High-K volcanism is attributed to the melting of pre-emplaced pockets of K-rich meatasomatized mantle by hot asthenophere that has rapidly replaced mantle lithosphere subsequent to instability detachment (e.g. Platt and England, 1993; Elkins-Tanton, 2005).

Deep earthquakes $(\sim 600 \mathrm{~km})$ observed in western North Island have been attributed to brittle failure within broken off pieces of the subducting slab (e.g. Barazangi et al., 1973; Anderson and Webb, 1994; Reyners et al., 2006). Using this interpretation Christoffel and Calhaem (1973) calculated an effective viscosity of $3.1 \times 10^{19} \mathrm{~Pa} \cdot s$ for the mantle, assuming breakoff occurred at a depth of $220 \mathrm{~km}$ and at $~ 3.8 \mathrm{Ma}$. As an alternative, Stern et al. (2006) also used considerations of mantle fluid mechanics, to show that a section of the mantle lid, detached from central North Island at $\sim 4 \mathrm{Ma}$, would 
in theory, also be capable of producing earthquakes at these depths. This is supported by Elkins-Tanton (2005) who demonstrated that a foundering piece of mantle-lithosphere, similarly to a broken piece of a subducting slab, would undergo dewatering, enabling brittle failure at great depths. This also fits well with the sudden uplift of the central north island initiating at $\sim 5$ Ma following detachment (Pulford and Stern, 2004).

This hypothesis provides a new mechanism for the long hypothesised timeprocessing pattern of southward basin migration within western North Island first recognised by Stern and Davy (1989). However, it leaves a number of questions unanswered. For example, it does not provide an obvious explanation for the rapid/abrupt change in lithospheric properties, north and south of the Taranaki-Ruapehu line. Likewise, it is unclear why there should be a -100 mgal gravity anomaly in Wanganui Basin after accounting for sediment fill, because this is too large to be explained by a single downwelling of the mantle-lid (Hoogenboom and Houseman, 2006).

\section{Combination of plate interface coupling and convective lithospheric downwelling}

Ewig (2009) implemented a finite element model of load distributions within Wanganui Basin to test the forces required to recreate basin subsidence. Vertical loads of up to $200 \mathrm{MPa}$ were required to create the vertical deformation observed and it was shown that even with a completely locked plate interface, the maximum vertical load in Wanganui Basin would be no greater than $176 \mathrm{Ma}$ and hence too small to account for subsidence. Thus, the vertical load driven by the foundering of a thickening mantle-lid was tested. This test showed that for a body $60 \mathrm{~km}$ the vertical load is $\sim 50 \mathrm{Mpa}$. Therefore, in theory, the combination of vertical loads from both a highly coupled plate interface, and foundering thickened mantle can account for the vertical load required to drive basin subsidence. An obvious complication for this hypoth- 
1.3. Contemporary tectonic Setting of the study region - Wanganui Basin

esis is an absence of accommodation space for the foundering mantle-lid. The Wadati-benioff zone shows that the subducting Pacific slab extends beneath the Wanganui Basin and into the Taranaki Basin to the west.

\section{Lithospheric delamination of the Australian plate}

Furlong and Kamp (2009) proposed an alternative theory for the evolution of the Hikurangi margin back-arc that focuses on the necessity to create accommodation space for emplacement of the Pacific Slab (Fig. 1.11). This theory also invokes the removal of the overlying Australian plates mantle-lid, however, they suggest lithospheric delamination in a style closer to that first described by Bird (1979) as opposed to convective removal as presented by Stern et al., (2006; 2010).

Using plate reconstructions to track the leading edge of the subducting Pacific slab over the last 20 Ma, Furlong and Kamp (2009) argued that the leading edge acts as a chisel to drive delamination of the previously thickened Australian plate lithosphere. They interpret a narrow area beneath Motueka as current position of delaminating Australian plate lithosphere based on deep seismicity (up to $250 \mathrm{~km}$ ) that appears isolated from that of the subducting slabs Wadati-Benioff Zone (Fig. 1.11c). They hypothesise that hot asthenopshere will fill the gap left between the slab and delaminated lithosphere, cool and stiffen, and become partially coupled to the sinking sliver of lithosphere, hence proving a driving force for subsidence at the surface. It is through this mechanism that these authors explain the migration of subsidence, sedimentary depocentres and extension observed in western North Island.

However, as yet this model remains entirely qualitative without any detailed numerical analysis. Thus, it is unclear whether the proposed delaminating sliver would generate sufficient force to create the observed downwarpping in Wanganui Basin. Furthermore, there is no explanation why the extent 

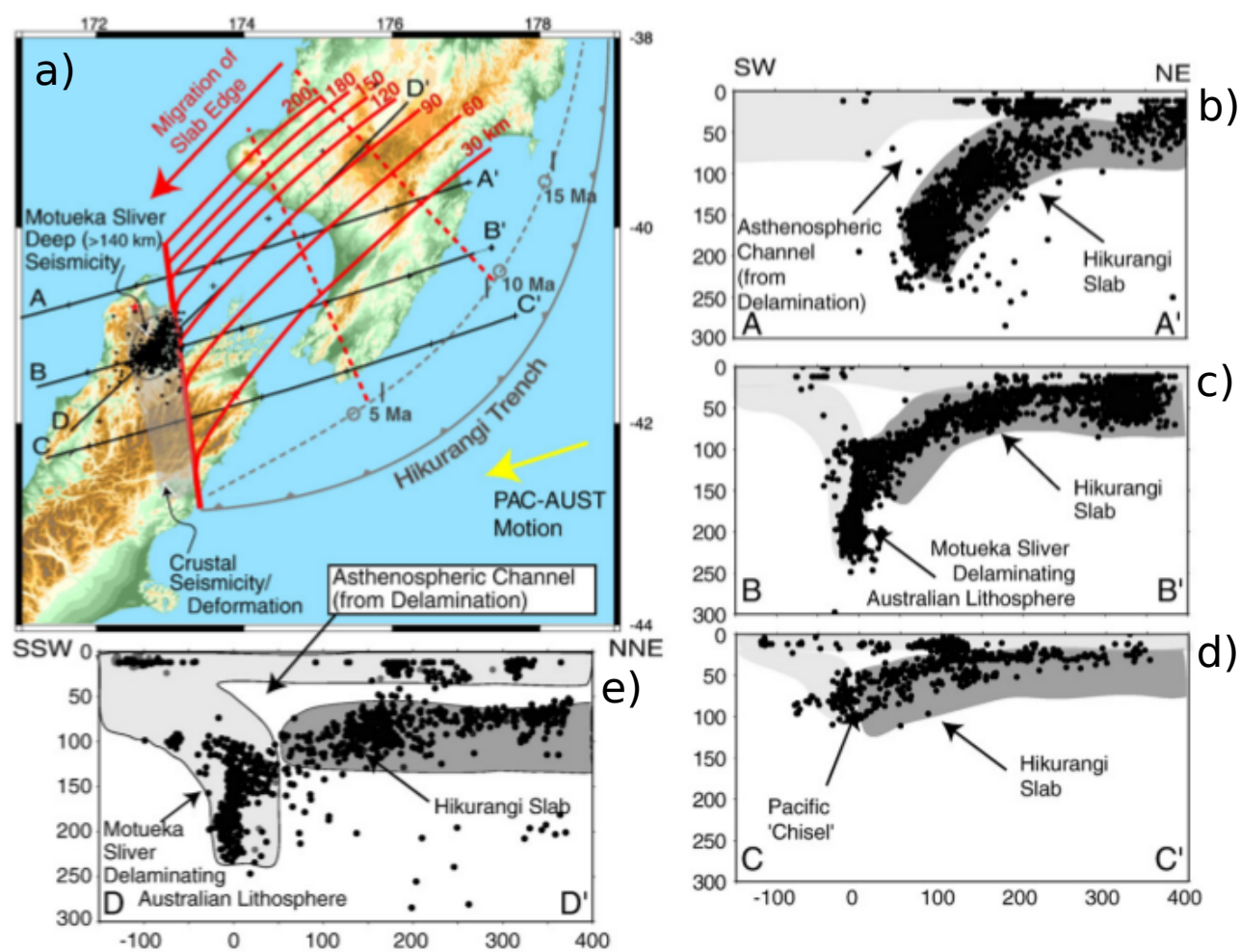

Figure 1.11: (a) Map showing the location of the cross sections of (b-e), the solid red line shows the proposed location of the Hikurangi slab leading edge and dashed lines are it's postion the times shown. Smaller red lines indicate the depth to the top of the plate interface. (a-c) Cross sections orientated perpendicular to the leading edge displaying seismicity, note the change from fully fledged subduction in (a) to subduction initiation in (c). (d) Cross section orientated in proposed direction of sliver migration. Note the seismicity group interpreted to represent the Motueka sliver (modified after Furlong and Kemp, 2009).

of the deliminating silver is restricted to only a small section of the leading edge (the Motueka sliver) or how it could result in the shape and position of the Wanganui Basin gravity anomaly. The proposed delaminating sliver is more straightforwardly interpreted as part of the subducting Pacific plate as suggested by numerous authors and summerised by Reyners (2011).

\subsubsection{Hikurangi margin kinematics and structure}

Contemporary oblique convergence between the Australian-Pacific plates occurs at trend of $\sim 50^{\circ}$ to the margin and a rate of $43 \mathrm{~mm} \mathrm{yr}^{-1}$ in the center of the Hikurangi margin (Beavan, 2002). This is partitioned between $34 \mathrm{~mm}$ 


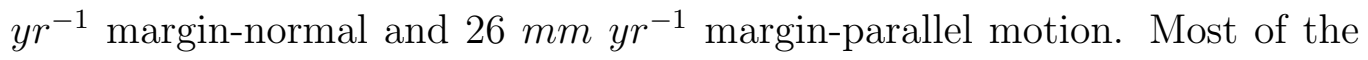
margin parallel motion is accommodated in the crust by strike-slip faulting along faults such as those of the North Island Dextral Fault Belt (e.g. Beanland, 1995; Van Dissen and Berryman, 1996; Wallace and Beavan, 2004) and by vertical axis fault block rotations (e.g. Walcott, 1987; Beanland, 1995; Lamb, 2011). In contrast, less than $20 \%$ of convergence is accommodated in the crust by folding and thrusting within the forarc, accretionary wedge (e.g. Nicol et al., 2007) and on back-arc structures such as the Kapiti-Manawatu Fault System (e.g. Lamarche et al., 2005; Nicol and Wallace, 2007). The remaining $>80 \%$ attributed to slip on the subduction interface.

Within this margin, slip conditions vary both along strike and down dip. Strain release occurs by a combination of microseismic, slow slip and coseismic events (Wallace and Beavan, 2010), with a lack of megathrust earthquakes events ( $\mathrm{Mw}>8$ ) over historical times (Webb and Anderson, 1998). GPS measurements show that, in the current interseismic period, a significant part of the subduction interface is "locked" i.e. there is no slip on the megathrust and elastic strain is accumulating (Fig. 1.12; Darby and Beavan, 2001; Wallace and Beavan, 2004, Wallace et al., 2009, 2010, 2012). However, the width of the zone of coupling varies along strike, so that in the northern section of the Hikurangi margin only a very narrow zone close to the trench is locked. Further south, in the vicinity of seismic lines analysed in this study, the locked zone broadens and spreads across the lower North Island, extending to depths of 25 - $30 \mathrm{~km}$ (e.g. Darby and Beavan, 2001).

Subduction within this margin is considered atypical owing to the presence of the relativity thick and potentially buoyant Hikurangi Plateau (Fig. 1.1). The Hikurangi Plateau is a Large Igneous Province (LIP) (Mortimer and Parkinson, 1996), interpreted as one of three sections that rifted apart from the once largest LIP on Earth, the Ontong Java-Manihiki-Hikurangi Plateau that was emplaced $\sim 120$ Ma (Taylor, 2006). Previous studies have esti- 
mated the thickness of the Hikurangi Plateau crust to be $12-16 \mathrm{~km}$ using gravity data offshore of the east coast of North Island (increasing from north to south) (e.g. Davy and Wood, 1994; Davy et al., 2008), and as up to 17 - $18 \mathrm{~km}$ at the northern end of the margin near East Cape, based on wideangle reflection and refraction surveying (Bassett et al., 2010). Furthermore, seismic reflection data indicate the presence of a thick section of the Hikurangi Plateau beneath the northern slope of the Chatham Rise (Davy et al., 2008), estimated to be as great as $23 \mathrm{~km}$ using gravity modelling (Davy and Wood, 1994). It has been suggested that because of its buoyancy the Hikurangi Plateau may have jammed along the Chatham rise at $\sim 100 \mathrm{Ma}$, marking the cessation of the Gondwana subducting margin (Davy et al., 2008). However, in this case it is surprising that the Hikurangi Plateau is being subducted within the Hikurangi margin today. It may be that that the Hikurangi Plateau is now jamming the Hikurangi subduction zone or will do so in the near future. Alternatively, it is plausible that a buoyancy limit for LIP subduction may exist (Davy et al., 2008) as predicted by buoyancy modelling (Cloos, 1993), hence allowing subduction to continue in the Hikurangi margin.

\subsection{Objective of this study}

The primary objective of this study is to constrain, for the first time, crustal structure in the behind-arc Wanganui Basin using controlled source seismic data. This is achieved using a combination of three complementary methods of seismic imaging. These are (1) onshore-offshore wide-angle reflection/refraction (2) onshore explosive wide-angle reflection/refraction and (3) multi-channel-seismic (MCS) reflection profiling.

The onshore-offshore technique utilizes onshore seismometers to record seismic waves emanating from offshore air-gun blasts fired during the acquisition 


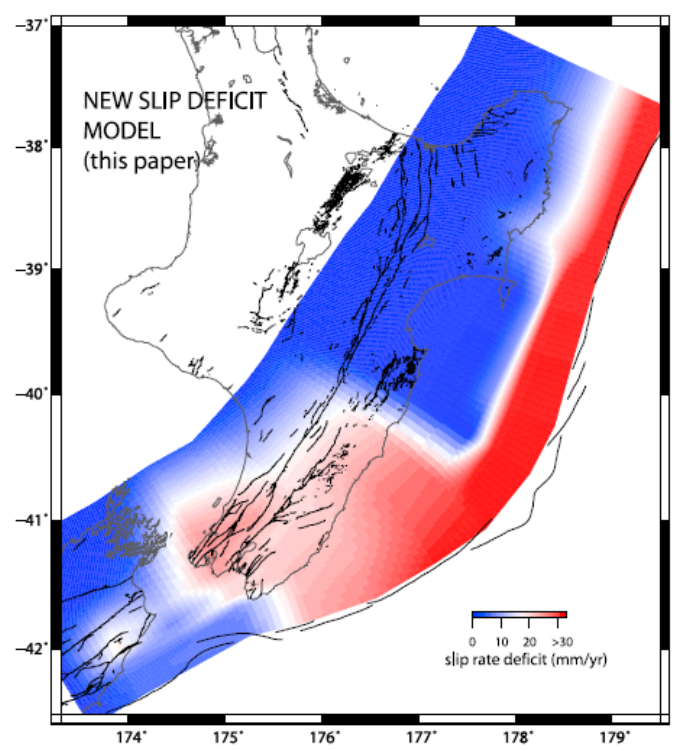

Figure 1.12: Map showing the interseismic coupling of the plate interface at the Hikurangi margin (as slip rate deficit relative to total plate convergence) determined by modelling of GPS measurements (after Wallace et al., 2012).

of MCS reflection profiles. In this study, two 2D MCS reflection profiles are analyzed and used together with onshore-offshore and onshore explosive data to constrain two crustal scale two-dimensional (2D) P-wave velocity models within Wanganui Basin. These are orientated perpendicular and sub-parallel to the Hikurangi margin and span lateral distances of 270 and 225 kilometres respectively.

Of particular focus are the geometries of the overlying Australian plate Mohorovicic discontinuity (Moho) and Australian-Pacific plate interface and the thickness of the subducting Pacific plate crust. The purpose of this analysis is to provide constraints on crustal structure that can provide a basis for numerical analysis of potential driving mechanisms of Wanganui Basin formation.

A secondary objective of this thesis is to determine the thickness of the subducting oceanic crust beneath Lower North Island in order to infer the 
down dip limit of the Hikurangi Plateau. If the crust is also anonymously thick at depth, we may be able to draw interferences on the likelihood of subduction choking as appears to have occurred along the Chatham Rise 100 Ma.

\subsection{Thesis outline}

This thesis is structured as follows:

\section{Chapter One - Introduction}

Chapter One provides an overview of the tectonics of back-arc basins and places the Wanganui Basin, the back-arc region investigated in this thesis, within the context of New Zealand's plate tectonic evolution and reviews the current theories of basin genesis. This chapter also introduces the primary scientific objective of this thesis.

\section{Chapter Two - Survey geometry and methodology}

Chapter Two outlines the survey geometry of the Seismic Array Hikurangi Experiment (SAHKE). A subset of data collected as part the SAHKE forms the focus of analysis conducted in this thesis. The methodology of onshoreoffshore seismic profiling is also reviewed. This chapter concludes by discussing the interpretation on the wide-angle reflection/refraction onshoreoffshore and onshore explosion data collected during SAHKE. Appendix A is complementary to this chapter and explains data processing in detail.

\section{Chapter Three - Velocity modelling technique}

Chapter Three discusses the rationale behind the use of various techniques for modelling crustal velocity structure and outlines the modelling strategy used in this thesis. A discussion of important pre-modelling considerations is also provided, with a detailed analysis of the effect of near surface low velocity zones (sedimentary fill and ocean water) and the nature of velocity 
model uncertainties.

Chapter Four - Two Dimensional Modelling of Crustal Velocity Structure: SAHKE03

Chapter Four details the process by which a two dimensional P-wave velocity model was constructed along a $275 \mathrm{~km}$ transect running sub-parallel to the Hikurangi margin through the center of Wanganui Basin, between Wellington city and Mt Ruapehu. This analysis includes the determination of sedimentary fill p-wave velocity structures using coincident MCS data, a comprehensive analysis of model constraints provided by previous studies and the modelling on onshore-offshore wide-angle reflection/refraction seismic data collected at nine onshore seismometers. The model is assessed using standard statistical techniques and is also subject to parameter resolution testing. The velocity structure determined in this model is described and compared with previous studies, as well as the coincident MCS reflection profile acquired as part of the SAHKE.

Chapter Five - Two Dimensional Modelling of Crustal Velocity Structure: SAHKE02

Chapter Five follows the same structure as Chapter Four. This chapter, however, focuses on the process by which a $2 \mathrm{D} \mathrm{Vp}$ model was constructed along a $225 \mathrm{~km}$ transect that runs perpendicular to the Hikurangi margin from Glendhu Rocks on the east coast of North Island to the center of Taranaki basin. This Chapter includes analysis of onshore-offshore wide-angle reflection/refraction seismic data collected at thirty nine onshore seismometers, in addition to twelve onshore dynamite explosions recorded at $\sim 900$ onshore seismometers along a coincident profile.

Chapter Six - Synthesis and conclusions

Chapter Six integrates the results from the two P-wave velocity models developed in Chapters 4 and 5. Inferences regarding the crustal structure within 
Wanganui Basin are drawn and related to previous and complementary studies.

\section{Appendix A}

Appendix A outlines in detail the survey geometry and instrumentation of the SAHKE as well as the procedure by which onshore-offshore data were retrieved, cut and processed into a set of common receiver gathers. Details regarding how these data were interpreted are also provided.

\section{Appendix B}

Appendix B provides figures from the MCS shot gathers used to constrain sedimentary velocities and basement structure in the offshore portion of the velocity model developed in Chapter Four.

\section{Appendix $C$}

Appendix $\mathrm{C}$ describes the process by which a static correction was developed and applied to account for a discrepancy in wave phase travel-times recorded at GeoNet seismometer KIW (located on Kapiti Island) in the velocity model developed in Chapter Four. 


\section{Chapter 2}

\section{Survey geometry and methodology}

\subsection{Introduction}

Determination of the crustal structure adjacent to plate boundaries is paramount if one is to understand the tectonic history of these systems and the tectonic forces acting within them. Previous studies have demonstrated that a combination of zero-offset reflection and wide-angle reflection/refraction seismic surveying provide the most detailed images of crustal structure (e.g. Babel working Group, 1992; Okaya et al., 2003; Bassett et al., 2010; Scherwath et al., 2010). These techniques complement one another as reflection profiling enables high resolution imagery of structures, while refraction data provides constraints on velocity and interface depths (Okaya et al., 2003).

Imaging subduction zone plate boundaries can, however, be complicated as these systems are often characterised by a transition between continental and oceanic environments. In the past this has meant separate marine and land based surveys are required to image these systems. This strategy is undesirable as it results in an imaging "gap" near the coast, as 
neither of these techniques are able to image beneath the continental-oceanic transition zone, an area central to these systems. In light of this drawback, the onshore-offshore wide-angle reflection/refraction seismic imaging technique has proven successful in imaging areas with onshore-offshore physiographies (e.g. BABEL working Group, 1993; Okaya et al., 2002; Okaya et al., 2003; Bassett et al., 2010; Scherwath et al., 2010). This method allows both the onshore and offshore sections of these systems, including the coastal transition transition zone, to be sampled simultaneously.

The Hikurangi subduction zone (Fig. 1.1) is one such plate boundary that is characterised by a coastal transition. Both the northern and central sections of this subduction zone have been subject to extensive active source seismic investigation over the last 20 years including onshore-offshore seismic imaging (e.g. Henrys et al., 2003; Henrys et al., 2006; Scherwath et al., 2010; Bassett et al., 2010).

As a continuation of these studies, a comprehensive seismic experiment termed the "Seismic Array HiKurangi Experiment"(SAHKE) was undertaken during December and March 2009-10 and May 2011. This was a collaborative project run between Victoria University of Wellington (VUW), Geological and Nuclear Sciences (GNS), Toyko University Earthquake Research Institute (ERI), University of South California (USC) and New Zealand Petroleum and Minerals (NZPM). The primary goal of the SAHKE is to determine in detail the crustal and lithospheric structure throughout the southern section of the Hikurangi subduction zone and behind-arc Wanganui Basin. Central to this experiment was an active source seismic survey consisting of two sections: SAHKE part 1 (SAHKE I) and SAHKE part 2 (SAHKE II) as described in section 2.2.

This thesis focuses on processing, interpretation and modelling of wide-angle reflection/refraction and multi-channel-seismic (MCS) data collected within 
Wanganui Basin as part of SAHKE. This research is undertaken in an attempt to gain insight into the tectonic evolution of this basin.

\subsection{SAHKE Survey Geometry}

SAHKE involved several phases of data acquisition (see Seward et al., 2010 and 2011). Figures 2.1 and 2.2 illustrate the active source survey geometries during the onshore-offshore MCS portion of SAHKE I and onshore SAHKE II surveys. This thesis focuses on data collected on the western side of North Island within Wanganui Basin. Specifically, MCS and onshore-offshore data acquired along the TRANSECT and WANGANUI deployments during the shooting of SAHKE lines 02 and 03, and onshore data acquired during SAHKE II. Collectively, these data are used to determine crustal velocity structure within this basin.

\subsubsection{SAHKE I}

During March 2010, 480 line km's of MCS reflection data were acquired along three transects, SAHKE01, SAHKE02 and SAHKE03 (Fig. 2.1). Together, SAHKE01 and SAHKE02 create a single profile orientated approximately perpendicular to the Hikurangi margin. SAHKE03 is orientated sub-normal to the SAHKE01/02 profile, running SSW-NNE through the centre of Wanganui Basin. For the duration of this survey, thirty nine temporary short period seismometers where installed along two separate profiles and used to record the seismic energy emanating from the offshore MCS air-gun blasts.

The TRANSECT deployment consisted of thirty short period and eight broadband temporary onshore seismometers and twenty temporary ocean bottom seismometers (OBS), deployed inline with the SAHKE01/02 MCS profiles (Fig. 2.1). 
2. Survey geometry and methodology

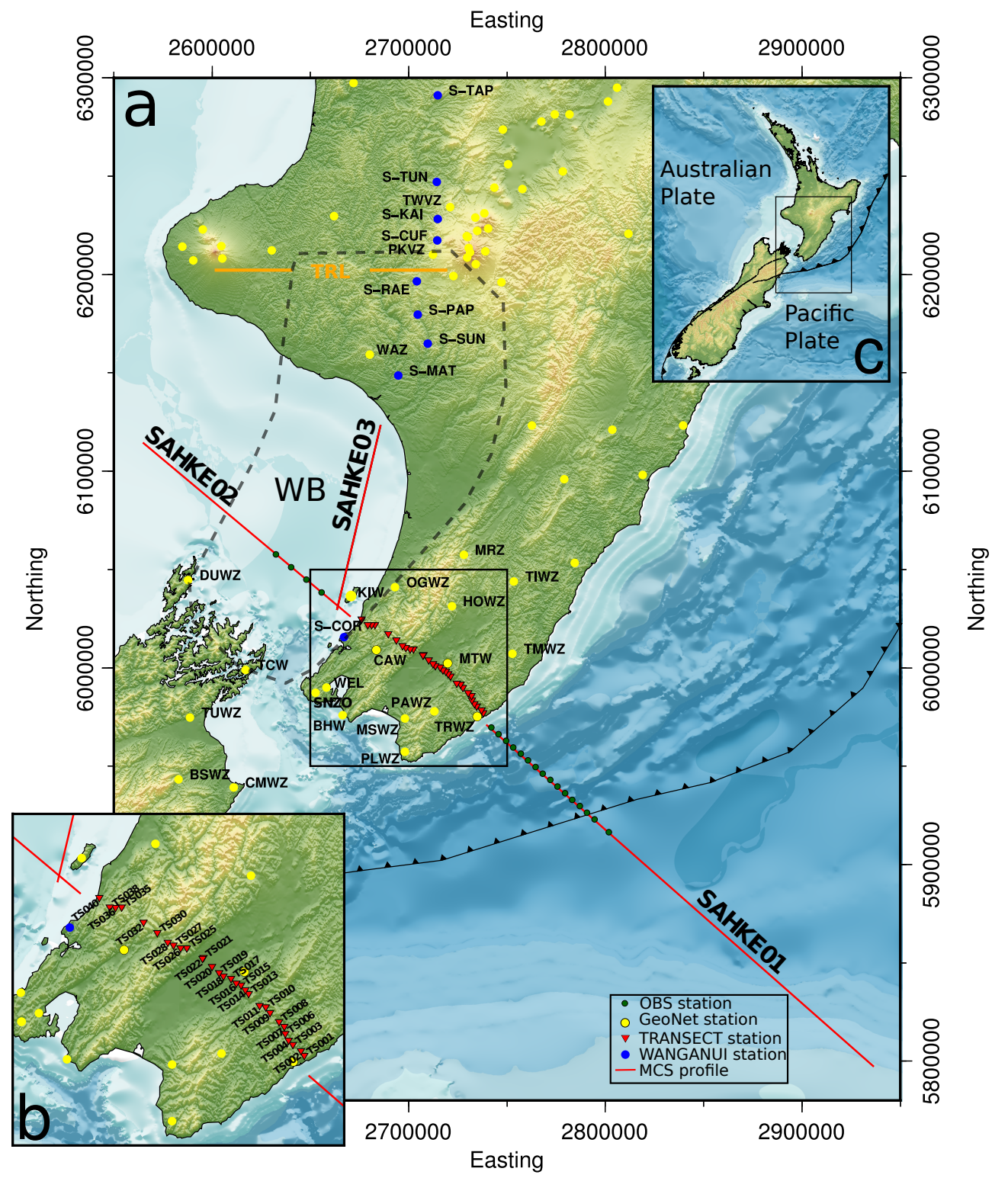

Figure 2.1: (a) Regional location map displaying the survey geometry of the onshore/offshore section of the "Seismic Array HiKurangi Experiment"(SAHKE). Red lines are MCS profile tracks, red triangles and blue circles are temporary short period seismometers belonging to the TRANSECT and WANGANUI deployments respectively. Yellow circles are permanent GeoNet seismometers. The dashed grey line outlines the extent of Wanganui Basin. The orange line indicates the position of the proposed Taranaki-Ruapehu Line (TRL). (b) Inset map showing the locations of short period temporary seismometers belonging to the TRASECT deployment. (c) Inset showing the location of (a) (black box). Bathymetry data are sourced from the National Institute Water and Atmospheric Research (NIWA) chart No. 85 (CANZ, 2008). 
The WANGANUI deployment consisted of nine short period temporary onshore seismometers, deployed inline with the SAHKE03 MCS profile (one south and eight north). These temporary sites are complemented by several permanent New Zealand Seismic Network (GeoNet) seismometers that lie along each profile. The WANGANUI deployment is further supplemented by one Global Seismic Network (GSN) seismometer, station SNZO (Fig. 2.1).

A detailed description of deployment locations and instrumentation used during this survey is supplied in Appendix A.

\subsubsection{SAHKE II}

During May 2011, an onshore wide-angle reflection/refraction dataset was acquired across the lower North Island from coast to coast, along a profile coincident with the SAHKE I TRANSECT profile (Fig. 2.2). This dataset consists of 12 shot gathers. The shots were located at an average spacing of $\sim 8 \mathrm{~km}$ and were recorded by 558 single-component and 277 three-component seismometers deployed at $\sim 100 \mathrm{~m}$ spacing between Glendu Rocks in the east and Paekakariki in the west (narrowed to $\sim 50 \mathrm{~m}$ spacing between Kaitoke and Featherston) (Fig. 2.2. A three component station was deployed at every third site. This survey was designed to sample crustal structure at depth beneath the subaerial North Island, an area that remained unsampled during SAHKE I due to geometrical constraints of the onshore-offshore survey technique (see section 2.4.1.1).

For a detailed description of deployment locations and instrumentation used during this survey see Appendix A. 


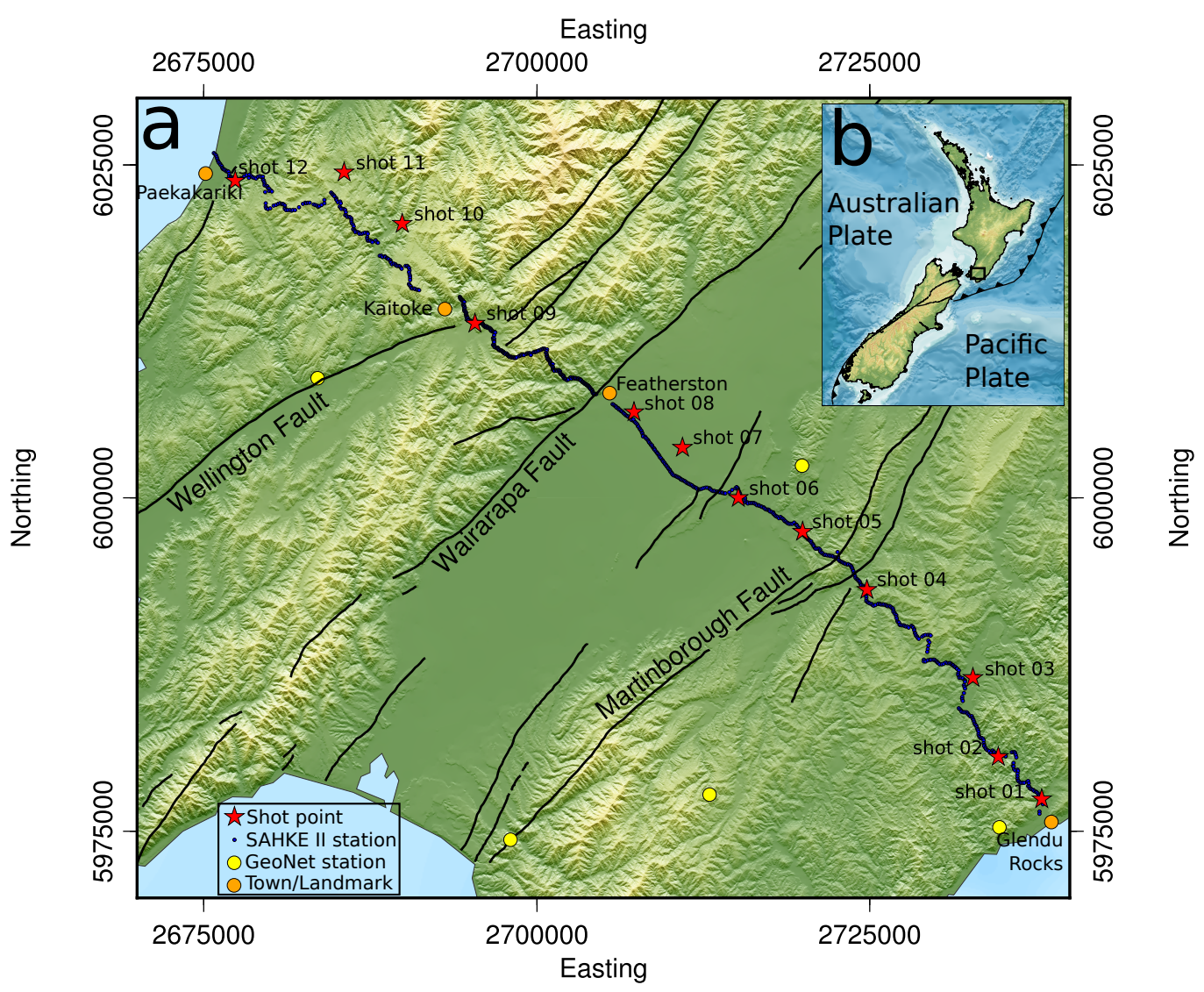

Figure 2.2: (a) Regional location map displaying the geometry of the onshore SAHKE II survey. Red stars are shot locations, blue circles are temporary short period seismometers sites and yellow circles are permanent GeoNet seismometers. Solid black lines are major mapped faults. (b) Inset showing the location of (a) (black box). Bathymetry data are sourced from the National Institute Water and Atmospheric Research (NIWA) chart No. 85 (CANZ, 2008).

\subsection{Data}

Three complementary datasets were acquired during the active source section of SAHKE:

1. Offshore Multi-channel-seismic reflection data.

2. Onshore-Offshore wide-angle reflection/refraction (receiver gather) data.

3. Onshore wide-angle reflection/refraction (shot gather) data. 
4. Offsohre OBS wide-angle reflection/refraction (receiver gather) data.

Datasets 1, 2 and 3 are used collectively to constrain two 2-D crustal scale $\mathrm{P}$-wave velocity models presented in Chapters 4 and 5 .

Appendix A outlines data acquisition parameters and processing of each of these datasets in detail.

\subsection{Seismic Surveying Methodology}

\subsubsection{Seismic wave theory}

The interpretation of seismic data within this thesis is chiefly concerned with travel-time analysis of $\mathrm{P}$-wave phase arrivals interpreted on wide-angle reflection and refraction gathers. When interpreting phase arrivals on gathers such as these, it is also important to consider simple ray theory when assessing apparent velocities (phase gradients) and phase amplitudes.

\section{Seismic ray theory}

It is assumed that seismic wave propagation can be approximated using raypaths opposed to a wave front. Although this method does not fully describe some important aspects of wave propagation, it greatly simplifies analysis when using travel-time data and provides a reasonable approximation of seismic wave behavior (Stein and Wysession, 2003).

\section{Seismic reflections}

When a $\mathrm{P}$-wave ray is obliquely incident to an interface, across which there is an acoustic impedance $(\mathrm{Z})$ contrast, the incident ray is split into both reflected and refracted $\mathrm{P}$ and S-waves (Fig. 2.3) of which the total energy is 


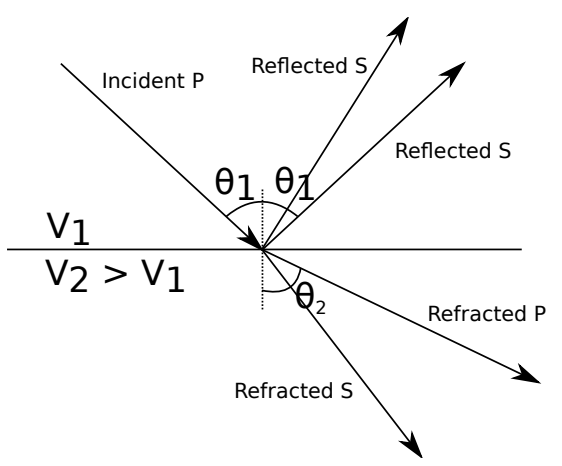

Figure 2.3: Schematic sketch illustrating Snell's Law and the partitioning of an incident wave into reflected and refracted $\mathrm{P}$ and $\mathrm{S}$-waves at an interface of acoustic impedance contrast. $\theta_{1}=$ angle of incidence/reflection, $\theta_{2}=$ angle of refraction, $v_{1}=$ medium velocity in layer one and $v_{2}=$ medium velocity in layer two.

equal to the incident ray (Kearey et al., 2002). The amplitude of the four phases are dependent on $\mathrm{Z}$ and the angle of incident $\theta$ where $\mathrm{Z}$ is calculated as

$$
Z=p v
$$

and $\rho$ is material density and $v$ is wave velocity. It is therefore important to consider potential variations in phase amplitude caused by different velocity and density contrasts and increasing source-receiver offset (incident angle) when interpreting wide-angle refections.

\section{Seismic refractions}

The angle of refraction (Fig. 2.3) is dependent on Snell's Law (Eq. 2.2 ), which states that the ratio of the sines of the angles of incidence $\theta_{1}$ and refraction $\theta_{2}$ across a boundary between two media, is equivalent to the ratio of phase velocities $v_{1}$ and $v_{2}$ within the two media. 


$$
\begin{array}{r}
\frac{\sin \theta_{1}}{\sin \theta_{2}}=\frac{V_{1}}{V_{2}} \\
\theta_{1}=\sin ^{-1}\left(\frac{V_{1} \cdot \sin \theta_{2}}{V_{2}}\right)
\end{array}
$$

When the incident angle reaches a certain angle, the critical angle $\left(\theta_{c}\right)$ the refraction angle becomes $90^{\circ}$ (Equation 2.3) and the refraction ray travels just below the layer interface at velocity $V_{2}$.

When considering crustal scale velocity structure, it is often the case that velocity will vary gradually as a function of depth, usually due to progressive compaction effects (Kearey et al., 2002). In this case, rays are continuously refracted such that they follow curved ray paths. These are known as "turning" or "diving waves" (Cerveny and Ravindra, 1971) and are central to the analysis conducted in this thesis.

$$
\theta_{c}=\sin ^{-1}\left(v_{1} / v_{2}\right)
$$

\subsubsection{Onshore-Offshore seismic surveying methodology}

As discussed in Section 2.1, onshore-offshore seismic profiling provides a robust method for imaging areas where important subsurface structure spans the coastline. This technique is applied by utilizing moderate-towidely spaced onshore seismometers to record seismic energy emanating from densely spaced offshore air-gun blasts (Fig. 2.4). 
a) Broadly spaced onshore seismometers

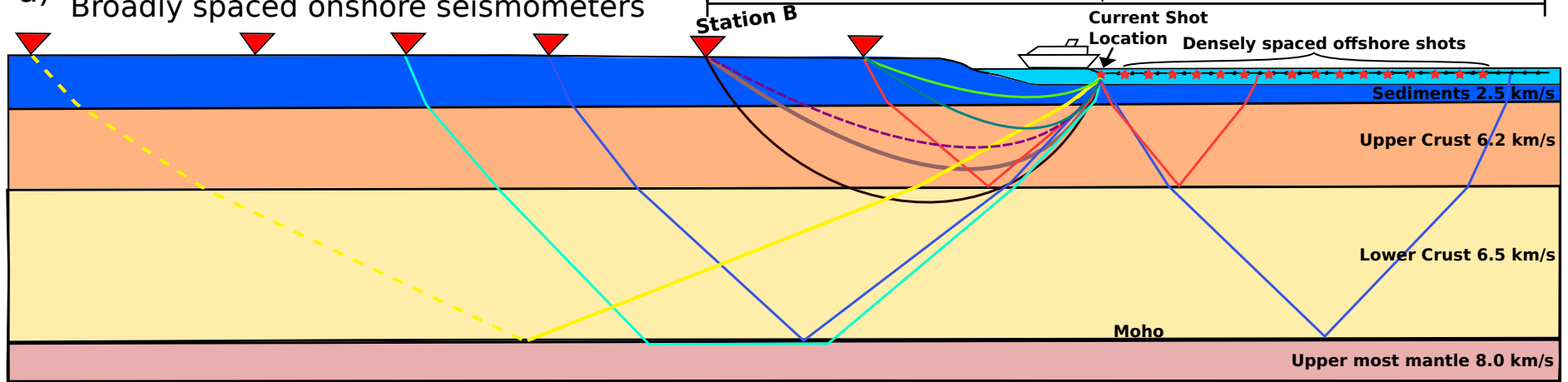

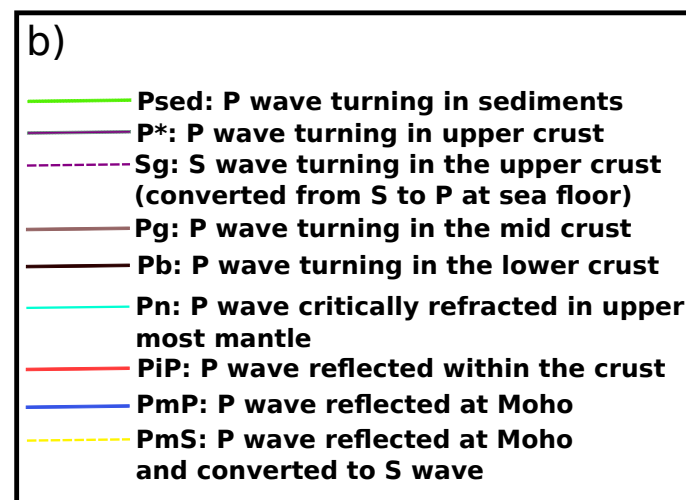
and converted to $S$ wave

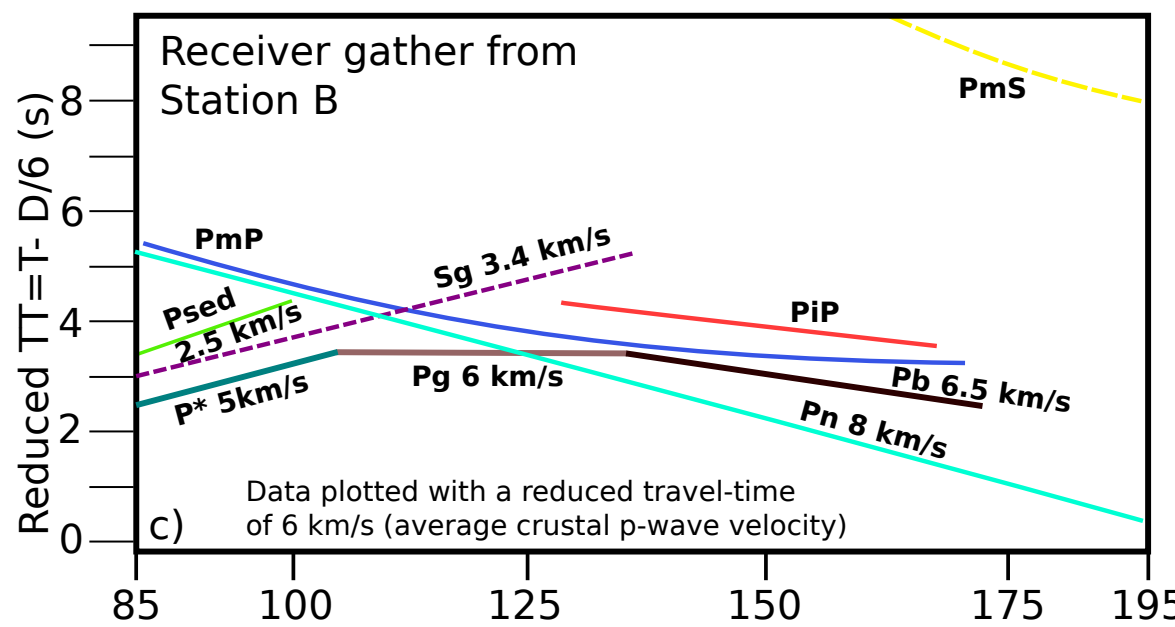

Distance $(\mathrm{km})$

Figure 2.4: Schematic illustration of onshore-offshore wide-angle reflection/refraction survey geometry. Coloured lines represent ray paths of typical wave phases observed on receiver gathers emanating from the current shot location (labelled red star) to several onshore seismometers (red triangles). Previous shot locations (red stars) are also shown. 
This allows a broad aperture of source-receiver offsets to be recorded at each seismometer, within which, all raypaths sample the subsurface both onshore and offshore, including the continental-oceanic transition (Okaya et al., 2003). Data recorded at each seismometer is then used to construct a "common-receiver" gather (see Section 2.4.1.2), that can be interpreted and inverted to solve for crustal velocity structure.

\subsubsection{Common receiver gather methodology}

The theory of wave reciprocity predicts that the path any given seismic wave travels, will be identical for equally positioned shot and receiver pairs (Knopoff and Gangi, 1959). For example, in figure 2.6, a ray traveling from shot 'A' to receiver ' $\mathrm{B}$ ' will travel an identical path to a ray traveling from shot 'B' to receiver ' $\mathrm{A}$ '. This result allows data recorded at a common-receiver during the shooting of an offshore MCS profile, to be used to compile a "common-receiver" gather. Essentially, a receiver gather is the equivalent of a classical shot gather in which the receiver becomes the shot location and the offshore air-gun sources become receivers.

Figure 2.4c shows a theoretical receiver gather constructed from data collected at the onshore station B (Fig. 2.4a). The seismic phases displayed on this gather are those typically recorded during crustal scale onshore-offshore surveying. In this study, interpretations are limited to P-waves only. Figure 2.5 shows an example of a receiver gather collected as part of the SAHKE. This gather was collected at station KIW during the shooting of MCS line SAHKE03. The gather is plotted with true source-receiver offset and a reduced travel-time of $6 \mathrm{kms}^{-1}$. The gap between traces at offsets $-5.4 \mathrm{~km}$ $5.4 \mathrm{~km}$ occurs because the MCS line SAHKE03 passes the location of station KIW (Fig. 2.5c), offsets to the north are plotted as positive and to the south as negative. All phase arrivals are interpreted on this gather, however, only $\mathrm{P}$-wave phases $P g, P p P_{1}$ and $P p P_{2}$ are used for further analysis in this 
thesis. $P p P_{1}$ and $P p P_{2}$ are interpreted as wide-angle reflections from the top of a subducted sediment sheet at the top of the Pacific slab and the top of subducted oceanic crust as discussed below. 
a)

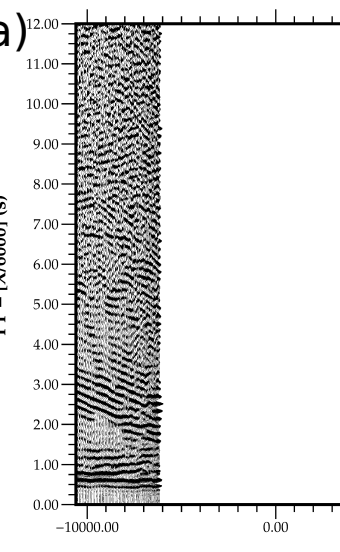

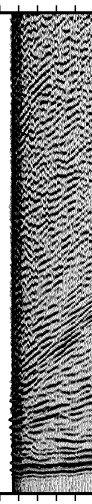
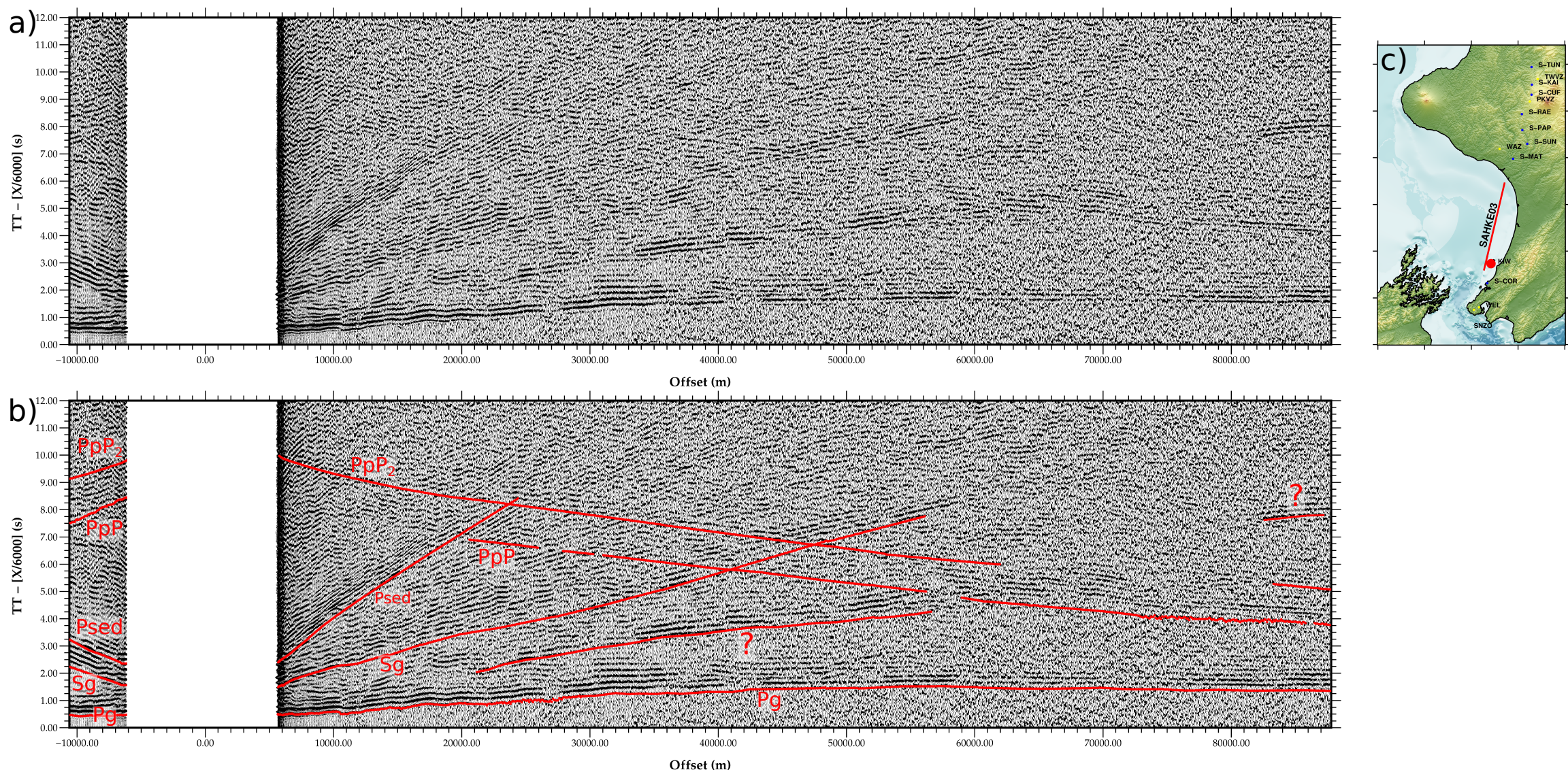

Figure 2.5: SAHKE03 receiver gather collected at station KIW displaying all identified phase arrivals (as labelled). This gather has been processed using a full trace length debias, $\left[\begin{array}{llll}1 & 3 & 8 & 12\end{array}\right] \mathrm{Hz}$ bandpass filter and $3000 \mathrm{~ms}$ window length automatic gain control. (a) Uninterpreted gather. (b) Same as in (a) with phase picks overlaid. (c) inset map showing the receiver location. 
2. Survey geometry and methodology
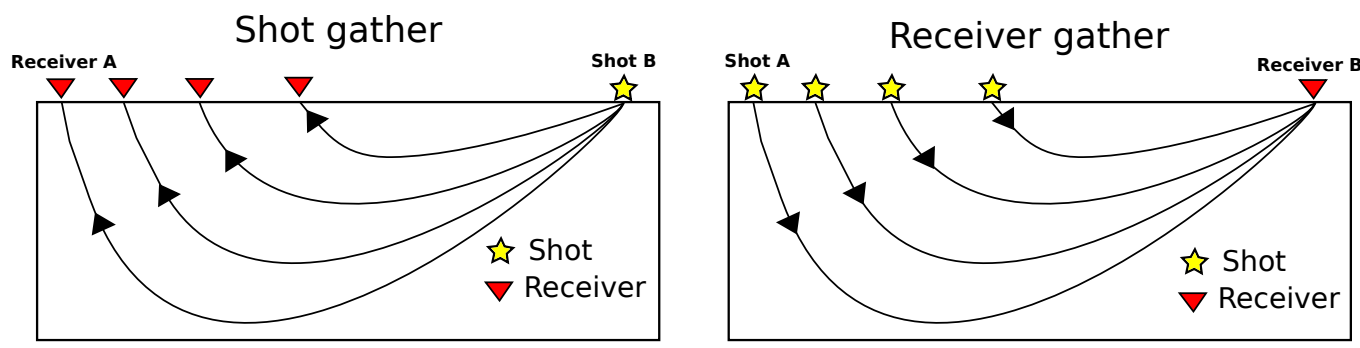

Figure 2.6: Schematic illustration showing a comparison of shot gather and receiver gather geometries. Shots are shown as yellow stars and receivers as red triangles. Note rays travelling between equally spaced shot-receiver pairs follow reciprocal raypaths.

A receiver gather is compiled by extracting set lengths of data (each representing an individual trace on the final gather) from a receivers continuous seismograph time series. The beginning of each trace is coincident with the time that the corresponding offshore air-gun shot was fired. Accurate timing between the offshore shot record and onshore seismometer is achieved by precisely synchronising the GPS shot-times recorded on-board the acquisition vessel with the internal clock of each seismometer. Traces are plotted side-by-side in ascending order according to shot number (and hence offset), thus creating a time vs. offset seismic gather. Wave phases visible on these gathers can then be interpreted as one would interpret a classical shot gather. This process is depicted in Figure 2.7.

\subsubsection{Receiver gather display: reduced travel-time}

Wide-angle reflection and refraction datasets usually include a large range of source-receiver offsets, ranging from a few kilometers to hundreds of kilometers. The SAHKE dataset is no exception, with offsets ranging from $\sim 100$ $\mathrm{m}$ to $280 \mathrm{~km}$. In order to aid in the identification of late arriving phases from far offsets that often exhibit weak coherency, a reduced time scale is used. The reduced travel-time $T$ for an event arriving at time $t$ and offset $x$ is calculated as:

$$
T=t-X / V_{r}
$$




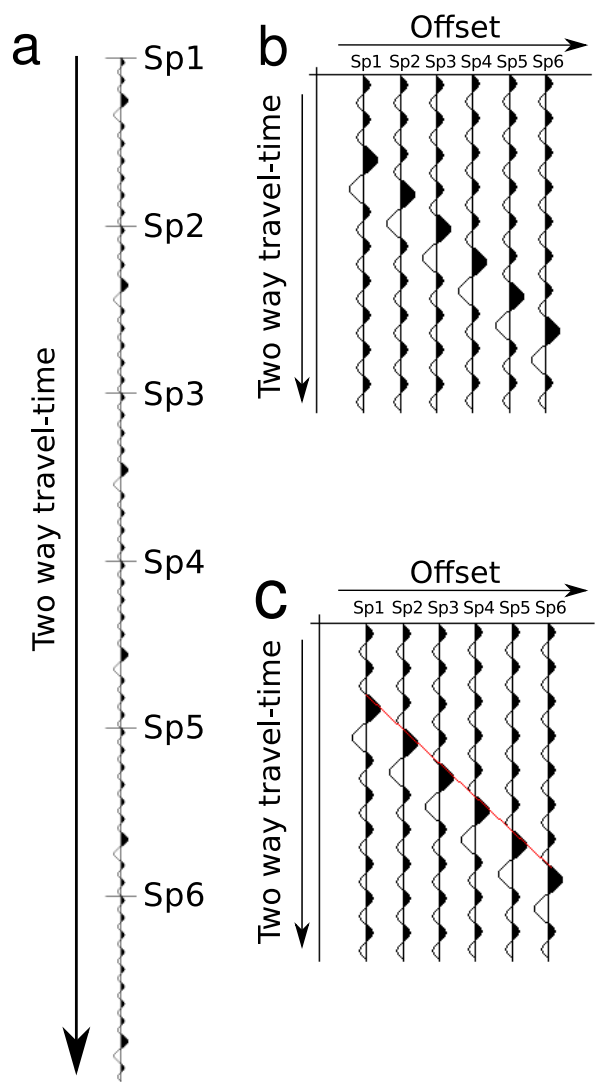

Figure 2.7: (a) A theoretical continuous seismogram time series recorded at an onshore seismograph during the shooting of an onshore-offshore MCS line. (b) A receiver gather created from (a) by extracting set lengths of data from the continuous seismogram based on the MCS shot points (labeled Sp 1-6). (c) Interpretation of a first arrival (red line) from receiver gather (b).

Where $V_{r}$ is a scaling factor known as reduction velocity (Kearey et al., 2002). This has the effect of progressively reducing travel-time as a function of offset, such that a wave phase with an apparent velocity equal to the reduction velocity will plot as a horizontal arrival (Pg, Fig. 2.4). Furthermore, a phase with a velocity greater than $V_{r}$ will plot a positive gradient (Pn, Fig. 2.4) and a phase with a velocity less than $V_{r}$ will plot with a negative gradient (P*, Fig. 2.4). 


\subsection{Data processing}

A suite of 44 receiver gathers were created from the subset of onshore/offshore wide-angle reflection and refraction data collected during SAHKE within the Wanganui Basin. This was achieved using IRIS Passcal (www.passcal.nmt.edu) utility codes. Furthermore, twelve onshore shot gathers, collected during SAHKE II, were complied by IRIS PASSCAL technicians.

Seismic processing of each gather was predominantly carried out interactively using the Seismic Viewer (sv) application embedded within the seismic processing software Globe Claritas $^{T M}$. A variety of seismic processing techniques were applied to each receiver gather in order to increase signalto-noise ratio in an attempt to 'illuminate' phase arrivals. The majority of these processing techniques were applied on-the-fly with the sv application, and were varied throughout the interpretation process in order to enhance the coherency of individual phase arrivals. These techniques included frequency filtering, automatic gain control, trace balancing, trace debiasing and traveltime reductions. After frequency filtering, manipulation of both the aspect ratio and data display type of each gather were the most useful tools for increasing wave phase clarity. Further processing included runmix trace summing and predictive deconvolution. These processes were unable to be applied within sv and therefore required creation of separate SEG-Y files. A comprehensive explanation of the steps and parameters used in the construction and processing these data is presented in Appendix A.

\subsection{Receiver gather interpretation and un- certainty}

Receiver gathers were interpreted using the sv application within Claritas. Picks were limited to P-wave arrivals and of the 44 receiver gathers and 12 
shot gathers created, from which picks were made on 41 receiver gathers and all shot gathers, with 142 individual phases interpreted and $\sim 45,000$ travel-time picks made.

Phases were identified by eye and picked using a semi-automated crosscorrelation function or manually when the signal-to-noise ratio (signalto-noise ratio) was sufficiently low. Initial picks were limited to those phases that were easily identified, namely first arrivals and some later arriving wide-angle reflections. These were used to develop preliminary P-wave velocity ( $\mathrm{Vp}$ ) models, from which synthetic travel-time arrivals where calculated and overlaid upon each receiver gather. These plots were used to aid in the identification of weakly coherent phases and test the reproducibility of original travel-time picks. In this way, picks were adjusted concurrently with the development of each model. An advantage to this approach is that it allowed for the systematic adjustment or removal of picks that were evidently erroneous when considered in relation to the fit of travel-time picks from proximal stations.

Pick uncertainties were assigned by inspection, while considering signal-tonoise ratio and coherency of each phase. Uncertainty values ranged from 70 $\mathrm{ms}$ to $200 \mathrm{~ms}$ with the vast majority set as $100 \mathrm{~ms}$.

\subsection{Data observations}

Interpretations of the receiver gathers constructed from onshore/offshore data acquired during SAHKE I, and shot gathers acquired during SAHKE II are presented here. The purpose of this section is to show the character of phase arrivals identified on these gathers as these are the primary constraints used to develop the two 2-D crustal velocity models presented in the Chapters 4 and 5 . 
2. Survey geometry and methodology

\subsubsection{SAHKE03 receiver gather observations}

Arrivals identified on receiver gathers collected on the SAHKE03 transect during the shooting of MCS line SAHKE03 are divided geographically into three distinct groups, a southern, central and northern group. The data quality of these gathers is mostly good, with clear phase arrivals identified on all gathers except the two most northern stations S-TUN and S-TAP. As expected, data quality generally decreases with increasing offset towards the north. However, the two gathers that make up the northern group (S-KAI and TWVZ) exhibit reflections that are amongst the most coherence within the dataset.

\subsubsection{Southern group}

The southern group consists of stations SNZO, WEL, S-COR and KIW (Fig. 2.1). Stations SNZO, WEL and S-COR are located south of the SAHKE03 MCS profile, while the final station, KIW, is located on Kapiti Island, adjacent to the eastern side of this profile.

Gathers recorded at stations SNZO, S-COR and KIW have a high signalto-noise ratio, and display highly coherent first arrivals at offsets between 5 and $110 \mathrm{~km}$ and reduced travels-times of 250 - 1500 msec (Figs. 2.8 and 2.10). Apparent velocities of these phase arrivals increase from $\sim 5$ $k m s^{-1}$ at near offsets to $\sim 6 k m s^{-1}$ at further offsets $(>45 \mathrm{~km})$. These phases are interpreted as upper crustal refractions $(P g)$. This phase is also visible on the gather from S-MAT, however the offset range is limited to 40 - $45 \mathrm{~km}$ due to a low signal-to-noise ratio. Combined with the coincident SAHKE03 MCS reflection data, these arrivals provide good constraints on sedimentary basin and upper crustal velocity structure at the southern end of the SAHKE03 model transect.

Stations SNZO, S-COR and KIW also exhibit a package of later ar- 
riving energy that tends to be curved and are prominent at far offsets. These are interpreted as a series of wide angle reflections. This package is characterised by a low coherent, low amplitude initial arrival (phase $P p P$; Figs. 2.8, 2.9, 2.10 and 2.11), followed by a series of complex later arrivals, some of which display much higher amplitudes and coherence relative to the initial arrival. The initial low amplitude arrival is interpreted as a reflection from the Australian-Pacific plate interface and the later arriving coda are attributed to short path multiples. These multiples may be caused by wave reverberations in the near surface and/or within the presumably complex plate interface zone. At near offsets, interference from crustal reverberations masks these arrivals and prevents confident identification of this phase.

On gather KIW, a second reflection, distinct from the package of reflectively related to phase $P p P$, is also interpreted $\left(\mathrm{PpP}_{2}\right.$; Fig. 2.10). This reflection has a curvature similar to that of $P p P$ and given the time of delay of $\sim 1.4$ s reduced travel-time between this reflection and $P p P$, is interpreted as the base of the plate interface zone and top of the subducting oceanic crust. A second reflection, PbaseP, is also identified on the SNZO gather. This reflection is only identified at far offsets $(125-140 \mathrm{~km})$ and is deep (3.5 - 4 sec reduced travel-time). This is interpreted as the base of the subducting oceanic crust. 


\section{gr}
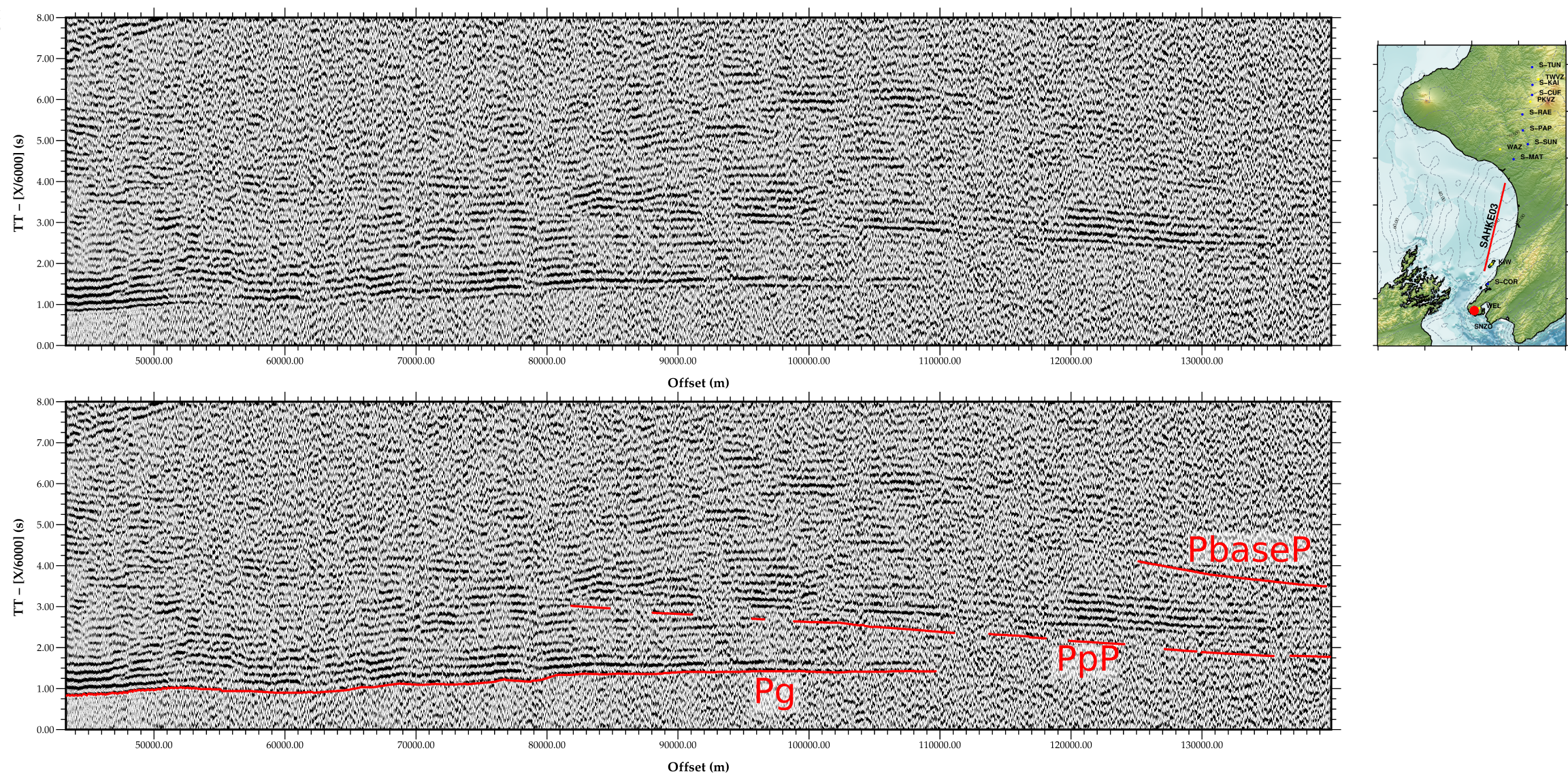

Figure 2.8: SAHKE03 receiver gather collected at station SNZO. (a) Uninterpreted gather processed using a full trace length debias, [1 38 12] Hz bandpass filter and $3000 \mathrm{~ms}$ window length automatic gain control. (b) Same as in (a) with phase picks overlaid. (c) inset map showing the receiver location. 

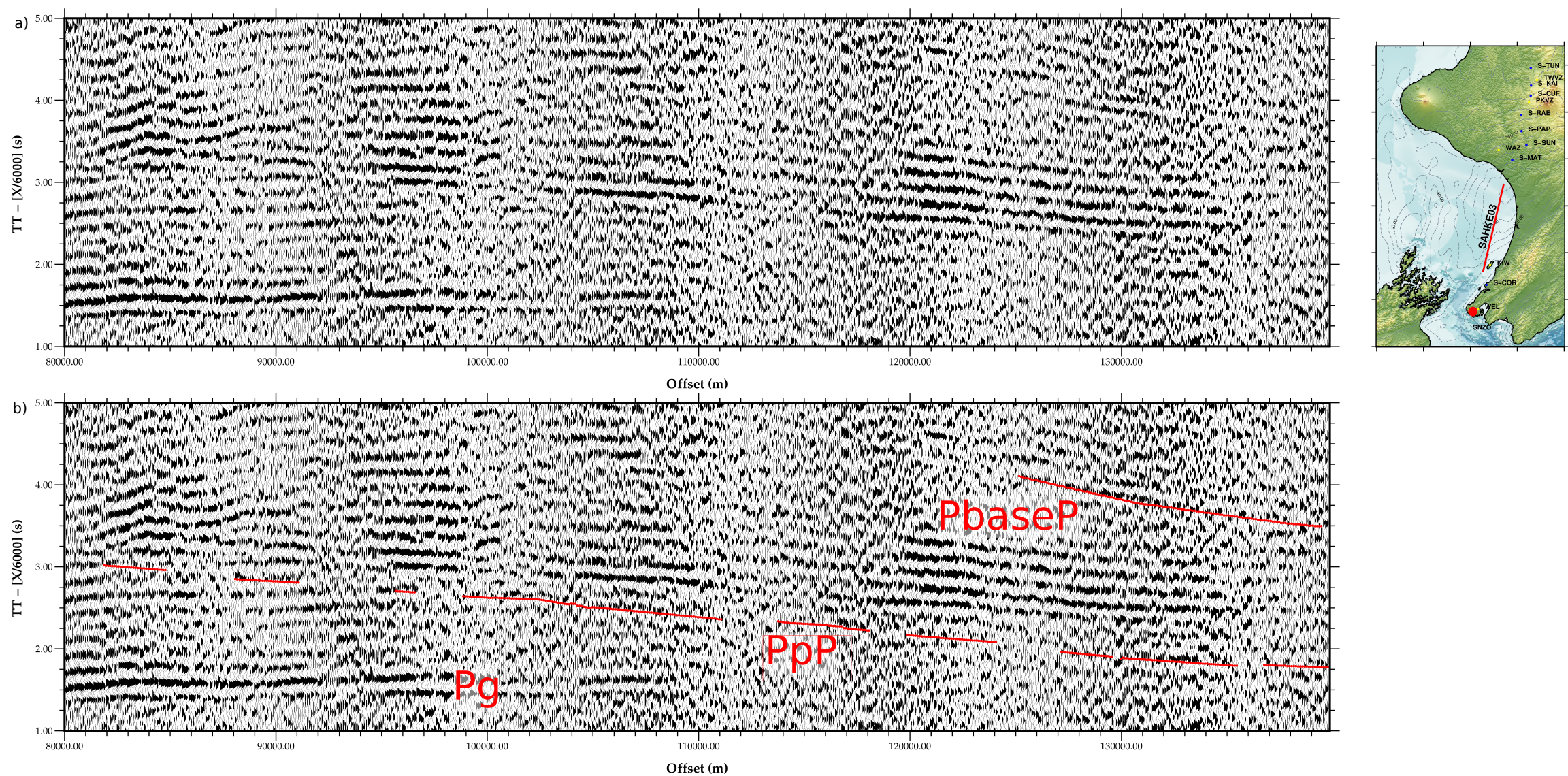

Figure 2.9: Selected section of the SAHKE03 receiver gather collected at station SNZO displaying identified wide angle reflections processed using a full trace length debias, $\left[\begin{array}{llll}1 & 3 & 8 & 12\end{array}\right] \mathrm{Hz}$ bandpass filter and $3000 \mathrm{~ms}$ window length automatic gain control. (a) Uninterpreted gather. (b) Same as in (a) with phase picks overlaid. (c) inset map showing the receiver location. 

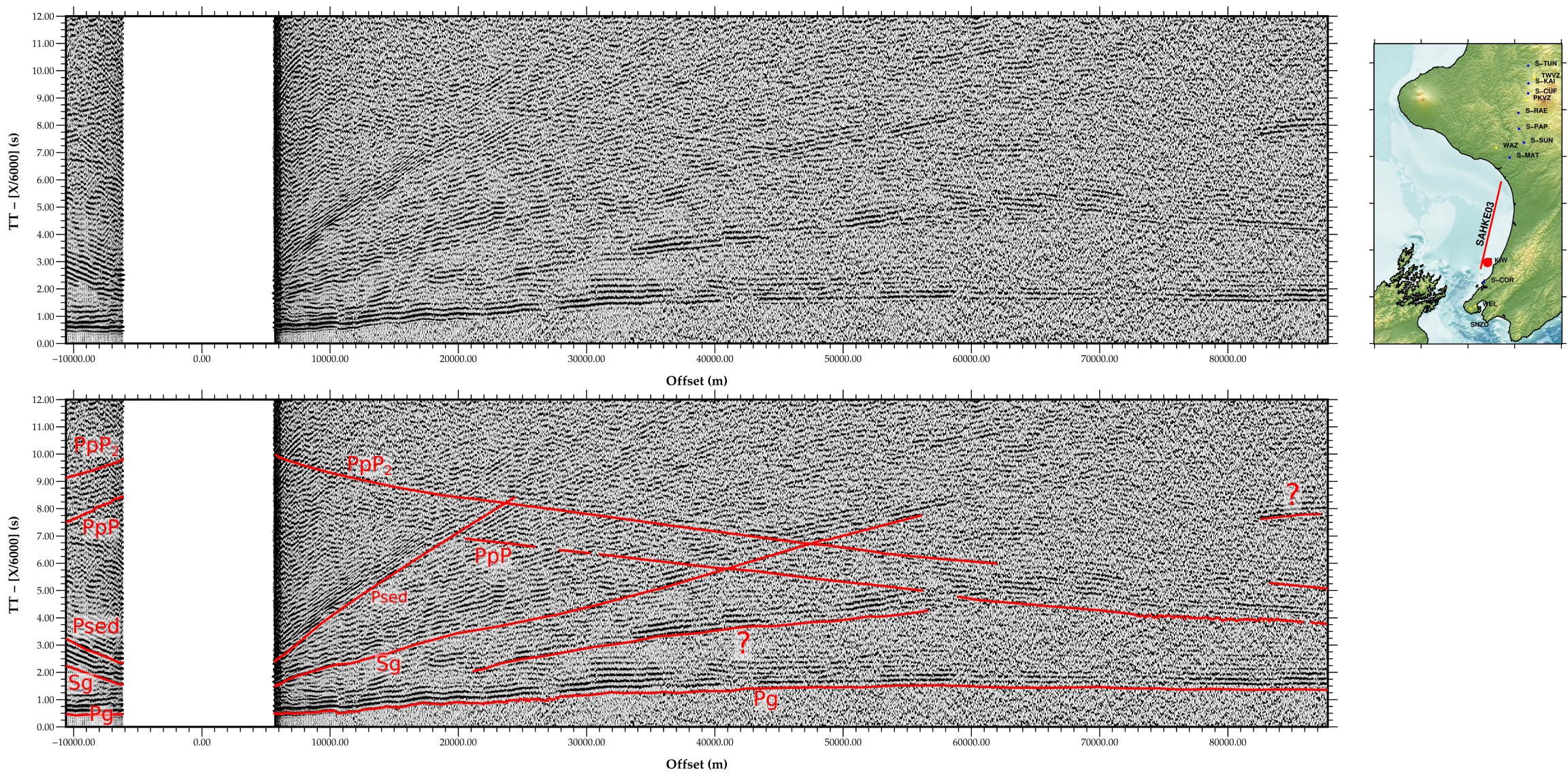

Figure 2.10: SAHKE03 receiver gather collected at station KIW. (a) Uninterpreted gather processed using a full trace length debias, $\left[\begin{array}{l}13 \\ 8\end{array} 12\right] \mathrm{Hz}$ bandpass filter and $3000 \mathrm{~ms}$ window length automatic gain control. (b) Same as in (a) with phase picks overlaid. (c) inset map showing the receiver location. 

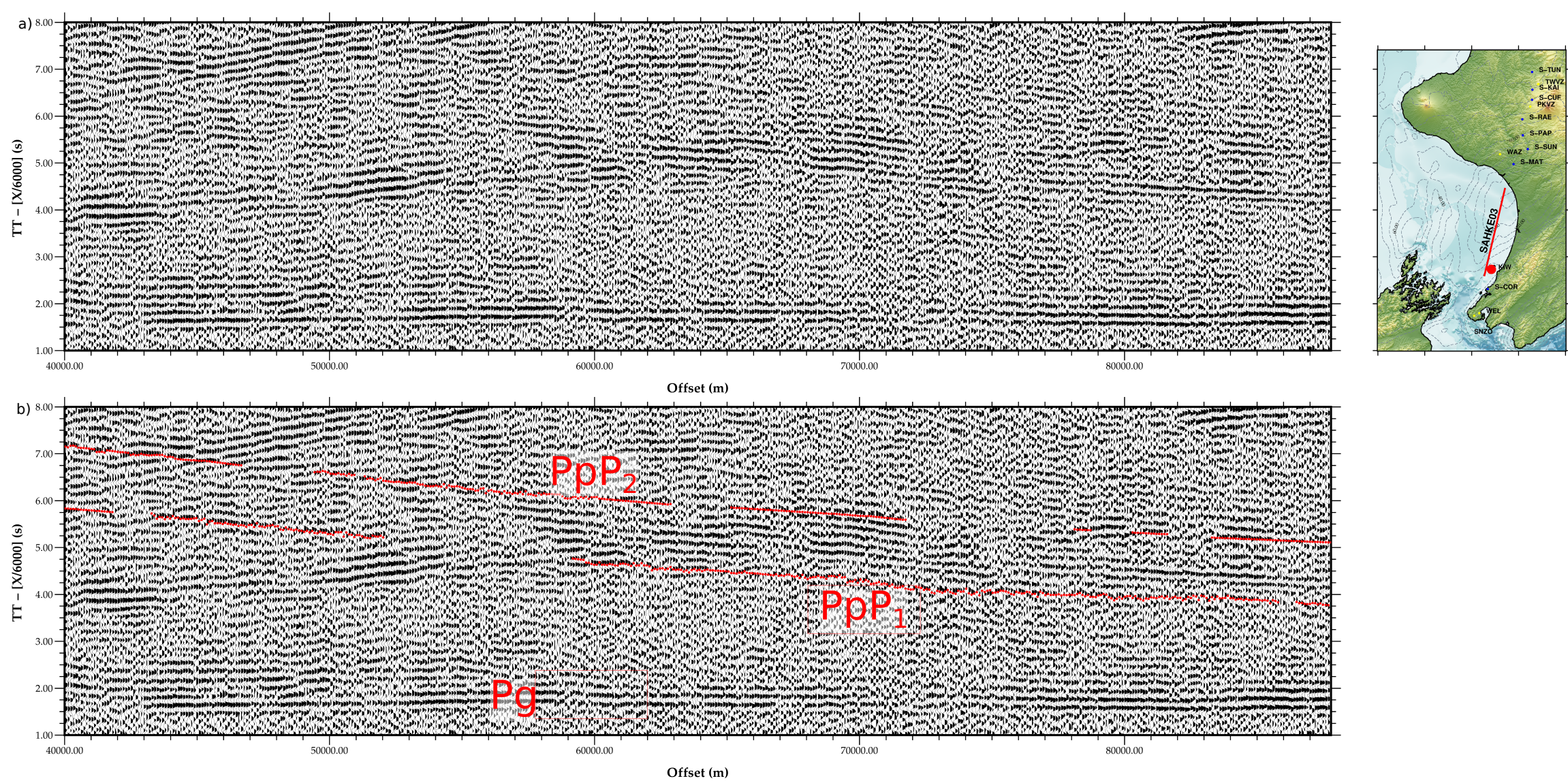

Figure 2.11: Selected section of the SAHKE03 receiver gather collected at station KIW displaying identified wide angle reflections processed using a full trace length debias, $\left[\begin{array}{llll}1 & 3 & 8 & 12\end{array}\right] \mathrm{Hz}$ bandpass filter and $3000 \mathrm{~ms}$ window length automatic gain control. (b) Same as in (a) with phase picks overlaid. (c) inset map showing the receiver location. 


\subsubsection{Central group}

The central group consists of stations between S-MAT and S-CUF (Fig. 2.1). At near offsets, these gathers display first arrivals similar to those observed on stations from the southern group, with apparent velocities of $\sim$ $6 \mathrm{kms}^{-1}$. At further offsets, first arrivals identified on gathers between WAZ and S-CUF display a marked change in apparent velocity increasing to $>7$ $k m s^{-1}$. These arrivals are interpreted as bending waves that sample higher velocity rocks at greater depths than those previously described, with ray tracing results suggesting this phase remains in the upper crust.

With the exception of S-MAT, a later arriving phase is also visible on all gathers in this group. These are interpreted as pre-critical wide angle reflections and are distinguishable at offsets between 70 and $180 \mathrm{~km}(\mathrm{PmP}$; Figs 2.12 and 2.13). These reflections are interpreted as the Australian plate Moho, which is thought to occur at depths of $\sim 35-42 \mathrm{~km}$ in the central section of the SAHKE03 model transect (Ewig, 2009; Salmon et al., 2011). 

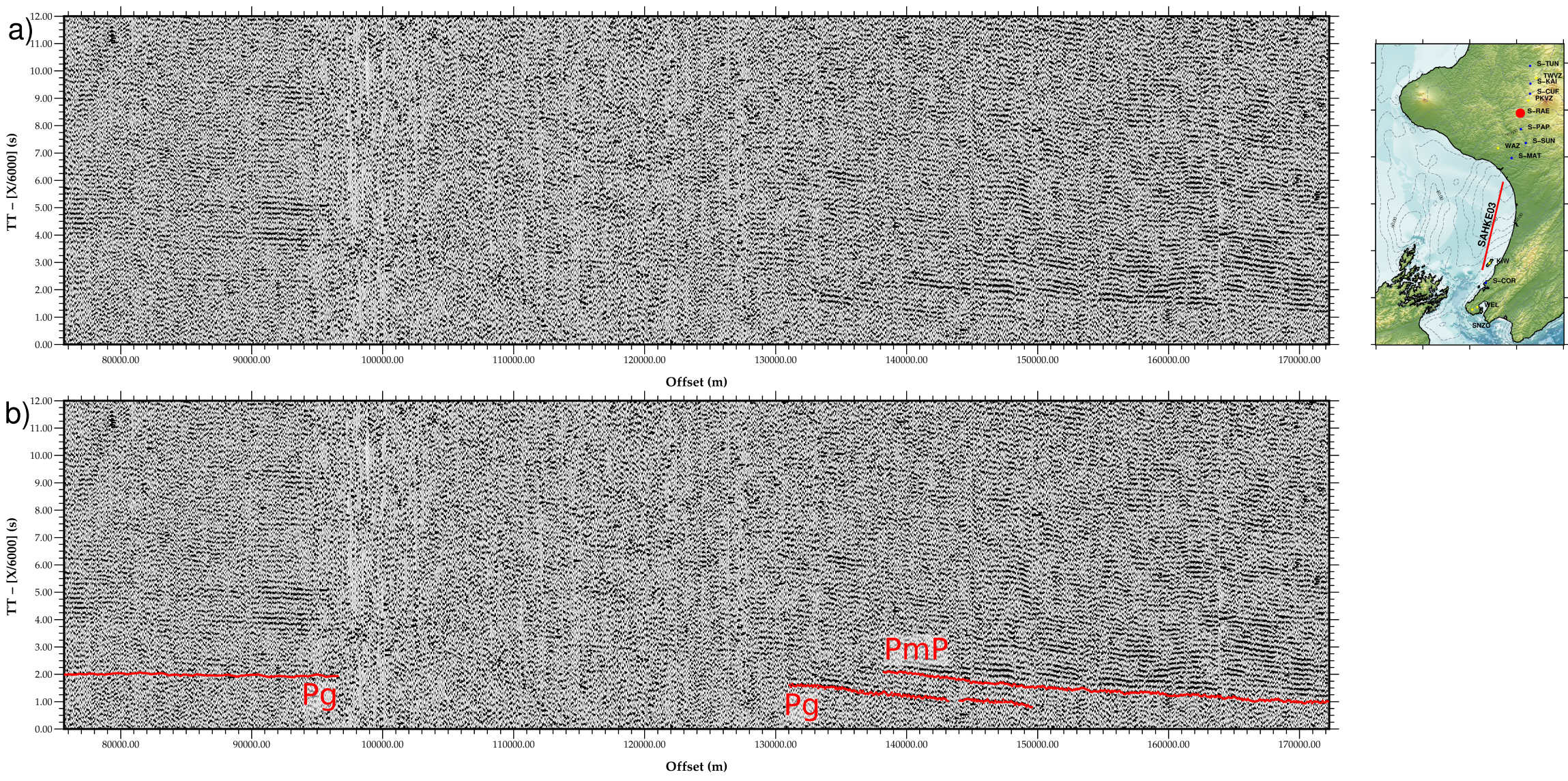

Figure 2.12: SAHKE03 receiver gather collected at station S-RAE. (a) Uninterpreted gather processed using a full trace length debias, [1 38 12] Hz bandpass filter and $3000 \mathrm{~ms}$ window length automatic gain control. (b) Same as in (a) with phase picks overlaid. (c) inset map showing the receiver location. 

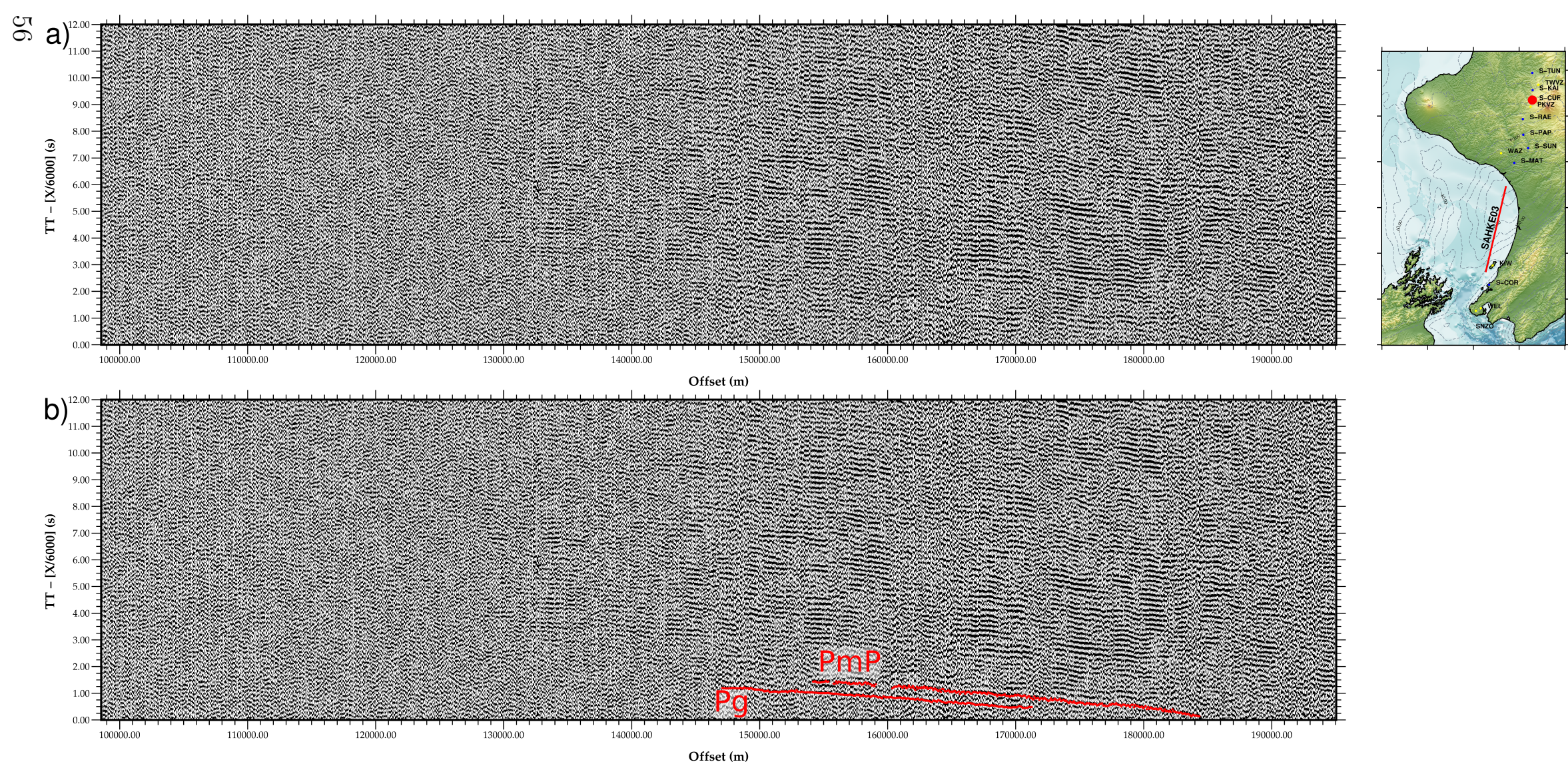

Figure 2.13: SAHKE03 receiver gather collected at station S-CUF. (a) Uninterpreted gather processed using a full trace length debias, [1 38 12] Hz bandpass filter and $3000 \mathrm{~ms}$ window length automatic gain control. (b) Same as in (a) with phase picks overlaid. (c) inset map showing the receiver location. 


\subsubsection{Northern group}

The northern group consists of stations S-KAI and TWVZ, located north of Mt Ruapehu, within the Otunui Basin. Both of these stations exhibit high amplitude phase arrivals at offsets between (109 - $140 \mathrm{~km})$, interpreted as wide angle reflections. The amplitudes of these reflections decrease rapidly at offsets of $\sim 140$ and $138 \mathrm{~km}$ at S-KAI and TWVZ respectively. Given the dramatic change in character of these reflectors, compared to those identified on gathers further to the south (Figs. 2.12 and 2.13), it appears these reflections are of a fundamentally different nature.

One possibility is that these reflections originate from a different interface to those observed gathers in the central groups, over which the acoustic impedance contrast is markedly higher. Alternatively, these reflections may originate from the same interface as those observed in the central section, with the high amplitudes resulting from an amplitude variation with offset (AVO) effect. That is, these reflections may have incidence angles close to the critical angle, at which the reflection coefficient reaches its maximum. Furthermore, within the offset range recorded on these gathers, it is possible that diffracted phase arrivals, from a deep ( $>20 \mathrm{~km}$ ) diffractor may occur with travel-times and normal-moveout velocities comparable to wide-angle reflections. A decrease in the amplitude of phase arrivals, like that visible within these gathers, is also characteristic of diffractions. Given that a step in crustal thickness of $\sim 7 \mathrm{~km}$ is proposed to occur a few kilometers south of these stations (TRL, Fig. 2.1; Salmon et al., 2011) diffracted arrivals may be expected from this structure. This possibility is explored in Section 6.9. 


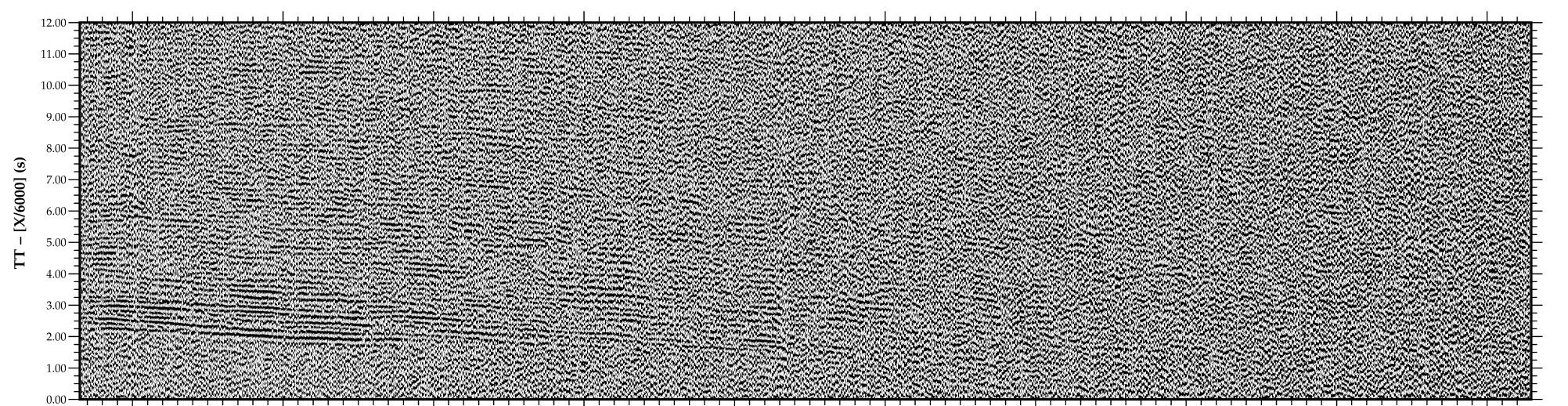

120000.00

130000.00

140000.00

15000.00

160000.0

Offset (m)
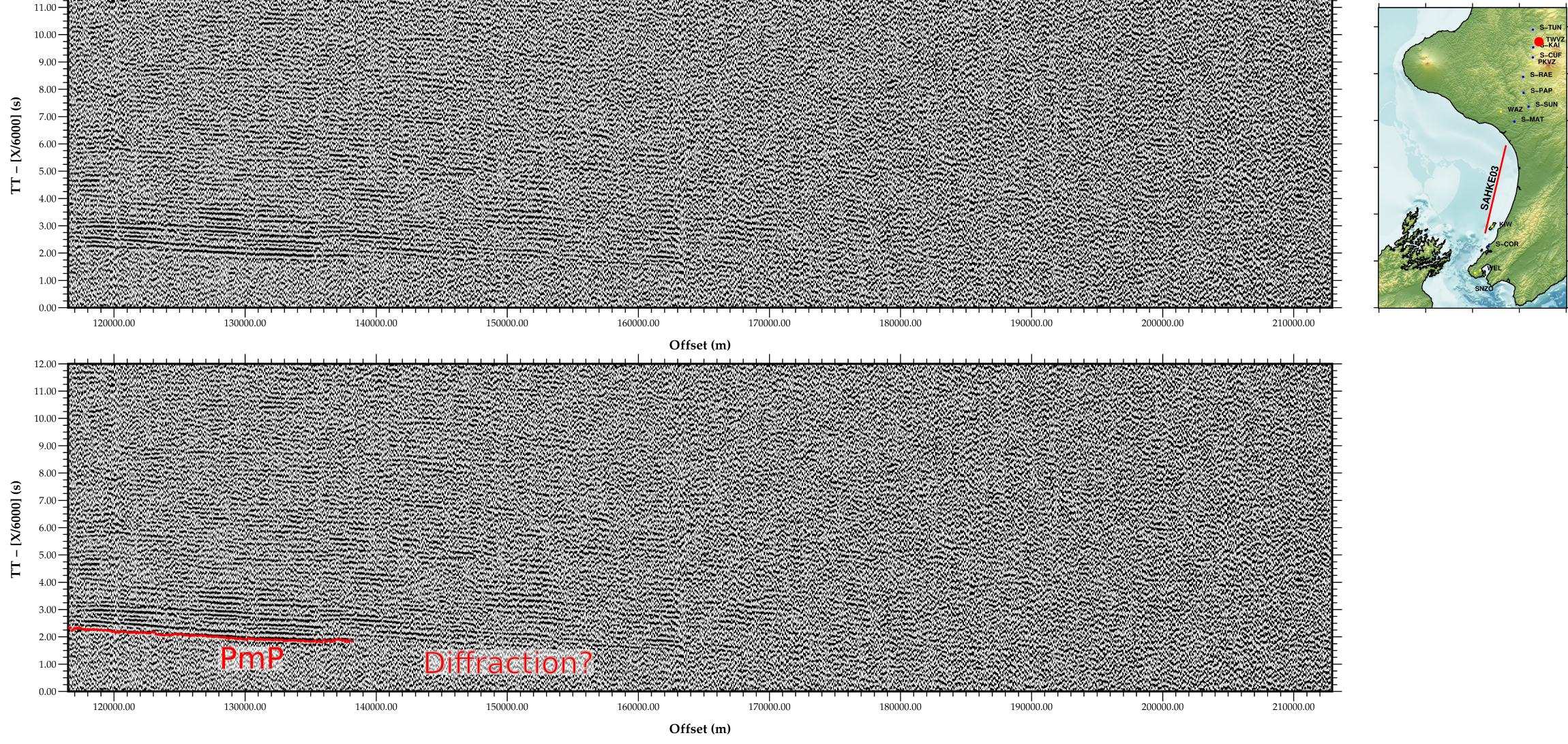

Figure 2.14: SAHKE03 receiver gather collected at station TWVZ. (a) Uninterpreted gather processed using a full trace length debias, [1 38 12] Hz bandpass filter and $3000 \mathrm{~ms}$ window length automatic gain control. (b) Same as in (a) with phase picks overlaid. (c) inset map showing the receiver location. 
2.7. Data observations

\subsubsection{SAHKE02 observations}

The character of phase arrivals identified on receiver gathers constructed from data collected on the SAHKE02 transect during the shooting of MCS line SAHKE02, are similar for all stations. The data quality of these gathers is good, but generally decreases from west to east. Furthermore, due to the curvature and layered complexity of the subducting Hikurangi Plateau, it is unclear as to whether late arriving reflections identified on each of these gathers are likely to have reflected from the same interface or several different interfaces. Hence, interpretations of the origin of these phase arrivals where made concurrent to their modelling (see Chapter 5).

Strongly coherent first arrivals are identified at offsets between 10 and $110 \mathrm{~km}$ and reduced travels-times of 750 - $1500 \mathrm{~ms}$ at stations between TS038 and TS006 (Pg; Figs. 2.15, 2.16 and 2.18). Apparent velocities of these phase arrivals are consistently $\sim 5.1 \mathrm{kms}^{-1}$ at near offsets $(<40 \mathrm{~km})$, increasing to $\sim 6.2 \mathrm{kms}^{-1}$ at further offsets. These are interpreted as upper crustal refractions $(\mathrm{Pg})$. These arrivals, in-conjunction with refractions recorded during SAHKE II (see Section 2.7.3), provide good constraint on the Vp structure of the upper crust within the SAHKE02 model developed in Chapter 5.

Interestingly, on gathers collected on the western side of the transect, these arrivals cease abruptly at offsets between $80-100 \mathrm{~km}$, as do those from a later reflection phase (Fig. 2.15). This is unusual given the high coherence and amplitude of these arrivals at nearer offsets. In the final model this limitation results in a ray coverage gap (see Chapter 5) that spatially corresponds to the eastern margin of Wanganui Basin and the basin bounding Taranaki Fault. One possible explanation for this gap is that a high attenuation zone exists in this location, or alternatively, thick-skinned thrusting on the Taranaki Fault Zone may have juxtaposed lower crustal, higher Vp rocks in within Wanganui Basin, adjacent to lower Vp rocks in Taranaki Basin, resulting in a Vp inversion that could potentially deflect 
rays away from the surface.

Additionally, two distinct pre-critical reflections are identified on these gathers. The first reflection occurs at offsets $<110 \mathrm{~km}$ and reduced travel-times between 6 and 2.5 seconds. This phase decreases in coherency on gathers from west to east between stations TS038 and TS014 (PpP; Figs. 2.15 and 2.16). Further eastward, between stations TS011 - TS001, the arrival time of this phase becomes increasingly later (2.9 seconds on TS011 and 3.2 seconds on TS002) and the coherency and amplitude of this phase increases dramatically ( $P p P$ and PbaseP; Figs. 2.17 and 2.19). Ray tracing results reveal the origin of this phase is not the same for all stations (see Chapter 5). At stations on western and central sections of the transect (TS038 - TS011), this phase appears to originate from the Australian/Pacific plate interface (phase PpP; Figs. 2.15 and 2.17). On stations east of TS011 (TS008 - TS001), this reflection traces to the Moho of the subducting oceanic crust (PbaseP; Figs 2.18 and 2.19). These results suggest an AVO effect, west to east along this transect, with no single gather exhibiting both of these arrivals. In contrast, shot gathers acquired during SAHKE II at more near vertical incidence angles, exhibit at least three distinct pre-critical reflections on a single gather (see Section 2.7.3).

The second reflection occurs at far offsets $(>100 \mathrm{~km})$ and reduced travel-times between 1 - 3.2 seconds, on gathers on the western side of the transect (stations TS038 - TS027). Given these offsets and travel-times, these arrivals are interpreted as Moho reflections from the base of the Australian plate crust (PmP; Fig. 2.15). An alternative interpretation is that these phase arrivals are refractions within the upper most mantle $(\mathrm{Pn})$ based on an apparent velocities of $7.5-8 \mathrm{kms}^{-1}$. However, using ray tracing, upper mantle refractions proved difficult to reconcile with the observed travel-time arrivals and hence the former interpretation is preferred in this study.

On gathers east of station TS025, this phase begins to arrive later and 
becomes less coherent, with an apparent velocity of $\sim 7.2 \mathrm{kms}^{-1}(P n$; Figs. 2.16, 2.18 and 2.19). These phases are interpreted as refractions within the subducting oceanic crust and provide the only velocity control on this layer within the SAHKE dataset.

Additionally, gathers collected at the western end of this transect (TS038 TS025) display two additional phases at offsets between $70-120 \mathrm{~km}\left(P_{?} P_{1}\right.$ and $P_{?} P_{2}$ Fig. 2.15). These phases have unrealistic high apparent velocities (50 and $16 \mathrm{kms}^{-1}$ ) and occur between the two prominent reflections ( $\mathrm{PmP}$ and $\left.P p P_{1}\right)$. Given the position of these arrivals and their high apparent velocities, it is likely these are reflections caused by complex out-of-plane structure associated with the intersection of the Australian plate Moho and subducting Pacific plate.

Moreover, the origin of several phases identified on gathers from the central and eastern sections of the transect were unable to be determined (phases labelled "?" on Figs. 2.17 and 2.19). These phases exhibit apparent velocities between 6 and $8 \mathrm{kms}^{-1}$. One possibility is that these are head waves originating from mid crustal velocity discontinuities or the subducting slab. However, these arrivals provided difficult to model using a ray tracing approach and are not investigated further in this study. 

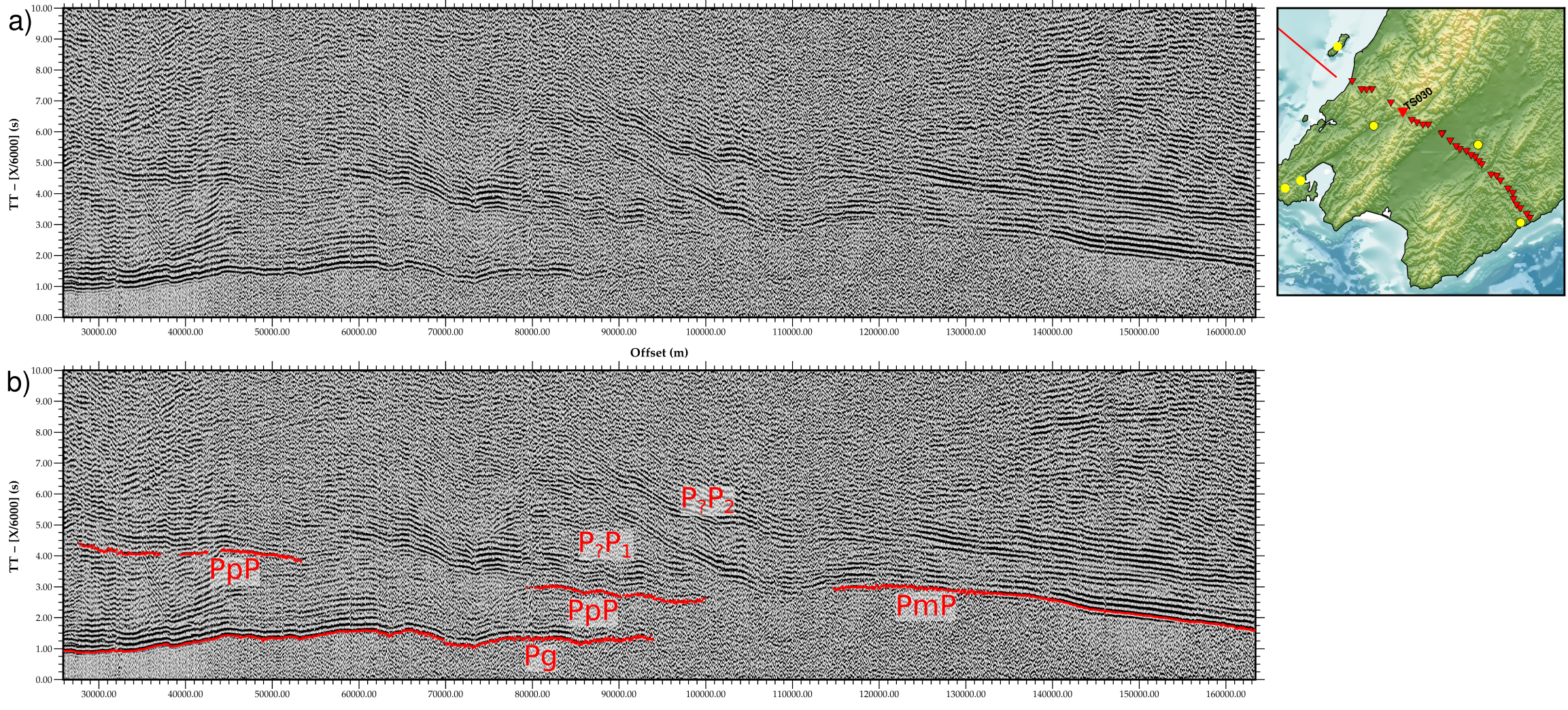

Figure 2.15: SAHKE02 receiver gather gather TS030 (a) Uninterpreted gather processed using a full trace length debias, [1 38 12] Hz bandpass filter and $3000 \mathrm{~ms}$ window length automatic gain control. (b) Same as in (a) with phase picks overlaid. (c) inset map showing the receiver location. 

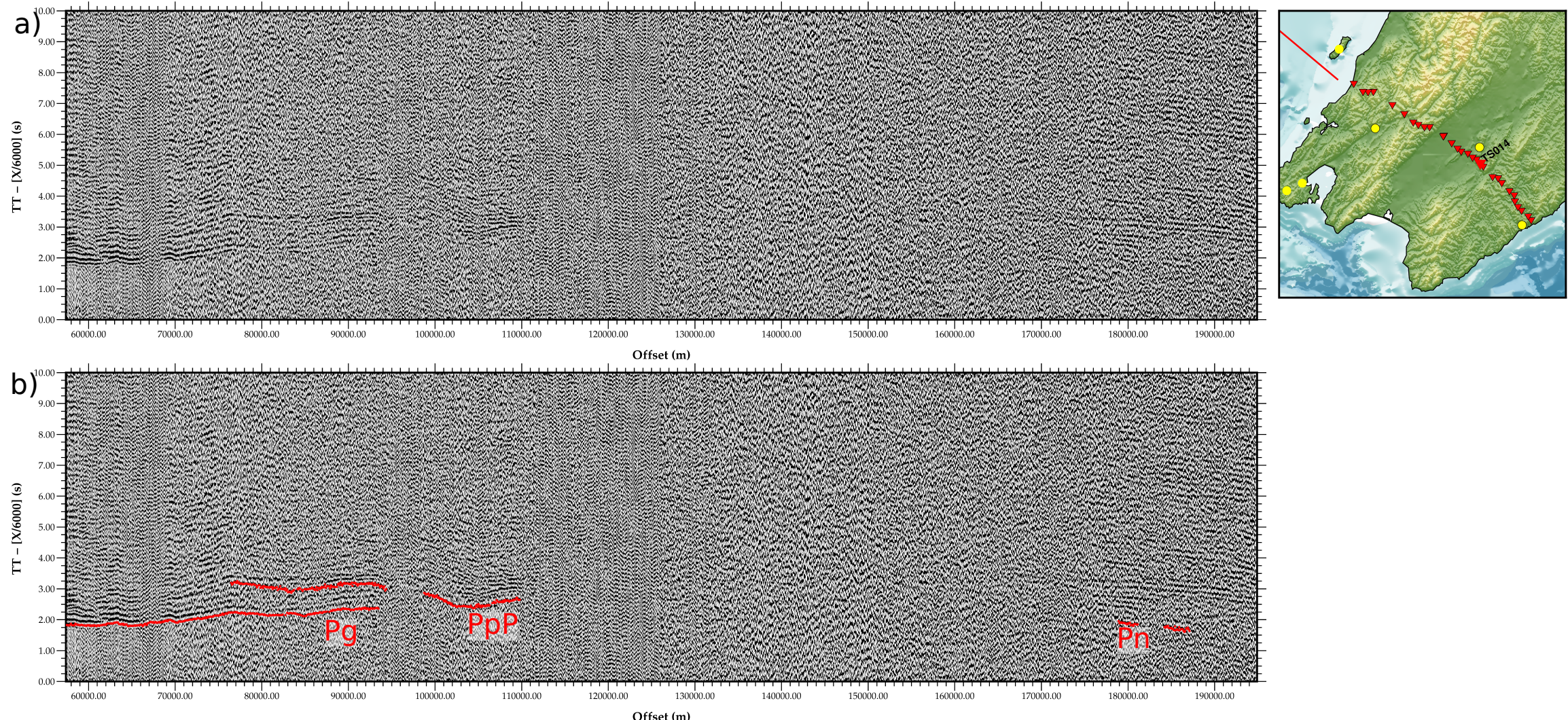

Figure 2.16: SAHKE02 receiver gather gather TS014 (a) Uninterpreted gather processed using a full trace length debias, [1 38 12] Hz bandpass filter and 3000 ms window length automatic gain control. (b) Same as in (a) with phase picks overlaid. (c) inset map showing the receiver location. 

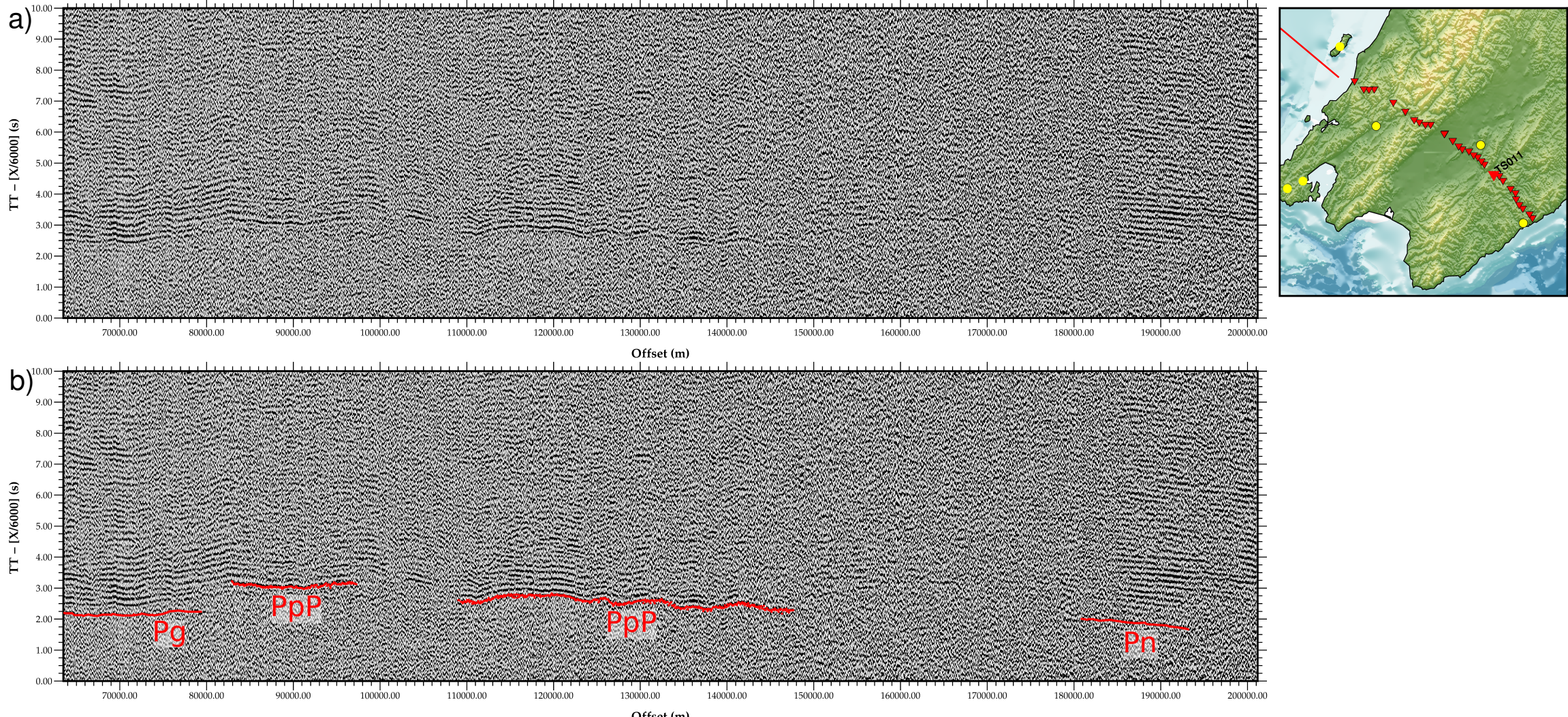

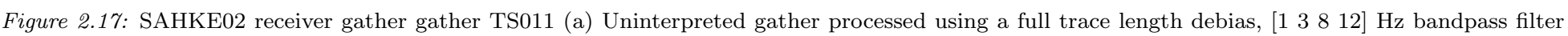
and $3000 \mathrm{~ms}$ window length automatic gain control. (b) Same as in (a) with phase picks overlaid. (c) inset map showing the receiver location. 

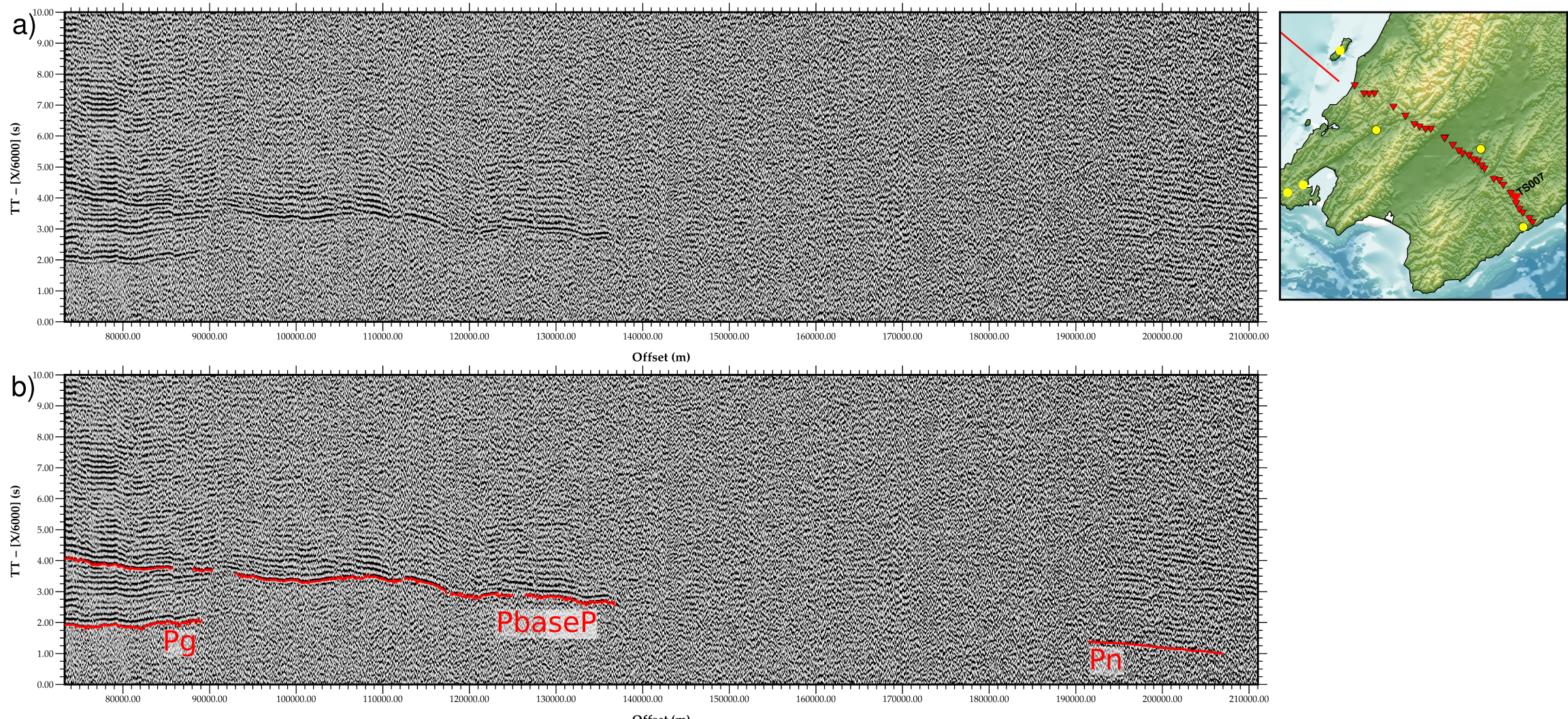

Offset (m)

Figure 2.18: SAHKE02 receiver gather gather TS007 (a) Uninterpreted gather processed using a full trace length debias, [1 38 12] Hz bandpass filter and 3000 ms window length automatic gain control. (b) Same as in (a) with phase picks overlaid. (c) inset map showing the receiver location. 

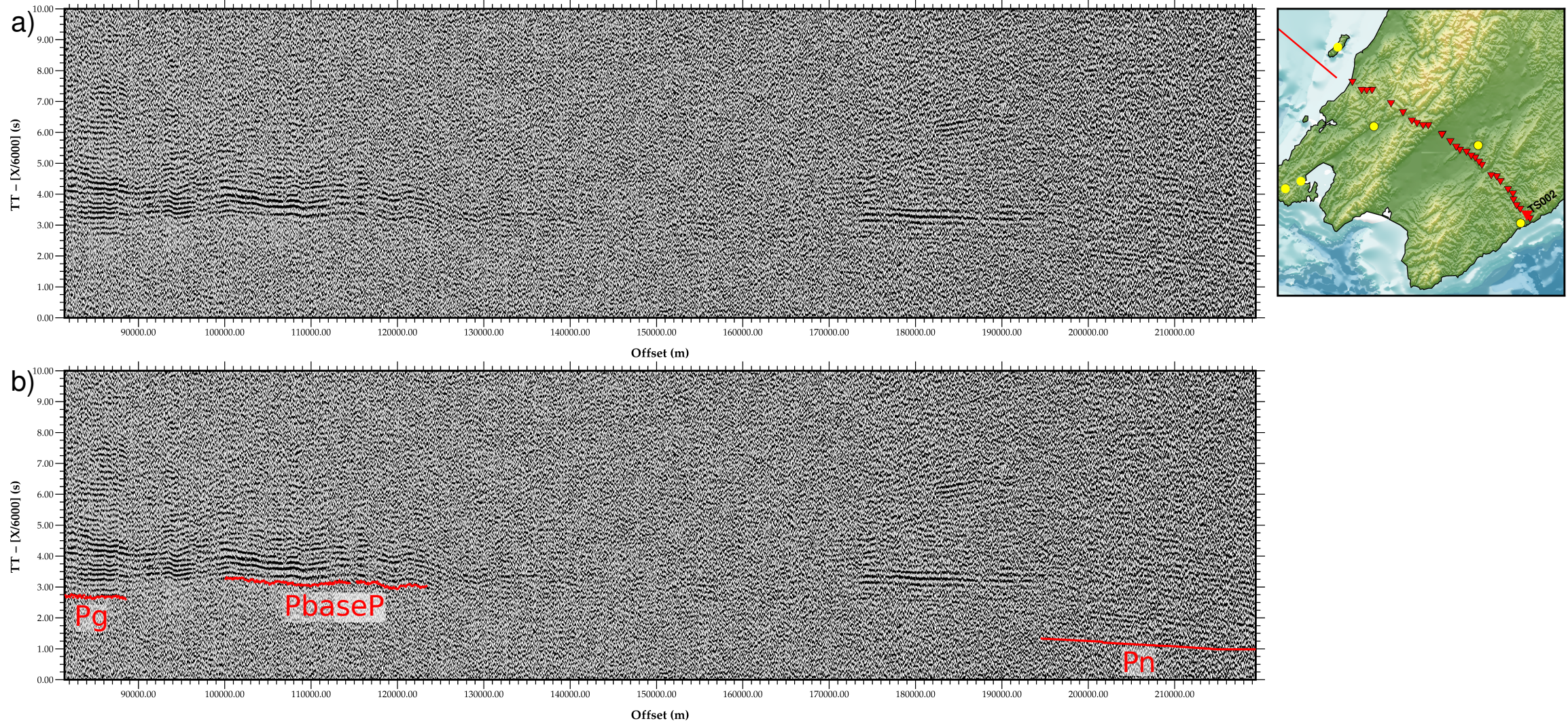

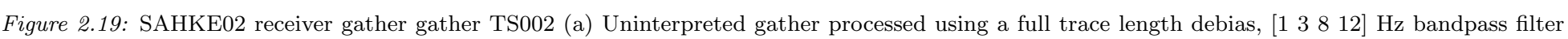
and $3000 \mathrm{~ms}$ window length automatic gain control. (b) Same as in (a) with phase picks overlaid. (c) inset map showing the receiver location. 


\subsubsection{SAHKE II observations}

All of the twelve shot gathers collected during SAHKE II display high quality data. Coherent first arrivals are visible on all gathers with a maximum offset of $\sim 72 \mathrm{~km}$ (Figs. 2.20, 2.21 and 2.22). These are interpreted as both sedimentary (Psed) and crustal (Pg) refractions. On gathers 01 - 08 the near offset arrivals $(<20 \mathrm{~km})$ display markedly slower apparent velocities $\left(3.4-4 \mathrm{kms}^{-1}\right)$ relative to those on gathers $09-12\left(4.3-5.6 \mathrm{kms}^{-1}\right)$. This is to be expected given the stations east of the Wairarapa Fault (01 - 08) are deployed within the East Coast Basin, where near offset arrivals sample slow, near surface sediments only. At further offsets these phases exhibit apparent crustal velocities between $5.8-6.2 \mathrm{kms}^{-1}$.

A group of at least three distinct reflections are also interpreted on gathers $07-12$ at offsets between $\sim 100$ and $48 \mathrm{~km}$. These are particularity prominent on gathers $06-12$ (PiP, PpP, PpP $P_{2}$; Figs. 2.20 and 2.21). The first arrival, $P i P$, is interpreted as a mid-crustal reflector and may be related to the Wairarapa fault or a change in metamorphic grade at a mid-crustal depth. The later arriving phases $\left(P p P\right.$ and $\left.P p P_{2}\right)$ are interpreted as reflections from the plate interface and top of the subducting Oceanic crust respectively.

An additional later phase reflection is also identified as a prominent arrival at far offsets $(>60 \mathrm{~km})$ on gathers $08-12$ and is also weakly visible at near offsets (PbaseP Fig. 2.20). This phase is interpreted as the base of the subducting Pacific plate. 


\section{$\stackrel{\infty}{\infty}$}
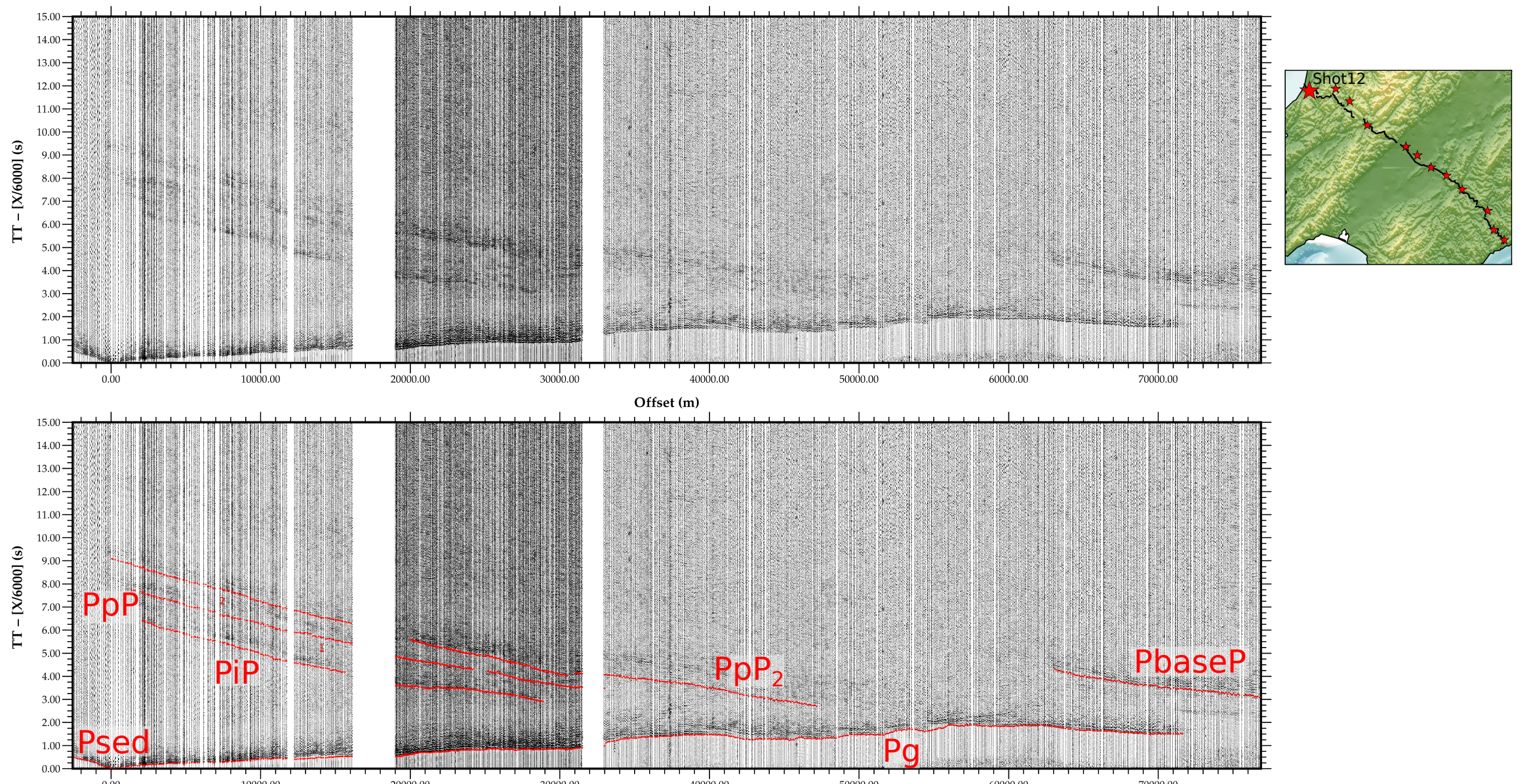

0.00
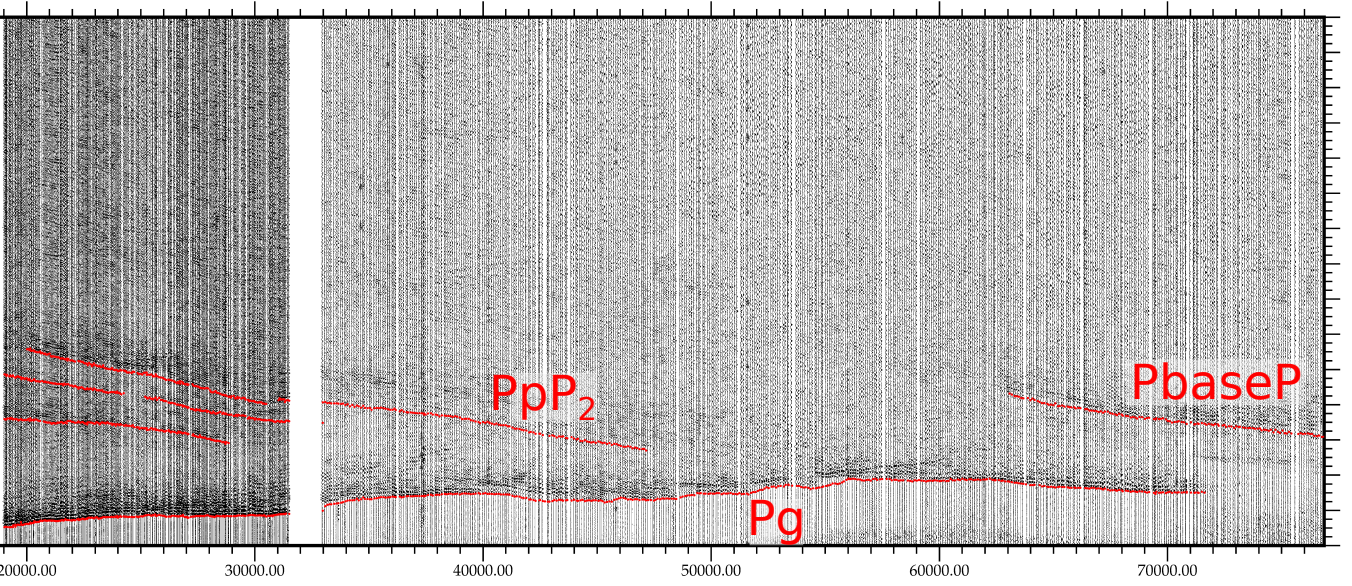

Figure 2.20: SAHKE II Shot gather 12 (Positive offsets are to the east). (a) Uninterpreted gather processed using a full trace length debias, [1 3.530 50] Hz bandpass filter and 3000 ms window length automatic gain control. (b) Same as in (a) with phase picks overlaid. (c) inset map showing the receiver location. 

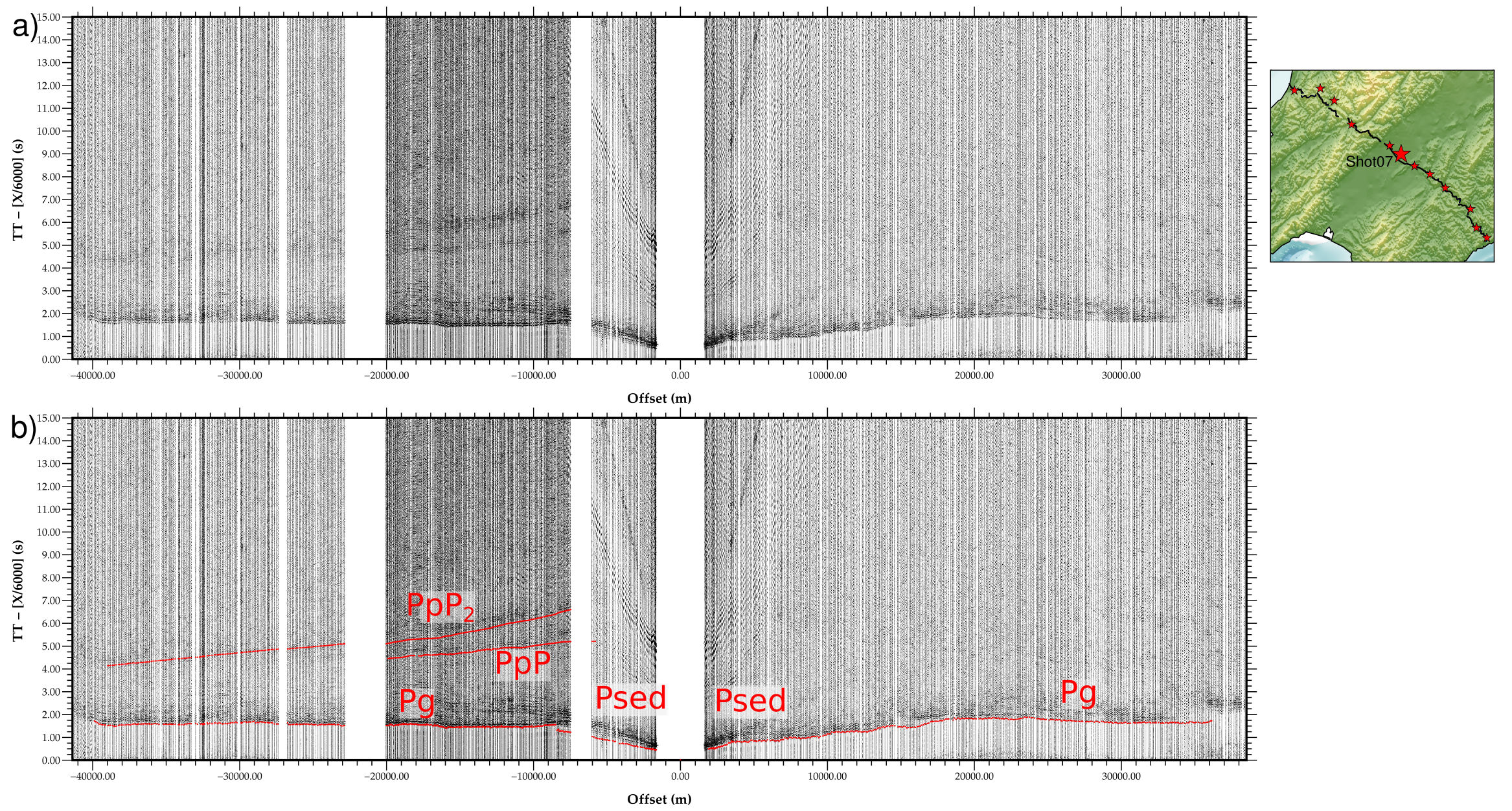

Figure 2 21: SAHKE II Shot gather 07 (Positive offsets are to the east). (a) Uninterpreted gather processed using a full trace length debias, [1 3.53050$]$ . $\mathrm{Hz}$ bandpass filter and $3000 \mathrm{~ms}$ window length automatic gain control. (b) Same as in (a) with phase picks overlaid. (c) inset map showing the receiver 

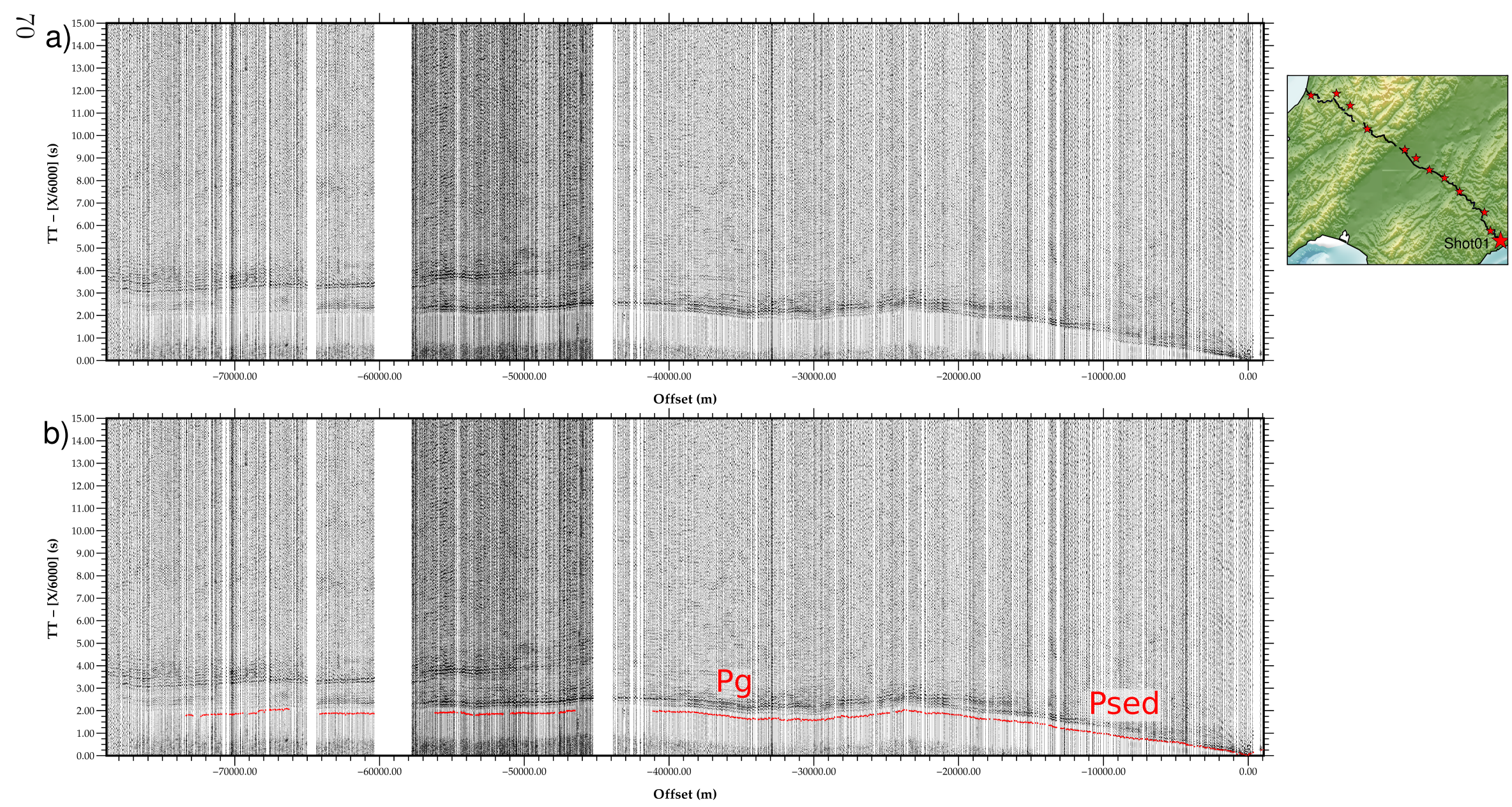

Figure 2.22: SAHKE II Shot gather 01 (Positive offsets are to the east). (a) Uninterpreted gather processed using a full trace length debias, [1 3.530 50] $\mathrm{Hz}$ bandpass filter and $3000 \mathrm{~ms}$ window length automatic gain control. (b) Same as in (a) with phase picks overlaid. (c) inset map showing the receiver location. 


\section{Chapter 3}

\section{Velocity Modelling technique}

\subsection{Introduction}

Analysis of seismic wave data is the primary method by which the internal structure of the Earth is determined. A variety of techniques exist for analysing different forms of seismic data, each of which provide information about the Earth at different depth scales. These range from high resolution seismic reflection analysis, that provide detailed structural information of the near surface, to ambient noise, virtual source and earthquake tomography techniques, that allow determination of the Earth's bulk velocity structure to depths of many hundreds of kilometres (e.g. Behr, 2011; Rawlinson et al., 2010).

The active source wide-angle reflection/refraction data collected as part of the "Seismic Array HiKurangi Experiment" (SAHKE) provide a unique set of phase arrivals that are useful for determining detailed velocity and interface structure within the crust.

This chapter outlines the technique and strategy used to model these data in order to develop two two-dimensional (2D) crustal scale P-wave (Vp) velocity models presented in chapters 4 and 5 . 
3. Velocity Modelling technique

\subsection{Two dimensional velocity modelling methods}

Several approaches exist for modelling two-dimensional wide-angle reflection/refraction data, each of which seeks to develop a model, or set of models, that fit observed travel-time data within uncertainties. Modelling of active source seismic data is usually done using either a trail-and-error forward modelling approach (e.g. Luetgert, 1992) or an inversion algorithm to automatically iterate towards a best-fit model (e.g. Hole, 1992; Rawlinson, 2005). Some methods (e.g. Zelt and Smith, 1992), are capable of combining both approaches such that only specified model parameters are inverted during each iteration, in a semi-automated forward modelling fashion.

As it is usual practice to seek a model that fits the data with the simplest possible structure (Zelt, 1999), an inverse approach is the preferred technique in many instances, as this method has a reasonable chance of avoiding overinterpreting or underutilising the data (Zelt, 1999). Using a forward modelling approach there is no realistic chance of achieving this goal, as unnecessary structure will almost certainly be incorporated in the model by the modeller (Zelt, 1999).

However, as discussed below in section 3.3, the decision as to which method should be used to model a dataset is dependent on several factors. These include the spatial resolution of the dataset and availability of independent constraining datasets.

\subsection{Choosing a modelling technique}

The resolution of a dataset determines which method will be most effective for modelling the data. Investigation of crustal velocity structure requires large source-receiver offsets (usually $>>100 \mathrm{~km}$ ), and previous studies have shown that fine shot and shot-receiver spacing is required in order to resolve 
3.4. Adopted modelling technique used in this study

geologically meaningful results using an inverse approach (e.g. Baldock, 2004; Bassett, 2009). Furthermore, velocity structure information provided by previous studies may provide important constraints for a model when data is coarse. Incorporation of these independently determined constraints may allow a reasonable fit of the data to be achieved in the absence of sufficient ray coverage within the model space.

The incorporation and preservation of such structure is usually much simpler to achieve using a forward modelling scheme, although this is possible with some inverse methods (e.g. Zelt and Smith, 1992).

\subsection{Adopted modelling technique used in this study}

Given the coarse receiver spacing of the SAHKE03 profile (see section 2.2) and the inherent limitation of unidirectional shot-receiver geometry of this dataset (i.e. no reverse direction gathers), the models developed in this thesis have been created using Zelt and Smith's (1992) ray tracing method for seismic travel-time inversion (RayInvr). This method is flexible as it allows the model to be adjusted both manually or by automatic inversion. Inversion can also be limited to specific layer and velocity nodes, enabling the preservation of specified parameters during inversion. Furthermore, another important advantage of this method is the ability to incorporate topography, preventing the need of static corrections.

In this method, each model layer is defined by an arbitrary number of spacing, boundary and velocity nodes connected by linear interpolation. The code operates by calculating synthetic phase arrival times by ray tracing through the model and compares these to the observed data. The misfit between the observed and calculated arrivals times were then reduced by manually adjusting model parameters, or, when appropriate, inverting specific parameters in 
a semi-automated fashion.

\subsection{Two-dimensional modelling assumptions}

Three two-dimensional modelling assumptions were made:

1. Velocity structure is homogeneous and isotropic perpendicular to each model line. This assumption is necessary as source-receiver pairs reside outside of the model plane (see section 3.7.1).

2. All phase picks are true first arrivals i.e are not multiple, multipathed or diffracted arrivals.

3. All phase arrivals modelled as reflections are reflected at a velocity discontinuity that resides in the model plane.

This assumption may be violated in the case of the SAHKE03 model as the Moho within Wangnaui Basin is expected to have a complex bowl shaped three dimensional structure (Ewig, 2009). This assumption is tested in figure 3.1. The Moho structure determined by Ewig (2009) is assumed and Moho depth contours are plotted perpendicular to the SAHKE03 model transect. These suggest that south of the Wanganui coast line, the shortest raypath to the Moho is likely out-of-plane to the east (A - A' red circle; Fig 3.1). North of the coast line, the wave length of the Moho is sufficiently long to insure the shortest raypath for Moho reflections occurs within the model plane.

Moreover, the plate interface strikes at an oblique angle to this transect (orange contours; Fig. 3.1) and reflections from this interface are also predicted to violate this assumption. 


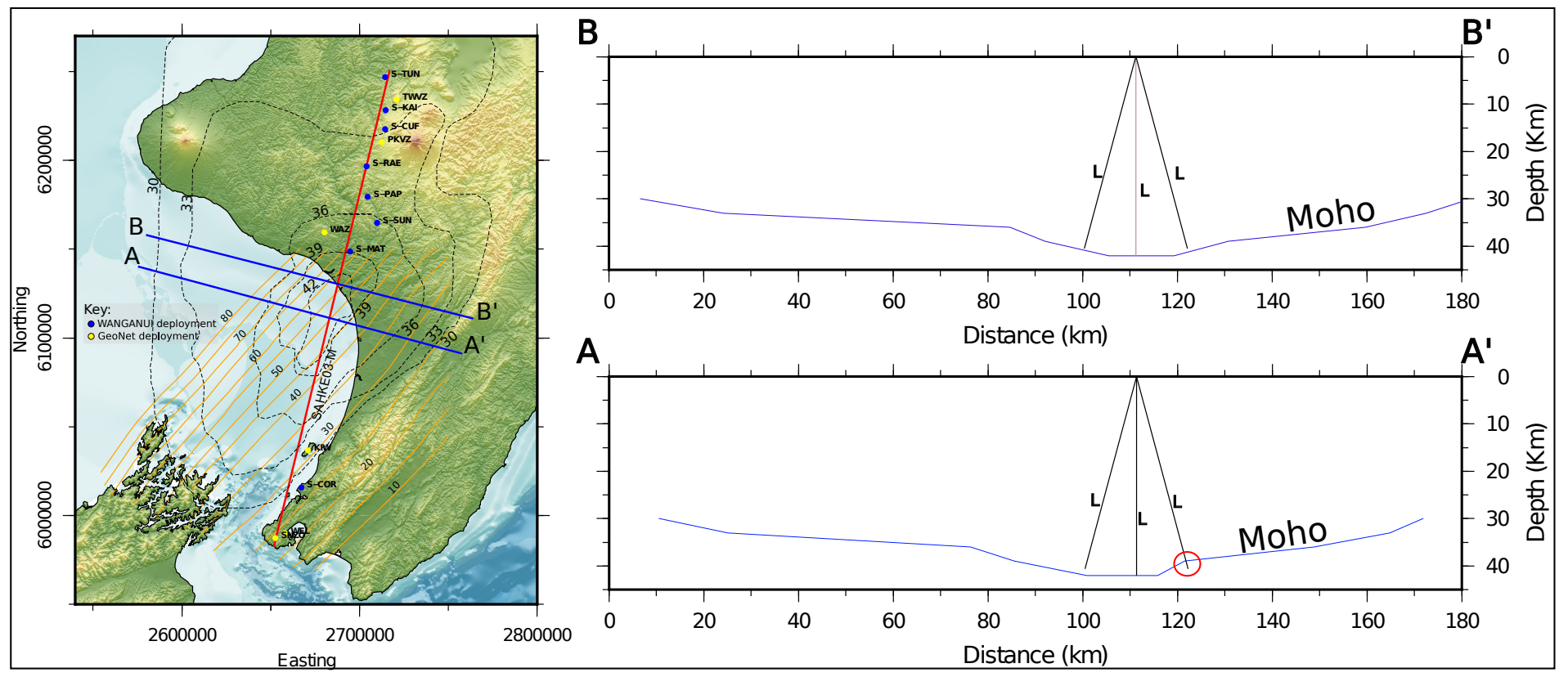

Figure 3.1: Illustration demonstrating the predicted shortest path for a reflection from the Moho (length L) in the center of Wanganui Basin. On transect A - A' out of plane reflections may arrive before the vertical incident reflection. Further to the north on transect B - B', the wavelength of the curvature of the Moho is sufficient to ensure the shortest path remains in the model plane. Moho contours are based on results of three-dimensional modelling of the gravity field (after Ewig, 2009). 


\subsection{Forward Modelling Strategy}

The careful development and application of a modelling strategy is useful for enabling the systematic development and assessment of a model. This becomes particularly apparent when forward modelling, as modelling strategies are inherently unique to each modeller (Zelt, 1999).

The strategy used to develop the Vp models presented in chapters 4 and 5 is divided into three distinct steps as listed below and explained in the following sections:

1. Pre-modelling considerations.

2. Modelling.

3. Model assessment.

\subsection{Pre-modelling considerations}

Pre-modelling considerations consist of general techniques and are usually applicable to any dataset. In the case of the two $2 \mathrm{D}$ models developed in this thesis, these include model line assessment, the application of static corrections and revision/incorporation of information from constraining datasets.

\subsubsection{Model Line Assessment}

\section{Survey line geometry}

Both survey lines SAHKE02 and SAHKE03 were designed to be modelled as 2D datasets. When deploying temporary seismometers and assigning shot positions for $2 \mathrm{D}$ surveys, it is desirable to position both shot and receivers within a $2 \mathrm{D}$ plane. In this way, the data are collected within 
a single plane, limiting distortion effects from out-of-plane structures. This allows data from multiple source-receiver pairs to be used collectively to constrain a single velocity model. However, when deploying temporary seismometers several factors must be considered.

The physiography of southern and western North Island provides a challenging environment for deployment in the form of rivers, valleys, steep slopes and ranges. Furthermore, permission from land owners, accessibly to sites and local geology are all factors that determine the final location of each seismometer. Data quality can be vastly improved if a seismometer is well coupled to the Earth; for example, it is preferable to deploy stations on dry bedrock opposed to soft loose sediment. The deployment location of each seismometer therefore involved a trade off between finding a site that adequately matched the criteria outlined above, while ensuring the geometry remain sufficiently $2 \mathrm{D}$.

\section{Defining model geometries}

For reasons outlined above, onshore seismometers where not deployed directly along straight profile lines. Additionally, the offshore MCS ship tracks are effectively slight wiggles due to swell and wind conditions. These survey characteristics create 3D geometries between sources and receivers, which result in rays arriving at slightly oblique angles. This is particularly the case for the SAHKE03 profile where seismometer locations north of Wanganui city were restricted to following State Highway 4 through the Kaimanawa Ranges. Furthermore, data recorded at New Zealand permanent (GEONET) stations have been used to supplement the data collected by temporary stations, with some of these sites having the most extreme 3D geometries within the dataset.

In order to use data recorded at out-of-plane seismometers to constrain 2D Vp models, lines of best fit (defined in a least squares sense) through all of the offshore shot points and onshore receivers were constructed. These were 
used to define model coordinates for each shot point and receiver. All shot locations were perpendicularly projected onto each model line (Fig. 3.2) and in order to preserve shot-receiver offsets, the receiver locations were radially projected onto each model line relative to each shot (Fig. 3.2). Topography and bathymetry at each shot and receiver location are also projected onto each line, in order to preserve raypath lengths.

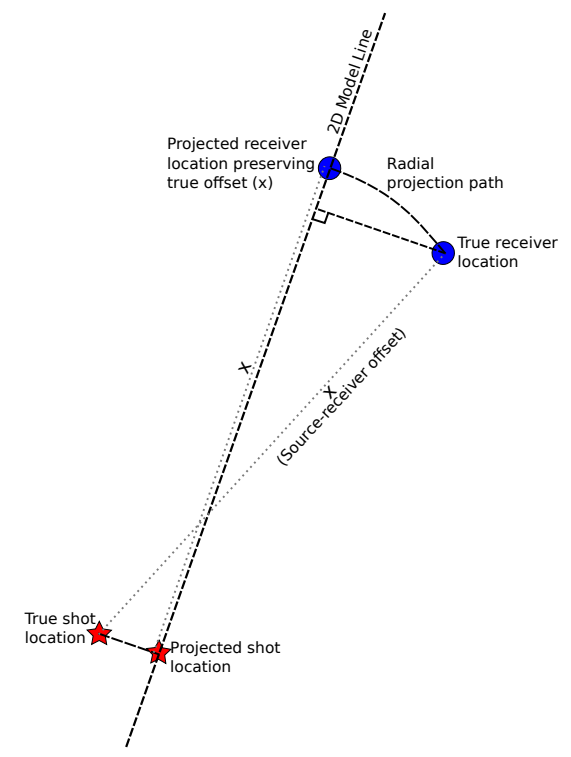

Figure 3.2: Schematic illustration demonstrating how each shot and receiver were projected onto a $2 \mathrm{D}$ model line. Note receiver locations are projected radially to preserve shot-receiver offset (distance $\mathrm{x}$ ). In this way, receiver locations are unique for each shot point (modified after Scherwath, 2002).

For a detailed description of seismograph, ship track and projected model coordinates see Appendix A.

\subsubsection{Near surface low velocity zone}

When considering lithospheric scale velocity structure, near surface layers, namely the ocean and sedimentary sections, represent significant low velocity zones. Accurately constraining the thickness and Vp of these layers is critical for crustal scale modelling, as errors in these parameters must be compensated for by much greater errors elsewhere in the model (Zelt, 1999; Stern 
et al., 2010).

This relationship is well explained by Sheriff and Geldart (1995), who demonstrated the non-linear response of model parameters to variations in near surface layers.

Consider the vertical delay time $\Delta$ t created when a rock unit of thickness $\mathrm{h}$ and velocity $V_{1}$ is replaced by a rock unit of equal thickness with velocity $V_{2}$ :

$$
\Delta t=h\left|\left(1 / V_{1}-1 / V_{2}\right)\right|
$$

Equation 3.1 implies that, for an equal error in velocity $\left(V_{2}-V_{1}\right), \Delta \mathrm{t}$ becomes increasingly greater for lower velocity mediums. For example, take a rock unit of thickness $3.5 \mathrm{~km}$ with a typical sedimentary velocity $V_{1}$ of $2.3 \mathrm{kms}^{-1}$. If $V_{2}$ is equal to $V_{1}+1=3.3 \mathrm{kms}^{-1}$, this equates to an error in velocity of $43 \%$ and delay time of $0.46 \mathrm{~s}$. An error of this magnitude may easily occur when constraining sedimentary velocities using wide-angle reflection and refraction data alone, a problem often encountered when using a tomographic modelling approach, as explained by Stern et al. (2010). Now consider the effect of replacing the same rock unit with a typical lower crustal velocity $V_{1}$ of $6.5 \mathrm{kms}^{-1}$ with $V_{2}$ of $V_{1}+1=7.5 \mathrm{kms}^{-1}$. $\Delta$ t is now $0.041 \mathrm{~s}$, over eleven times less than for the sedimentary case (Fig. 3.3a).

Figure 3.3b illustrates the response of Moho depth to an increase in sedimentary section velocity. Using the two-way travel time of a vertical incident Moho reflection phase, figure 3.3b shows the Moho will deepen by $3.8 \mathrm{~km}$ and $5.7 \mathrm{~km}$ for a 0.5 or $1 \mathrm{kms}^{-1}$ increase in sedimentary velocity respectively. These are however maximum values as it is assumed that the error in sedimentary velocity is compensated entirely by the thickness of the lower crust. Realistically, errors in sedimentary velocities will be compensated for by several model parameters, rather than Moho depth alone. Nonetheless, the overall net effect of overestimating near surface velocities will be to artificially thicken the crust Stern et al. (2010). 
3. Velocity Modelling technique

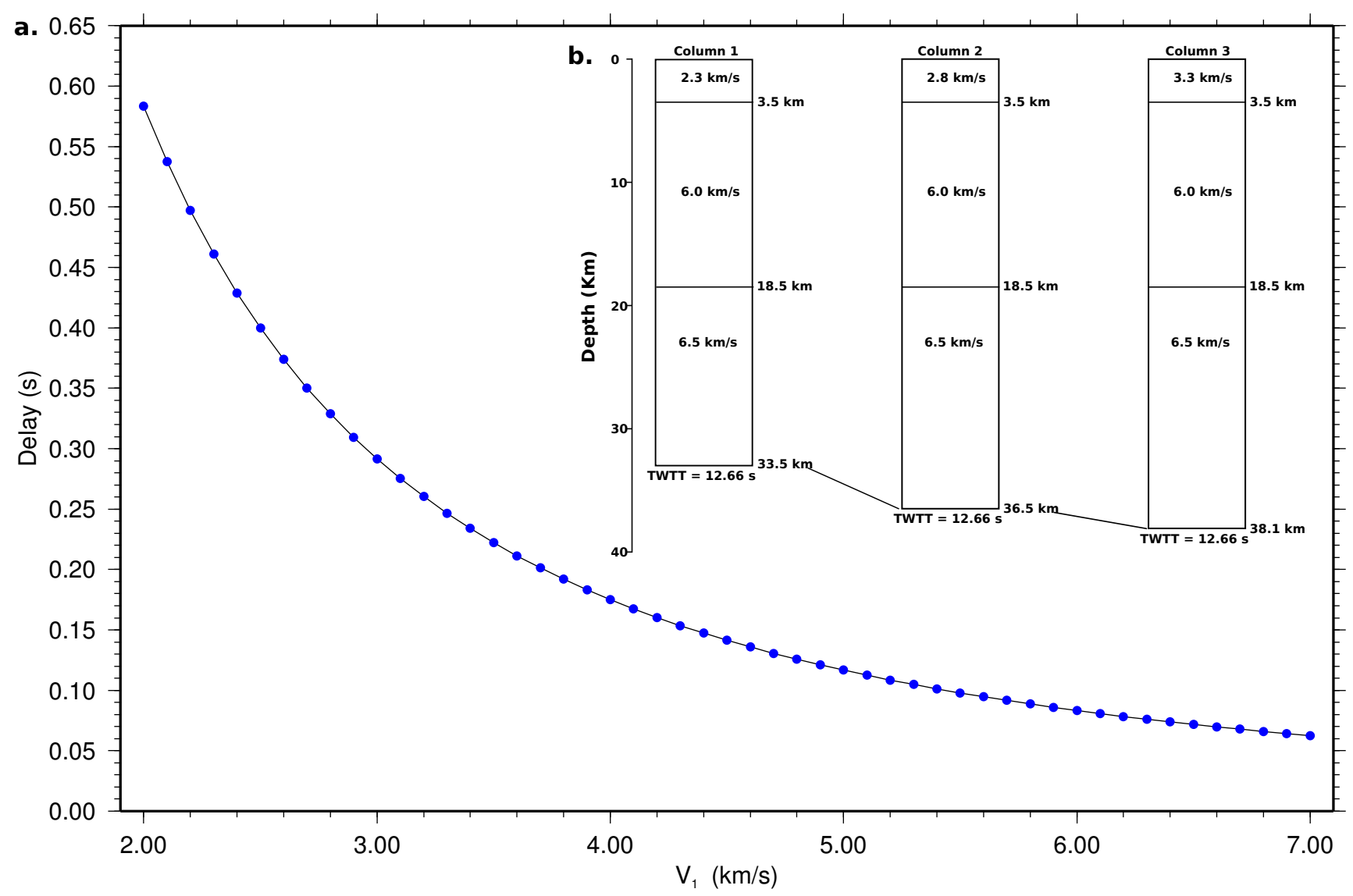

Figure 3.3: (a) Graph illustrating the non-linear response of delay-time for a $3.5 \mathrm{~km}$ thick section to an increase in material velocity when velocity $V_{1}$ is replaced by velocity $V_{2}=\left(V_{1}+1\right)$. (b) Three crustal columns with equal two-way travel-times for a vertical incident PmP moho reflection phase, given different sedimentary section velocities. Sedimentary velocity of column 1 is based on the average velocity of PlioPleistocene sediments in SWanganui Basin derived in this study (see section 4.2.1). Columns two and three show that a $0.5 \mathrm{kms}^{-1}(21.7 \%)$ or $1 \mathrm{kms}^{-1}(43.5 \%)$ overestimation of sediment velocity will result in a $3 \mathrm{~km}$ or $4.6 \mathrm{~km}$ increase in Moho depth respectively, assuming these errors are compensated entirely by the thickness of the lower crust (modified after Stern et al. 2010).

\subsection{Modelling}

In contrast to pre-modelling considerations, the modelling step is an ambiguous process and therefore required a carefully planned strategy. The modelling strategy developed in this study follows a shallow-to-deep approach, in which the model is constructed by first constraining near 
3.9. Model assessment

surface velocity structure before working downwards through increasingly deeper sections. This approach has the important advantage of ensuring that near surface sedimentary sections are well constrained before modelling deeper structure. This is critical for ensuring meaningful results, as the sedimentary sections represent significant low velocity zones (LVZ), that if modelled incorrectly, can result in large errors percolating into deeper sections of the model (see section 3.7.2).

Modelling was achieved by systematically adjusting velocity and interface nodes in a trial and error forward modelling fashion, or by automatic inversion of specified model parameters where ray coverage was sufficient for this process. Constraints provided by independent datasets were also incorporated into each starting model. These constraints were important in areas of the model where poor ray coverage limited the resolution of the SAHKE data. In areas where good ray coverage exists concurrently with independent constraints, these constraints were modified throughout the modelling process in order to test compatibility with ray tracing results and explore model space.

\subsection{Model assessment}

Once a model of sufficiently good fit was resolved, model assessment techniques were employed and results from these used to further improve the model solution.

Assessment techniques were used to measure both the goodness of fit and non-uniqueness of the model solution. These techniques include statistical assessment of travel-time fits, ray coverage/density analysis, reflector and velocity resolution testing and synthetic waveform modelling.

Statistical assessment provides a first order evaluation of travel-time fit, while ray density plots provide a visual aid of model resolution. Resolution testing and synthetic wave form modelling were used to assess the robustness 
of specific model features.

\subsubsection{Errors}

Errors are classified as either model-dependent or data-dependent errors.

\section{Model-dependent errors}

These are caused by the inherit non-uniqueness of the model solution. That is to say, an infinite number of models may exist that fit the traveltime data equally well. Errors of these type are difficult to quantify; however, these can be explored using direct model assessment techniques as defined by Zelt (1999). In this study, direct model assessment is achieved using multi-parameter uncertainty inversions, in order to test the robustness of specific model parameters for fitting the observed travel-time picks. These tests are discussed for each model in sections 4.4 .3 and 5.4 .3 respectively.

\section{Data-dependent errors}

Data-dependent errors may arise due to (a) equipment recording errors of phase arrival times, owing to timing errors within the data recording system and/or (b) interpretation errors when picking phase arrivals.

As no equipment timing errors where discovered in this dataset, these errors are not considered. In order to account for interpretation errors, error values were assigned for each pick during the the interpretation process by estimating both the individual wavelet pick error and phase pick error. Within the data interpreted in this study, wavelet pick error was usually estimated as $\pm 5 \mathrm{~ms}$ and phase error as $\pm 45 \mathrm{~ms}$, providing a total pick error of $100 \mathrm{~ms}$. Overall picking errors varied between $70 \mathrm{~ms}$ and $150 \mathrm{~ms}$ depending on signal-to-noise and the frequency of the arrival.

During the modelling process the primary objective was to fit all phase 
travel-times within pick time uncertainties. To assess the goodness of fit of modelled travel-times a normalized chi-square $\left(\chi^{2}\right)$ approach was used. This statistic is calculated as

$$
\chi^{2}=\frac{1}{n-1} \sum_{i=1}^{n}\left[\frac{\left(t_{(i)} \text { calc }-t_{(i)} o b s\right)}{\sigma_{(i)}}\right]^{2},
$$

where $t_{(i)}$ calc and $t_{(i)}$ obs are the $i$ th calculated and observed travel-times, $n$ is the number of picks and $\sigma_{(i)}$ is the pick uncertainty. A $\chi^{2}$ value of one indicates the best possible fit, while values greater than one are under fitted and values less than one are over fitted (Zelt and Smith, 1992). This approach is superior to that of using root-mean-squared travel-time misfit stand error alone, as the $\chi^{2}$ statistic also takes into consideration travel-time pick error. 
3. Velocity Modelling technique 


\section{Chapter 4}

\section{Two Dimensional Modelling of Crustal Velocity Structure: SAHKE03}

\subsection{Introduction}

This chapter details the forward modelling of wide-angle reflection and refraction data collected within Wanganui Basin as part of the "Seismic Array HiKurangi Experiment" (SAHKE).

A two-dimensional (2D) P-wave velocity (Vp) model, SAHKE03-M, is developed and used to determine crustal velocity structure within Wanganui Basin, along a profile sub-parallel to the Hikurangi margin (Fig. 4.1). This model is constructed following the modelling strategy discussed in Chapter 3, using data collected on the WANGANUI deployment during the shooting of the multi-channel-seismic (MCS) line SAHKE03 (see Chapter 2). Interpretations and implications of this model are presented in Chapter 6 . 
4. Two Dimensional Modelling of Crustal Velocity Structure: SAHKE03

\subsection{Pre-modelling Constraints}

\subsubsection{Constraining near surface layers}

Several datasets provide constraints on the thickness and velocity of near surface layers within the Vp model developed in this chapter. These include previous reflection and refraction seismic experiments, receiver functions studies, borehole data and geological maps. The processes by which these constraints were incorporated into the SAHKE03-M model is described in this section.

\subsubsection{Bathymetry}

The depth to the seafloor was determined using MCS seafloor reflection data acquired during the SAHKE, in addition to data obtained during previous MCS surveys, supplied freely by the US National Geophysical Data Center (www.ngdc.noaa.gov). Seafloor nodes were incorporated into the model at a lateral resolution of $4 \mathrm{~km}$, with ocean water $\mathrm{P}$-wave velocity set at a constant of $1.5 \mathrm{~km} \mathrm{~s}^{-1}$.

\subsubsection{Sedimentary section}

Offshore the thickness and velocity of the sedimentary section within the SAHKE03-M model were constrained using MCS data acquired along the SAHKE03 profile (Fig. 4.1). Onshore, data from previous studies were used as no onshore data were collected along the SAHKE03 transect during the SAHKE survey.

\section{Offshore sedimentary sections}

All of the MCS data acquired during SAHKE were processed by Geotrace $(\mathrm{R})$ as contracted by The New Zealand Petroleum and Minerals 
(NZPM). Migrated CDP stacks of each SAHKE reflection profile, in addition to stacking velocity files developed by Geotrace@ $\mathrm{R}$ were supplied by NZPM for use in this thesis.

The SAHKE03 stacking velocity file was converted into an interval velocity file using Dix's equation and used to preform a depth conversion of the SAHKE03 stacked section (Fig. 4.2). The acoustic basement from the depth converted stack was digitised and the overlying sedimentary section incorporated into the SAHKE03-M model as a single layer. The interval velocity file was used as the preliminary sedimentary section velocity field. This layer was further constrained by modelling a series of seafloor reflection arrivals interpreted on the MCS shot gathers (Fig. 4.3). Table 4.1 shows the goodness of fit of these reflection arrivals and the shot gathers and corresponding basement picks are shown in appendix B. The resultant near surface velocity field was held constant during the modelling of onshore-offshore wide angle reflection and refraction data (section 3.8). 


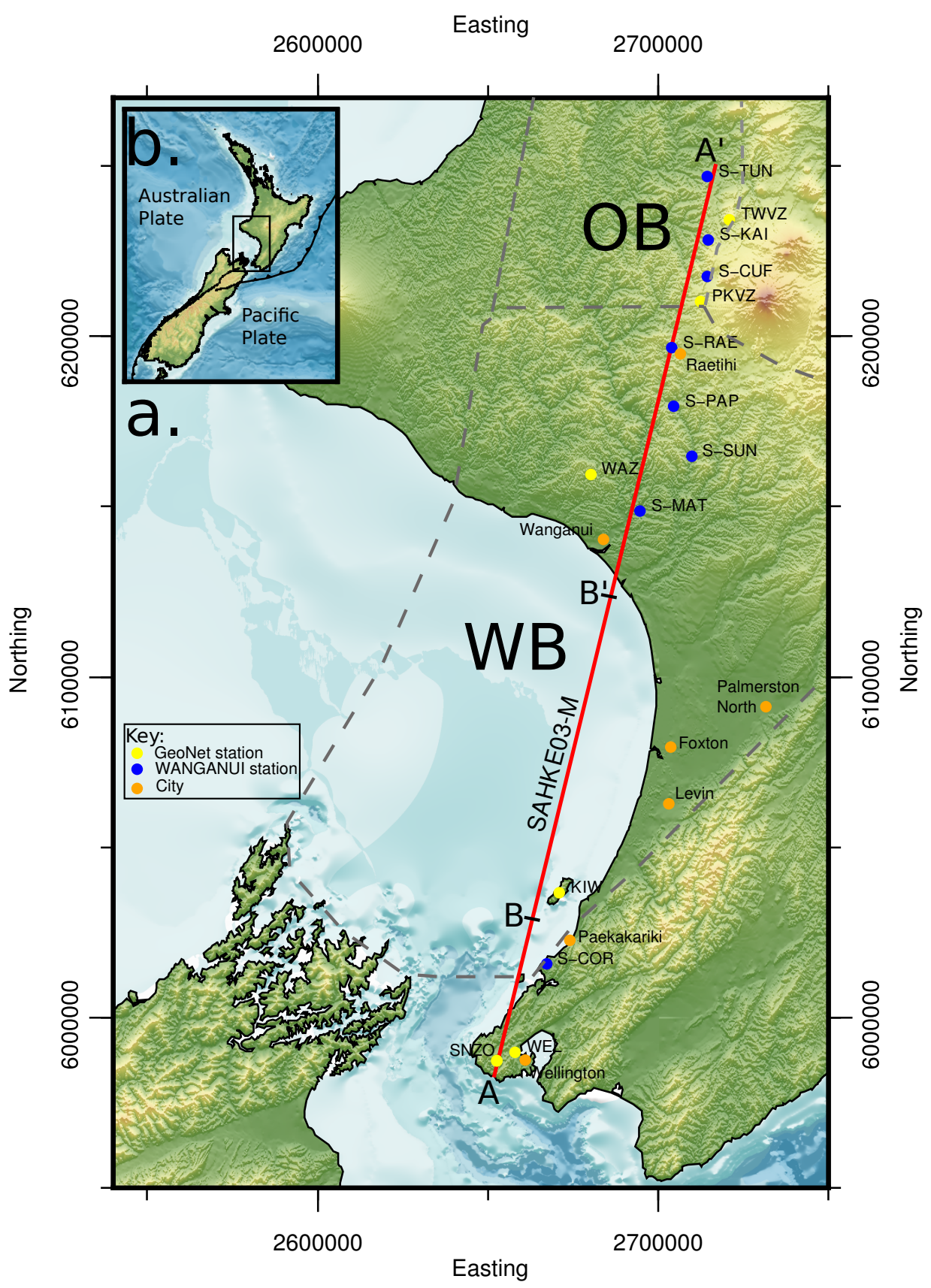

Figure 4.1: (a) Map showing the location of the SAHKE03-M model line (A - A'), the SAHKE03 multichannel-seismic line (B - B') and the temporary WANGANUI deployment and permanent GeoNet seismograph sites from which data is used to constrain the $\mathrm{P}$-wave velocity model presented in this Chapter. Wanganui Basin = Wanganui Basin $\mathbf{O B}=$ Otunui Basin. Grey lines are basin boundaries. (b) Inset map showing the bounding box of (a). 

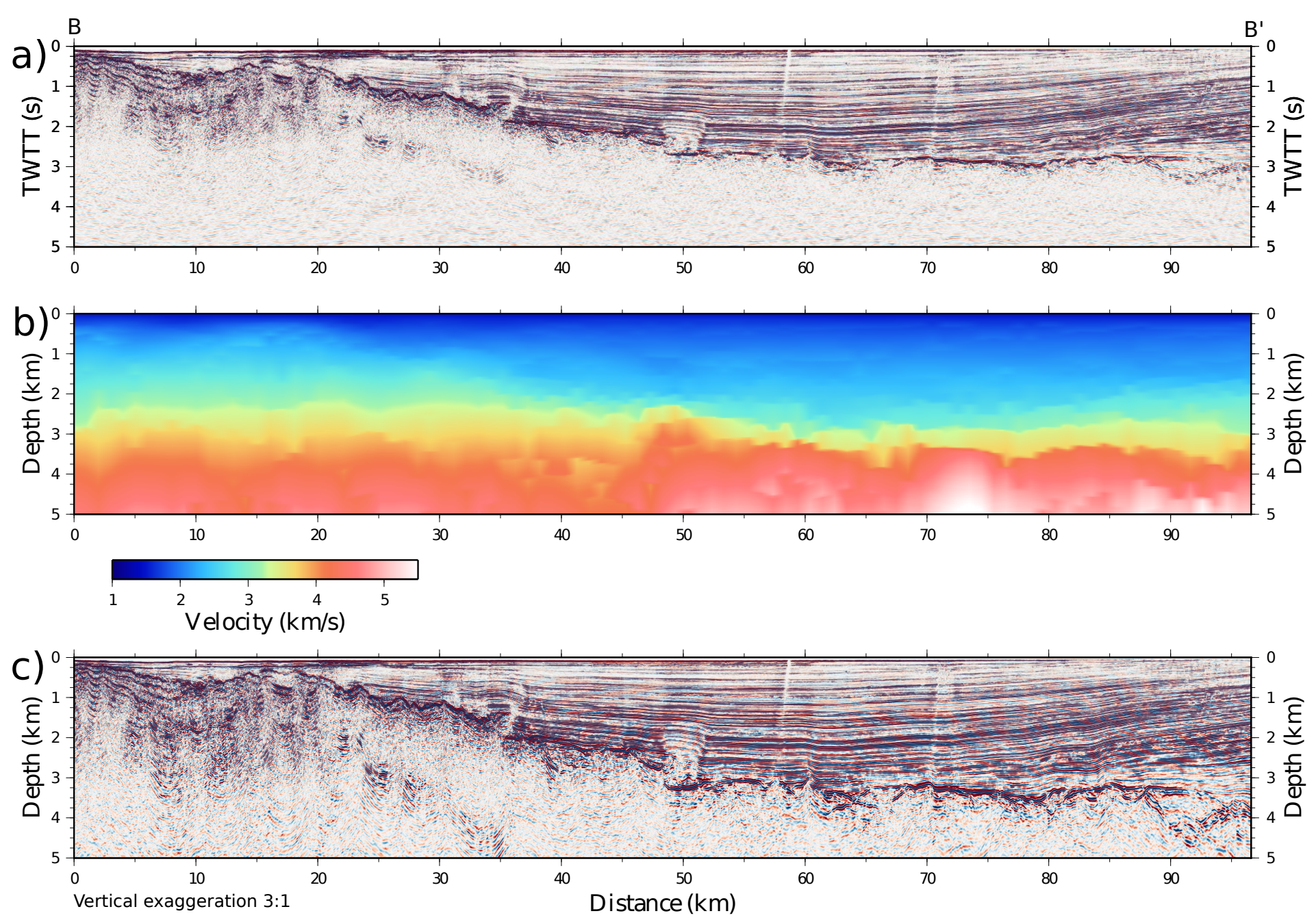

Figure 4.2: a) Final seismic reflection stack of MCS line SAHKE03 (location B - B' shown on figure 4.1). b) Interval velocity field created by converting the stacking velocity field using Dix's equation. c) Depth converted SAHKE03 final seismic reflection stack from which the acoustic basement was picked

and incorporated into the SAHKE03-M model. 

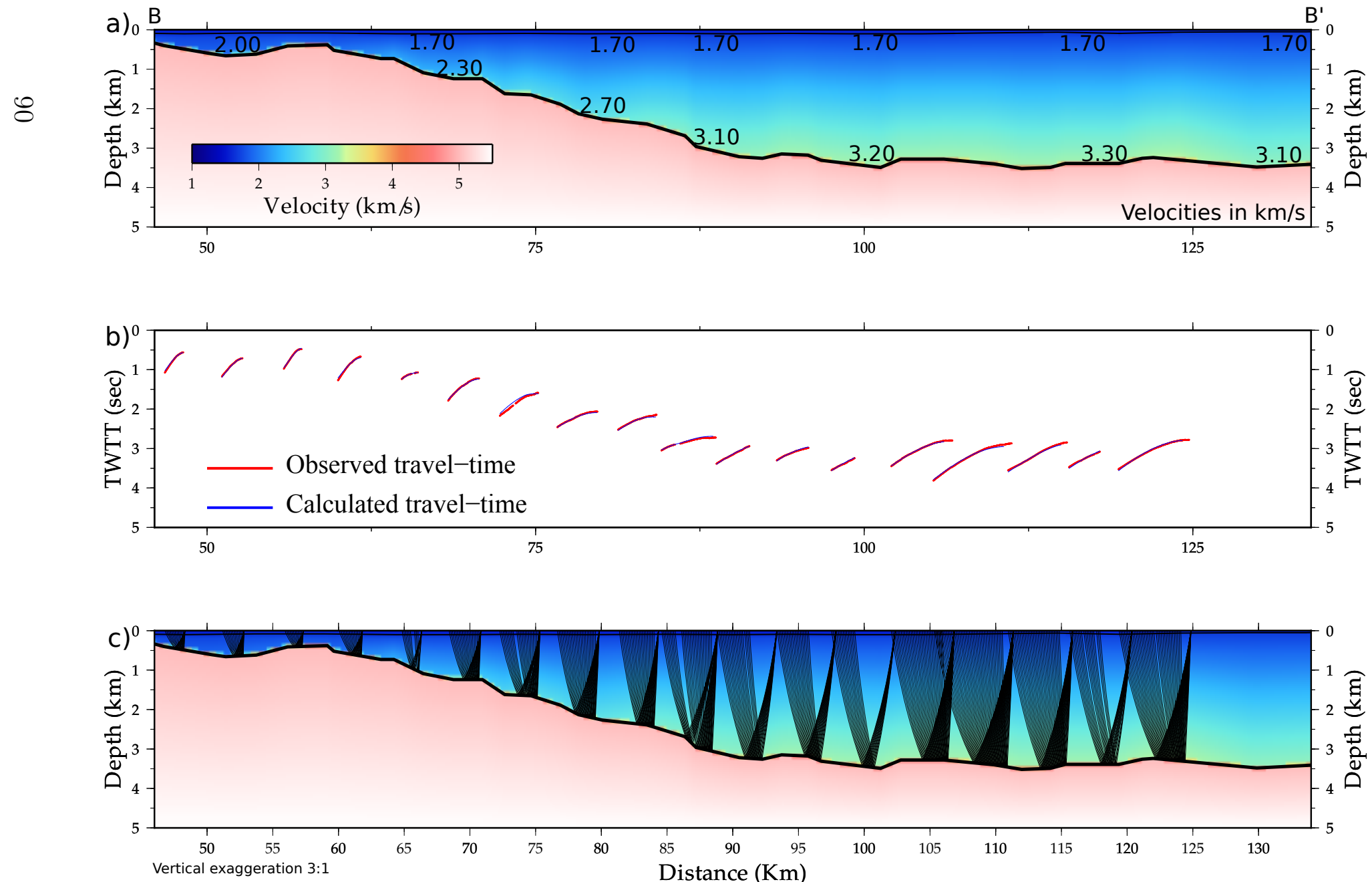

Figure 4.3: a) Final sedimentary basin velocity model using in the SAHKE03-M model (location B - B' shown on figure 4.1). Velocities overlain are in $\mathrm{kms}^{-1}$. b) Calculated (blue) and observed (red) travel-times for basement reflections interpreted on SAHKE03 multi-channel-seismic shot gathers (see Appendix B). c) Same as in (a) showing moddelled raypaths that provide the calculated travel-times in (b). Horizontal scale is in SAHKE03-M coordinates (see figure 4.10). 
4.2. Pre-modelling Constraints

\begin{tabular}{cccccc}
\hline $\begin{array}{c}\text { Shot } \\
\text { gather }\end{array}$ & $\begin{array}{c}\text { Shot location in } \\
\text { model coor. }(\mathrm{km})\end{array}$ & $\mathrm{N}^{*}$ & $\begin{array}{c}\text { Pick error } \\
(\mathrm{sec})\end{array}$ & $\begin{array}{c}\text { RMS travel- } \\
\text { time residual }(\mathrm{sec})\end{array}$ & $\chi^{2}$ \\
\hline 54 & 48.32 & 113 & 0.05 & 0.021 & 0.498 \\
104 & 52.82 & 126 & 0.05 & 0.011 & 0.144 \\
154 & 57.32 & 109 & 0.05 & 0.012 & 0.157 \\
204 & 61.83 & 140 & 0.05 & 0.027 & 0.805 \\
254 & 66.33 & 84 & 0.05 & 0.006 & 0.039 \\
304 & 70.83 & 189 & 0.05 & 0.012 & 0.148 \\
354 & 75.33 & 221 & 0.05 & 0.055 & 2.704 \\
404 & 79.84 & 243 & 0.05 & 0.014 & 0.216 \\
454 & 84.34 & 231 & 0.05 & 0.018 & 0.345 \\
504 & 88.84 & 285 & 0.05 & 0.023 & 0.588 \\
554 & 93.34 & 199 & 0.05 & 0.01 & 0.12 \\
604 & 97.84 & 194 & 0.05 & 0.015 & 0.246 \\
654 & 102.34 & 142 & 0.05 & 0.014 & 0.218 \\
704 & 106.84 & 322 & 0.05 & 0.008 & 0.067 \\
754 & 111.35 & 431 & 0.05 & 0.023 & 0.586 \\
804 & 115.85 & 324 & 0.05 & 0.017 & 0.332 \\
854 & 120.35 & 176 & 0.05 & 0.018 & 0.37 \\
904 & 124.85 & 387 & 0.05 & 0.014 & 0.23 \\
\hline
\end{tabular}

Table 4.1: RMS travel-time residuals and Chi-square values from the forward modelling of basement reflections of eighteen MCS shot gathers collected along the SAHKE03 profile (Fig. 4.3). $\mathrm{N}^{*}=$ number of travel-time picks per gather.

\section{SAHKE03-M onshore sedimentary section}

The onshore portion of the SAHKE03-M sedimentary section was constrained using borehole and seismic data acquired as part of oil exploration (St John, 1964; Watson and Allen, 1964; Gerrard, 1971), in addition to sediment thickness calculations (Anderton, 1981) and a geological cross-section (Townsend et al., 2008).

Five exploration well sites, located between Wanganui city and Mt Ruapehu, are in close proximity to the SAHKE03-M model line (Fig. 4.4). Each of these were drilled to basement and provide ground-truthed constraints on the thickness of the sedimentary section. These sites were projected onto the SAHKE03-M transect and the basement depth from each used as an initial 
constraint on sediment thickness. Anderton's (1981) sedimentary thickness calculations (Fig. 4.4), in conjunction with cross-section data (Townsend et al., 2008), were used to constrain sedimentary thickness between each well site.

The P-wave velocity of the sedimentary fill calculated offshore using the MCS stacking velocity field (as discussed above) was also used in the onshore section. North of station S-CUF (Fig. 4.1), within the Otunui Basin, Miocene and Oligocene sediments were encountered in three boreholes, Tupapakurua-1, Koporongo-1 and Kaitieke-1 (St John, 1964; Gerrard, 1971). These sediments are modelled with a constant $\mathrm{Vp}$ of $3.4 \mathrm{kms}^{-1}$ following the results of onshore seismic refraction analysis conducted by Watson and Allen (1964). At the southern end of the model, Triassic basement outcrops on the Kapiti coast near Porirua city (Fig. 1.5), hence the Plio-Pleistocene sedimentary section is pinched out at this locality. The $\mathrm{Vp}$ of these basement rocks were measured by Garrick (1968) who interpreted data from a seismic reflection survey that ran from just north of Wellington $170 \mathrm{~km}$ north to the Mangaweka area (see Fig. 4.5). Garrick (1968) interpreted a thin $(0.42 \mathrm{~km})$ layer with $\mathrm{Vp}$ of $4.42 \mathrm{kms}^{-1}$ at the surface, underlain by a $5 \mathrm{~km}$ thick layer with a $\mathrm{Vp}$ of $5.43 \mathrm{kms}^{-1}$. These layers were interpreted as unconsolidated and consolidated Mesozoic greywacke basement terrains respectively and these velocities are used at the southern end of the initial SAHKE03-M model.

\begin{tabular}{ccccc}
\hline Well & Elv $(\mathrm{m})$ & Basement depth $(\mathrm{m})$ & Easting & Northing \\
\hline Whangaehu-1 & 7 & 3488 & 2692399.19 & 6127776.99 \\
Parikino-1 & 21 & 2292.1 & 2693886.90 & 6154005.64 \\
Tupapakurua-1 & 315 & 1127.8 & 2707844.91 & 6222375.85 \\
Koporongo-1 & 278 & 536.5 & 2709739.24 & 6230561.77 \\
Kaitieke-1 & 300 & 381 & 2708889.46 & 6236659.63
\end{tabular}

Table 4.2: Well sites located within Wanganui Basin, used to constrain sedimentary fill thickness. Elevation is relative to mean sea level and basement depth is measured from the Earths surface. Coordinates are in New Zealand Map Grid. 


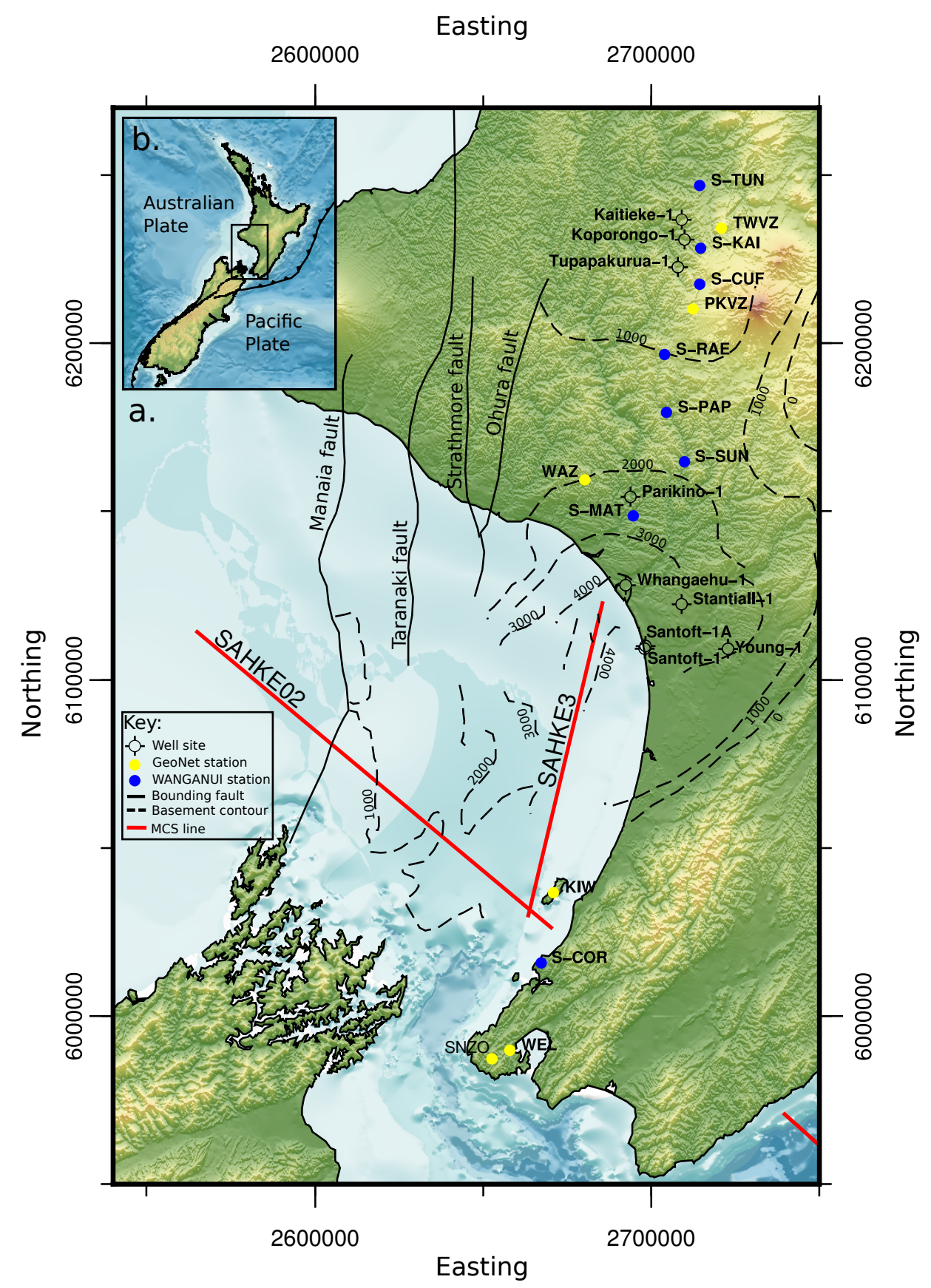

Figure 4.4: (a) Map showing the location of exploration borehole sites used to constrain basement depth in model SAHKE03-M, table 4.2 lists the depth to basement in each borehole. Dashed black lines are sedimentary thickness calculations (metres) determined by Anderton (1981). Solid black lines are major Wanganui Basin bounding faults. (b) Inset map showing the bounding box of (a). 


\subsubsection{Kapiti Island static correction}

The southern end of the SAHKE03 MCS line passes the western side of Kapiti Island (Fig. 4.1), where the GeoNet seismometer KIW is located at an elevation of $381 \mathrm{~m}$. Due to the proximity of KIW to the SAHKE03 MCS line, the seismic phases recorded at this station are among the most coherent within the SAHKE03 receiver gather dataset (Fig. 2.10).

In order to include phases recorded at KIW in the SAHKE03-M model, the location of KIW was perpendicularly projected onto the model transect, as were all other shot locations (see Section 3.7.1). The topographic elevation from each shot location was also projected onto the model transect, in order to honor raypath lengths.

However, the projection of topography from KIW onto the model transect results in a discrepancy in the ray lengths for phases emanating from all other shot points, as the projected location of KIW overlaps with receiver locations (The SAHKE03 MCS profile). It is necessary that model topography is fixed at sea level in order to remain consistent with the lengths of seismic rays emanating from all other shot points. This results in a discrepancy in ray length for phases recorded at KIW.

Thus, a static correction was developed to account for this discrepancy. Appendix $\mathrm{C}$ details the process by which this correction was calculated and applied to travel-time picks interpreted on the receiver gather from station KIW.

\subsubsection{Crustal structure constraints}

Previous interpretations of crustal structure within Wanganui Basin provide constraints on deeper model parameters and these were incorporated into an initial Vp model. In contrast to near surface constraints (section 4.2.1), however, these constraints were not necessary honoured if their modification was deemed necessary in order to reconcile observed travel-times.

These constraints were derived from 3D gravity modelling of Wanganui Basin 


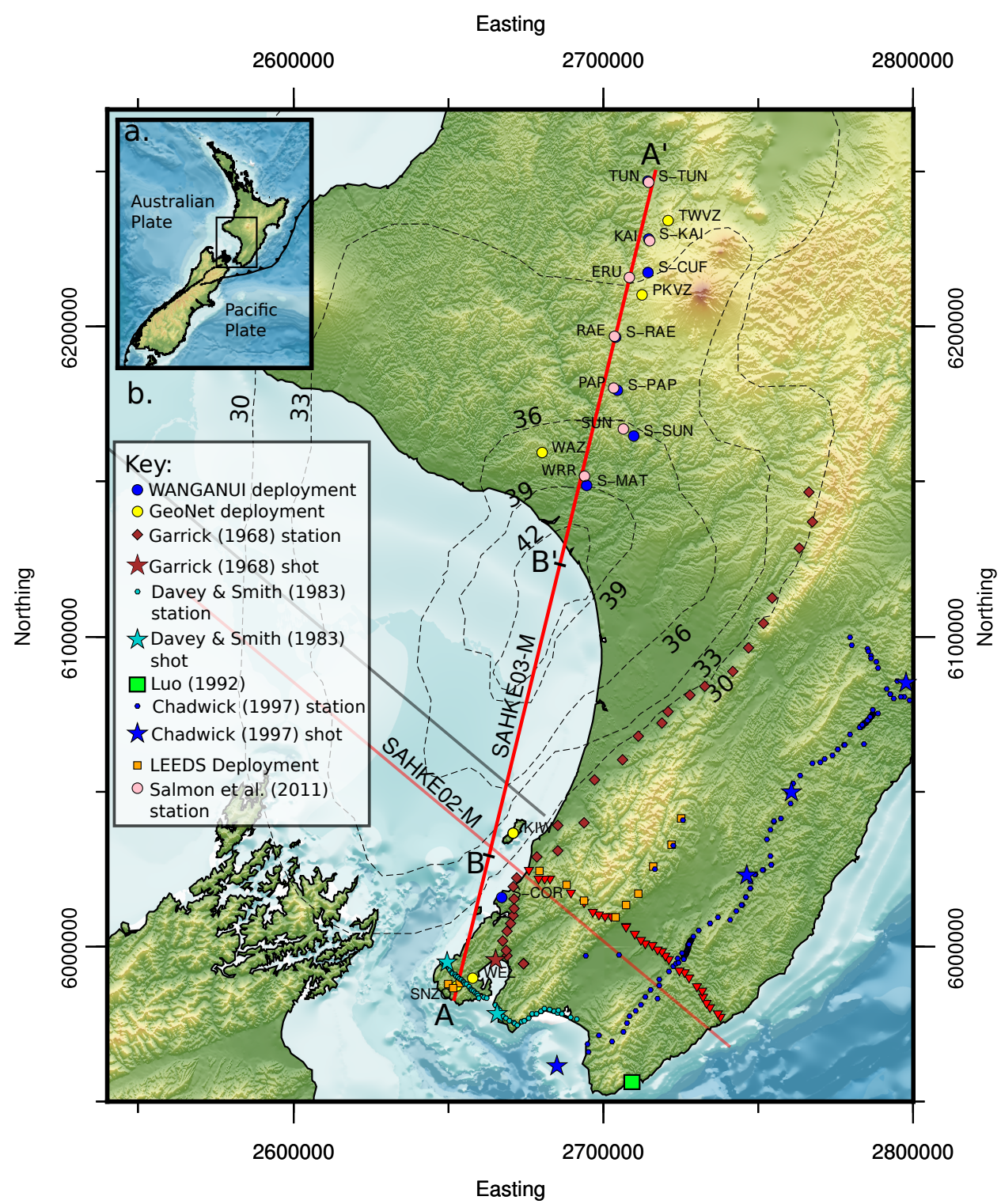

Figure 4.5: a) Map showing the location of the SAHKE03-M model line (A - A') and the SAHKE03 multichannel-seismic line (B - B'), seismograph stations belonging to the temporary WANGANUI deployment (blue circles) and permanent GeoNet network (yellow circles) used in this study. Survey components from previous studies (as discussed in the text) are also shown. Salmon et al. (2011) temporary deployment (pink circles), Garrick (1968) Wellington crustal refraction profile (maroon diamonds and star), Davey and Smith (1983b) refraction profile (light blue circles and star), Stern and Davey (1990) MCS reflection line (grey line), Chadwick (1997) Hikurangi margin seismic refraction experiment (dark blue circles and stars), Leed's receiver function deployment (orange squares), Luo (1992) Cape Palliser study (green square), dashed black lines are Moho depth contours determined by Ewig (2009). (b) Inset map showing the bounding box of (a). 
Moho depth (Ewig, 2009), receiver function analysis (Ewig, 2009; Salmon et al., 2011), 3D earthquake tomography (Eberhart-Phillips et al., 2010), active source seismic refraction studies (Watson and Allen, 1964; Garrick, 1968), Pn (upper mantle refraction) travel-time delay times (Haines, 1979) and plate interface interpretations based on earthquake hypocenter locations (M. Reyners, personal communication, 21 November 2011).

\subsubsection{Plate Interface}

Earthquake hypocenters from the national GNS earthquake catalog were recently relocated using the nation wide 3D tomography model of EberhartPhillips et al. (2010) and supplied by Martin Reyners (M. Reyners, personal communication, 21 November 2011) for use in this study. Hypocenters located within $25 \mathrm{~km}$ of the SAHKE03 model line are used to define the Australian-Pacific plate interface in the initial model (Fig. 1.7). Furthermore, constraints from a receiver function constructed by (Ewig, 2009) using teleseismic earthquake data recorded at GeoNet station KIW (Figs. 4.5 and 4.6) were also incorporated into the initial model. Ewig (2009) imaged the top of plate interface at depth of $25 \mathrm{~km}$ beneath this station (Fig. 4.6) and also deduced a $5.6 \mathrm{~km}$ thick low velocity zone below the plate interface, interpreted as a subducted sedimentary layer.

\subsubsection{Australian plate Moho}

The depth and geometry of the Australian plate Moho remains unresolved by seismic data in the offshore portion of Wanganui Basin. The best constraint for crustal thickness is from the results of three dimensional modelling of the free-air/isostatic gravity anomaly associated with Wangnaui Basin by Ewig (2009) combined with deep seismic reflections within the adjacent Taranaki Basin (Stern and Davey, 1990; Fig. 4.7). Ewig's (2009) analysis implies a downwarp of the crust three times that of the overlying sedimentary basin (see contours on Fig. 4.5), with the Moho reaching a maximum depth of $>$ $42 \mathrm{~km}$ in the center of the basin. The downwarp of both the sedimentary 


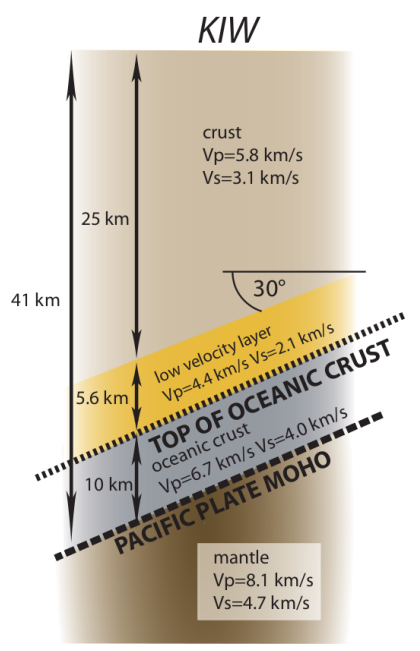

Figure 4.6: Teleseismic Receiver function interpretation at GeoNet station KIW located on Kapiti Island (after Ewig, 2009).

basin and Moho closely parallel the shape of the freeair/isostatic gravity anomaly (Fig. 1.8), with the maximum crustal thickness occurring in the region of the maximum gravity anomaly (- 160 mgal).

Onshore, Salmon et al. (2011) created a central conversion point receiver function stack using eight temporary seismographs deployed along a profile coincident to the northern section of the SAHKE03 profile (pink circles, Fig. 4.5). This provides an initial constraint on Moho depth of $\sim 34-35 \mathrm{~km}$ beneath stations WAZ and S-MAT (Fig. 4.8).

These authors also interpreted a vertical step in the Moho of $\sim 7 \mathrm{~km}$ located between stations RAE and ERU - the "Taranaki-Ruapehu line" (Fig. 4.8). This step is investigated in this study using the data collected at stations S-KAI and TWVZ as discussed in Section 6.9.

\subsubsection{Crustal and upper most mantle velocity structure}

Initially the crustal portion of the model is divided into four discrete layers (below the sedimentary fill), through which wide-angle reflected and refracted rays are predicted to have passed through. 

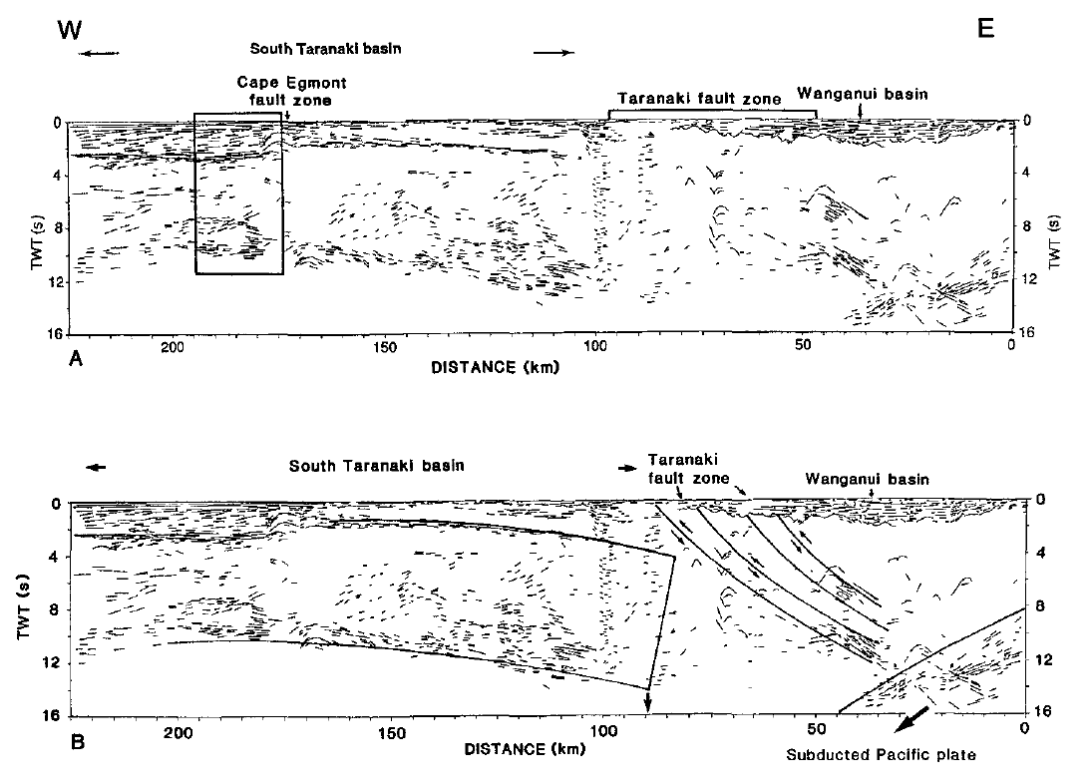

Figure 4.7: Seismic reflection profile from Stern and Davey (1990) showing deep reflections within the Taranaki Basin. The location of this profile is shown on figure 4.5.

These are:

i. Continental Australian Plate Upper crust.

ii. Continental Australian Plate Lower crust.

iii. Australian Plate upper most mantle.

iv. Subducting Oceanic crust.

Several studies provide constraints on velocity structure within each of these layers. Table 4.3 summarises previous velocity calculations for these layers and indicates what values were assigned within the initial model. For this purpose, velocities determined for Mesozoic basement terrains are considered upper crustal velocities.

These velocities were derived using a variety of techniques, namely, active source seismic profiling (Watson and Allen, 1964; Garrick, 1968; Chadwick, 


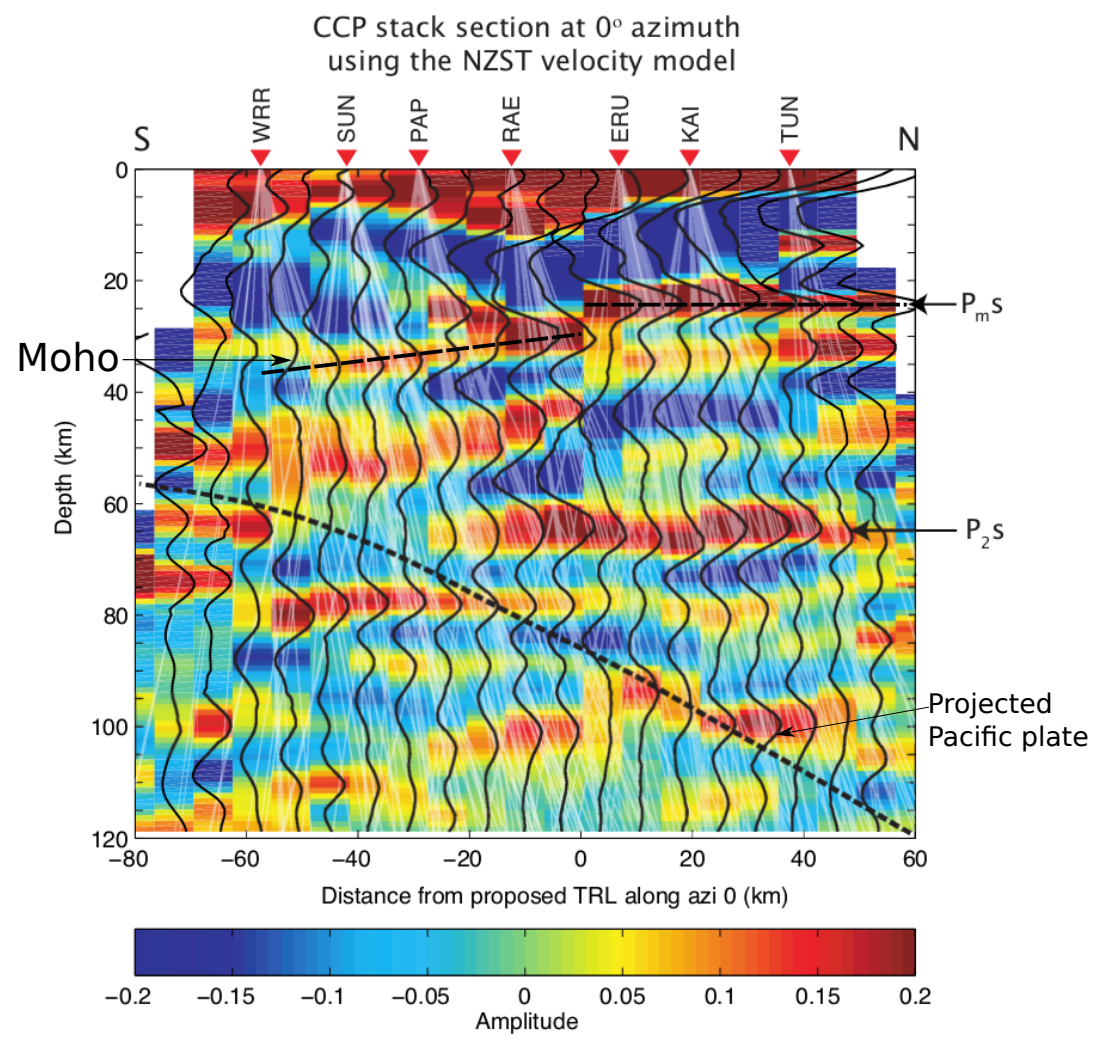

Figure 4.8: Central conversion point receiver function stack created by Salmon et al. (2011) along a profile coincident with the onshore portion of the SAHKE03-M transect. Station locations are shown on figure 4.5 .

1997; Bassett et al., 2010), earthquake wave delay time analysis (Haines, 1979; Bourne and Stuart, 2000; Ewig, 2009), one dimensional (Robinson, 1986; Luo, 1992) and three dimensional (Reading et al., 2001) earthquake wave travel-time inversion and three dimensional earthquake tomography (Eberhart-Phillips et al., 2010). Although the tomographic technique does not produce a layered model, velocities for each layer from the tomographic solution of Eberhart-Phillips et al. (2010) where chosen based on velocity profiles within the model (Fig. 4.9).

Velocity values for the initial model were chosen based on proximity to the SAHKE03-M transect and reliability of each of these constraining datasets. 


\begin{tabular}{l||cccc}
\multicolumn{1}{l||}{ Author } & $\begin{array}{c}\text { Upp. } \\
\text { Crust }\end{array}$ & $\begin{array}{c}\text { Low. } \\
\text { Crust }\end{array}$ & $\begin{array}{c}\text { Upp. } \\
\text { Mantle }\end{array}$ & $\begin{array}{c}\text { Oceanic } \\
\text { Crust }\end{array}$ \\
\hline \hline Watson and Allen, (1964) & $5.3-5.5$ & - & - & - \\
Garrick, (1968) & $5.43-6.21$ & 6.46 & 8.08 & - \\
Haines, (1979) & - & - & 7.8 & - \\
Robinson, (1986) & $5.85-6.03$ & 6.03 & - & $6.75-7.82$ \\
Luo, (1992) & 3.4 & 5.0 & - & 5.9 \\
Chadwick, (1997) & $4.3-5.6$ & - & - & $6.7-7.2$ \\
Reading, (2001) & $5.6-5.8$ & $6.2-6.6$ & - & $6.4-6.8$ \\
Ewig, (2009) & 5.8 & 6 & 8.1 & $6.7-6.8$ \\
Bassett et al. (2010) & - & - & - & $4.9-7.3$ \\
Eberhart-Phillips et al. (2010) & $5.5-6.5$ & $6.5-7.5$ & $7.5-8$ & $7.0-8.5$ \\
\hline \hline Used for starting model & $5.4-6.2$ & $6.3-6.8$ & 7.9 & $6.8-7.2$
\end{tabular}

Table 4.3: Summary of crustal velocity calculations (in $\mathrm{kms}^{-1}$ ) from previous studies in the region of the SAHKE03-M model. Upp. Crust Australian Plate Upper Crust low. Crust Australian Plate lower Crust Upp. Mantle Australian Plate Uppermost mantle. Velocities used in the initial model are also shown.

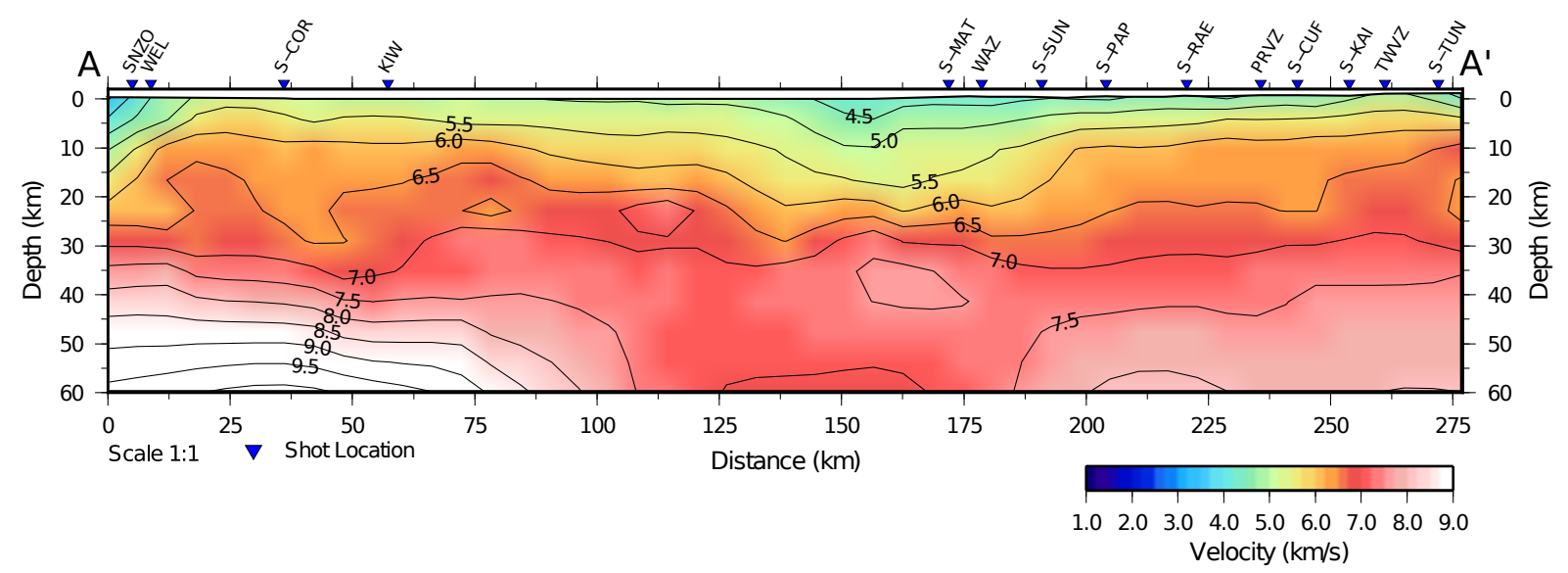

Figure 4.9: Vertical slice through Eberhart-Phillips et al. (2010) nation wide tomographic model along the SAHKE03-M transect (A - A', shown on Fig. 4.1). Velocity nodes are projected from $10 \mathrm{~km}$ either side of the transect and contoured at gird increments of $\mathrm{X}$ and $\mathrm{Y}=6 \mathrm{~km}$. Blue triangles are the shot locations for receiver gathers from the SAHKE03 WANGANUI deployment.

For example, although the refraction profile of Garrick (1968) runs approximately parallel to that of SAHKE03-M, this profile was shot unidirectionally and hence the velocities reconciled are likely to be ambiguous. Furthermore, the tomographic technique of Eberhart-Phillips et al. (2010) 
uses node spacings of approximately $8 \mathrm{~km}$ and therefore smooths velocity variations through the model. For this reason, only velocity values below 8 $\mathrm{km}$ depth are considered reliable as near surface values appear to contain deeper crustal overprinting (i.e. $5.2 \mathrm{kms}^{-1}$ at the surface, Fig. 4.9).

\subsection{Modelling results}

The final SAHKE03-M velocity model is displayed in figure 4.10. The model is sampled by rays over a lateral distance of $\sim 265 \mathrm{~km}$ and to a maximum depth of $42 \mathrm{~km}$, however, several gaps in ray coverage exist due to sparse receiver spacing (Fig. 4.10b). The interpretation and implications of this model are discussed in Chapter 6. 

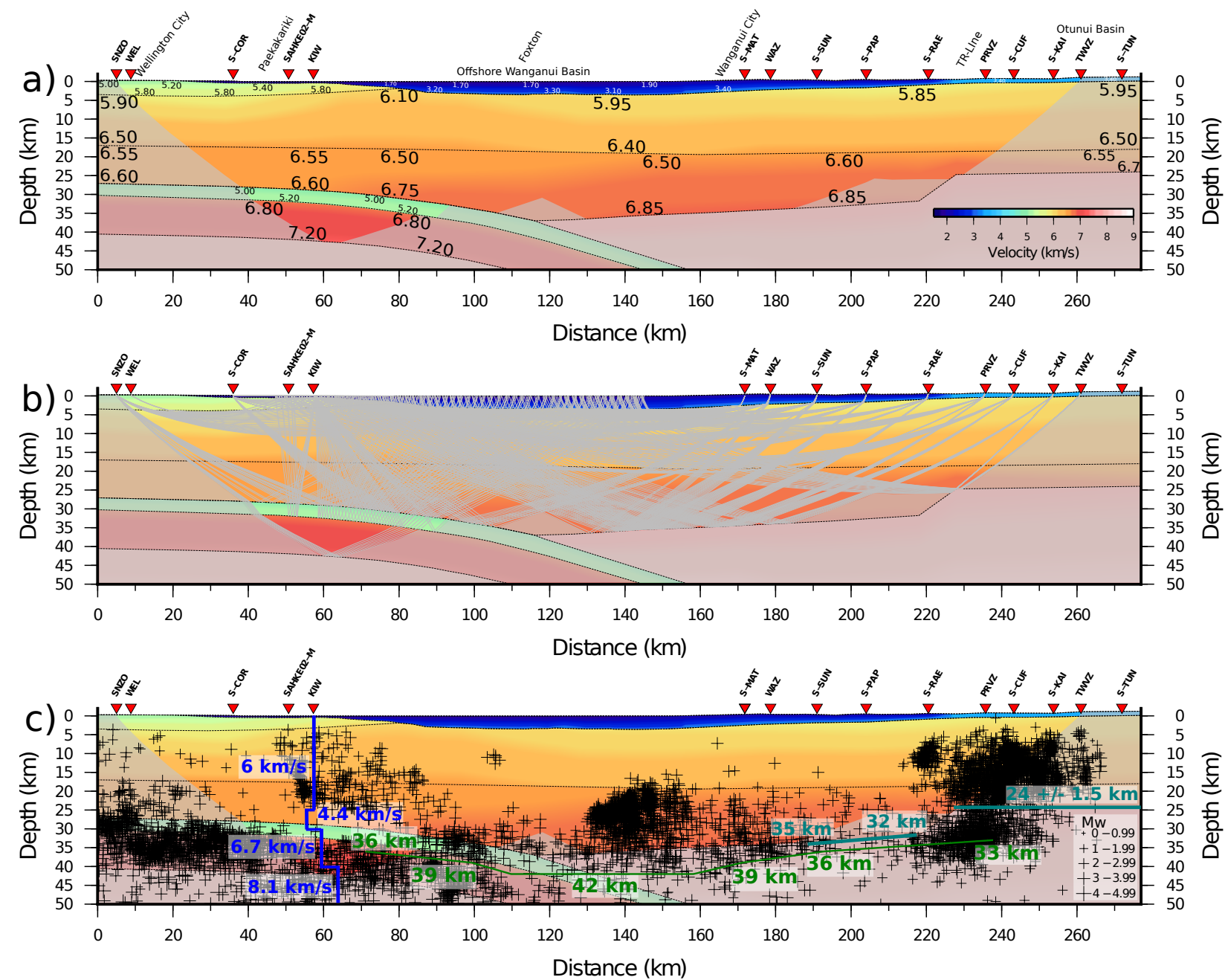

Figure 4.10: (a) Final SAHKE03-M model displaying a selection of velocity node values in $\mathrm{kms}^{-1}$. TRL $=$ Taranaki-Ruapehu Line. The grey shaded area indicates the unconstrained region with no ray coverage. (b) Same as in (a) but showing model ray coverage. (c) Same as in (a) but showing the relationship between the model derived in this study and constraining data sets. Black crosses are earthquake hypocenters scaled to magnitude recorded by the national GeoNet seismograph network between January 2001 and March 2011 and relocated using the nation wide 3D velocity model of Eberhart-Phillips et al. (2010), supplied by Martin Reyners (M. Reyners, personal communication, 21 November 2011). Also shown are the results of receiver function analysis from Ewig (2009) at KIW (blue line) and Salmon et al. (2011) (light blue lines). The green line shows the depth to the Moho determined by Ewig (2009) using 3D gravity modelling. Figure continued... 

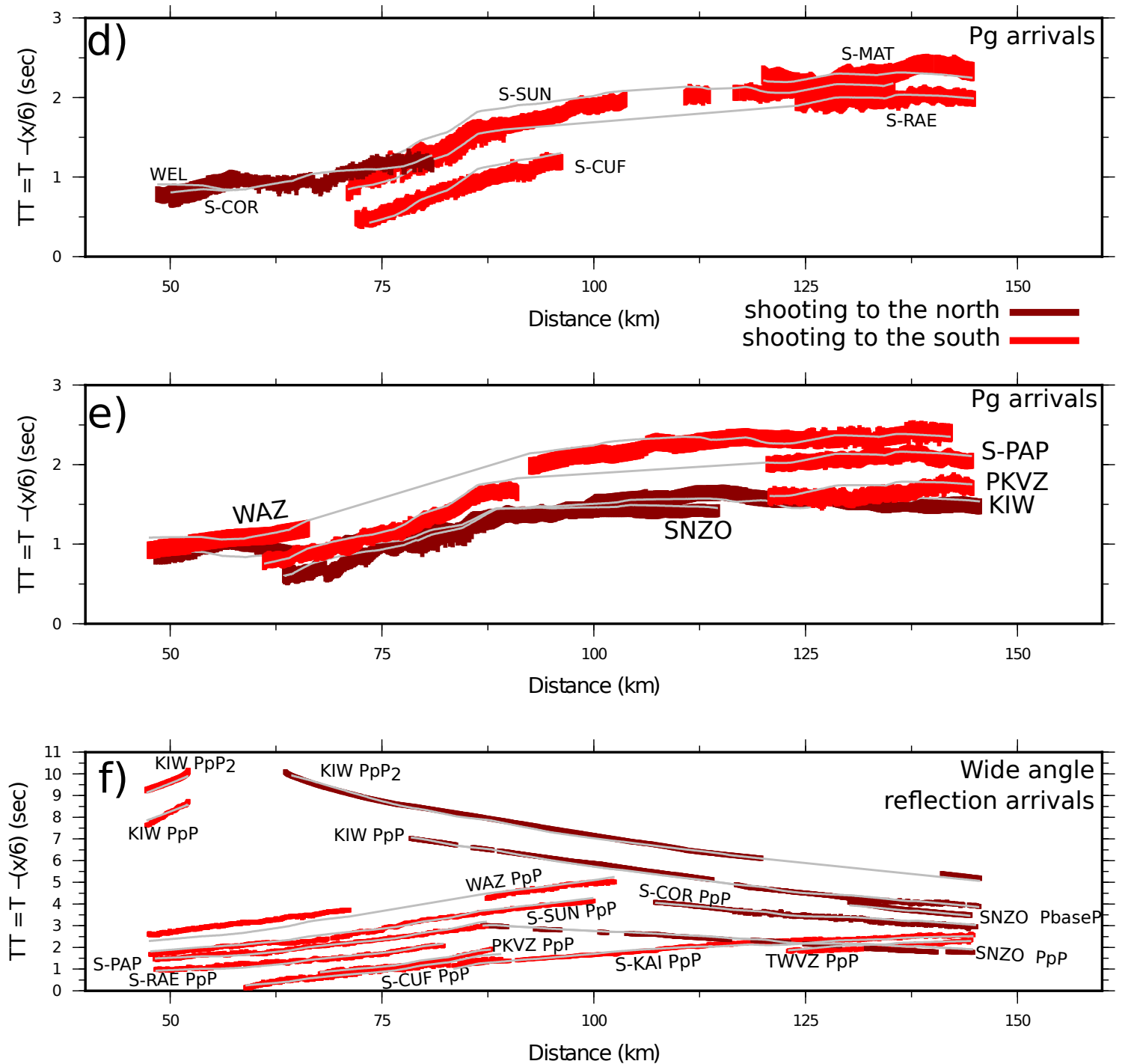

Figure 4.10: (d, e and f) Observed (red and dark red) and calculated (gray) travel-times. Red observed travel-times are from station north of the MCS line, while dark red are south. (d) shows $P g$ refractions from stations WEL, S-COR, S-MAT, S-SUN, S-RAE and S-CUF (e) shows $P g$ refractions from stations SNZO, KIW WAZ, S-PAP and PKVZ and (f) shows $P m P, P p P, P p P_{1}$ and $P p P_{2}$ reflections from all stations. 


\subsubsection{Australian plate velocity structure}

Plio-Pleistocene sediment fill with Wanganui Basin is modelled as a single low-velocity layer $\left(1.7-3.4 \mathrm{kms}^{-1}\right)$. Mio-Oligocene sediments in the King Country Basin (north of station S-RAE) are modelled with a constant velocity of $3.4 \mathrm{kms}^{-1}$ (Fig. 4.10a). As discussed in Section 4.2.1.2, these velocities were deduced from SAHKE03 MCS stacking velocities and refraction profiling conducted by Watson and Allen (1964) respectively.

Ray coverage within the upper crust of central Wanganui Basin is relatively dense (Fig. 4.10b) and this layer is modelled as a high velocity region $\left(\sim 5.85-6.5 \mathrm{kms}^{-1}\right)$, with an average crustal velocity of $\sim 6.2$ $\mathrm{kms}^{-1}$. At the southern end of the line, beneath the Wellington region, a relatively slower layer $\left(5-5.80 \mathrm{kms}^{-1}\right)$ reaching a maximum thickness of $\sim 4 \mathrm{~km}$ is required to fit first arrivals from stations SNZO, WEL and S-COR.

These crustal velocities are broadly consistent with those of the tomographic model of Eberhart-Phillips et al. (2010) (Fig. 4.9). The near surface sedimentary fill velocities are, however, consistently $1.5-3.1 \mathrm{kms}^{-1}$ faster in their model. This may be attributed to sparse node spacing $(\sim 8 \mathrm{~km})$ and smoothing of velocities in the tomographic solution, resulting in unrealistically high velocities in the near surface. As discussed in Section 3.7.2, high near surface velocities such as there would result in large over-estimations of interface depths were this model used to analyse the wide-angle reflection data examined in this study.

The lower crust remains unsampled by refracted rays in this study and so the velocity structure of this layer is poorly resolved. Hence, this layer's velocity structure was constrained using results from previous studies (Garrick, 1968; Eberhart-Phillips et al., 2010) and by reflections. In the final model the velocity of this layer ranges from $6.50-6.85 \mathrm{kms}^{-1}$. Resolution testing confirms these velocities are most consistent with $\operatorname{PmP}$ reflection arrival times (see Section 4.4.3). 
4.3. Modelling results

\subsubsection{Moho structure}

The Moho of the Australian plate is resolved by wide-angle reflections to be at depths between 33.5 - $36.6 \mathrm{~km}$ in the central section of Wanganui Basin (Fig. 4.10a). As discussed in Section 3.5, south of the Wanganui coast line these depths become minima due to the possibility of out-of-plane reflections, owing to the inherit three-dimensional structure of this interface. This interface is relatively planar and has an apparent dip of $2.9^{\circ}$ to the south-south-west. Thickening of the crust parallels the thickening of the overlying sedimentary basin. Onshore, this result is consistent with receiver function analysis that of Salmon et al. (2011) who image the Moho at a depth of $\sim 33-34 \mathrm{~km}$ beneath stations S-SUN and WAZ (Fig. 4.10c). South of station S-PAP these depths are, however, consistently $\sim 3-4.5$ $\mathrm{km}$ shallower than those calculated by Ewig (2009) using gravity data (Fig. $4.10 \mathrm{c})$.

The best fit of reflections recorded at stations S-KAI and TWVZ is achieved using a shallower interface, at a depth of $\sim 25$ and dip of $\sim 0.5^{\circ}$ to the south-south-west. Following results from Salmon et al. (2011), these reflections are also interpreted as Moho arrivals and although ray coverage is sparse (Fig. 4.10b), imply a step in the Moho of $\sim 7 \pm 3 \mathrm{~km}$ over a lateral distance of $<30 \mathrm{~km}$ (see Section 6.9).

\subsubsection{Plate interface structure}

The Australian-Pacific plate interface is resolved at depths of $28.15-35.6 \mathrm{~km}$ between the latitudes of Paekakariki and Foxton (Figs. 4.1 and 4.10a). This interface is relatively uniform with an apparent dip to the north-north-east increasing from 2.3 to $9.5^{\circ}$. At Kapiti Island the depth to the plate interface is resolved as $28.9 \pm 0.5 \mathrm{~km}$. This exceeds that predicted by the receiver function analysis of Ewig (2009) by $\sim 4.0 \mathrm{~km}$. Additionally, the plate interface is $\sim 3 \mathrm{~km}$ shallower than that defined in the initial model using relocated 
seismicity (M. Reyners, personal communication, 21 November 2011). There also appears to be an aseismic zone at this interface between station S-COR and $\sim 10 \mathrm{~km}$ north of Kapiti Island (Fig. 4.10c).

Similarly to the Moho in the central section of the model, the depth to the plate interface determined in this model is likely a minimum. Plate contours based on microseismicity (Orange contours, Fig. 3.1) suggest the shortest path for waves between shots and receivers is likely out-of-model plane in the updip (north-west) direction.

\subsubsection{Subducting oceanic crust structure}

The subducting oceanic crust is modelled as two layers. Each of these layers are sampled by reflecting rays from a single station only (KIW and SNZO respectively) and are therefore poorly resolved in this model (Fig. 4.10b). In light of this poor range coverage, resolution tests were conducted to ascertain the combinations of layer thicknesses and velocities that fit the travel-time data. These tests assumed constant layer thicknesses and velocity profiles (see Section 4.4.3). These results were compared to constraints provided by previous studies (table 4.3) and in the final model, the upper layer is modelled as a $3.0-4.0 \mathrm{~km}$ thick low velocity $\left(5.0-5.2 \mathrm{kms}^{-1}\right)$ layer, while the lower layer is modelled as a $10 \mathrm{~km}$ thick high velocity $\left(6.8-7.2 \mathrm{kms}^{-1}\right)$ layer. These are interpreted as a subducted sediment sheet and anomalously thick oceanic crust as discussed in Chapter 6.

\subsection{Model Assessment}

The goodness of fit of the final SAHKE03-M model and degree to which model features are resolved are assessed using travel-time misfit statistics, ray density analysis and resolution testing of specific model parameters.

Errors in model velocities and interface depths are assigned based on results of resolution testing (see Section 4.4.3). These errors are considered 
minimum formal errors, as they do not consider perturbations of all model parameters.

\subsubsection{Travel-time fit and ray coverage}

Table 4.4 lists the final model travel-time root-mean-squared (RMS) and $\chi^{2}$ values for each phase modelled. Figure 4.11 visually illustrates the RMS fit and ray coverage.

Almost all phases are modelled within reasonable uncertainty. $\chi^{2}$ values range between 0.173 and 1.938, with the vast majority $\sim 1$ and a single out-lier of 7.623 is discussed in Section 4.4.2. These values are acceptable given the coarse station spacing and lack of complete ray coverage.

Figure $4.11 \mathrm{~b}$ illustrates that the velocity structure of the offshore section of the Wanganui Basin is well resolved to a depth of $\sim 15 \mathrm{~km}$, whereas adjacent areas are poorly resolved or remain unsampled. This figure also shows that the Moho and plate interface are best resolved between model coordinates 140 - $165 \mathrm{~km}$ and 60 - $90 \mathrm{~km}$ respectively. 
Table 4.4: RMS travel-time residuals and Chi-square values for the final SAHKE03-M model (Fig. 4.10). $\mathrm{N}^{*}=$ number of travel-time picks per gather.

\begin{tabular}{|c|c|c|c|c|c|c|}
\hline Station & $\begin{array}{l}\text { station location } \\
\text { model coor. }(\mathrm{Km})\end{array}$ & Phase and direction & $\mathrm{N}^{*}$ & $\begin{array}{c}\text { pick } \\
\text { error (sec) }\end{array}$ & $\begin{array}{l}\text { RMS travel- } \\
\text { time residual }(\mathrm{ms})\end{array}$ & $\chi^{2}$ \\
\hline SNZO & 5 & $P g$ right & 664 & 0.08 & 0.072 & 0.821 \\
\hline WEL & 8.837 & $P g$ right & 97 & 0.11 & 0.093 & 0.722 \\
\hline S-COR & 35.996 & $P g$ right & 321 & 0.08 & 0.076 & 0.906 \\
\hline KIW & 57.8 & $P g$ right & 875 & 0.1 & 0.071 & 0.503 \\
\hline KIW & 57.8 & $P g$ left & 89 & 0.1 & 0.060 & 0.363 \\
\hline S-MAT & 171.828 & $P g$ left & 245 & 0.12 & 0.076 & 0.399 \\
\hline WAZ & 178.638 & $P g$ left & 703 & 0.11 & 0.079 & 0.515 \\
\hline S-SUN & 190.962 & $P g$ left & 475 & 0.1 & 0.139 & 1.938 \\
\hline S-PAP & 204.04 & $P g$ left & 543 & 0.1 & 0.071 & 0.51 \\
\hline S-RAE & 220.534 & $P g$ left & 388 & 0.1 & 0.051 & 0.26 \\
\hline PKVZ & 235.693 & $P g$ left & 241 & 0.1 & 0.104 & 1.081 \\
\hline S-SUF & 243.243 & Pg left & 228 & 0.1 & 0.101 & 1.018 \\
\hline SNZO & 5 & $P p P$ right & 393 & 0.11 & 0.112 & 1.037 \\
\hline S-COR & 35.996 & $P p P$ right & 381 & 0.11 & 0.078 & 0.507 \\
\hline KIW & 57.8 & $P p P$ right & 619 & 0.11 & 0.084 & 0.590 \\
\hline KIW & 57.8 & $P p P$ left & 87 & 0.11 & 0.096 & 0.769 \\
\hline "WAZ & 178.638 & 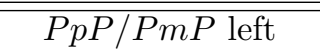 & 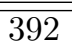 & 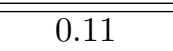 & $\overline{0.303}$ & 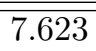 \\
\hline S-SUN & 190.962 & $P m P$ left & 518 & 0.1 & 0.109 & 1.182 \\
\hline S-PAP & 204.04 & $P m P$ left & 390 & 0.1 & 0.071 & 0.503 \\
\hline S-RAE & 220.534 & $P m P$ left & 341 & 0.1 & 0.081 & 0.662 \\
\hline PKVZ & 235.693 & $P m P$ left & 202 & 0.1 & 0.084 & 0.716 \\
\hline S-SUF & 243.243 & $P m P$ left & 288 & 0.12 & 0.104 & 0.752 \\
\hline S-KAI & 253.77 & $P m P$ left & 305 & 0.1 & 0.101 & 1.027 \\
\hline TWVZ & 261.065 & $P m P$ left & 218 & 0.1 & 0.114 & 1.306 \\
\hline KIW & 57.8 & $\overline{P p P_{2} \text { right }}$ & 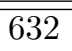 & $\overline{0.12}$ & 0.116 & 0.603 \\
\hline KIW & 57.8 & $P p P_{2}$ left & 89 & 0.15 & 0.093 & 0.595 \\
\hline SNZO & 5 & $P p P_{3}$ right & 144 & 0.12 & 0.050 & 0.173 \\
\hline
\end{tabular}



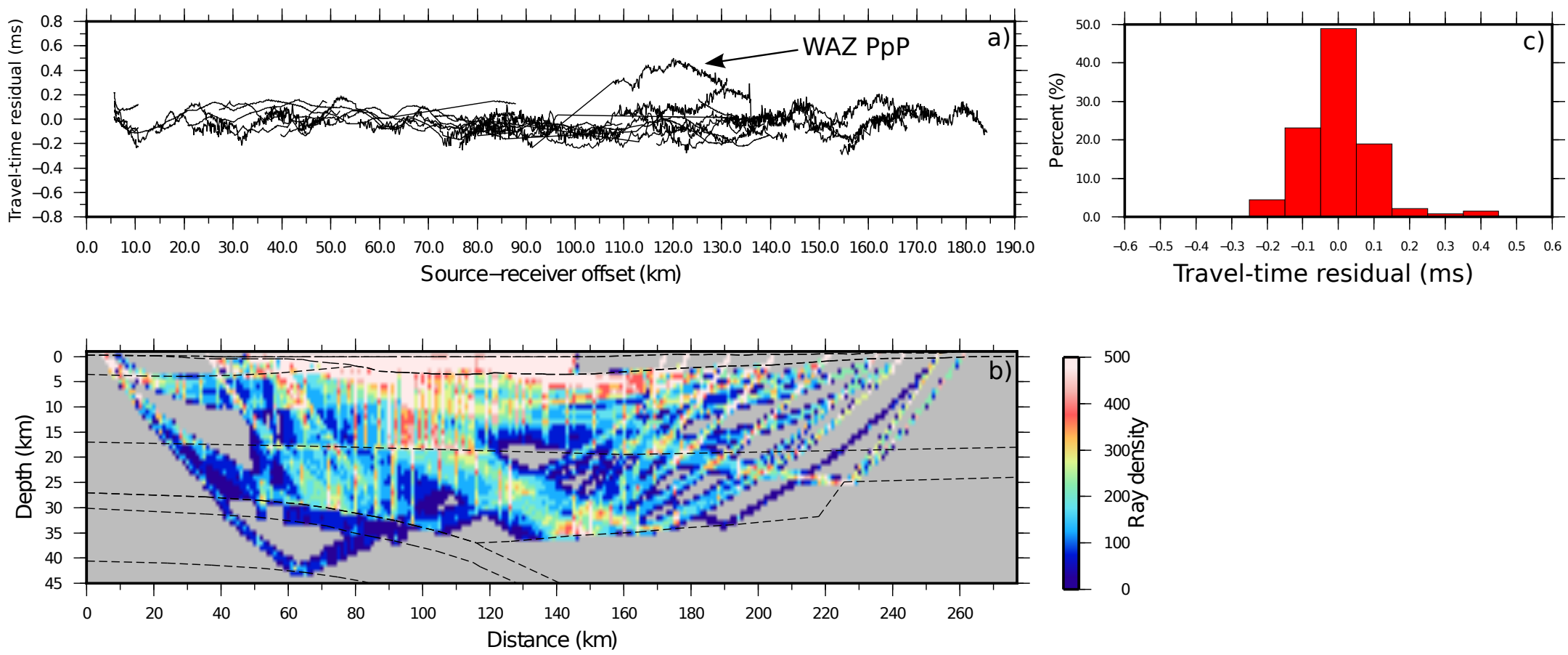

Figure 4.11: (a) Root-mean-squared (RMS) travel-time residuals for all modelled phase arrivals plotted against true source-receiver offset. (b) Ray coverage diagram computed with $1 \times 1 \mathrm{~km}$ grid cells, dashed black lines are model layers. (c) same data as in (a) plotted as a percentage histogram binned at $50 \mathrm{~ms}$ intervals. 


\subsubsection{Problematic arrivals}

Almost all phase picks are modelled within pick uncertainty bounds (table 4.4). Only rays modelled as wide angle reflections from station WAZ exhibit a significant $\left(\chi^{2}\right)$ misfit (Table 4.4; arrow Fig. 4.11a). This phase is modelled as a reflection from the Australian/Pacific plate interface and Australian plate Moho. The misfit of this phase arises from the plate interface portion of the arrival. Given the crustal refraction and Moho reflection recorded at WAZ are modelled with reasonable fits, the misfit of the reflection phase is unlikely to be due to inhomogeneity in the crustal $\mathrm{Vp}$ structure. It is more likely that this discrepancy arises due to the limitation of the 2D approach to model the 3D nature of the plate interface. Station WAZ is located furthest from the model transect and hence these reflections probably originate from out of the model plane in the downdip direction of the plate interface. Furthermore, a deeper reflection interface is consistent with early arrival times predicted by the final model for this phase.

\subsubsection{Resolution testing}

In light of the inherent non-uniqueness of the model solution, automated scripts were developed to test the resolution of specific model parameters by iterating over possible parameter combinations. This process is especially relevant to those areas of the model where refracted rays are absent, and hence velocities are poorly constrained. These tests are also used to assign minimum errors to interface depths and layer velocities.

\section{Interface depths}

The resolution of the depth to the Moho and plate interface are resolved were tested by iterating over a series of lower crustal velocities and interface depth combinations using travel-time arrivals from specific receiver gathers. For this purpose, the velocity structure of the upper crust is kept constant and a table is provided outlining the parameterisation of the lower crust and 
reflector structure. The depth to the Moho is analysed both north and south of the TRL. For both of these tests the structure of the Moho is assumed planar and is defined by two nodes $N_{1}$ and $N_{2}$. In contrast, the curvature of the plate interface is assumed from the final SAHKE03-M model and the depth relative to each node remains constant. In each test, the lower crustal $\mathrm{Vp}$ is set as a constant profile between $V_{1}$ and $V_{2}$ for a series of $V_{1}$ values.

\section{Moho depth south of the Taranaki-Ruapehu Line}

The resolution with which the depth to the Moho is resolved in the central section of Wanganui Basin was tested using PmP reflections from stations S-SUN, S-PAP, S-RAE, PKVZ and S-CUF. Table 4.5 and figure 4.12a show the parameteristion of this test.

\begin{tabular}{cccccc}
\hline$V_{1}\left(k m s^{-1}\right)$ & $V_{2}\left(k m s^{-1}\right)$ & $V_{1}$ inc. $\left(k m s^{-1}\right)$ & $N_{1}(\mathrm{~km})$ & $N_{2}(\mathrm{~km})$ & N inc. $(\mathrm{km})$ \\
\hline $6.5-7.0$ & $V_{2}=V_{1}+0.30$ & 0.1 & $25-40$ & $25-40$ & 0.5
\end{tabular}

Table 4.5: Parameterisation for SAHKE03-M Moho resolution test. Model parameters are shown in figure $4.12 \mathrm{a}$.

Figure $4.12 \mathrm{~b}$ illustrates the results from this test. The results show that the best RMS fit of these reflections is achieved using a lower crust with a velocity profile of $6.5-6.8 \mathrm{kms}^{-1}$ and a Moho increasing from $29.5 \mathrm{~km}$ to $36.5 \mathrm{~km}$ between $N_{1}$ and $N_{2}$ at an apparent dip of $3.9^{\circ}$. Velocities below 6.5 - $6.8 \mathrm{kms}^{-1}$ are not considered given the high upper crustal velocities (up to $6.5 \mathrm{kms}^{-1}$ ) resolved with refraction data.

Considering an average pick uncertainty of $0.104 \mathrm{~s}$ for the phases modelled, minimum errors of Moho depth of \pm 1.5 and $\pm 1.0 \mathrm{~km}$ are resolved for nodes $N_{1}$ and $N_{2}$ respectively. These results are consistent with the final model, as the parameter values used in the final model are within these uncertainties, while also satisfying all other phase arrivals.

These results also show that is unlikely that the lower crustal velocities 


\section{Two Dimensional Modelling of Crustal Velocity Structure: SAHKE03}
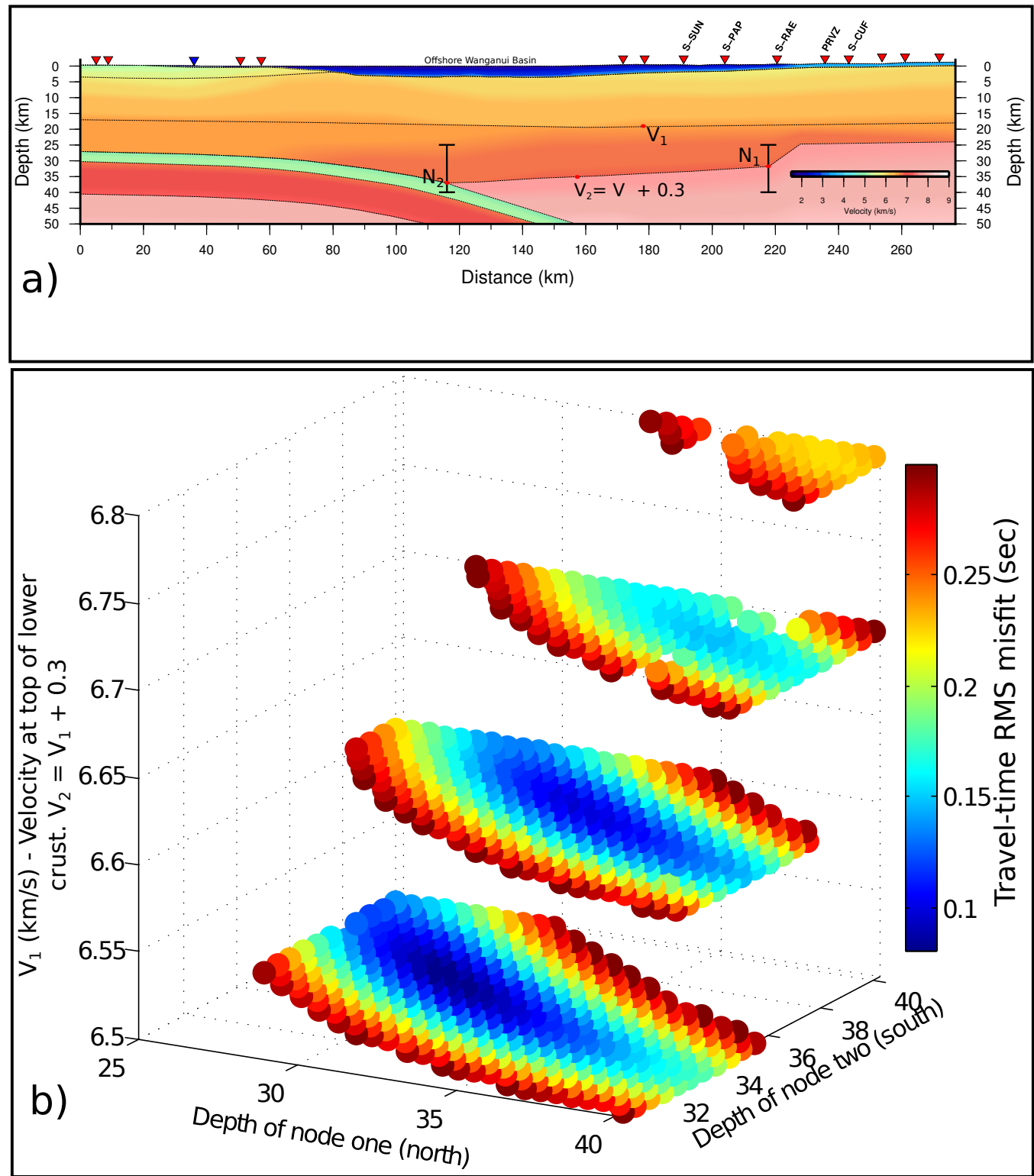

Figure 4.12: (a) Model parameterisation setup for a resolution test of Moho depth south of the TaranakiRauephu Line. (b) RMS travel-time misfit results from the resolution test, plotting only those values $₹$ 0.3

exceed $6.60-6.90 \mathrm{kms}^{-1}$ in the central section of the model.

Moho depth north of the Taranaki-Ruapehu Line 
The resolution of the depth to the Moho north of the Taranaki-Rauephu line was tested using PmP reflections from station S-KAI and TWVZ. Table 4.6 and figure $4.13 \mathrm{a}$ show the parameteristion of this test.

\begin{tabular}{lccccc}
\hline$V_{1} k m m s^{-1}$ & $V_{2} k m s^{-1}$ & $V_{1}$ inc. $k_{m s}^{-1}$ & $N_{1} \mathrm{~km}$ & $N_{2} \mathrm{~km}$ & $\mathrm{~N}$ inc. $(\mathrm{km})$ \\
\hline $6.5-6.8$ & $V_{2}=V_{1}+0.20$ & 0.1 & $22-26$ & $22-26$ & 0.2 \\
Table 4.6: Parameterisation for SAHKE03-M Moho resolution test. Model parameters are shown in figure \\
4.13a.
\end{tabular}

Figure 4.13b illustrates the results from this test. Given a pick error of $0.1 \mathrm{~s}$ this analysis suggests no combination fits the data within uncertainty, with the lowest RMS residual (0.116 s) achieved using $N_{1}=24.6, N_{2}=25.2$ and $V_{1}=6.6 \mathrm{kms}^{-1}$. If we extend pick uncertainty to $150 \mathrm{~ms}$ a minimum error of node depth of $\pm 1 \mathrm{~km}$ is obtained for both $N_{1}$ and $N_{2}$.

These results also indicate it is unlikely that the lower crustal Vp exceeds $6.6-6.8 \mathrm{kms}^{-1}$ in the northern section of the model.

\section{Horizontal resolution of the Taranaki-Ruapehu Line}

The resolution of the horizontal transition in crustal thickness across the Taranaki-Ruapehu Line was tested by trailing different horizontal widths for this step. Table 4.7 shows the results of these tests and indicates the the horizontal transition is not well resolved, but, is less $30 \mathrm{~km}$. Figure 4.14 shows the ray tracing results from using a broad $30 \mathrm{~km}$ step. This shows that most travel-times fit within pick error; however, arrivals at station S-KAI are unable to be reconciled. In the final model, the horizontal distance for this transition is set as $8 \mathrm{~km}$, following receiver function results of Salmon et al. (2011).

\section{Plate interface depth}




\section{Two Dimensional Modelling of Crustal Velocity Structure: SAHKE03}
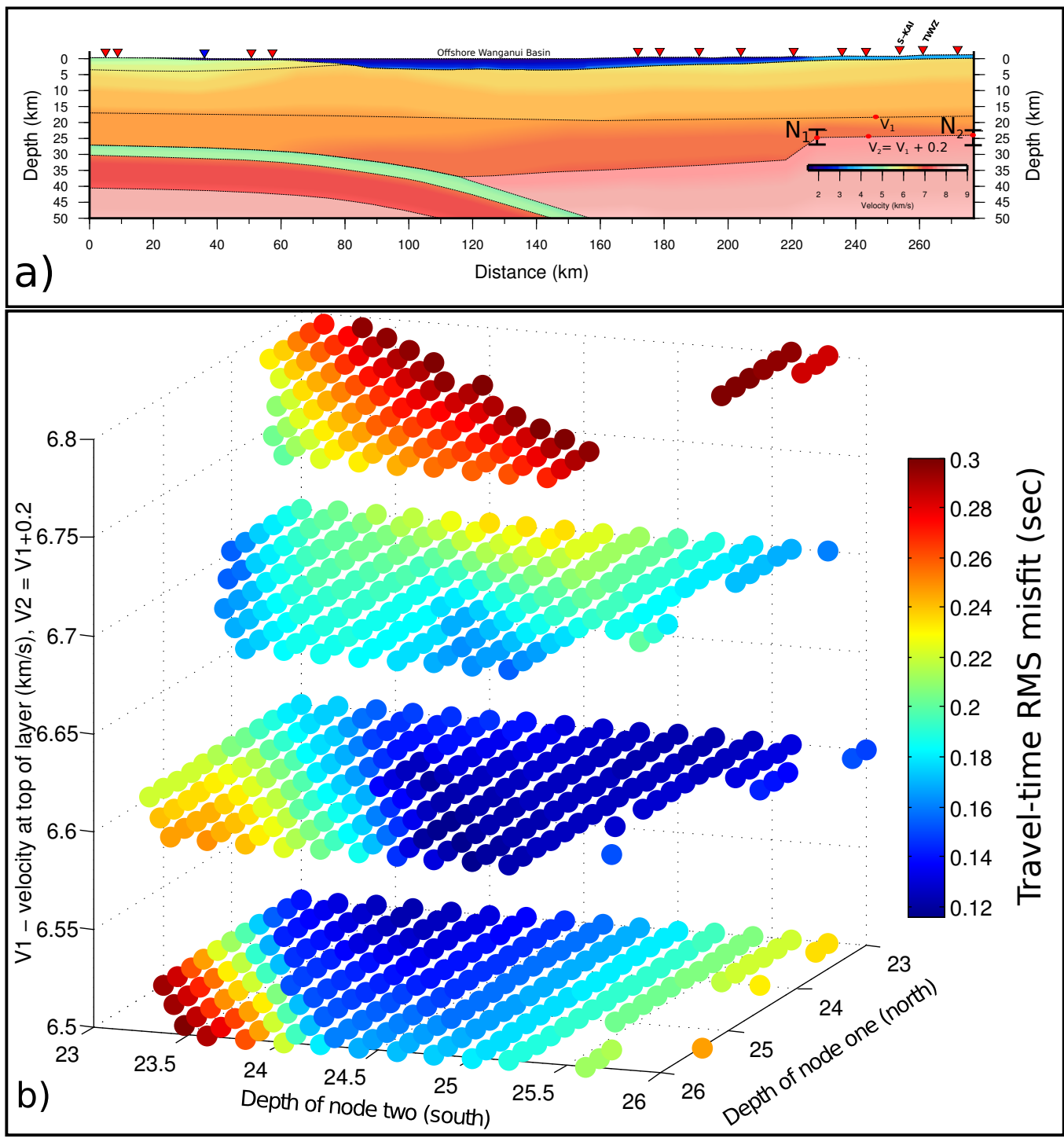

Figure 4.13: (a) Model parameterisation setup for a resolution test of Moho depth north of the TaranakiRuapehu Line. (b) RMS travel-time misfit results from the resolution test, plotting only those values ₹ 0.3

The resolution with which the depth to the plate interface is resolved at the southern end of model was tested using PpP reflections from stations SNZO, S-COR and KIW. Table 4.8 and figure 4.15 show the parameteristion of this test. 

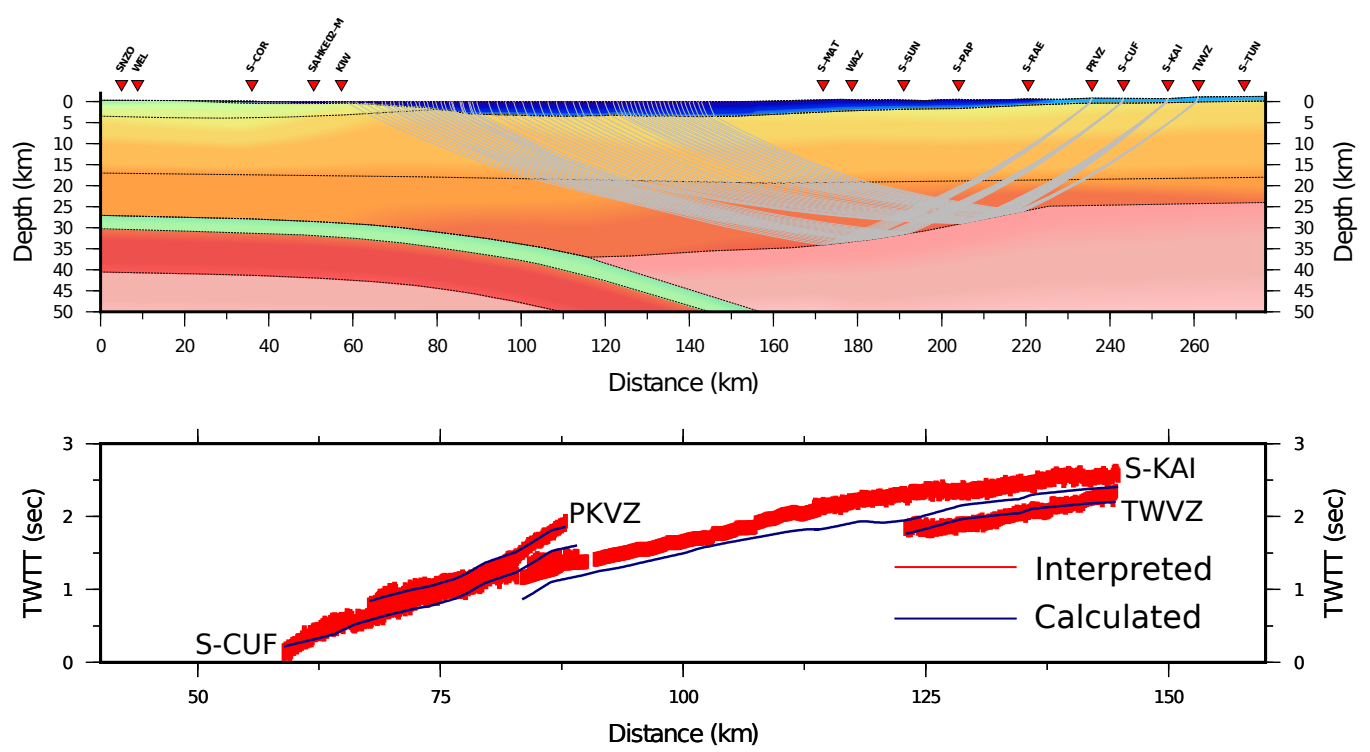

Figure 4.14: (a) Modelling of reflections from the four northern most stations of the SAHKE03-M transect using a broad $30 \mathrm{~km}$ transition across the Taranaki-Ruapehu Line. Note that although most travel-times fits are acceptable, those from S-KAI are unable to be reconciled using this model. (b) Travel-time misfit for each phase.

\begin{tabular}{ccc}
\hline Width of Step $(\mathrm{km})$ & time residual $(\mathrm{ms})$ & $\chi^{2}$ \\
\hline 0 & 0.1 & 0.925 \\
10 & 0.101 & 0.957 \\
20 & 0.119 & 1.351 \\
30 & 0.166 & 2.689
\end{tabular}

Table 4.7: Results from testing the horizontal resolution of the TR-Line crustal thickness transition.

\begin{tabular}{ccccc}
\hline$V_{1} k m s^{-1}$ & $V_{2} k m s^{-1}$ & $V_{1}$ inc. $k m s^{-1}$ & Interface depth km & depth inc. km \\
\hline $6.5-7.0$ & $V_{2}=V_{1}+0.20$ & 0.1 & $\pm 2 \mathrm{~km}$ & 0.5
\end{tabular}

Table 4.8: Parameterisation for SAHKE03-M plate interface resolution test. Model parameters are shown in figure $4.15 \mathrm{a}$.

Figure $4.15 \mathrm{~b}$ illustrates the results of this test.

The results show that the best RMS fit for these reflections is achieved using a lower crust Vp of $6.6-6.8 \mathrm{kms}^{-1}$ and a plate interface depth 0.5 $\mathrm{km}$ deeper than that of the final model, while depths equal to that of the 
4. Two Dimensional Modelling of Crustal Velocity Structure: SAHKE03
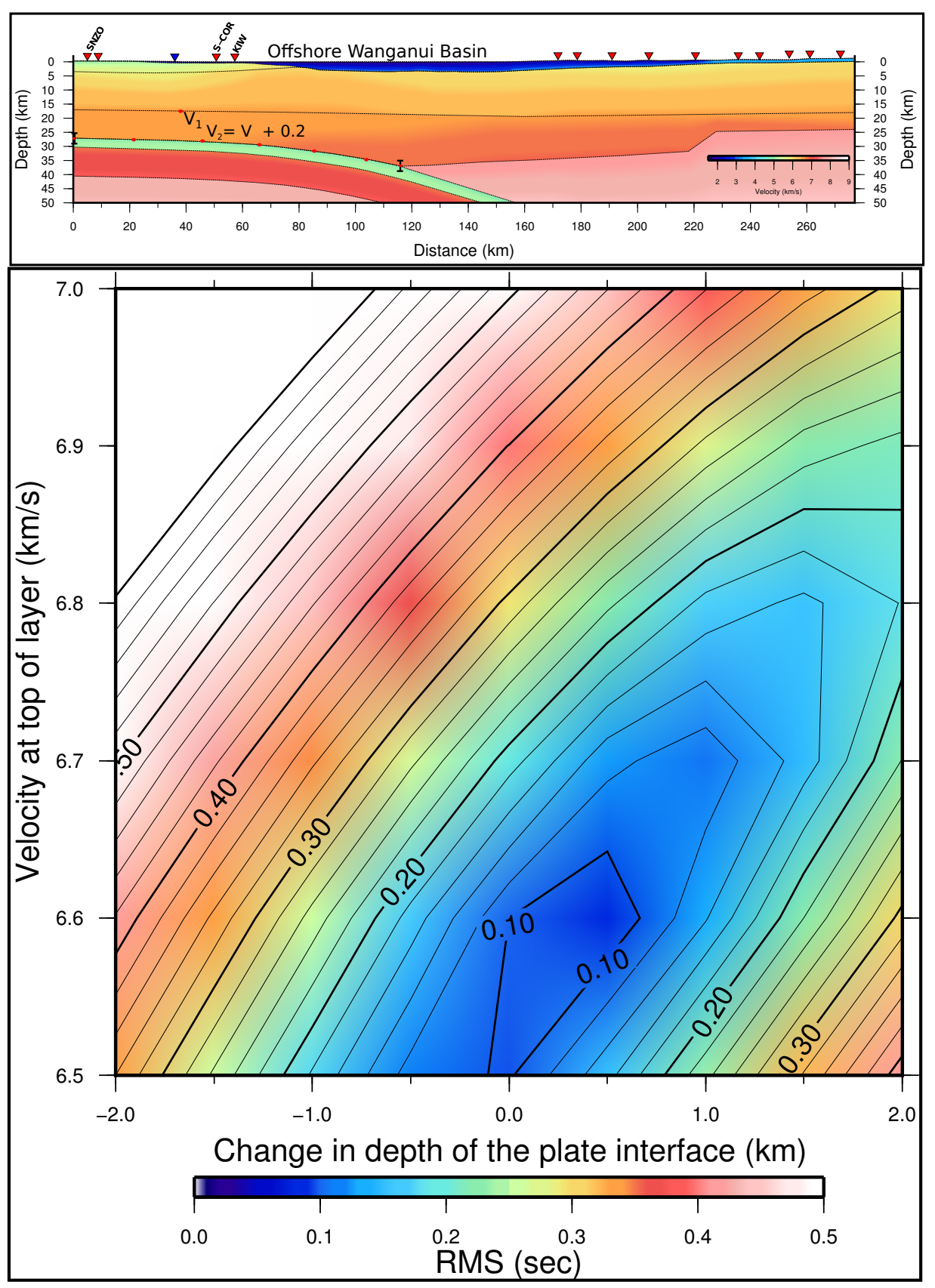

Figure 4.15: (a) Model parameterisation setup for a resolution test of plate interface depth. (b) RMS travel-time misfit results from the resolution test.

final model with Vp of $6.5-6.7 \mathrm{kms}^{-1}$ and $6.6-6.8 \mathrm{kms}^{-1}$ also fit the data 
within uncertainties (RMS $=0.097 \mathrm{~ms}$; Table 4.4). Considering an average pick uncertainty of .11 seconds for these phases, a minimum error for plate interface depth of \pm 0.5 is resolved. These results are consistent with the final model, as the parameter values used in the final model reside within these uncertainties, while also satisfying all other phase arrivals.

These results also show that is unlikely that the lower crustal velocity exceeds $6.7-6.9 \mathrm{kms}^{-1}$ in the southern section of the model.

\section{Subducted Oceanic crust thickness and velocities}

In the final SAHKE03-M model the subducting Oceanic crust is divided into two layers, an upper thin, low velocity layer and a lower, thick, high velocity layer. Each of these layers are modelled based on reflection arrivals from a single station only (KIW and SNZO respectively). Although, reflections interpreted from coincident reflectors are visible on several gathers within the SAHKE02 dataset (as discussed in Chapter 5). The top layer is inferred as a low velocity "blind zone" , as no refraction arrivals exist for this layer. For the second layer, the $\mathrm{Vp}$ at the top of this layer is constrained as $6.8 \mathrm{kms}^{-1}$ from modelling of Pn arrivals in the SAHKE02-M model (as discussed in Chapter 5). The velocity profile of this layer, however, remains unconstrained. Hence, resolution tests were designed to determine possible layer thickness/velocity combinations for each of these layers, given the inherit trade-off that exists between these parameters in the absence of refraction data. These tests assumed constant layer thicknesses and velocity profiles.

\section{Subducted sediment sheet}

Reflections from this layer are only identified on gather KIW (Fig. 2.10) within the SAHKE03 dataset. Table 4.9 shows the parameterisation used to test possible velocity and thickness combinations of this layer. 
4. Two Dimensional Modelling of Crustal Velocity Structure: SAHKE03

\begin{tabular}{ccccc}
\hline$V_{1} \mathrm{kms}^{-1}$ & $V_{2} \mathrm{kms}^{-1}$ & $V_{1}$ inc. $\mathrm{kms}^{-1}$ & layer thickness $\mathrm{km}$ & thickness inc. $\mathrm{km}$ \\
\hline $1.0-7.0$ & $V_{2}=V_{1}+0.20$ & 0.1 & $1-6$ & 0.1 \\
Table 4.9: Parameterisation for SAHKE03-M model low velocity layer resolution test.
\end{tabular}

The results of this test are shown in figure 4.16. These results exhibit a relatively linear velocity-depth tradeoff with an estimated function of:

$$
V_{1}=0.94 \times \text { thickness }+1.26
$$

It is clear a large range of velocity/thickness combinations fit the data equally well; however, this test does suggest the velocity of this layer is unlikely to exceed $5.2 \mathrm{kms}^{-1}$ (0.14 seconds RMS contour; Fig 4.16). In the final model, this layer is modelled with a thickness of $3.5-4 \mathrm{~km}$ and velocity of $5-5.20 \mathrm{kms}^{-1}$. These values are adopted as they are within pick error (120 ms) and are most consistent with the results from the SAHKE02-M model (see Chapter 5) and previous studies (Chadwick, 1997; Bourne and Stuart, 2000; Savage et al., 2007; Ewig, 2009).

\section{Subducted Oceanic crust}

Reflectors from this layer are only identified on gather SNZO (Fig. 2.8) within the SAHKE03 dataset. Both reflections and refractions are identified for this layer on the SAHKE02-M transect, with the Vp of $6.8 \mathrm{kms}^{-1}$ derived at the top of this layer adopted for this model. In order to test which velocity profiles best fit the reflections from the base of this layer, a resolution test was designed. Table 4.10 shows the parameterisation of possible velocity and thickness combinations of this layer used in this test.

The results of this test are shown in figure 4.17. Similarly to the upper layer, these results exhibit a relatively linear velocity-depth tradeoff with an 
4.4. Model Assessment
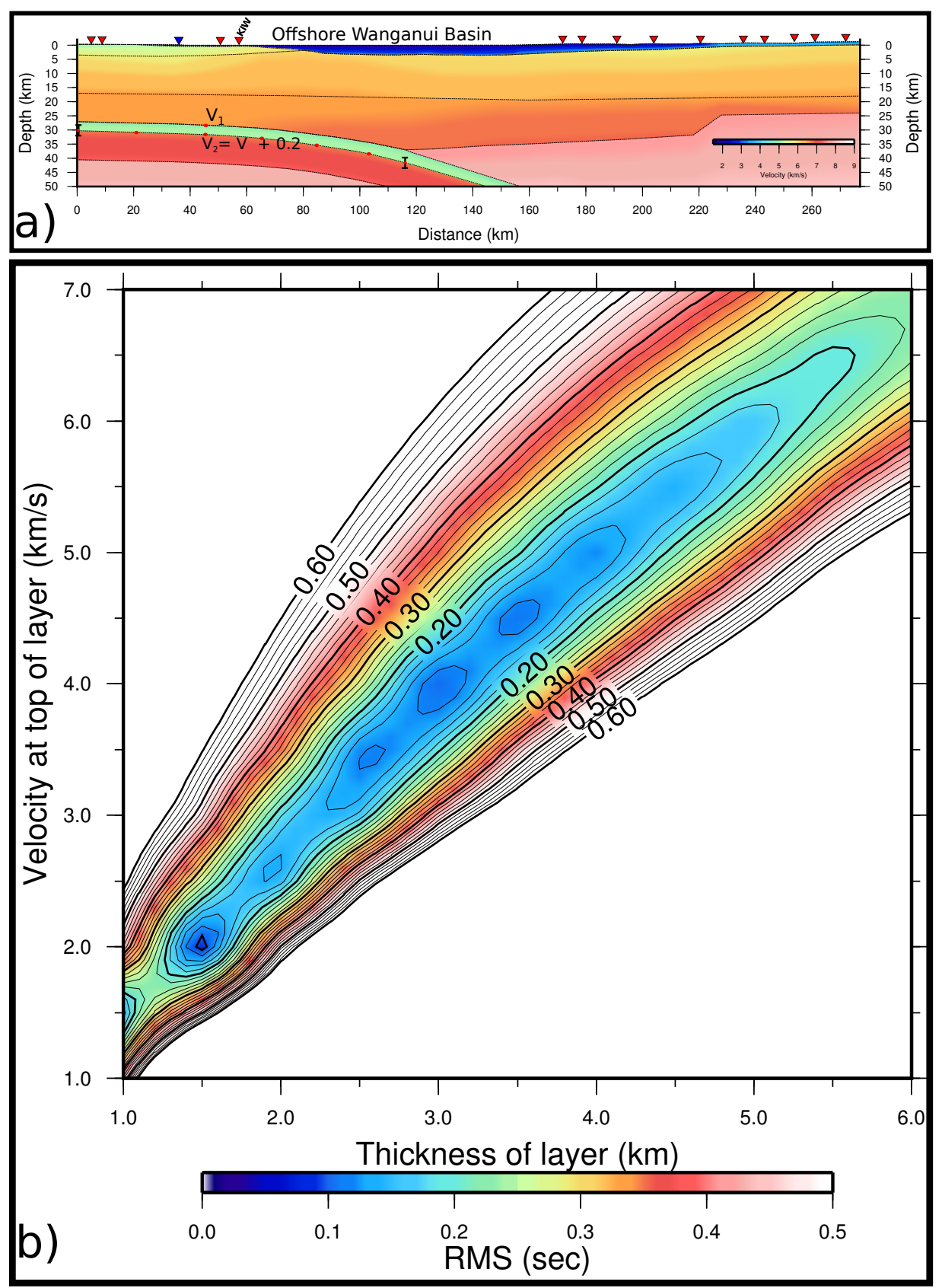

Figure 4.16: RMS travel-time misfit results from the resolution test concerning the thickness and velocity of the upper layer of the subducting oceanic crust.

estimated function of: 
4. Two Dimensional Modelling of Crustal Velocity Structure: SAHKE03
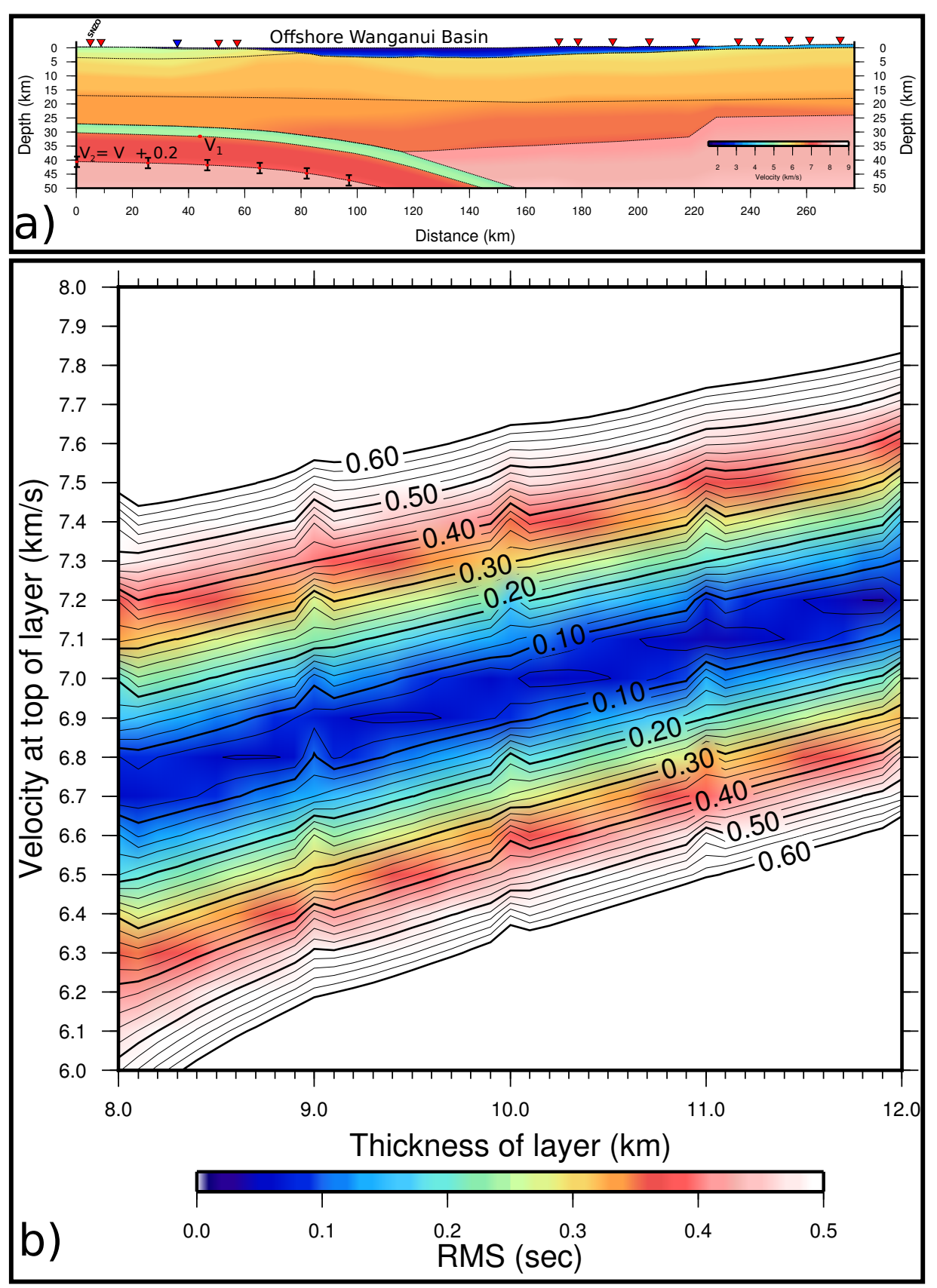

Figure 4.17: RMS travel-time misfit results from the resolution test concerning the thickness and velocity of the lower layer of the subducting oceanic crust.

$$
V_{1}=0.127 \times \text { thickness }+5.684
$$


4.5. Comparison to multi-channel-seismic data

\begin{tabular}{ccccc}
\hline$V_{1} \mathrm{kms}^{-1}$ & $V_{2} \mathrm{kms}^{-1}$ & $V_{1}$ inc. $\mathrm{kms}^{-1}$ & layer thickness $\mathrm{km}$ & thickness inc. $\mathrm{km}$ \\
\hline $6.0-8.0$ & $V_{2}=V_{1}+0.20$ & 0.1 & $8-12$ & 0.1 \\
Table 4.10: Parameterisation for SAHKE03-M model subducting crust lower layer resolution test.
\end{tabular}

In the final model, this layer is modelled with a thickness of $10 \mathrm{~km}$ and velocity profile of $6.8-7.2 \mathrm{kms}^{-1}$, increasing to $6.9-7.2 \mathrm{kms}^{-1}$ down dip, based on results from modelling of the SAHKE02 dataset (see Chapter 5) and this resolution test.

\subsection{Comparison to multi-channel-seismic data}

The SAHKE03 MCS line was shot to a total depth of $17 \mathrm{~s}$ two-way traveltime (TWTT). Although complete processing of this dataset is outside the scope of this study, pre-stack processing was applied to the raw shot gathers for interpretation. Furthermore, a brute stack compiled to $15 \mathrm{~s}$ TWTT by Geotrace (R) was supplied by Stuart Henrys from GNS for use in this study. In order to compare this brute stack and the $\mathrm{Vp}$ model developed in this chapter, the final SAHKE03-M model was converted to TWTT (Fig. 4.20).

The brute stack exhibits a band of deep reflection energy between 12 - 15 s TWTT at the northern end of the profile (Fig. 4.21). Shot gathers show that this reflectivity is highest in amplitude between 12.5 - $13 \mathrm{~s}$ and confirm that this band diminishes below $\sim 14.5 \mathrm{~s}$ (Fig. 4.19). This reflectivity is interpreted as the Australian Plate Moho. Moho reflectivity of similar character has been observed in the adjacent Taranaki Basin (Holt and Stern, 1994) as well as in continental crust at other locations around the World (e.g. Mooney et al., 1987; Long et al., 1994; Cook, 2002; Oueity 


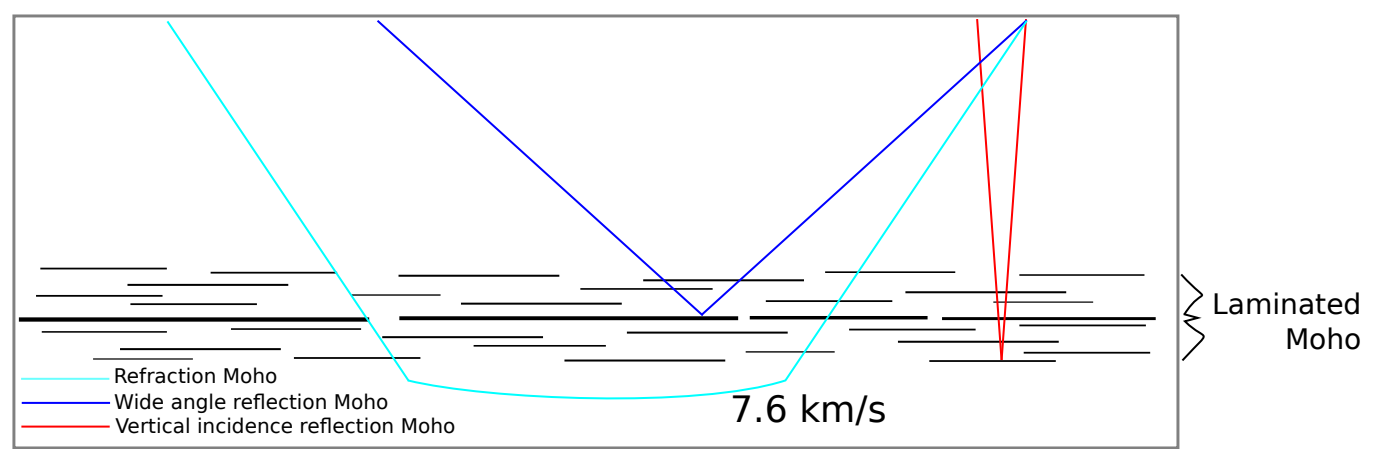

Figure 4.18: Schematic illustration showing potential Moho interpretations as defined by vertical incident reflections (red) wide-angle reflections (dark blue) and refractions (light blue).

and Clowes, 2010). Both Long et al. (1994) and Oueity and Clowes (2010) showed that sequences of reflectivity such as this are best represented by a laterally and vertically heterogeneous crust-mantle transition zone spanning a few kilometers (Fig. 4.18).

Specifically, Oueity and Clowes (2010) showed that, when observed at wide-angles, a transition such as this should produce long Moho reflection coda, similar in character to the wide angle reflections observed on the WANGANUI receiver gathers (Figs. 2.12 and 2.13). The Moho determined using wide-angle data is consistent with the highest amplitude section of this reflectivity at $\sim 13 \mathrm{~s}$ (Fig. 4.20b).

Previous studies have termed the "reflection Moho" as the base of the reflectively zone often observed within the lower crust on vertical incident reflection profiles (e.g. Mooney et al., 1987; Long et al., 1994) and a separate "refraction Moho" determined using the depth at which refracted p-wave velocities increase rapidly above $7.6 \mathrm{kms}^{-1}$, or alternatively, in absence of a steep velocity gradient, any depth were $\mathrm{Vp}$ exceeds $7.6 \mathrm{kms}^{-1}$ (e.g. Cook, 2002 and references therein). Furthermore, the refraction Moho can be either coincident or separate from the reflection Moho with the refraction Moho often corresponding to the base of crustal reflectivity.

As explained by Cook (2002) the correlation between these two boundaries 
is uncertain as Moho refractions may result from gradual vertical changes in velocity and density over several kilometers, whereas reflection arrivals must be the result of narrow (less than $100 \mathrm{~m}$ ) vertical discontinuities.

Additionally, it has been shown that the highest amplitude reflection observed within vertical incident sections will not necessarily correspond with the base of the reflectivity zone as constructive interference within the laminated reflection Moho zone may amplify earlier arrivals (Mooney et al., 1987).

On the SAHKE03 transect, the reflection Moho determined using wide-angle data corresponds with the highest amplitude arrival on the vertical incident MCS section, which may be caused by a large velocity discontinuity within a complex laminated zone (Fig. 4.20). Following the definition above, this is not coincident with the reflection Moho, which is shown by the MCS shot gather data to be $\sim 1.5$ seconds TWTT deeper (Fig. 4.19). It is therefore proposed that the Moho determined in the wide-angle model developed in this chapter may be shallower than would be determined using vertical incident profiling.

Further to the south, the plate interface determined using wide-angle data matches reasonably well with deep reflectivity that dips to the northnorth-east. This reflectivity is, however, attenuated and masked by noise further to the south. Two additional lower-crustal reflectors occur at $\sim 10$ and 11 seconds TWTT near the northern end of the profile. These span lateral distances of $\sim 20 \mathrm{~km}$ and are not interpreted in the wide-angle data. Interestingly, these reflections occur above the intersection point between the Moho and plate interface, as determined using wide-angle reflections. Similar lower crustal reflectivity is also evident above this intersection point on the SAHKE02 MCS profile (see Section 5.5). One interpretation is that this reflectively may represent buckling of the overlying crust as a result of compression between the two plates. 
4. Two Dimensional Modelling of Crustal Velocity Structure: SAHKE03

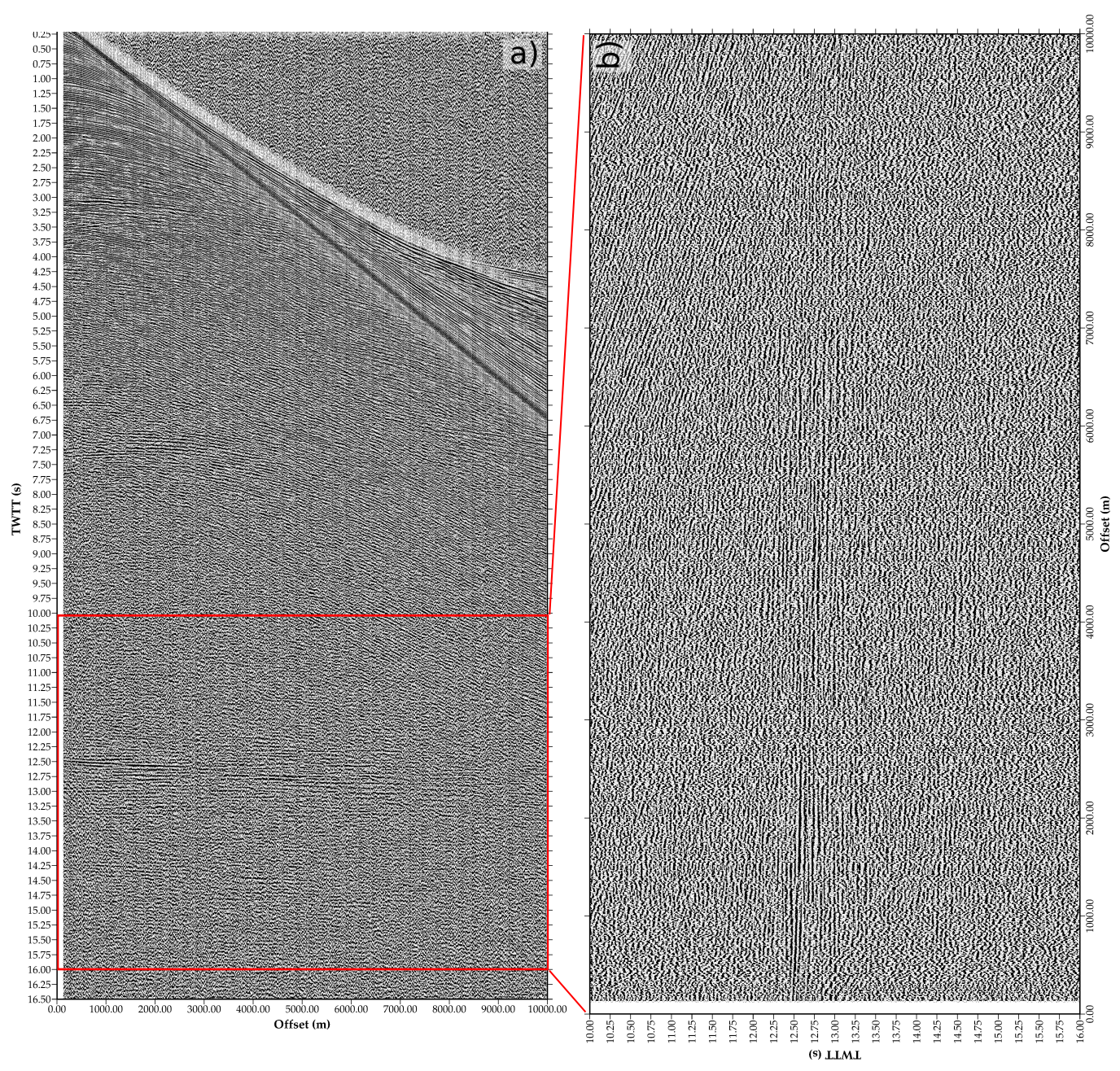

Figure 4.19: (a) SAHKE03 MCS shot gather from the northern end of the transect. Proccessed using a full trace length debias, [ $\left.\begin{array}{llll}5 & 10 & 40 & 60\end{array}\right] \mathrm{Hz}$ bandpass filter and a $500 \mathrm{~ms}$ window length automatic gain control. Note the strong reflection energy between $\sim 12-13.5 \mathrm{~s}$. The red box shows the extent of (b). (b) Scaled section between $10-16 \mathrm{~s}$. 

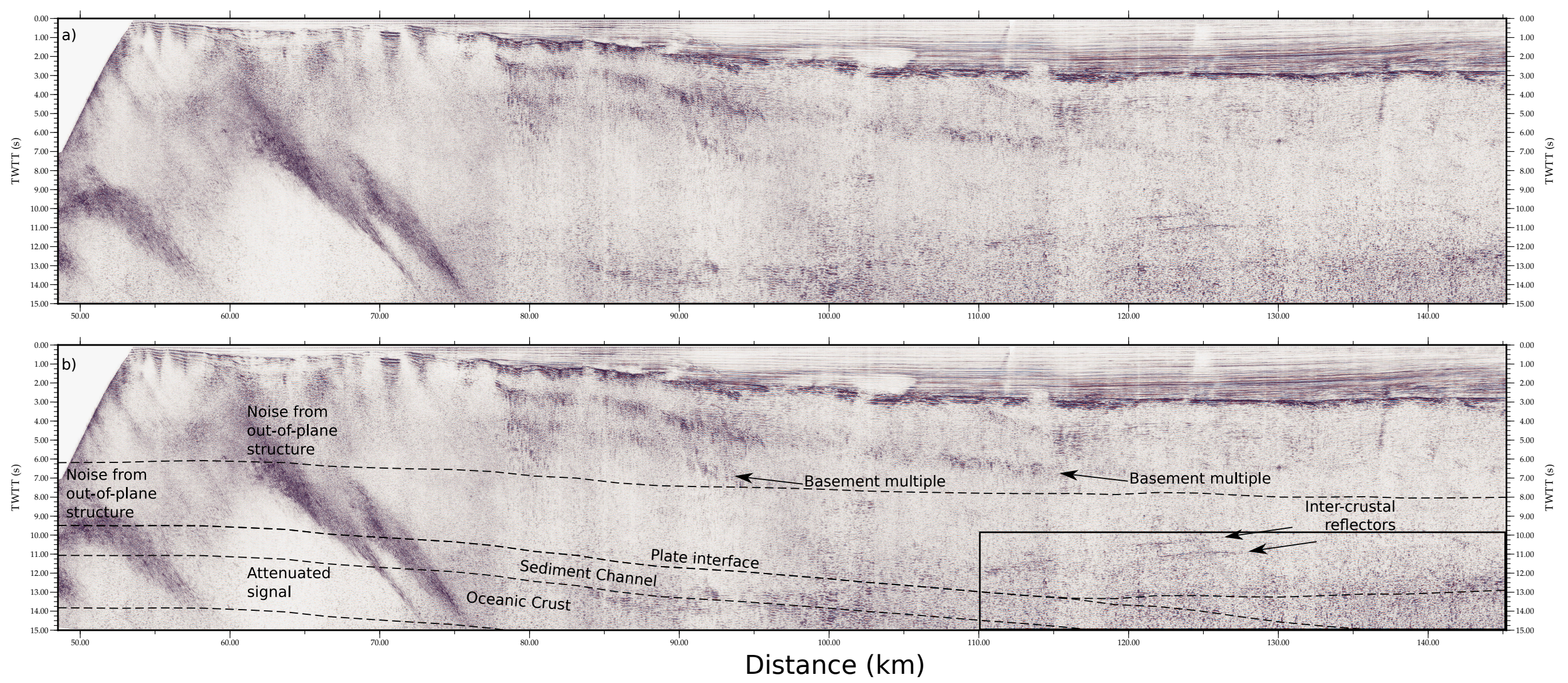

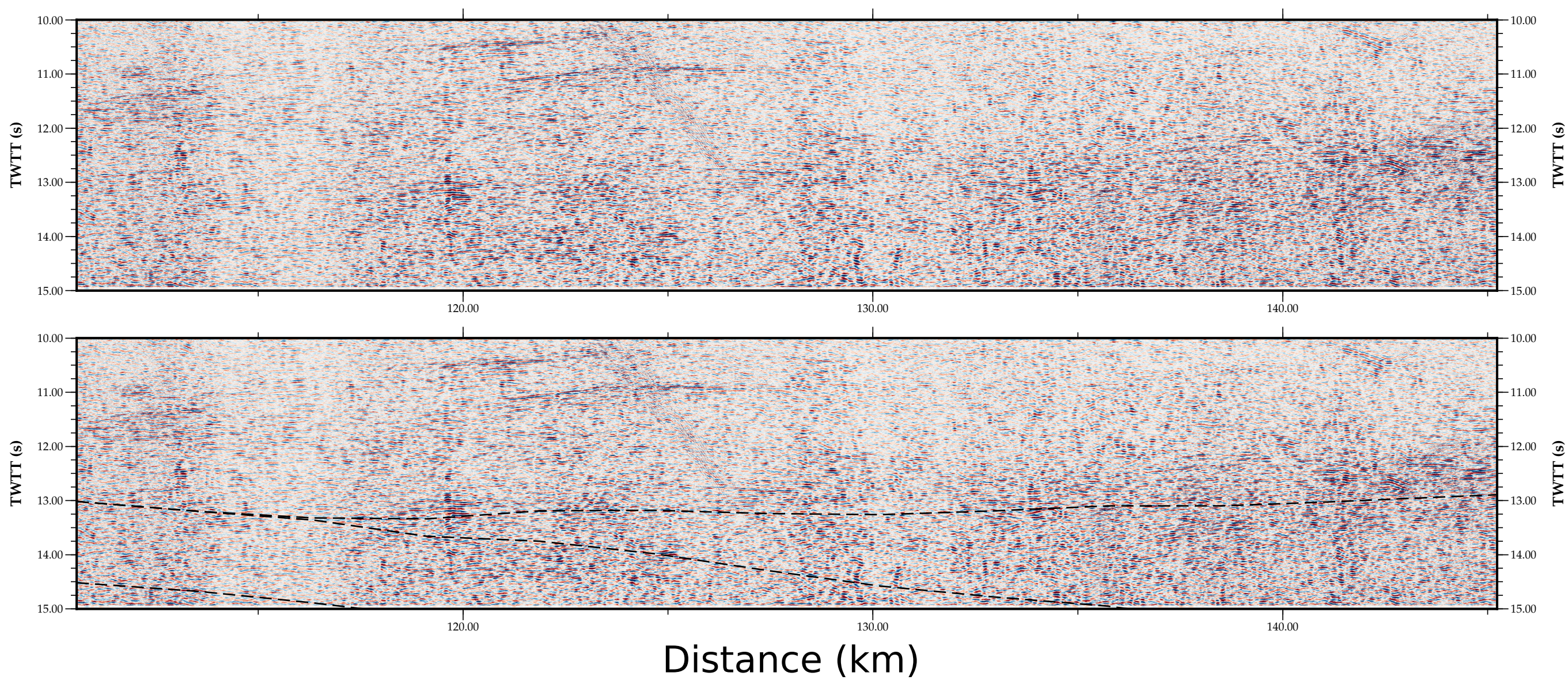

Figure 4.21: (a) Deep reflections at the northern end of the SAHKE03 brute created by Geotrace $\AA$. The black box in bottom left of figure 4.1 shows the extent of this figure. (b) interpretation of (a) with model layers from the final SAHKE03-M model (Fig. 4.10) converted to two-way travel-time and overlain (black dashed lines). 


\section{Chapter 5}

\section{Two Dimensional Modelling of Crustal Velocity Structure: SAHKE02}

\subsection{Introduction}

This chapter details the modelling of wide-angle reflection and refraction data collected within Wanganui Basin along the SAHKE02 transect as part of the "Seismic Array HiKurangi Experiment"(SAHKE) (Fig. 5.1). A two-dimensional (2D) P-wave velocity ( $\mathrm{Vp}$ ) model, SAHKE02-M, is developed and used to determine crustal velocity structure within Wanganui Basin, perpendicular to the Hikurangi margin. This model is constructed following the modelling strategy discussed in Chapter 3 using data collected on the TRANSECT seismograph deployment during the shooting of the multi-channel-seismic (MCS) line SAHKE02, in addition to onshore explosion data collected during SAHKE II (see Section 2.2.2). Interpretations and implications of this model are presented in Chapter 6 . 


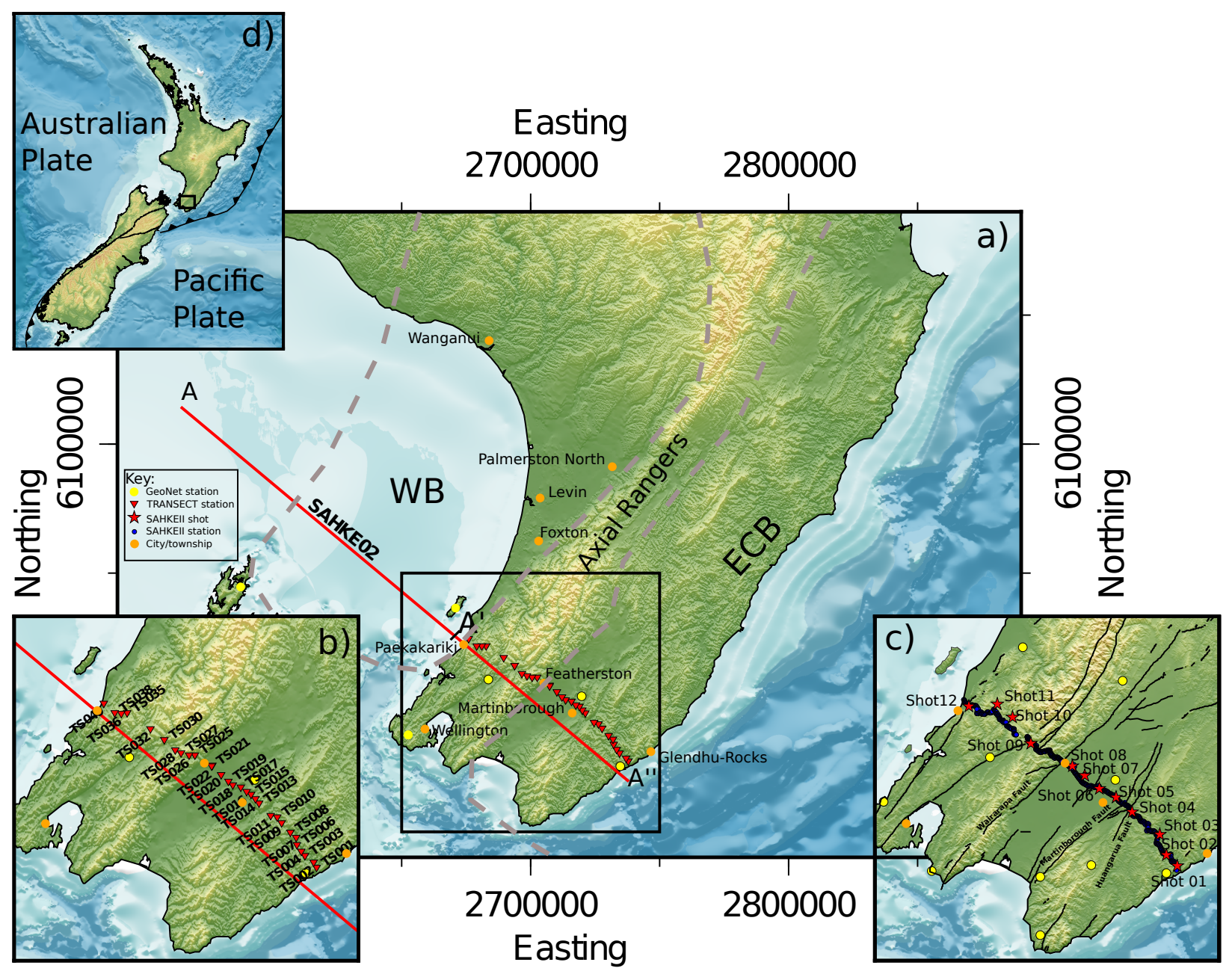

Figure 5.1: (a) Map showing the location of the SAHKE02 Multi-channel sesimic line (A - A'), and SAHKE02-M model line (A - A"), temporary TRANSECT deployment and permanent GeoNet seismograph sites from which data is used to constrain the p-wave velocity model presented in this Chapter. Black box outlines the limit of (b) and (c). (b) Inset map showing the TRANSECT deployment seismometers (red triangles). (c) Inset map showing the SAHKE II seismometers (blue circles) and shot locations (red stars). (d) Inset map showing the bounding box of (a). Wanganui Basin = Wanganui Basin ECB

$=$ East Coast Basin, grey dashed lines show the extent of these basins respectively.

\section{$5.2 \quad$ Pre-modelling Constraints}

\subsubsection{SAHKE02-M sedimentary section}

Results from previous studies place constraints on the thickness and P-wave velocities of the sedimentary section within the SAHKE02-M model. The 
offshore sedimentary section was constrained using the coincident SAHKE02 MCS reflection profile and associated stacking velocity file, constructed by Geotraceß). This analysis was conducted by Daniel Bassett and supplied as part of a preliminary model for use in this study by Stuart Henrys (S. Henrys, personal communication, February 20, 2011).

Onshore, information from previous studies was used to construct a preliminary model of near surface velocity structure that was further constrained by modelling a dense set of crustal refraction (Pg) phases recorded during the onshore SAHKE II survey (see section 2.2.2).

Interpretations of crustal structure from seismic experiments carried out in the vicinity of the SAHKE02-M line prior to 1997 were summarised by Chadwick (1997). These experiments are are shown in figure 5.4. The velocity of near surface layers derived from these studies were used to define initial velocities for these layers. More recently, Nicol et al. (2002) interpreted an onshore reflection survey near Martinborough (Fig. 5.4). These authors performed a depth conversion of this section, and this was used to define the initial thickness of sedimentary basins adjacent to two major Hikurangi forarc thrust faults, the Huangarua and Martinborough faults (Fig. 5.1c). Away from this survey area, sedimentary thickness estimates obtained from geological mapping (Begg et al., 2000) were used to define initial sediment thicknesses in the SAHKE02-M model.

\subsubsection{SAHKE II refraction modelling}

Crustal refractions recorded during the onshore SAHKE II explosion survey (see section 2.2.2) were modelled and used to constrain the near surface ( $<10 \mathrm{~km}$ depth) velocity structure within the onshore portion of the SAHKE02-M model (Fig. 5.2). 
5. Two Dimensional Modelling of Crustal Velocity Structure: SAHKE02

\subsubsection{SAHKE II modelling limitations}

Contemporary Pacific/Australian plate convergence occurs at a rate of $\sim 42 \mathrm{~mm} / \mathrm{yr}$ (in southern North Island (Nicol et al., 2007). This is partly accommodated within the crust by a complex system of dextral strike-slip and thrust faults and folds that have developed since subduction commenced $\sim 20$ Myr ago (e.g. Ballance, 1976). A large proportion $(\sim 70$ $\%$ ) of margin-parallel plate motion is accommodated by dextral strike-slip displacement on the NNE-striking faults of the North Island Dextral fault belt (NIDFB) (e.g. Beanland, 1995; Van Dissen and Berryman, 1996). A relatively smaller component of margin-normal plate motion $(\sim 4-5 \mathrm{~mm} / \mathrm{yr})$ is accommodated on thrust structures predominantly east of the axial ranges (e.g. Nicol et al., 2007). Slip on these faults has resulted in the formation of a complex forearc fold-thrust belt (e.g. Nicol et al., 2002; Nicol et al., 2007) that produces a highly variable near surface velocity structure (Fig. 5.2).

The complex near surface structure of lower North Island proved difficult to model using a ray tracing approach. This is due, in part, to model instabilities that develop as a result of large velocity variations over small lateral distances. These variations are required, in order to model juxtaposed basement thrust blocks against sedimentary basins. In addition, the modelling software proved unable to model a realistic representation of thrust structures, as layer nodes must increase positively in the horizontaldirection (i.e. a layer node may not be placed behind the previous node). Areas adjacent to thrust structures (namely the Wairarapa, Matinborough, Huangarua and Mangopari Faults) where ill-favored basement velocities exist due to these limitations are masked grey (Fig. 5.2). Furthermore, the complex interface geometries prevented the tracing of ray paths between some shot and receiver pairs.

Despite these limitations, a reasonable fit of the data was achieved, with an overall RMS traveltime misfit of $0.130 \mathrm{~s}$ and $\chi^{2}$ value of 1.702 . The final model was incorporated into the crustal scale SAHKE02-M model and held 
constant during the modelling of deeper crustal phases (see Section 5.3).

\subsubsection{SAHKE II modelling results}

Figure 5.2 shows the final model obtained from modelling all Pg phase arrivals picked from the twelve onshore SAHKE II shot gathers. Vp values of Miocene to Pleistocene sediments east of the Wairarapa fault are modelled as $2.20-2.50 \mathrm{kms}^{-1}$ at the surface, increasing to a maximum of $3.60 \mathrm{kms}^{-1}$ at a depth of $2.70 \mathrm{~km}$ east of the Huangarua fault. At the eastern end of the transect, near the Mangopari fault, Cretaceous sediments outcrop at the surface (Begg et al., 2000). Vp values of these sediments are set to be 2.90 $3.00 \mathrm{kms}^{-1}$ at the surface, increasing to $3.60-4.00 \mathrm{kms}^{-1}$ at depths of 1.8 and $1.6 \mathrm{~km}$ respectively. Vp values of Triassic greywacke basement rocks, that outcrop on the western side of the transect, west of the Wairarapa fault, are estimated as $4.20-4.30 \mathrm{kms}^{-1}$ at the surface. These increase to 5.55 and $5.30 \mathrm{kms}^{-1}$ at depths of $3 \mathrm{~km}$ and $4.65 \mathrm{~km}$ at the western and eastern ends of the basement block respectively. The higher $\mathrm{Vp}$ values obtained on the western side of the profile may be attributed to the up thrusting of deeper rocks with higher $\mathrm{Vp}$ west of the Wairarapa fault, or alternatively, as the boundary between the younger Pahau (to the east) and older Rakaia (to the west) basement terrains, as defined by Mortimer (2004). At the bottom of this basement rock layer an increase of $\sim 0.10$ and $0.15 \mathrm{kms}^{-1}$ is required across an interface boundary to fit observed travel-times in the west and east respectively. This $\mathrm{Vp}$ increase may be the result of an increase in metamorphic grade as proposed by Garrick (1968) at a depth of $4.46 \mathrm{~km}$ near Wellington. Vp values reach a maximum of $\sim 6.00 \mathrm{kms}^{-1}$ at $\sim 11 \mathrm{~km}$ depth in the center of the model transect.

The maximum depth of the sedimentary basins adjacent to major thrust faults are modelled as 2.16, 1.24 and $2.7 \mathrm{~km}$ for the Wairarapa, Martinborough and Mangopari faults respectively. 

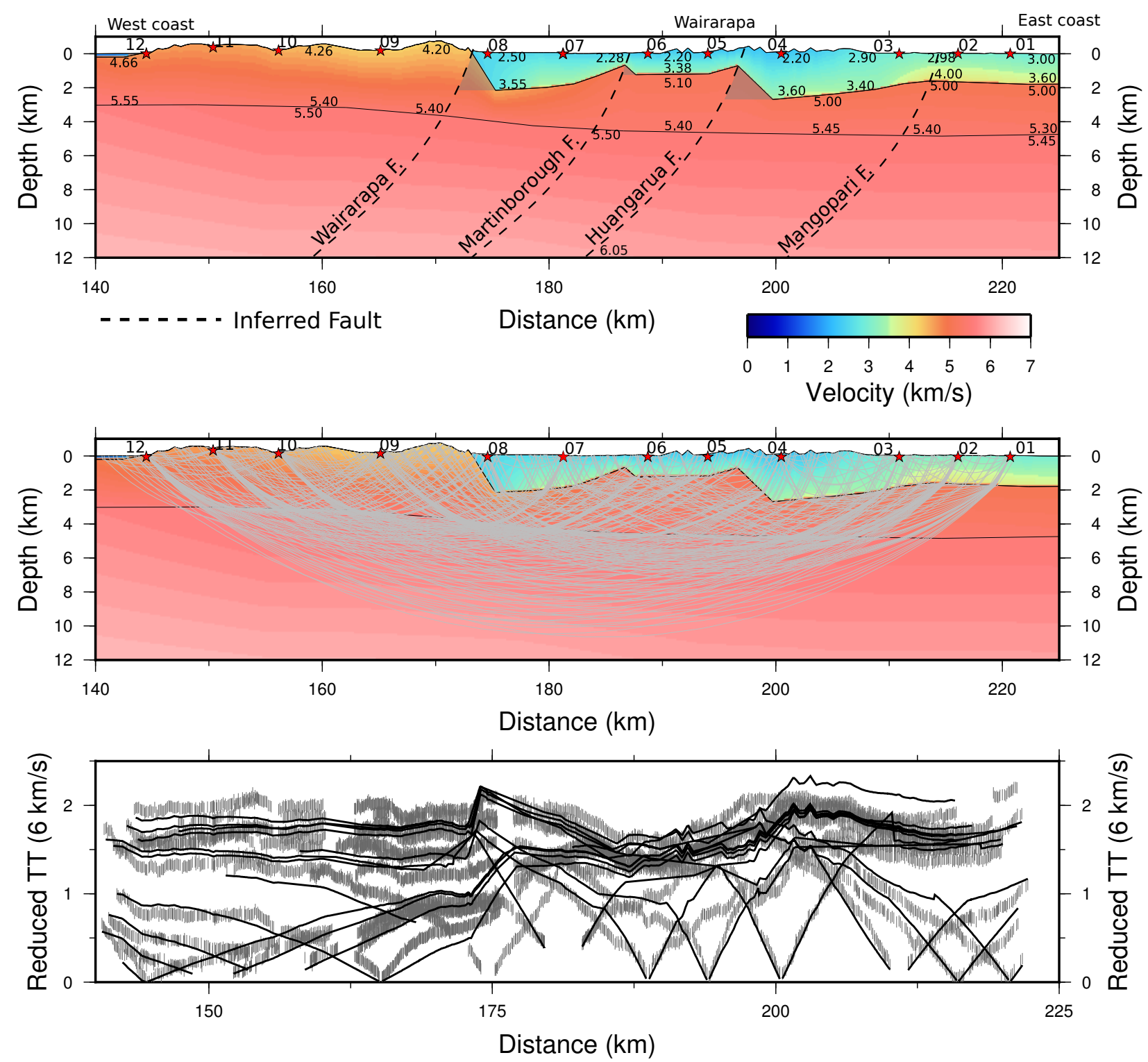

Figure 5.2: a) Final SAHKE II refraction model. Red stars are shot locations. A selection of velocity node values are shown in $\mathrm{kms}^{-1}$. Dashed black lines indicate the postion of inferred major faults. Areas where velocities are higher than predicted are shaded grey and are the result of limitations within the modelling software. b) same as in (a) showing the ray coverage of the final model. c) Observed (grey) and modelled (black) traveltimes of the phase arrivals used to constrain this model. 


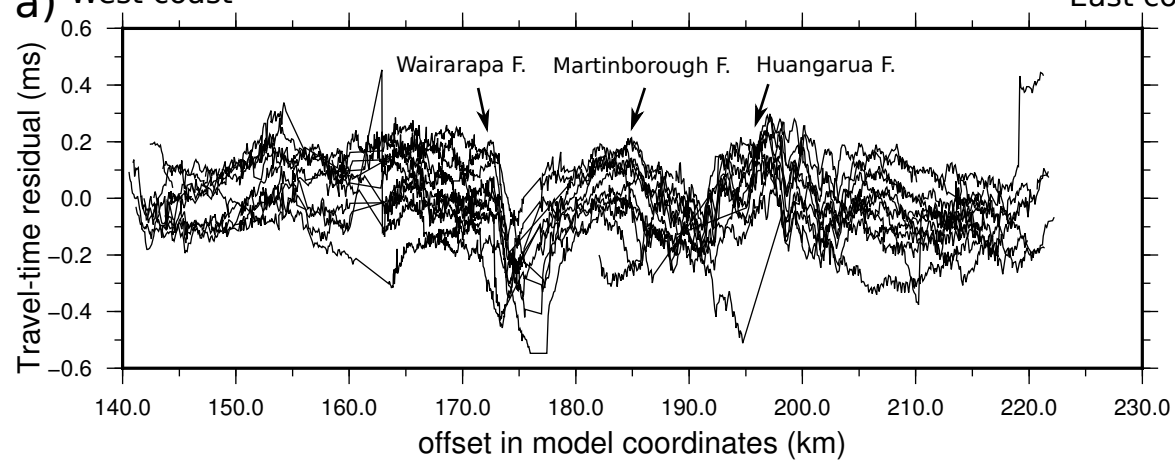

a) West coast

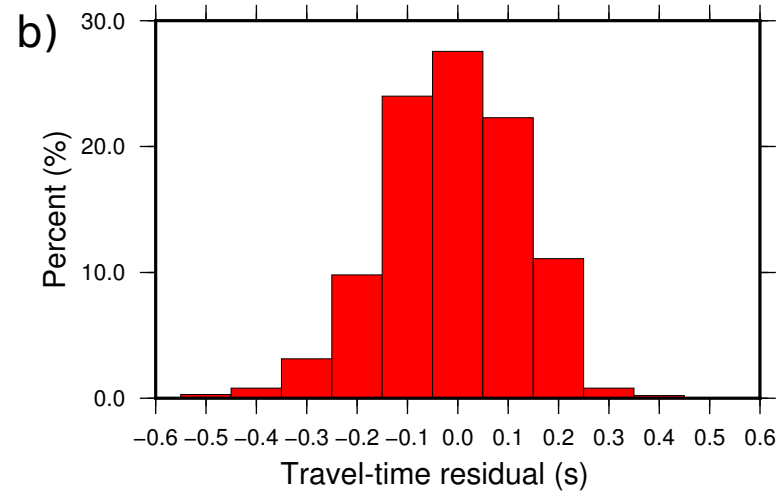

East coast

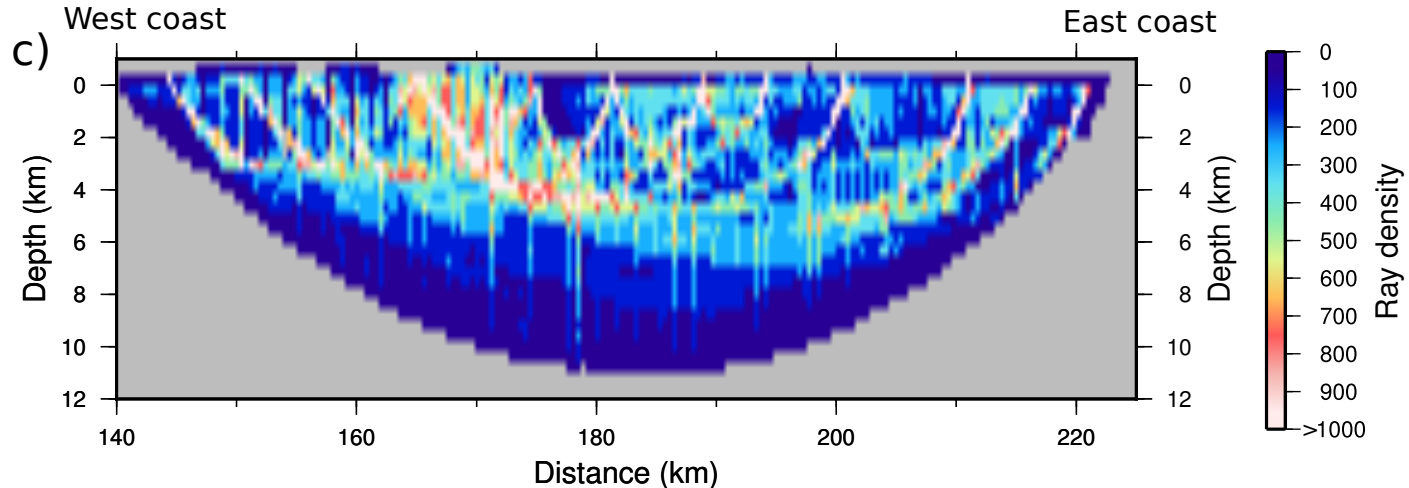

Figure 5.3: a) Root-mean-squared (RMS) travel-time residuals for all modelled phase arrivals plotted against model coordinates. (b) Ray coverage diagram computed with $1 \times 1 \mathrm{~km}$ grid cells. (c) same data as in (a) plotted as a percentage histogram binned at \pm 50 ms intervals. 
5. Two Dimensional Modelling of Crustal Velocity Structure: SAHKE02

\begin{tabular}{cccccc}
\hline $\begin{array}{c}\text { Shot } \\
\text { number }\end{array}$ & $\begin{array}{c}\text { Ray } \\
\text { direction }\end{array}$ & $\mathrm{N}^{*}$ & $\begin{array}{c}\text { Pick } \\
\text { error (sec) }\end{array}$ & $\begin{array}{c}\text { RMS travel- } \\
\text { time residual (sec) }\end{array}$ & $\chi^{2}$ \\
\hline shot12 & left & 22 & 0.1 & 0.15 & 2.353 \\
shot12 & right & 785 & 0.1 & 0.14 & 1.952 \\
shot11 & left & 87 & 0.1 & 0.065 & 0.424 \\
shot11 & right & 719 & 0.1 & 0.094 & 0.88 \\
shot10 & left & 133 & 0.1 & 0.108 & 1.174 \\
shot10 & right & 676 & 0.1 & 0.106 & 1.123 \\
shot09 & left & 218 & 0.1 & 0.094 & 0.883 \\
shot09 & right & 608 & 0.1 & 0.15 & 2.254 \\
shot08 & left & 229 & 0.1 & 0.168 & 2.834 \\
shot08 & right & 330 & 0.1 & 0.209 & 4.376 \\
shot07 & left & 470 & 0.1 & 0.157 & 2.462 \\
shot07 & right & 300 & 0.1 & 0.124 & 1.53 \\
shot06 & left & 531 & 0.1 & 0.153 & 2.348 \\
shot06 & right & 251 & 0.1 & 0.171 & 2.943 \\
shot05 & left & 432 & 0.1 & 0.111 & 1.237 \\
shot05 & right & 228 & 0.1 & 0.098 & 0.958 \\
shot04 & left & 571 & 0.1 & 0.144 & 2.084 \\
shot04 & right & 200 & 0.1 & 0.096 & 0.931 \\
shot03 & left & 722 & 0.1 & 0.102 & 1.037 \\
shot03 & right & 104 & 0.1 & 0.154 & 2.389 \\
shot02 & left & 749 & 0.1 & 0.102 & 1.05 \\
shot02 & right & 49 & 0.1 & 0.115 & 1.357 \\
shot01 & left & 643 & 0.1 & 0.129 & 1.668 \\
shot01 & right & 6 & 0.1 & 0.067 & 0.535
\end{tabular}

Table 5.1: RMS travel-time residuals and Chi-square values from the modelling of refraction phases recorded during SAHKE II. $\mathrm{N}^{*}=$ number of travel-time picks per gather.

\subsubsection{Crustal structure constraints}

Interpretations of crustal structure from previous studies across the Hikurangi margin and within Wanganui Basin provide constraints on model parameters and were used to construct an initial Vp model. These constraints were derived from receiver function studies (Savage et al., 2007; Ewig, 2009), crustal refraction and wide angle reflection surveys (Garrick, 1968; Davey and Smith, 1983a; Chadwick, 1997), velocity and 
attenuation 3D earthquake travel-time tomography (Eberhart-Phillips et al., 2005; Reyners and Eberhart-Phillips, 2009; Eberhart-Phillips et al., 2010), earthquake travel-time analysis (Luo, 1992), ScSp earthquake phase conversions (Bourne and Stuart, 2000), earthquake hypocenter locations (Ansell and Bannister, 1996; Reyners and Eberhart-Phillips, 2009; (M. Reyners, personal communication, 21 November 2011) and 3D gravity modelling of Wanganui Basin Moho depth (Ewig, 2009). In contrast to near surface constraints, these were allowed to vary during the modelling process, if their modification was deemed necessary in order to fit observe travel-times.

\subsubsection{Plate interface}

Initially the geometry and depth of the Australian/Pacific plate interface was defined using GeoNet earthquake hypocenter locations, relocated using the nation wide tomography model of Eberhart-Phillips et al. (2010) supplied by Martin Reyners (M. Reyners, personal communication, 21 November 2011, Fig. 5.5) and receiver function analysis at GeoNet station KIW (Ewig, 2009), as described in Section 4.2.2.1. In addition to these data, Savage et al. (2007) report an increase in plate interface depth from 17 to $28 \mathrm{~km}$ over a distance of $43.3 \mathrm{~km}\left(14^{\circ} \mathrm{dip}\right)$ following receiver function analysis from nine seismographs deployed in an L shape, slightly north of the SAHKE02-M model line (orange squares Fig. 5.4). These authors also report a $4 \mathrm{~km}$ thick LVZ interpreted as a sedimentary layer. (Bourne and Stuart, 2000) studied ScSp wave conversions at stations coincident to those of Savage et al. (2007) and also interpreted a LVZ at the plate interface, however they suggest a thickness of $1-2 \mathrm{~km}$. Furthermore, two crustal scale seismic refraction surveys conducted by Davey and Smith (1983a) and Chadwick (1997) place this interface at a depth of $22 \mathrm{~km}$ and $\sim 14 \mathrm{~km}$ beneath Wellington and central Wairarapa respectively (light blue and dark blue symbols, Fig. 5.4). Chadwick (1997) also suggests the presence of a LVZ directly beneath the place interface, with a preferred thickness of $3.6 \mathrm{~km}$ beneath central Wairarapa. 


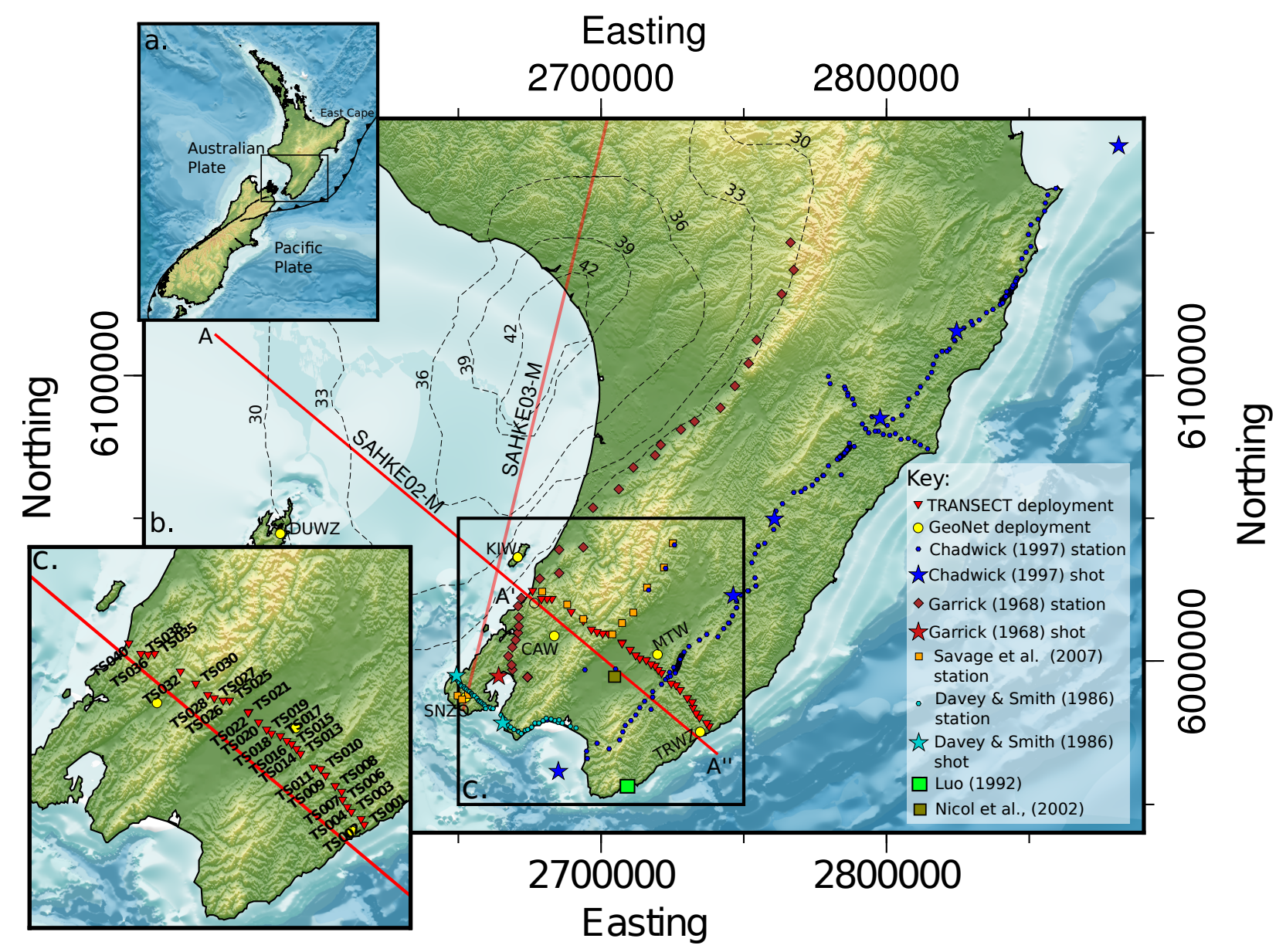

Figure 5.4: (a) Map showing the location of the SAHKE02-M model line (A - A") and the SAHKE02 multichannel-seismic line $\left(\mathrm{A}-\mathrm{A}^{\prime}\right)$, seismograph stations belonging to the temporary TRANSECT deployment (red triangles) and permanent GeoNet network (yellow circles) used in this study. Survey components from previous studies (as discussed in the text) are also shown. Garrick (1968) Wellington crustal refraction profile (maroon diamonds and star), Davey and Smith (1983a) refraction profile (light blue circles and star), Chadwick (1997) Hikurangi margin seismic refraction experiment (dark blue circles and stars), Leed's receiver function deployment (orange squares), Luo (1992) Cape Palliser study (green square), Nicol et al. (2002) onshore reflection study (brown-green square), dashed black lines are Moho depth contours determined by Ewig (2009). (b) Inset map showing the bounding box of (a).

\subsubsection{Subducting oceanic plate structure}

Contemporary subduction within the Hikurangi margin is considered atypical due to the presence of the thick Hikurangi Plateau previously emplaced upon the more regular oceanic crust. Previous studies have estimated the thickness of the oceanic crust and overlying Hikurangi Plateau as 12 - 16 


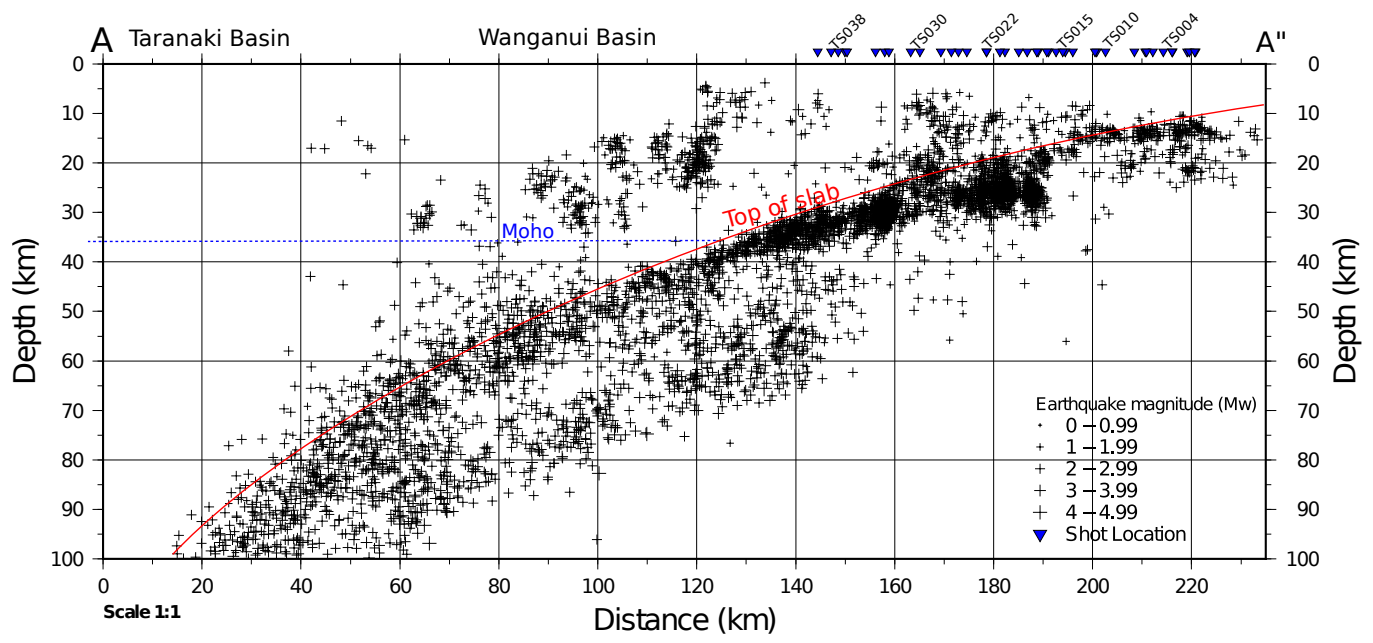

Figure 5.5: Cross section coincident to the SAHKE02-M profile (A - A"; Fig. 5.1) displaying a swath of microseismicity located within $\pm 20 \mathrm{~km}$ of the cross section. These earthquakes were recorded by the national GeoNet seismograph network between January 2001 and March 2011, were relocated using the nation wide 3D velocity model of Eberhart-Phillips et al. (2010) and supplied for use in this study by Martin Reyners (pers. comms. 2011). Blue triangles are SAHKE TRANSECT station locations. Red dashed line shows the estimated plate interface and blue dashed line is estimated Moho location.

$\mathrm{km}$ offshore the east coast of North Island (increasing from north to south) using gravity data (Davy and Wood, 1994; Davy et al., 2008) and as 17 $18 \mathrm{~km}$ at the northern end of the margin near East Cape based on wideangle reflection and refraction surveying (Bassett et al., 2010). Onshore, at the southern end of the margin, near the SAHKE02-M transect, Bourne and Stuart (2000) modelled the oceanic crustal thickness as $11-14 \mathrm{~km}$ based on delay times between ScSp phase conversions beneath seismometers deployed on the western side of southern North Island (orange squares, Fig. 5.4). Using data from coincident seismographs, Reading et al. (2001) also used delay times between wave phases to determine a thickness of $16 \pm 2 \mathrm{~km}$. In contrast to Bourne and Stuart (2000), Reading et al. (2001) did not detect a low velocity sediment layer and hence the thickness reconciled (i.e. 11 - 14 +1 - $2 \mathrm{~km}$ compared to $16 \pm 2 \mathrm{~km}$ ) are similar. 


\section{Two Dimensional Modelling of Crustal Velocity Structure: SAHKE02}

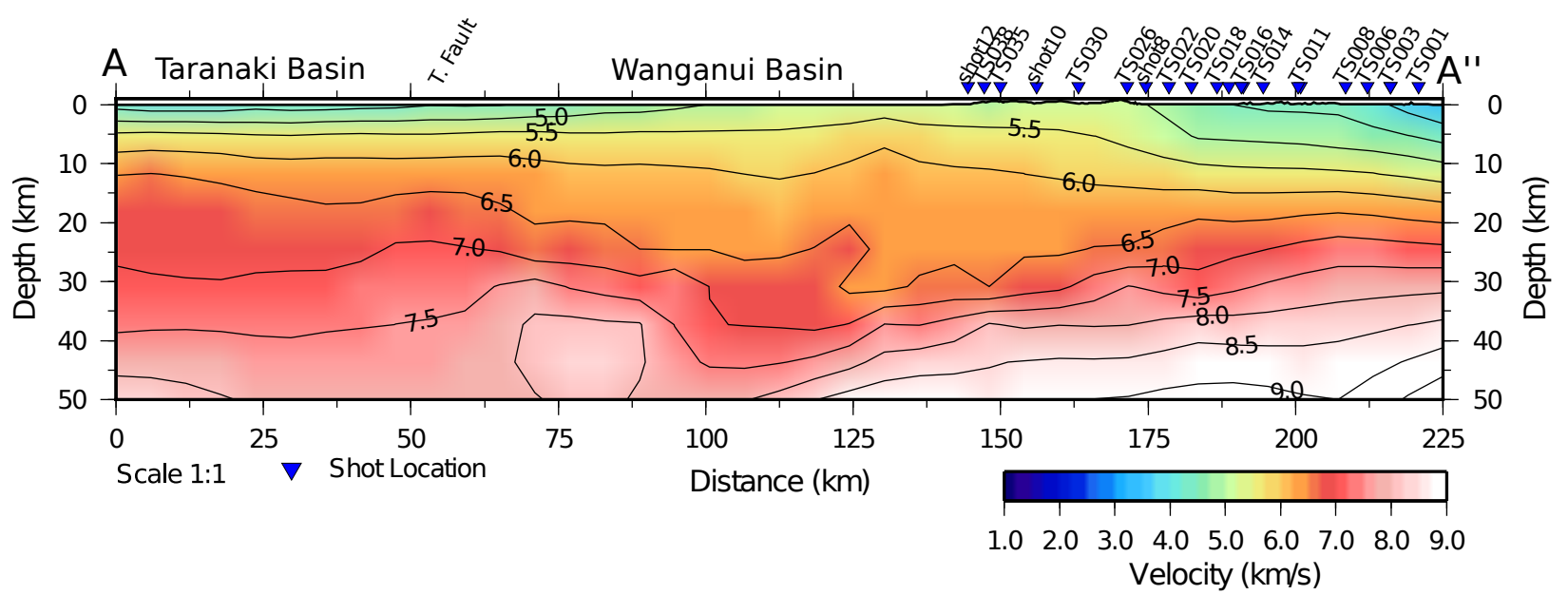

Figure 5.6: Vertical slice through Eberhart-Phillips et al. (2010) nationwide tomographic model along the SAHKE2-M transect (A - A"; Fig. 5.1). Velocity nodes are projected from $10 \mathrm{~km}$ either side of the transect and contoured at gird increments of $\mathrm{X}$ and $\mathrm{Y}=6 \mathrm{~km}$. Blue triangles are shot locations of receiver/shot gathers from the SAHKE02 transect. T. Fault = Taranaki Fault.

\subsubsection{Australian plate Moho}

As discussed in section 4.2.2.2 the depth and geometry of the Australian plate Moho is largely unresolved west of southern North Island. Three dimensional modelling of the free-air/isostatic gravity anomaly associated with Wanganui Basin, conducted by Ewig (2009), places the Moho at depths between 30 and $36 \mathrm{~km}$ along the SAHKE02-M model line (Fig. 5.4). Near the west coast of North Island, however, these contours overlap with an area where the subducted Pacific slab is expected to occur at a shallower depth $(<25$ $\mathrm{km}$ ) and therefore act in place of the Moho. Furthermore, Ewig (2009) also constructed a receiver function using teleseismic earthquake data collected at station DUWZ on D'Urville Island south of the SAHKE02-M transect (Fig. 5.4). Here the Moho is resolved at depth of $37 \mathrm{~km}$, in excess of that predicted from gravity modelling $(\sim 30 \mathrm{~km})$.

\subsubsection{Crustal P-wave velocity structure}

Results from previous studies that place constraints on the Vp structure within lower North Island are presented in section 4.2.2.3. Figure 5.6 shows 
a Vp slice through Eberhart-Phillips et al. (2010) national wide tomographic model coincident to the SAHKE02-M transect. Vp values used in the initial SAHKE02-M model are the same as those presented in table 4.3.

\subsection{Modelling results}

The final SAHKE02-M model is displayed in figure 5.7. The model is sampled by rays over a lateral distance of $\sim 220 \mathrm{~km}$ and to a maximum depth of $35.5 \mathrm{~km}$; however, several gaps in ray coverage exist (Fig. 5.7b). The interpretation and implications of this model are discussed in Chapter 6. 

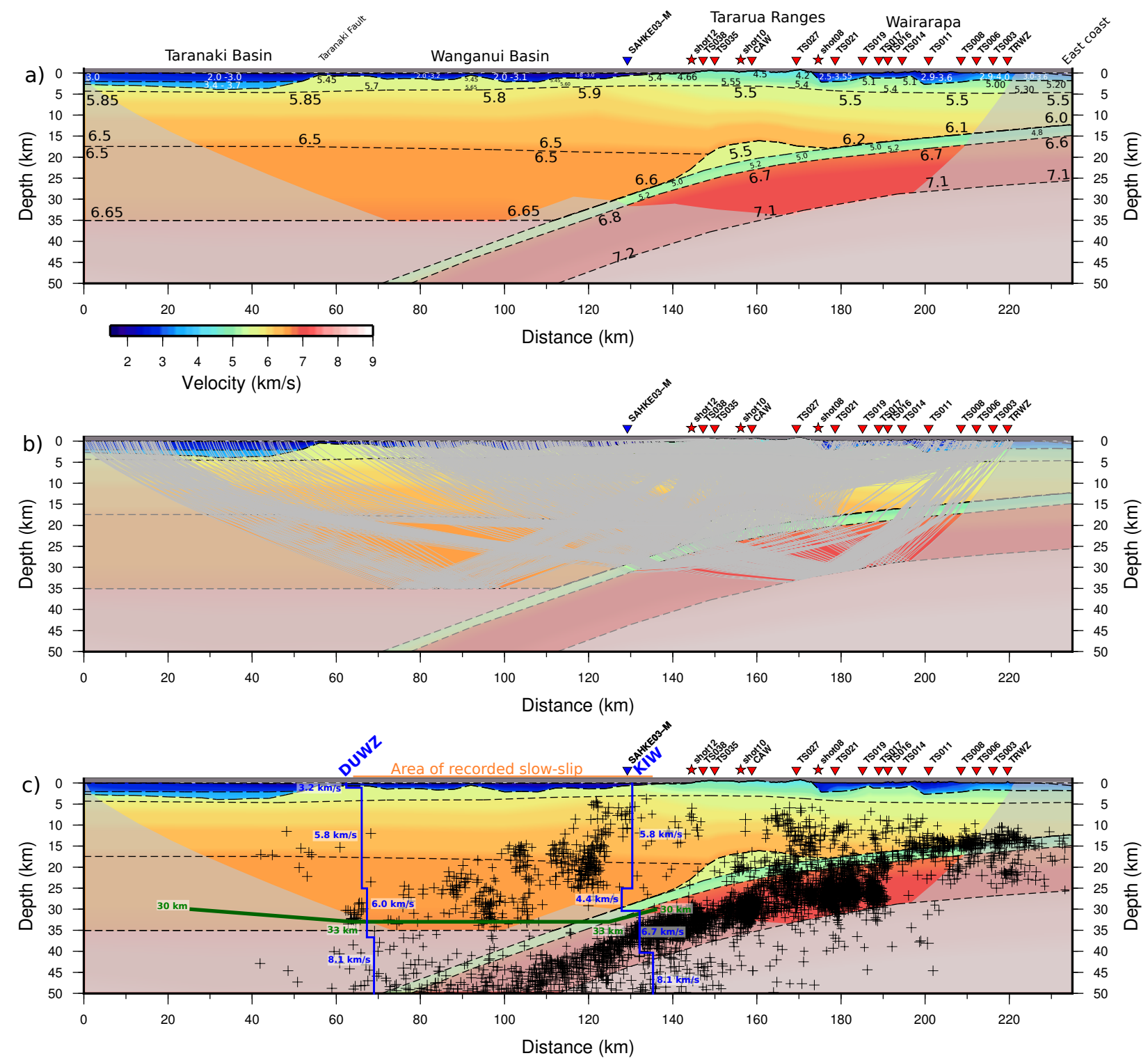

Figure 5.7: (a) Final SAHKE02-M model displaying a selection of velocity node values. The grey shaded area indicates the unconstrained region with no ray coverage. (b) Same as in (a) but showing model ray coverage. (c) Same as in (a) but showing the relationship between the model derived in this study and constraining data sets. Black crosses are earthquake hypocenters scaled to magnitude recorded by the national GeoNet seismograph network between January 2001 and March 2011 and relocated using the nation wide 3D velocity model of Eberhart-Phillips et al. (2010), supplied by Martin Reyners (M. Reyners, personal communication, 21 November 2011). Also shown are the results of receiver function analysis from Ewig (2009) at GeoNet stations DUWZ and KIW (blue lines). The green line shows the depth to the Moho determined by Ewig (2009) using 3D gravity modelling. Figure continued... 

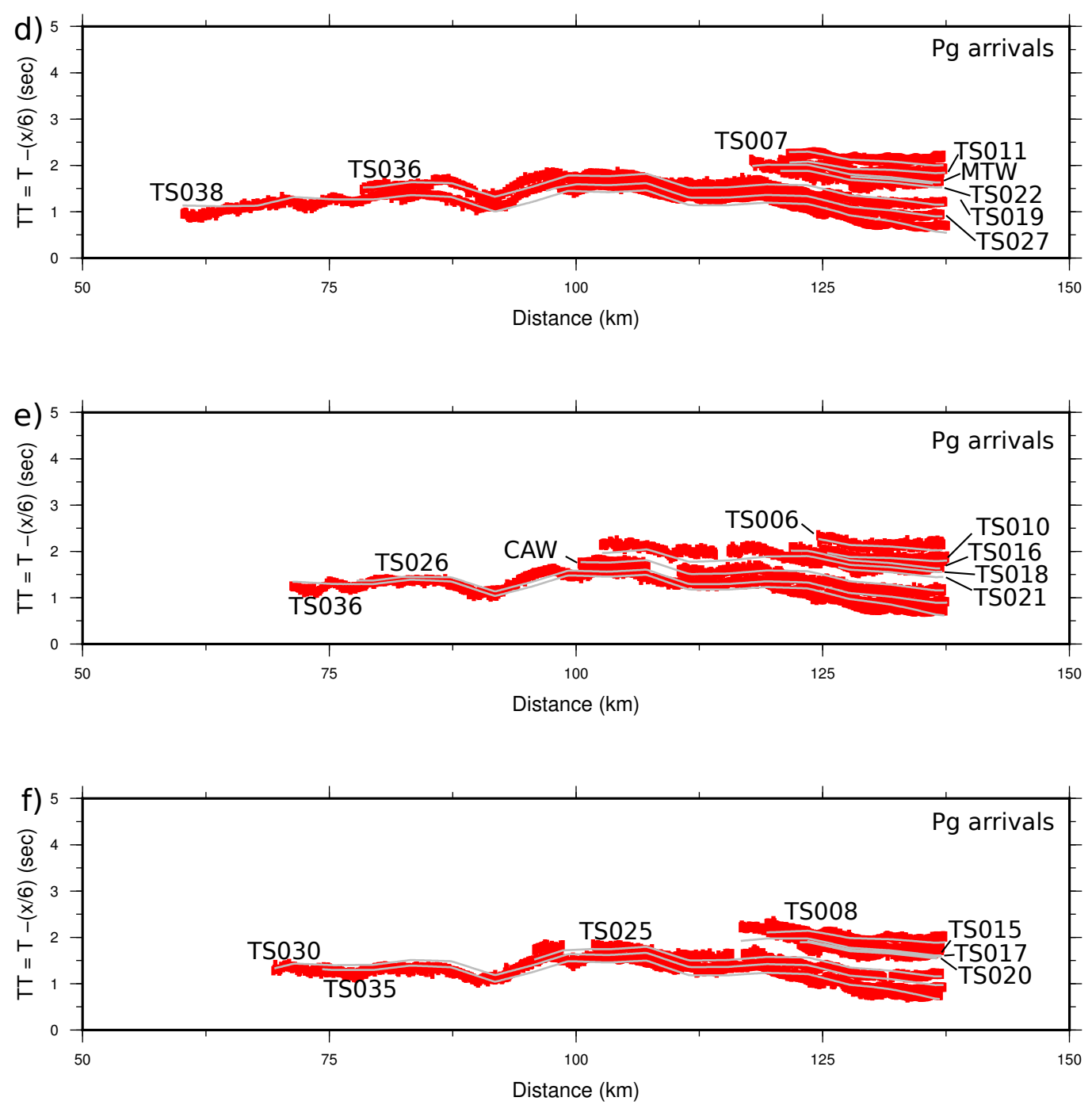

Figure 5.7: figure continued.. 

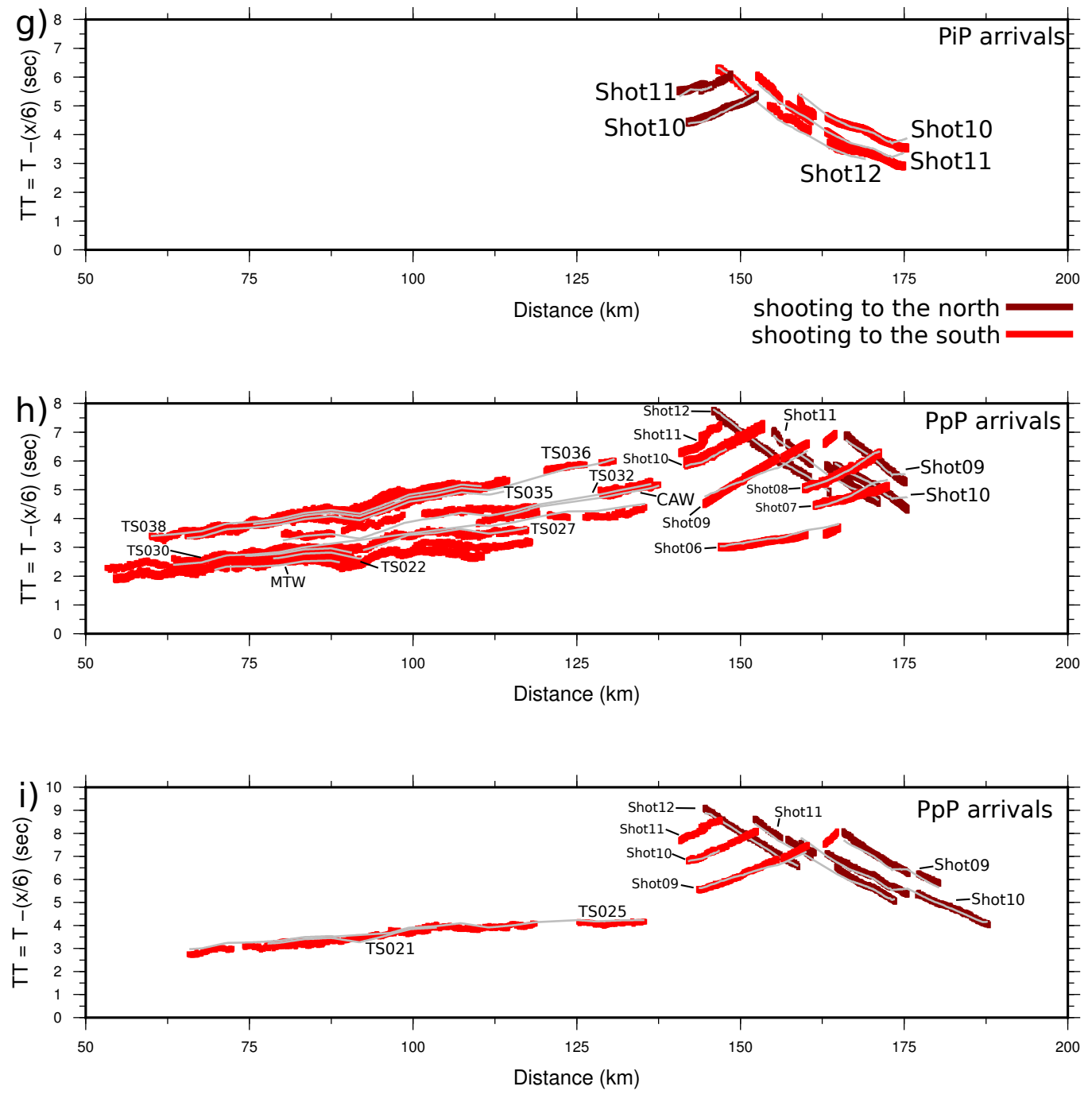

Figure 5.7: figure continued... 

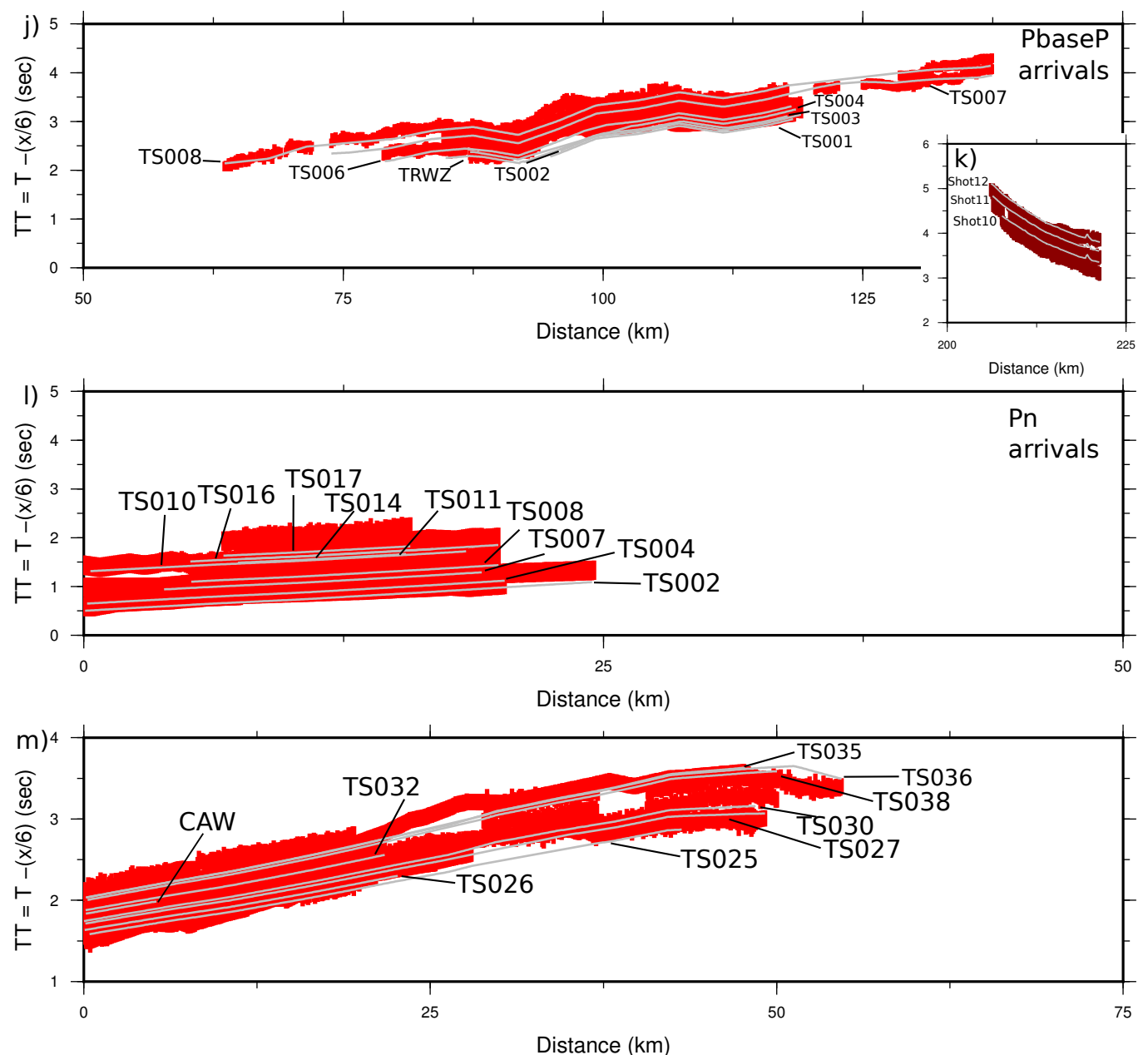

Figure 5.7: (d, e, f, h, i, j, k, l and m) Observed (red and dark red) and calculated (gray) travel-times. Red observed travel-times are from stations east of shot points, while dark red are west. (d, e and f) show $P g$ refraction arrivals, (g) show PiP reflection arrivals (h and i) show $P p P$ reflection arrivals (j and $\mathrm{k}$ ) show Pbase $P$ reflection arrivals $(1$ and $\mathrm{m}$ ) show $P n$ refraction arrivals. 


\subsubsection{SAHKE02 Australian plate velocity structure}

Similarly to the SAHKE03-M model, the Vp structure and depth of the sediment fill offshore from the west coast were constrained using coincident MCS data. These sediments display a constant Vp of $1.7 \mathrm{kms}^{-1}$ at the top of this layer, increasing to a maximum of $3.2 \mathrm{kms}^{-1}$. Sediments within the Taranaki Basin, west of Wanganui Basin, are modelled as two layers: a $2 \mathrm{~km}$ thick upper layer of $\mathrm{Vp} 2.0-3.0 \mathrm{kms}^{-1}$; and a lower layer with a maximum thickness of $2 \mathrm{~km}$ and $\mathrm{Vp}$ of $3.4-3.7 \mathrm{kms}^{-1}$, thinning to the west. Onshore, across lower North Island, near surface velocities of Triassic greywacke basement rocks and East Coast Basin sediments within the Wairarapa region were constrained using the crustal refractions recorded during SAHKE II as discussed in section 5.2.2.

The upper crustal velocity structure beneath Wanganui Basin and lower North Island is well constrained in this study by a high Pg ray density (Fig. 5.9). Beneath North Island, upper crustal Vp is $5.5 \mathrm{kms}^{-1}$ at a depth of $\sim 5 \mathrm{~km}$ and increases to $6.0-6.2 \mathrm{kms}^{-1}$ above the plate interface, with $\mathrm{Vp}$ also increasing from east to west at depth. Further west, beneath Wanganui Basin, Vp increases by $0.3-0.4 \mathrm{kms}^{-1}$ to $5.9 \mathrm{kms}^{-1}$ and 6.5 $k m s^{-1}$ at depths of $\sim 5 \mathrm{~km}$ and $17 \mathrm{~km}$ respectively. Further west still, Vp remains relatively constant at $\sim 5.85-6.5 \mathrm{kms}^{-1}$.

These results are consistent with those of the SAHKE03 line, and upper crustal Vp structure within Wanganui Basin appears both (a) relatively fast compared with standard continental crust globally and around New Zealand (e.g. Scherwath et al., 2003; Stern et al., 2010) and (b) isotropic in the sense that there is no azimuthal anisotropy resolved when compared with the SAHKE03-M model.

The lower crust is only sampled by reflections and refractions that turn within the subducting oceanic crust. The $\mathrm{Vp}$ of this layer therefore remains poorly resolved in this study. Similarly to the SAHKE03 model, 
this layer's Vp was first defined using results from previous studies (Garrick, 1968; Eberhart-Phillips et al., 2010) and further constrained using Moho reflections. In the final model the velocity of this layer ranges from 6.50 $6.65 \mathrm{kms}^{-1}$.

As in the SAHKE03-M model, these velocities are broadly consistent with those of the tomographic model of Eberhart-Phillips et al. (2010) between depths of $3-20 \mathrm{~km}$ (Figs. 5.6 and 5.7a). In the near surface, Vp values determined in this model are, however, between $0.5-3.3 \mathrm{kms}^{-1}$ slower, similar to that observed on the SAHKE03-M model. These differences are smallest below onshore North Island, indicating the mismatches offshore are partly a result of limited ray coverage inherent in earthquake tomography, given the onshore bias of station locations and minimal seismicity in the upper $5 \mathrm{~km}$. Additionally, velocities below $25 \mathrm{~km}$ within Wanganui Basin are also consistently faster in the Eberhart-Phillips et al. (2010) model. In comparison with findings from other previous studies, the crustal $\mathrm{Vp}$ values derived in this study are found to be reasonably consistent near the surface, but exceed all previous studies at depth by at least $0.3 \mathrm{kms}^{-1}$ (see Table 4.3 for $\mathrm{Vp}$ values and Fig. 5.4 for locations).

\subsubsection{Plate interface structure}

The Australian-Pacific plate interface is imaged at a depth of $16 \mathrm{~km}$ beneath Featherston and increasing to $33 \mathrm{~km}$ west of Kapiti Island. Between these locations, the interface displays a relatively smooth curvature, with dip increasing from $5.4^{\circ}$ beneath Featherston, to $8.4^{\circ}$ below the Tararua Ranges, where the interface kinks slightly, steepening to $14^{\circ}$ at the west coast and reaching $19^{\circ}$ beneath central Wanganui Basin (Fig. 5.7a). Protruding from the interface is a dome structure between the west coast and Featherston that reaches a maximum thickness of $\sim 3.5 \mathrm{~km}$. The geometry of this feature is constrained by $\mathrm{PiP}$ reflections from the SAHKE II onshore shots 10, 11 and 12 (Figs. 2.20 and 5.8) in this study and is a prominent feature 


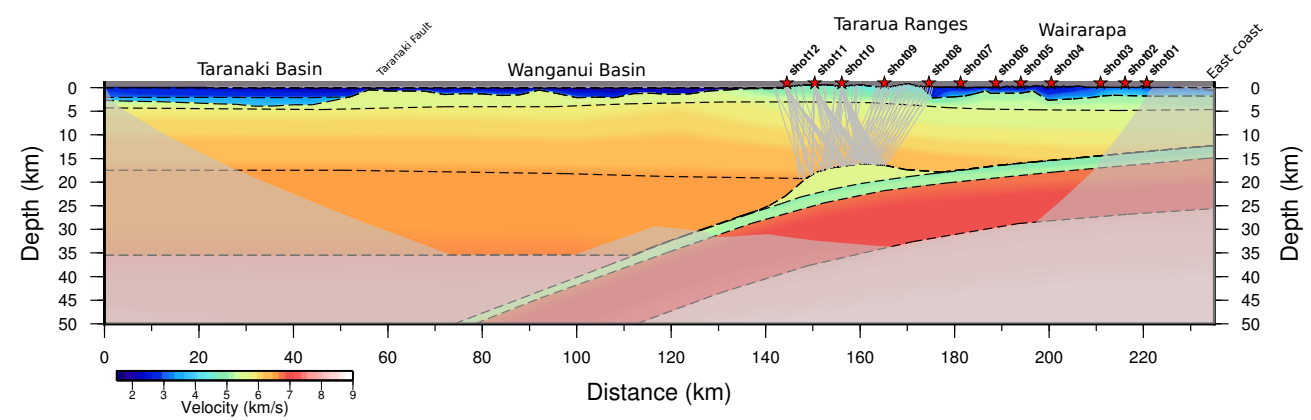

Figure 5.8: Final SAHKE02-M model displaying a selection of modelled PiP reflection (e.g. figures 2.20 and $5.7 \mathrm{~g}$ ) ray paths. The grey shaded area indicates the unconstrained region with no ray coverage.

on a low-fold reflection stack constructed along this transect by Henrys et al. (in prep) using both onshore/offshore and onshore data. Vp of this feature is not constrained in this study and is modelled with a constant $\mathrm{Vp}$ of $5.5 \mathrm{kms}^{-1}$, following the results of first arrival tomography analysis of the entire SAHKE dataset (Henrys et al., in prep). Beneath this structure, reflections from the underlying plate interface remain prominent on both the onshore and onshore-offshore data. It appears that this feature may represent the pooling of underplated sedimentary material, similar to that interpreted by Scherwath et al. (2010) and Bassett et al. (2010) within the Raukumara basin at the Northern end of the Hikurangi margin.

As in the SAKE03-M model, the plate interface is modelled at a shallower depth $(\sim 5 \mathrm{~km})$ than that defined using relocated earthquake seismicity. The depth to the plate interface beneath Kapiti Island resolved in this model is $28.5 \mathrm{~km}, 0.4 \mathrm{~km}$ shallower than in the SAHKE03-M model, however, still 3.4 $\mathrm{km}$ deeper than that determined by receiver function analysis (Ewig, 2009). As no plate interface reflections are interpreted east of Martinborough, it is unclear if the result from the active-source profile of Chadwick (1997) (Fig. 5.4), which is orientated perpendicular to the SAHKE02-M line and places the plate interface at a depth of $14 \mathrm{~km}$ beneath central Wairarapa, is consistent with this study. Projection of the plate interface updip from the area of ray coverage, does however, suggest a similar depth of $14 \mathrm{~km}$ at this 
locality.

\subsubsection{Subducting oceanic crust structure}

The subducting oceanic crust is sampled by both reflections and refractions and is modelled as two layers. The upper layer is sampled by reflections between the west coast and Featherston. No refraction arrivals are interpreted from this layer and hence resolution tests and results from previous studies were used to determine the thickness and $\mathrm{Vp}$ of this layer. In the final model, this layer is modelled as a $1.5-2 \mathrm{~km}$ thick low Vp $\left(5-5.2 \mathrm{kms}^{-1}\right)$ layer. This is $\sim 2 \mathrm{~km}$ thinner than that resolved beneath Kapiti Island in the SAHKE03-M model.

The lower layer is sampled by refractions interpreted on the onshore/offshore data (Pn, Fig. 2.17) and Vp at the top of this layer is constrained as $6.7-6.8$ $\mathrm{kms}^{-1}$. As these refractions turn within the top $\sim 3-4 \mathrm{~km}$ of this layer, a resolution test was used to determine the likely velocity profile and thickness of this layer (see Section 5.4.3). In the final model, this layer is modelled as 9.5 - $10 \mathrm{~km}$ thick with a lateral change in the Vp profile from $6.7-7.1 \mathrm{kms}^{-1}$ beneath the Wairarapa to $6.8-7.2 \mathrm{kms}^{-1}$ downdip beneath the west coast.

\subsubsection{Moho structure}

The Australian plate Moho is modelled as a horizontal interface with a depth of $35.5 \mathrm{kms}^{-1}$ (Fig. 5.7a). This depth is unexpected given the isostatic gravity anomaly in this area is $\sim-30--50 \mathrm{mgal}$, which is over 100 mgal greater than the maximum -160 mgal reached in the center of Wanganui Basin, where on the SAHKE03-M model, the Moho is resolved at a similar depth of $\sim 35-36.5 \mathrm{~km}$. This discrepancy is discussed in Section 6.2.

In contrast to the SAHKE03-M model, the Moho resolved on this transect is deeper than that determined by Ewig (2009) using gravity data (Fig. 5.7c), however, is shallower than the $37 \mathrm{~km}$ depth determined using 
receiver function analysis at GeoNet station DUWZ located on D'Urville Island $\sim 35 \mathrm{~km}$ south of the SAHKE02-M transect (Ewig, 2009).

\subsection{Model Assessment}

The goodness of fit of the final SAHKE23-M model and degree to which model features are resolved are assessed using travel-time misfit statistics, ray density analysis and resolution testing of specific model parameters.

Errors in model velocities and interface depths are assigned based on results of resolution testing (see Section 4.4.3). These errors are considered minimum formal errors, as they do not consider perturbations of all model parameters.

\subsubsection{Travel-time fit and ray coverage}

Table 5.2 lists the final model travel-time root-mean-squared (RMS) and $\chi^{2}$ values for each phase modelled. Figure 5.9 visually illustrates the RMS fit and ray coverage.

Almost all phases are modelled within reasonable uncertainty with $\chi^{2}$ values ranging between 0.1 and $\sim 3$ with and the vast majority $\sim 1$. These values are acceptable given the predominantly unidirectional shooting direction (east to west) and onshore bias of receiver locations.

Figure 5.9b illustrates that the velocity structure of the Wanganui Basin and onshore North Island is well resolved within a cone shape of high ray density, reaching a maximum depth of $\sim 33 \mathrm{~km}$. Deeper areas of Wanganui Basin are less well constrained, however, are sampled by reflections from the plate interface and Moho of both the Australian and Pacific plates, as well as refractions that turn within the Pacific plate crust. The plate interface and top of the oceanic crust are best resolved between model coordinates 
$130-180 \mathrm{~km}$. 


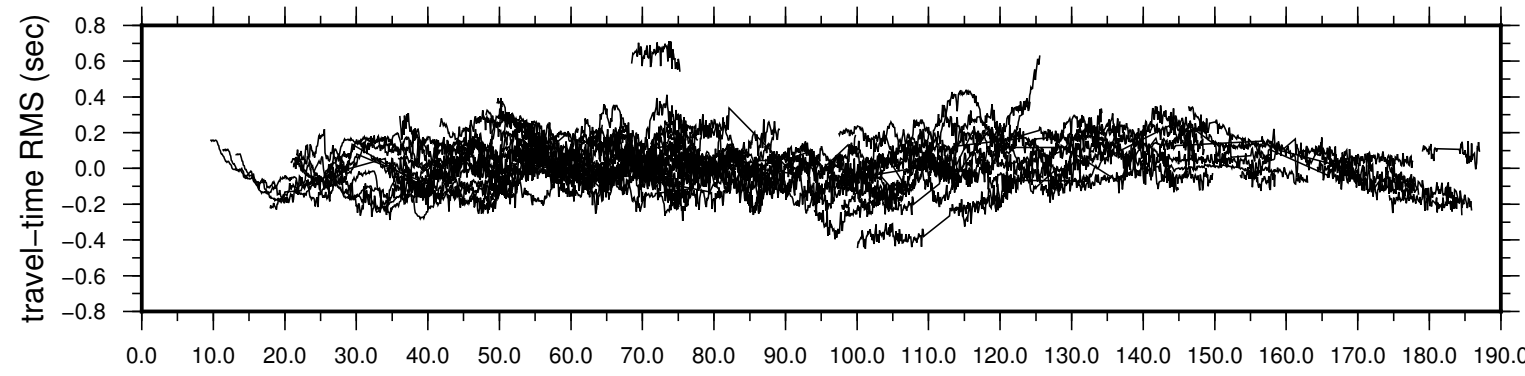

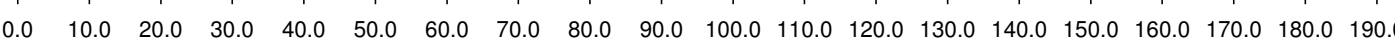
Source-receiver offset $(\mathrm{km})$
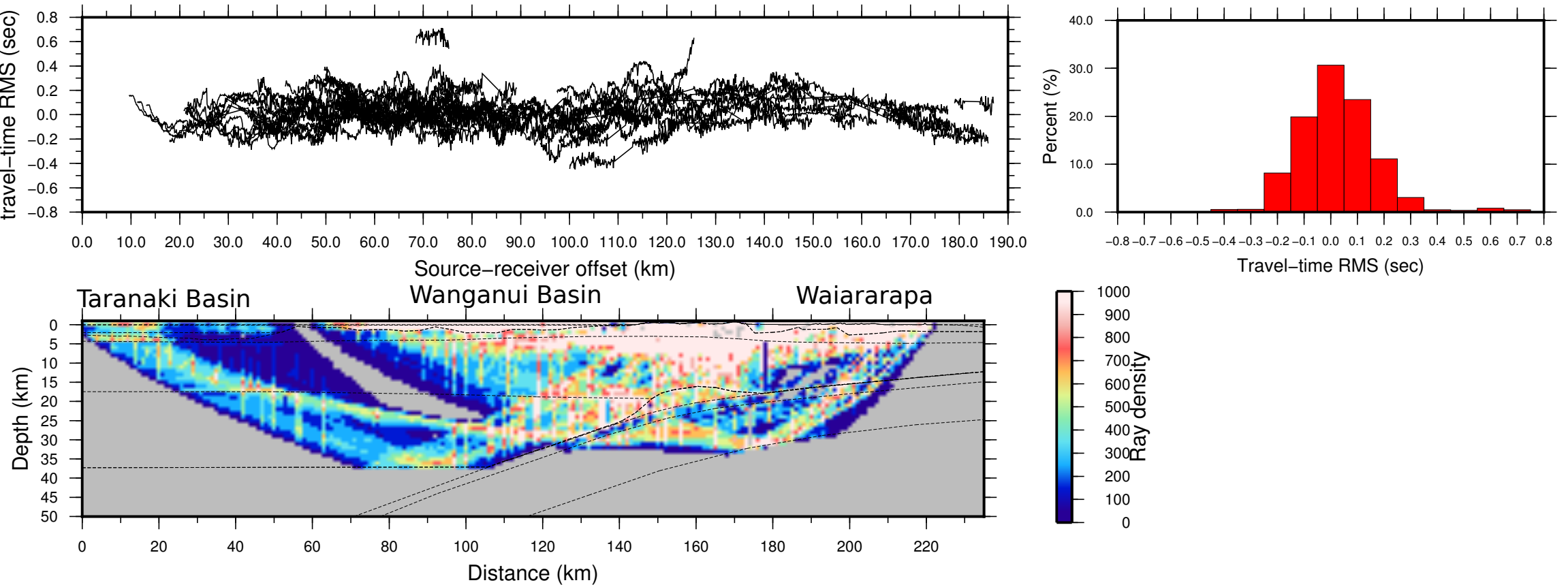

Figure 5.9: (a) Root-mean-squared (RMS) travel-time residuals for all modelled phase arrivals plotted against true source-receiver offset. (b) Ray coverage diagram computed with $1 \times 1 \mathrm{~km}$ grid cells, dashed black lines are model layers. (c) same data as in (a) plotted as a percentage histogram binned at $50 \mathrm{~ms}$ intervals. 
5.4. Model Assessment

station location $\quad$ pick RMS travelStation model coor. $(\mathrm{Km})$ Phase and direction $\quad \mathrm{N}^{*}$ error $(\mathrm{sec})$ time residual $(\mathrm{ms}) \quad \chi^{2}$

\begin{tabular}{|c|c|c|c|c|c|c|}
\hline TS006 & 212.203 & $P g$ left & 124 & 0.12 & 0.058 & 0.236 \\
\hline TS007 & 210.688 & $P g$ left & 160 & 0.11 & 0.061 & 0.307 \\
\hline TS008 & 208.481 & $P g$ left & 183 & 0.11 & 0.072 & 0.433 \\
\hline TS010 & 202.572 & $P g$ left & 129 & 0.11 & 0.08 & 0.533 \\
\hline TS011 & 200.831 & $P g$ left & 160 & 0.12 & 0.073 & 0.372 \\
\hline TS015 & 192.641 & $P g$ left & 139 & 0.11 & 0.071 & 0.416 \\
\hline TS016 & 191.116 & $P g$ left & 335 & 0.11 & 0.125 & 1.304 \\
\hline MTW & 190.769 & $P g$ left & 84 & 0.1 & 0.144 & 2.092 \\
\hline TS017 & 188.973 & $P g$ left & 143 & 0.11 & 0.067 & 0.373 \\
\hline TS018 & 186.741 & $P g$ left & 110 & 0.12 & 0.206 & 2.968 \\
\hline TS019 & 185.108 & $P g$ left & 168 & 0.11 & 0.183 & 2.795 \\
\hline TS020 & 182.318 & $P g$ left & 200 & 0.11 & 0.12 & 1.197 \\
\hline TS021 & 178.577 & $P g$ left & 153 & 0.11 & 0.127 & 1.343 \\
\hline TS022 & 178.55 & $P g$ left & 197 & 0.11 & 0.128 & 1.36 \\
\hline TS025 & 172.866 & $P g$ left & 373 & 0.11 & 0.103 & 0.885 \\
\hline TS026 & 171.476 & $P g$ left & 344 & 0.12 & 0.106 & 0.783 \\
\hline TS027 & 169.359 & $P g$ left & 596 & 0.1 & 0.088 & 0.771 \\
\hline TS030 & 163.217 & $P g$ left & 685 & 0.1 & 0.144 & 2.09 \\
\hline CAW & 158.798 & $P g$ left & 528 & 0.1 & 0.111 & 1.24 \\
\hline TS032 & 157.972 & $P g$ left & 390 & 0.1 & 0.091 & 0.836 \\
\hline TS035 & 149.96 & $P g$ left & 637 & 0.1 & 0.106 & 1.132 \\
\hline TS036 & 148.615 & $P g$ left & 669 & 0.1 & 0.112 & 1.267 \\
\hline TS038 & 147.192 & $P g$ left & 780 & 0.1 & 0.114 & 1.311 \\
\hline Shot12 & 144.476 & $P i P$ right & 226 & 0.15 & 0.193 & 1.67 \\
\hline Shot11 & 150.368 & $P i P$ left & 75 & 0.15 & 0.112 & 0.569 \\
\hline Shot11 & 150.368 & PiP right & 301 & 0.15 & 0.187 & 1.563 \\
\hline Shot10 & 156.143 & $P i P$ left & 109 & 0.15 & 0.069 & 0.216 \\
\hline Shot10 & 156.143 & $P i P$ right & 282 & 0.15 & 0.151 & 1.021 \\
\hline 144.476 & Shot12 & $P p P_{1}$ right & 141 & 0.15 & 0.059 & 0.155 \\
\hline 147.192 & TS038 & $P p P_{1}$ left & 507 & 0.11 & 0.128 & 1.346 \\
\hline 148.615 & TS036 & $P p P_{1}$ left & 477 & 0.11 & 0.121 & 1.217 \\
\hline 149.96 & TS035 & $P p P_{1}$ left & 485 & 0.11 & 0.122 & 1.241 \\
\hline 150.368 & Shot11 & $P p P_{1}$ right & 200 & 0.15 & 0.126 & 0.706 \\
\hline 156.143 & Shot10 & $P p P_{1}$ left & 67 & 0.15 & 0.114 & 0.329 \\
\hline 156.143 & Shot10 & $P p P_{1}$ right & 230 & 0.2 & 0.113 & 0.57 \\
\hline 157.972 & TS032 & $P p P_{1}$ left & 427 & 0.11 & 0.177 & 2.587 \\
\hline 158.798 & CAW & $P p P_{1}$ left & 143 & 0.1 & 0.081 & 0.542 \\
\hline 163.217 & TS030 & $P p P_{1}$ left & 406 & 0.11 & 0.155 & 1.989 \\
\hline 165.135 & Shot09 & $P p P_{1}$ left & 153 & 0.15 & 0.197 & 1.740 \\
\hline 165.135 & Shot10 & $P p P_{1}$ right & 181 & 0.15 & 0.113 & 0.568 \\
\hline 169.359 & TS027 & $P p P_{1}$ left & 253 & 0.11 & 0.105 & 0.916 \\
\hline 174.596 & Shot08 & $P p P_{1}$ left & 216 & 0.15 & 0.066 & 0.194 \\
\hline 181.254 & Shot07 & $P p P_{1}$ left & 243 & 0.15 & 0.158 & 1.111 \\
\hline 188.713 & Shot06 & $P p P_{1}$ left & 172 & 0.15 & 0.125 & 0.702 \\
\hline
\end{tabular}


5. Two Dimensional Modelling of Crustal Velocity Structure: SAHKE02

\begin{tabular}{|c|c|c|c|c|c|c|}
\hline 178.550 & TS022 & $P p P_{1}$ left & 165 & 0.12 & 0.104 & 0.753 \\
\hline 190.769 & MTW & $P p P_{1}$ left & 188 & 0.14 & 0.119 & 0.723 \\
\hline 144.476 & Shot12 & $P p P_{2}$ right & 141 & 0.15 & 0.079 & 0.28 \\
\hline 150.368 & Shot11 & $\mathrm{PpP}_{2}$ right & 273 & 0.15 & 0.147 & 0.968 \\
\hline 156.143 & Shot10 & $P p P_{2}$ left & 52 & 0.15 & 0.089 & 0.357 \\
\hline 156.143 & Shot10 & $\mathrm{PpP}_{2}$ right & 384 & 0.15 & 0.132 & 0.776 \\
\hline 165.135 & Shot09 & $P p P_{2}$ left & 160 & 0.15 & 0.148 & 0.974 \\
\hline 165.135 & Shot09 & $P p P_{2}$ right & 224 & 0.15 & 0.191 & 1.63 \\
\hline 172.866 & TS025 & $P p P_{2}$ left & 237 & 0.12 & 0.105 & 0.770 \\
\hline 178.577 & TS021 & $P p P_{2}$ left & 524 & 0.15 & 0.185 & 2.392 \\
\hline 144.476 & Shot12 & PbaseP right & 134 & 0.15 & 0.179 & 1.436 \\
\hline 150.368 & Shot11 & PbaseP right & 134 & 0.15 & 0.136 & 0.828 \\
\hline 156.143 & Shot10 & PbaseP right & 145 & 0.15 & 0.106 & 0.502 \\
\hline 208.481 & TS008 & PbaseP left & 523 & 0.1 & 0.103 & 1.071 \\
\hline 210.688 & TS007 & PbaseP left & 566 & 0.1 & 0.173 & 2.999 \\
\hline 212.203 & TS006 & PbaseP left & 372 & 0.12 & 0.157 & 1.720 \\
\hline 214.305 & TS004 & PbaseP left & 312 & 0.12 & 0.118 & 0.972 \\
\hline 216.113 & TS003 & PbaseP left & 214 & 0.1 & 0.073 & 0.534 \\
\hline 219.153 & TS002 & PbaseP left & 227 & 0.2 & 0.275 & 1.893 \\
\hline 219.571 & TRWZ & PbaseP left & 330 & 0.2 & 0.292 & 2.145 \\
\hline 220.839 & TS001 & PbaseP left & 219 & 0.2 & 0.240 & 1.447 \\
\hline 219.153 & TRWZ & $P n$ left & 248 & 0.2 & 0.242 & 1.468 \\
\hline 214.305 & TS004 & $P n$ left & 203 & 1.2 & 0.123 & 0.378 \\
\hline 210.688 & TS007 & $P n$ left & 155 & 2.2 & 0.027 & 0.018 \\
\hline 208.481 & TS008 & $P n$ left & 149 & 3.2 & 0.057 & 0.082 \\
\hline 202.572 & TS010 & $P n$ left & 183 & 4.2 & 0.085 & 0.181 \\
\hline 200.831 & TS011 & $P n$ left & 124 & 5.2 & 0.097 & 0.239 \\
\hline 194.519 & TS014 & $P n$ left & 53 & 6.2 & 0.138 & 0.485 \\
\hline 191.116 & TS016 & $P n$ left & 117 & 7.2 & 0.111 & 0.308 \\
\hline 188.973 & TS017 & $P n$ left & 90 & 8.2 & 0.269 & 1.825 \\
\hline 147.192 & TS038 & $P m P$ left & 468 & 0.1 & 0.083 & 0.692 \\
\hline 148.615 & TS036 & $P m P$ left & 419 & 0.1 & 0.134 & 1.794 \\
\hline 149.96 & TS035 & $P m P$ left & 373 & 0.1 & 0.176 & 3.105 \\
\hline 157.972 & TS032 & $P m P$ left & 219 & 0.1 & 0.040 & 0.157 \\
\hline 158.798 & CAW & $P m P$ left & 49 & 0.1 & 0.121 & 1.484 \\
\hline 163.217 & TS030 & $P m P$ left & 487 & 0.1 & 0.093 & 0.873 \\
\hline 169.359 & TS027 & $P m P$ left & 329 & 0.1 & 0.103 & 1.063 \\
\hline 171.476 & TS026 & $P m P$ left & 227 & 0.12 & 0.085 & 0.500 \\
\hline 172.866 & TS025 & $P m P$ left & 283 & 0.12 & 0.113 & 0.89 \\
\hline
\end{tabular}

Table 5.2: RMS travel-time residuals and Chi-square values for the final SAHKE02-M model (Fig. 5.7). $\mathrm{N}^{*}=$ number of travel-time picks per gather. 


\subsubsection{Problematic arrivals}

Although the inclusion of an low velocity sedimentary body protruding from the plate interface (Fig. 5.7) satisfies the observed PiP reflection arrivals, this also prevents ray tracing of $P p P$ reflections from several shot locations. Specifically, the tracing of rays from stations east of station TS022 (MTW - TS011) are limited or completely inhibited. This problem is due to limitations of the ray tracing software in determining ray paths through complex layer geometries. This can be overcome by replacing the sedimentary body with a "floating reflector". In the final model, however, the low velocity sediment body is included and rays from these stations remain untraced.

\subsubsection{Resolution testing}

Resolution tests are used to assign minimum formal errors to model interface depths and P-wave velocities, as explained in Section 4.4.3.

\section{Subducted Oceanic crust thickness and velocities}

In the final SAHKE02-M model the subducting Pacific plate is divided into two layers: an upper, thin, low Vp layer and a lower, thick high Vp layer. The top layer is a low Vp "blind zone", as no refraction arrivals exist for this layer. In the second layer, $\mathrm{Vp}$ is constrained by $\mathrm{Pn}$ refractions. However, these phases turn within the top $\sim 3 \mathrm{~km}$ and hence the velocity profile is unconstrained. Hence, resolution tests were designed to determine possible layer thickness/velocity combinations for each of these layers. These tests assumed constant layer thicknesses and velocity profiles.

\section{Subducted sediment sheet}


Reflections from this layer occur beneath the subducted sediment body (Fig. 5.7 ) and for this test the thickness of the sediment body was kept constant. Table 5.3 and figure 5.10 show the parameterisation used to test possible velocity and thickness combinations of this layer.

\begin{tabular}{ccccc}
\hline$V_{1} k m s^{-1}$ & $V_{2} k m s^{-1}$ & $V_{1}$ inc. $k m s^{-1}$ & layer thickness $\mathrm{km}$ & thickness inc. $\mathrm{km}$ \\
\hline $3.0-7.0$ & $V_{2}=V_{1}+0.2$ & 0.2 & $1.0-5.0$ & 0.2
\end{tabular}

Table 5.3: SAHKE02-M resolution test parameterisation for layer one of the subducting oceanic crust

The results of this test are shown in figure 5.10. These results exhibit a relatively linear velocity-depth tradeoff for velocities above $4.4 \mathrm{kms}^{-1}$ with an estimated function:

$$
V_{1}=1.195 \times \text { thickness }+2.06
$$

This function is similar to that obtained for this layer on the SAHKE03-M model (Equation 4.4.3), and it is clear a range of velocity/thickness combinations fit the data equally well. Given an average pick error of $0.12 \mathrm{~s}$, however, these results suggest the $\mathrm{Vp}$ of this layer is between $5.2-6.0 \mathrm{kms}^{-1}$ (0.12 s RMS contour, Fig. 5.10). In the final model, this layer is modelled with a thickness of $\sim 1.5-2.0 \mathrm{~km}$ and velocity profile of $5-5.20 \mathrm{kms}^{-1}$. Errors in these values are unassigned due to the trade-off that exists between thickness and $\mathrm{Vp}$. These values are adopted as they are within pick error (0.12 s), are consistent with other phase travel-times and the results from the SAHKE03-M model (see Chapter 4) and results from previous studies (Chadwick, 1997; Bourne and Stuart, 2000; Savage et al., 2007; Ewig, 2009; Plaza Faverola et al., 2012 in review).

\section{Subducted Oceanic crust thickness and velocities}




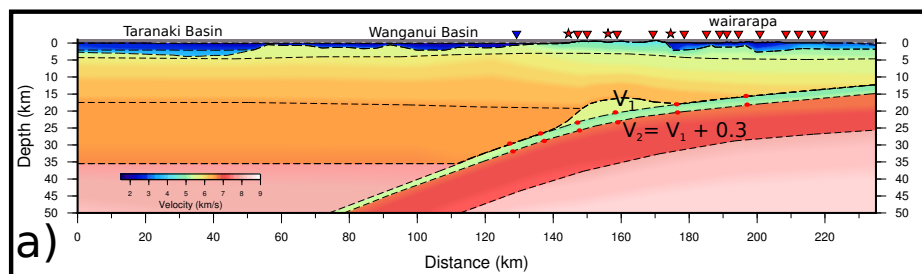

a)

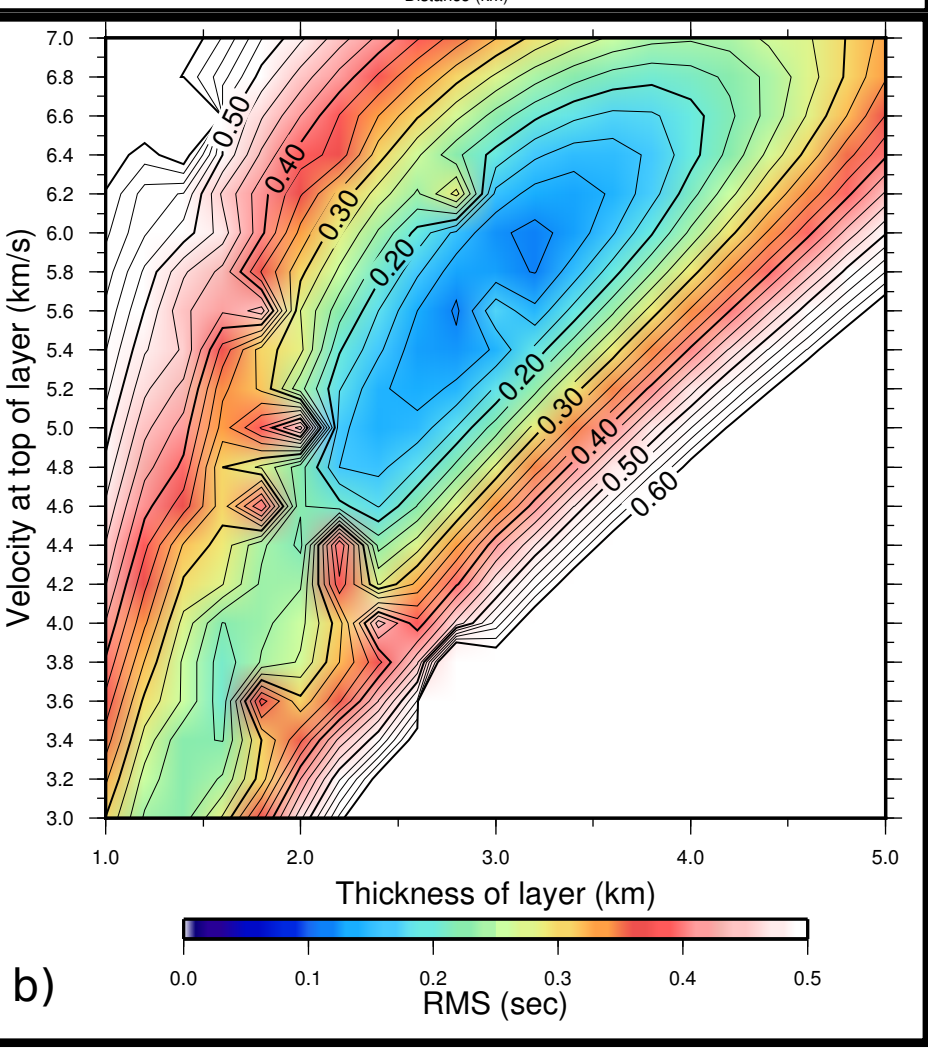

Figure 5.10: RMS travel-time misfit results from the resolution test concerning the thickness and velocity of the low p-wave velocity upper layer of the subducting oceanic crust.

The resolution of $\mathrm{Vp}$ within the subducting Pacific plate crust is tested using Pn refractions from stations TS017 - TS002. Table 5.4 and figure 5.11 a show the parameteristion of this test.

The results show that the best RMS fit for these refractions is achieved using a $\mathrm{Vp}$ between 6.6 and $6.8 \mathrm{kms}^{-1}$ at the top of the layer $\left(V_{1}\right)$. However, this test is insensitive to both layer thickness and Vp profile and hence these 
5. Two Dimensional Modelling of Crustal Velocity Structure: SAHKE02

\begin{tabular}{ccccc}
\hline$V_{1} k m^{-1}$ & $V_{2} k m m s^{-1}$ & $V_{1}$ inc. $k m s^{-1}$ & layer thickness $\mathrm{km}$ & thickness inc. $\mathrm{km}$ \\
\hline $6.0-8.0$ & $V_{2}=V_{1}+0.40$ & 0.2 & $7.0-14.0$ & 0.2
\end{tabular}

Table 5.4: RMS travel-time misfit results from the resolution test concerning the thickness and velocity of the lower layer of the subducting oceanic Pacific plate crust.

remain unresolved. This is because the Pn rays turn within the top $\sim 3-4$ $\mathrm{km}$ of this layer and hence are insensitive to velocities below these depths. Considering an average pick uncertainty of $0.2 \mathrm{~s}$, the $\mathrm{Vp}$ at the top of the Pacific plate crust is resolved as $6.7 \pm 0.15 \mathrm{kms}^{-1}$. This is slightly less than that determined in the SAHKE03 model $\left(6.8 \mathrm{kms}^{-1}\right.$, Fig. 4.10).

Resolution testing of reflections from the Moho of the subducting Pacific plate crust proved inconclusive due to a tradeoff between two groups of arrivals. The best fit for rays travelling updip is achieved using a thinner layer $(\sim 9.5 \mathrm{~km})$ compared to the $10 \mathrm{~km}$ thick layer for rays travelling downdip. In the final model, the arrivals from each group are reconciled using a lateral change in the Vp profile from $6.7-7.1 \mathrm{kms}^{-1}$ beneath the Wairarapa to $6.8-7.2 \mathrm{kms}^{-1}$ downdip beneath the west coast.

\section{Australian plate Moho depth}

The resolution of the depth to the Australian plate Moho was tested using PmP arrivals. Unfortunately the geometry between the subducting oceanic plate and the Australian plate Moho prevented the application of automated resolution testing. Hence, the resolution of the Australian plate Moho was tested by adjusting Moho depth manually, while holding the Vp field constant. Table 5.5 shows the results from this test. The best fit for these reflections was found using a lower crust Vp profile of $6.5-6.65 \mathrm{kms}^{-1}$. With this Vp profile, a Moho depth of $35.5 \mathrm{~km}$ provides the best fit to the data. The RMS misfit is, however, slightly higher than average pick uncertainty of $0.104 \mathrm{~s}$. If we extend the pick uncertainty by $\sim 50 \mathrm{~ms}$ to 


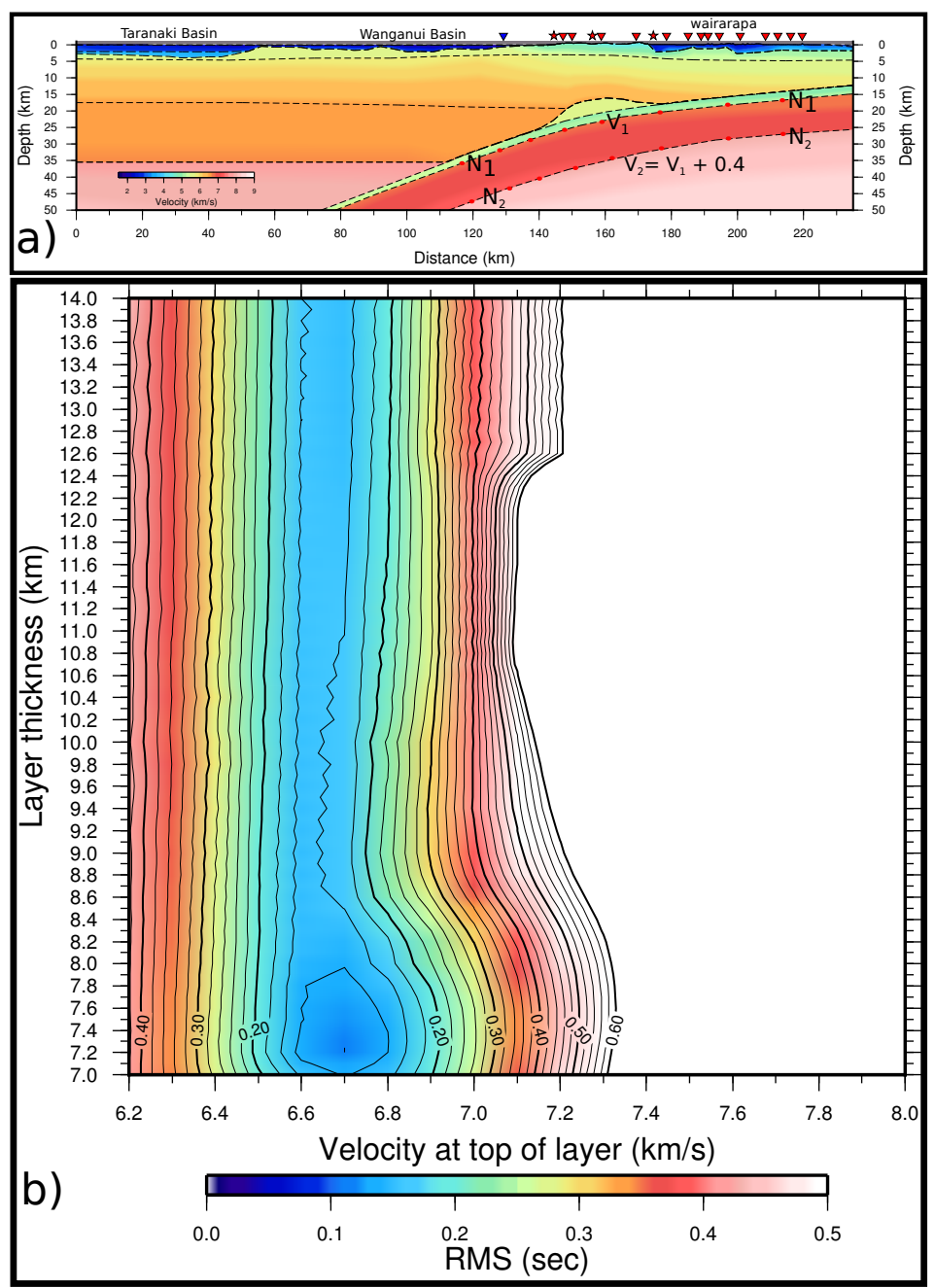

Figure 5.11: RMS travel-time misfit results from the resolution test concerning the thickness and velocity of the subducting oceanic crust.

$0.150 \mathrm{~s}$, a minimum Moho depth uncertainty is $\sim \pm 0.75 \mathrm{~km}$.

\section{Plate interface depth}

The geometry between the base of the upper crust, the subducting oceanic plate, the subducted sediment body and the Australian plate Moho prevented the application of automated resolution testing of plate interface 
5. Two Dimensional Modelling of Crustal Velocity Structure: SAHKE02

\begin{tabular}{ccc}
\hline Moho depth (km) & $\begin{array}{c}\text { RMS travel-time } \\
\text { residual }\end{array}$ & $\chi^{2}$ \\
\hline 34.5 & 0.162 & 2.422 \\
35 & 0.126 & 1.478 \\
35.5 & 0.113 & 1.206 \\
36 & 0.129 & 1.639 \\
36.5 & 0.169 & 2.81
\end{tabular}

Table 5.5: Results from the Australian plate Moho depth resolution test.

depth. Hence, the resolution of the plate interface was tested by adjusting the plate interface depth manually while holding the Vp field constant. This was further complicated by downdip variations in the results of resolution testing; however, a minimum depth error of $\pm 0.5 \mathrm{~km}$ is assigned for this surface.

\subsection{Comparison to multi-channel-seismic data}

The SAHKE02 MCS line was shot to a total depth of $15 \mathrm{~s}$ two-way traveltime (TWTT). Although complete processing of this dataset is outside the scope of this study, a brute stack compiled to 15 s TWTT by Geotrace $\mathbb{R}$ was supplied by Stuart Henrys from GNS for use in this study. In order to compare this brute stack and the Vp model developed in this chapter, the final SAHKE02-M model was converted to TWTT (Fig. 5.12). 

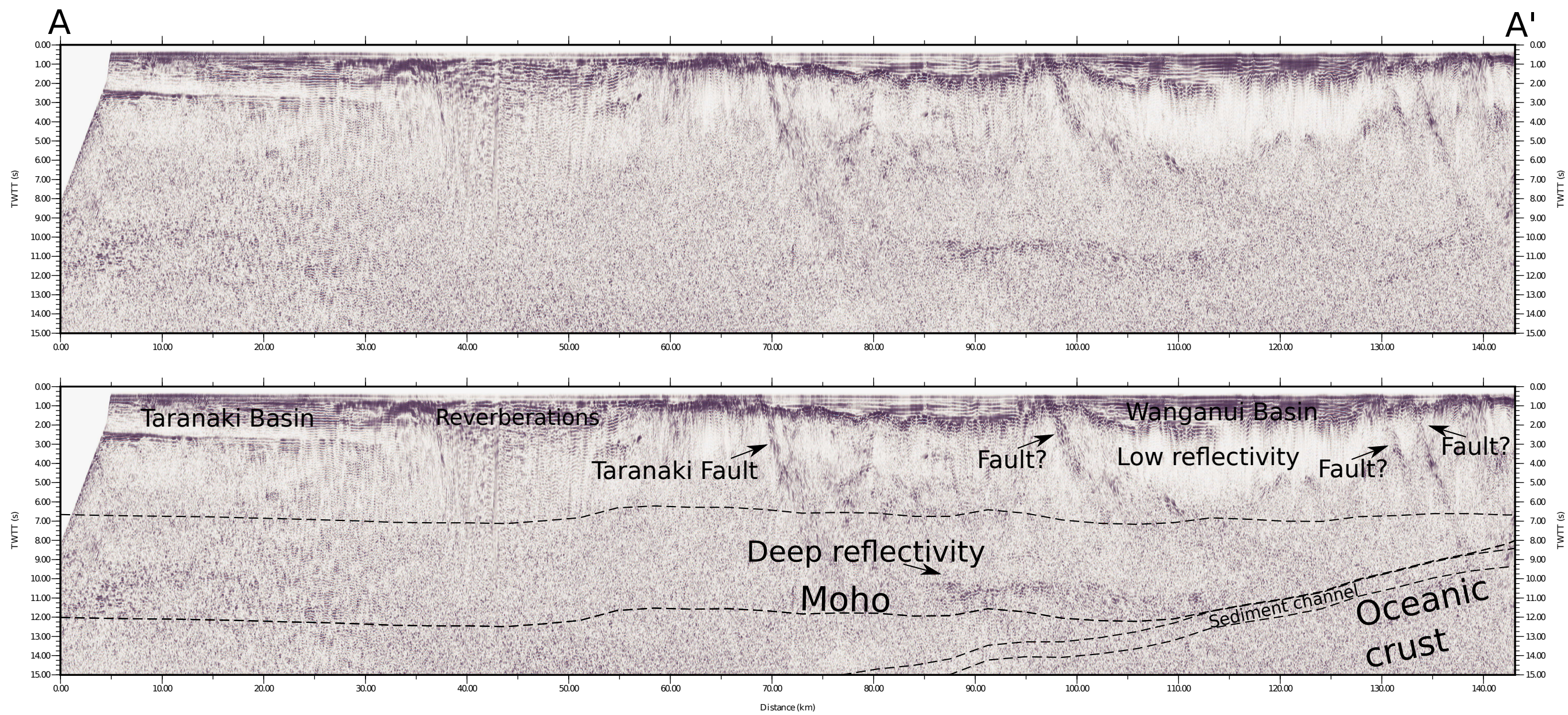

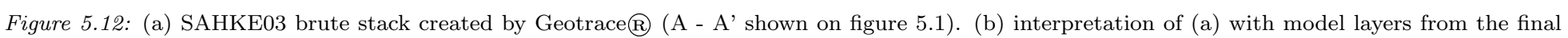
SAHKE02-M model (Fig. 5.7) converted to two-way travel-time and overlain (black dashed lines). 
The brute stack exhibits a band of deep reflectivity between $\sim 10-12$ s two-way travel-time (TWTT) beneath the center of Wanganui Basin, near the intersection between the subducting Pacific plate and overlying Australian plate (Fig. 5.12). This reflectivity is interpreted as either the reflection Moho (as discussed in section 5.5), similar to that interpreted on the SAHKE03 brute stack (Fig. 4.20), or alternatively inter-crustal reflectivity caused by buckling of the overlying crust at the intersection between the two plates. The wide-angle reflection Moho occurs at the base of this band of reflectivity. This contrasts with what is observed on the SAHKE03 brute stack, where the wide-angle reflection Moho occurs in the center of the vertical incident reflectively (Fig. 4.20).

Several eastwardly dipping structures are also visible within the brute stack. These features may represent high-angle thrust faults, and the western-most feature is interpreted as the Taranaki Fault. These features do not appear to penetrate the overlying sediment fill and may represent part of the thrust fault belt that is predicted to have facilitated shortening through central and western North Island during the Miocene (see Fig. 1.2 modified after King, 2000). However, given only prestack processing has been applied to this stack, it cannot be ruled out that these features are some form of coherent noise. 


\section{Chapter 6}

\section{Synthesis}

\subsection{Introduction}

This chapter integrates the results from the two P-wave velocity models developed in Chapters 4 and 5. Inferences regarding the crustal structure within Wanganui Basin are drawn and related to both previous and complementary studies. Specifically, (1) the nature of the Taranaki-Ruapehu Line is explored; (2) a comparison is made between the models developed in this thesis and the Wadati-Benioff Zone defined by both the traditional GeoNet and recently relocated GeoNet earthquake catalogues; and (3) the results from recent Continuous Global Positioning System (cGPS) elastic dislocation modelling are discussed in the context of the SAHKE02-M transect.

\subsection{Australian plate Moho structure}

The Australian plate Moho is constrained on both the SAHKE03-M and SAHKE02-M models (Figs. 6.1 and 6.2). On the SAHKE03-M transect, there is an increase in the depth of the Moho of $\sim 3.1 \mathrm{~km}$ at an apparent dip of $\sim 2.9^{\circ}$ between model coordinates 190 and $130 \mathrm{~km}$ (Fig. 6.1). The structure of the Moho appears surprisingly planar compared to the more curved morphology predicted by gravity modelling (Ewig, 2009). However, 
6. Synthesis

as expected, the increase in crustal thickness is in the direction of both the maximum gradient of the negative isostatic/freeair gravity anomaly and increase in sediment thickness (Fig. 6.1). The minima of the isostatic/freeair gravity anomaly approximately coincides with the intersection between the Moho of the Australian Plate and the subduction Pacific plate interface. On the SAHKE02-M model, the Moho can only be resolved as a horizontal interface at $35.5 \mathrm{~km}$ depth between the Patea-Tongaporutu High and $20 \mathrm{~km}$ west of Kapiti Island (Fig. 6.2). On the SAHKE03-M model, the Moho/plate interface intersection coincides approximately with the isostatic/freeair gravity anomaly minima.

A discrepancy between the crustal thickness determined along the SAHKE02 and SAHKE03 lines (near equal, Figs. 5.1b and 5.1b) and the amplitude of the free-air/isostatic gravity anomaly (up to 100 mgal difference, Figs. 5.1b and $5.1 \mathrm{~b}$ ) can be explained by a recently created a three-dimensional density model of offshore Wanganui Basin (Arenz, 2012 unpublished Master's thesis). The discrepancy is compensated by variations in sediment thickness, the position and thickness of the subducting slab and the depth and position of the eclogite transition in the slab while holding crustal thickness equal to that determined in this study (Arenz, 2012 unpublished Master's thesis).

The Vp models presented in this study confirm that the crust within Wanganui Basin is anomalously thick. The maximum thickness of 36.5 $\mathrm{km}$, is however, at least $5.5 \mathrm{~km}$ less than the maximum thickness of $>$ $42 \mathrm{~km}$ previously determined using three dimensional gravity modelling (Ewig, 2009). A portion of this mismatch is reconciled when comparing the SAHKE03-M wide-angle reflection model with deep reflectivity recorded on the coincident SAHKE03 multi-channel-seismic reflection stack (see Section 4.5). This comparison shows that the wide-angle reflection Moho represents the strongest reflector on the multi-channel-seismic data that occurs at $\sim$ 13 s two-way-travel-time (TWTT) in a band of reflectivity that spans $\sim$ 
2.5 s TWTT from 12 - 14.5 s TWTT. The vertical incident reflection Moho is usually considered the base of the lower crustal reflectivity zone (e.g. Cook, 2002), in which case the Moho may be 1 - 1.5 s TWTT deeper than that determined in the SAHKE03-M model using wide-angle reflections. It is unknown whether this relationship will extend to other parts of the basin. Nevertheless, an extra $1.5 \mathrm{~s}$ TWTT equates to an additional $5.0 \mathrm{~km}$ of crustal thickness (i.e total thickness of $\sim 41.5 \mathrm{~km}$ ), which is closer to, but may still falls short of the $>42 \mathrm{~km}$ determined by Ewig (2009).

An important implication regarding potential driving mechanisms for Wanganui Basin subsidence (e.g. Stern et al., 1992; Ewig, 2009), is that a thinner crust beneath Wanganui Basin requires less vertical force to drive crustal thickening. 


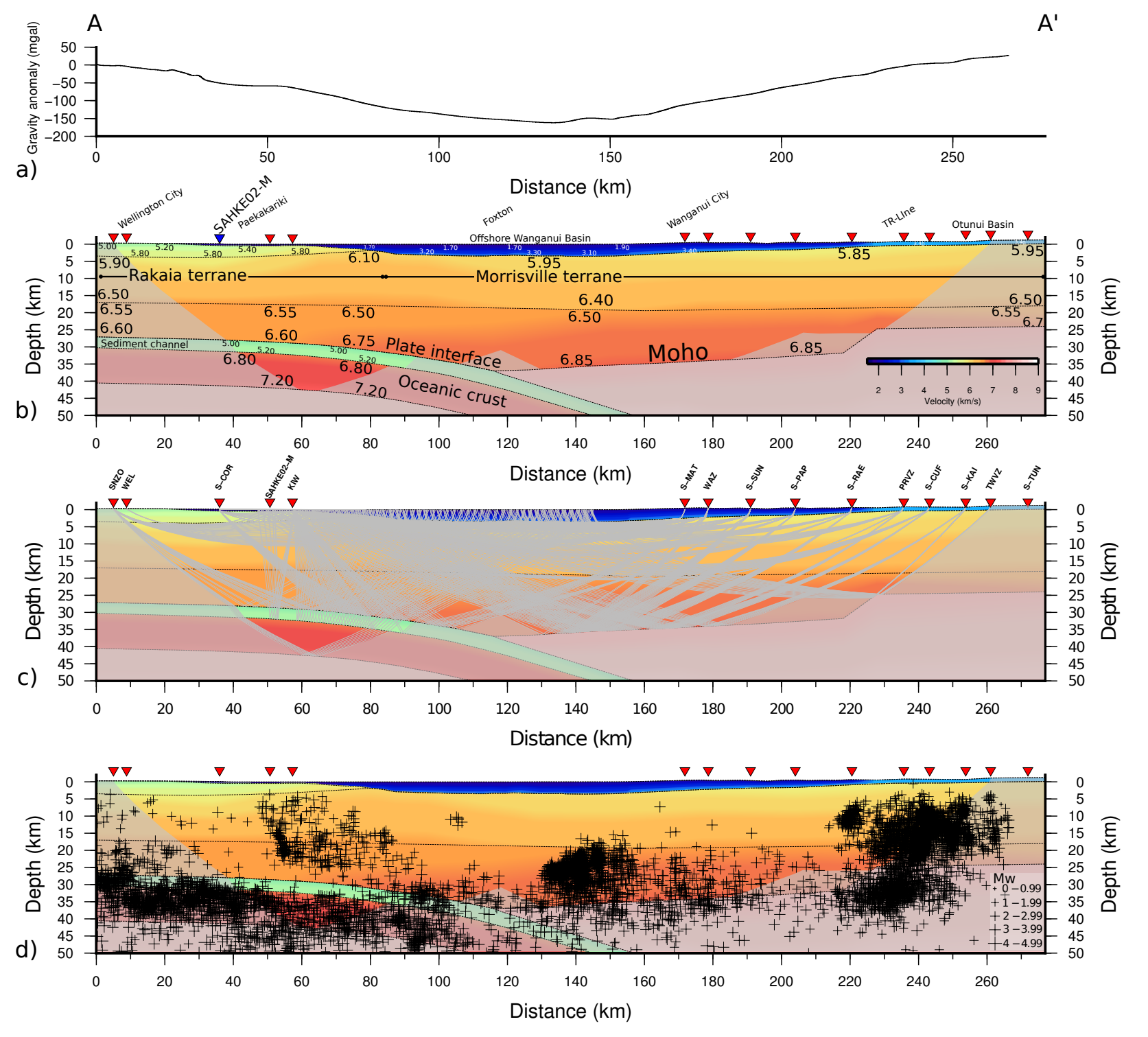

Figure 6.1: (a) Freeair/isostatic gravity anomaly. (b) Final SAHKE03-M P-wave velocity model. Model features and the extent of basement terranes are labelled. (c) Model ray coverage. (d) same as in (a) but with earthquakes from $25 \mathrm{~km}$ either side of the model line, recorded by the national GeoNet seismograph network between January 2001 and March 2011 and relocated using the nation wide 3D velocity model of Eberhart-Phillips et al. (2010), supplied by Martin Reyners (M. Reyners, personal communication, 21 November 2011) overlain (black crosses). A - A' shown on figure 4.1. The grey shaded area indicates the unconstrained region with no ray coverage. 


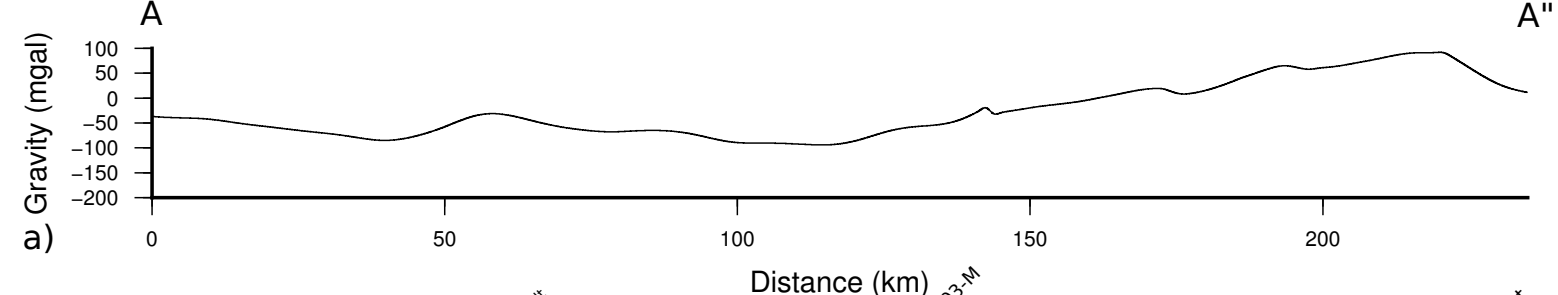

b)

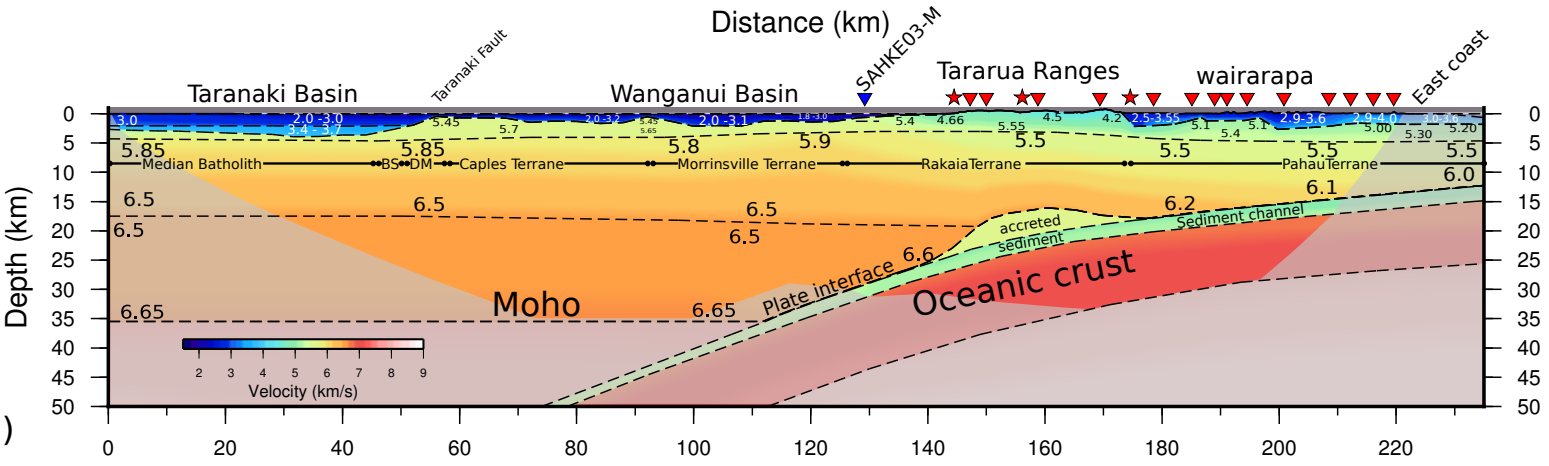

c)
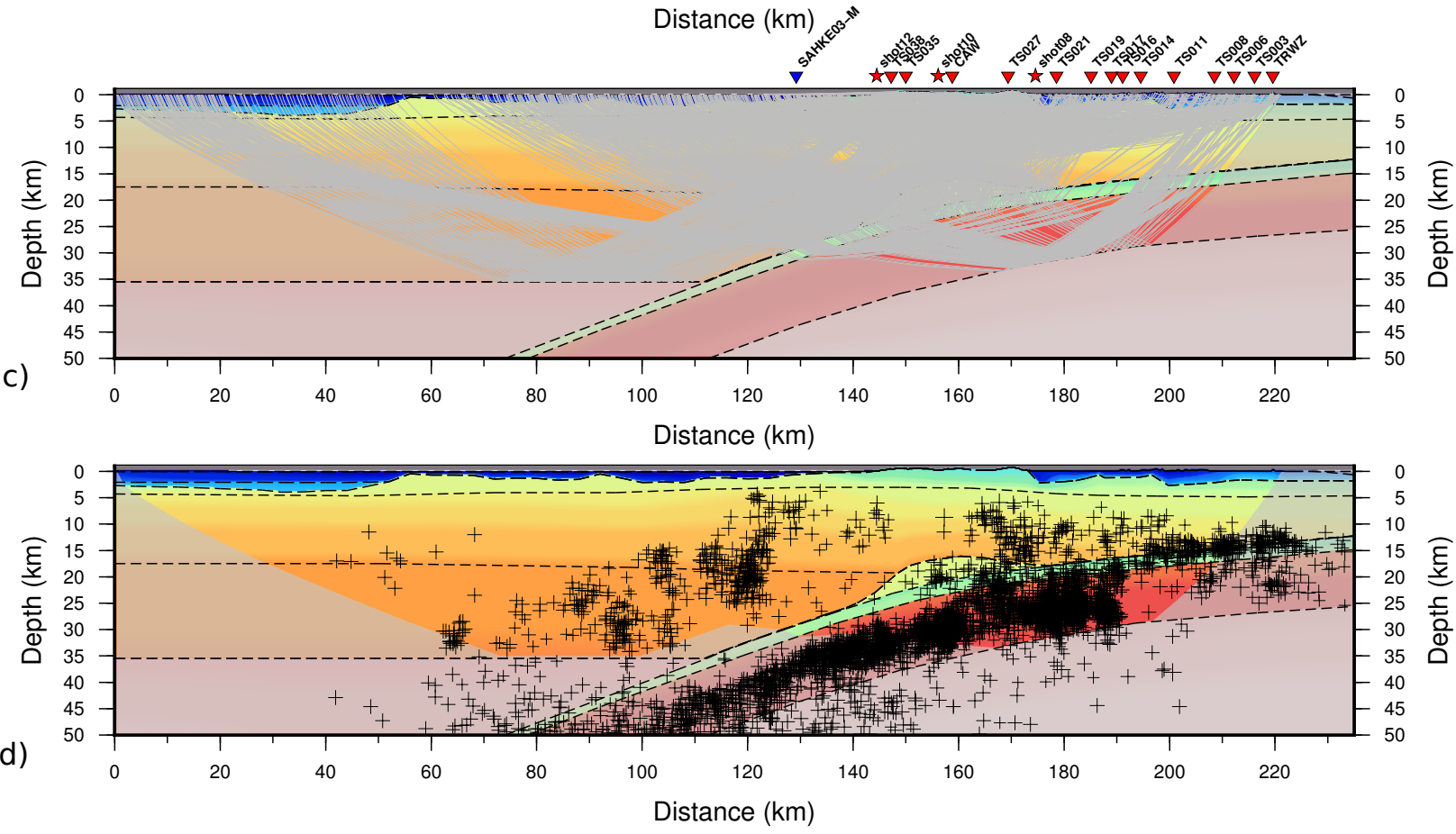

Figure 6.2: (a) Freeair/isostatic gravity anomaly. (b) Final SAHKE02-M P-wave velocity model. Model features and the extent of basement terranes are labelled. (c) Model ray coverage. (d) same as in (a) but with earthquakes from $25 \mathrm{~km}$ either side of the model line, recorded by the national GeoNet seismograph network between January 2001 and March 2011 and relocated using the nation wide 3D velocity model of Eberhart-Phillips et al. (2010), supplied by Martin Reyners (M. Reyners, personal communication, 21 November 2011)overlain (black crosses). A - A" shown on figure 5.1. BS = Brook Street Terrane DM $=$ Dun Mountain - Maitai Terrane. The grey shaded area indicates the unconstrained region with no ray coverage. 
6. Synthesis

\subsection{Australian plate velocity structure}

Basement terranes of New Zealand's Eastern Province (Fig. 1.6) are relatively young $(<500 \mathrm{Ma})$ compared to the average age of continental crust $\sim 2 \mathrm{Ga}$ (e.g. Hawkesworth et al., 2010). Furthermore, detailed active source seismic experiments (e.g. Scherwath et al., 2003; Baldock, 2004; Brikke, 2010) have shown that in the South Island the Rakaia terrane which has a similar lithology to the basement terranes underlying Wanganui Basin (see Section 1.3.1) exhibits slightly below average P-wave velocity of $\sim 6 \mathrm{kms}^{-1}$ compared to the global average for orogens of $6.39 \mathrm{kms}^{-1}$ (Christensen and Mooney, 1995). The velocity models developed in this thesis place the first active source constraints on the crustal scale velocity profile of basement terranes within Wanganui Basin.

\subsection{Upper crust}

Within Wanganui Basin, the upper crustal Vp structure is modelled as a relatively homogeneous layer with an average gradient of $\sim 5.9-6.5 \mathrm{kms}^{-1}$. In the SAHKE02-M transect there is a clear decrease in upper crustal Vp east of Kapiti Island, near the edge of Wanganui Basin, where $\mathrm{Vp}$ values are estimated as $\sim 5.5-6.2 \mathrm{kms}^{-1}$ (Fig. 6.2). This $0.3-0.4 \mathrm{kms}^{-1}$ decrease may reflect a change in basement petrology as this transition occurs in close proximity to the plane view contact between the Morrinsville terrane to the west and Rakaia terrane to the east (Fig. 6.2). Furthermore, cracks and fracturing due to faulting in the North Island Dextral Fault Belt may contribute to lowering these velocities. This velocity transition is also evident in the results of ambient noise surface wave tomography, which exhibit a sharp $0.2 \mathrm{kms}^{-1}$ step in group velocity when analysed using 8 and $13 \mathrm{~s}$ period waves that image the top $\sim 13 \mathrm{~km}$ of the crust (Lin et al., 
2007). To the west, no significant velocity change is detected between the Morrinsville terrane and Caples terrane, while upper crustal refractions are absent beyond the Taranaki Fault and hence velocities are largely unconstrained west of this feature.

Interestingly, a ray coverage gap exists at the western edge of Wanganui Basin and appears to correlate with the location of the Taranaki Fault (Fig. 5.9b). This gap is represented in the onshore/offshore seismic data as an abrupt cut-off of both reflection and refraction phase arrivals, for example phases $\mathrm{Pg}$ and $\mathrm{PpP}$ on figure 2.15). One possible explanation for this ray coverage gap is that a high attenuation zone exists near the Taranaki Fault. Alternatively, thick-skinned thrusting in the Taranaki fault zone may have juxtaposed lower crustal, higher Vp rocks within Wanganui Basin, adjacent to lower Vp rocks within Taranaki Basin, while the fault zone itself may act as a low velocity zone, as is observed at the Alpine Fault in the South Island (e.g. Scherwath et al., 2003). This may result in a velocity inversion that could potentially deflect rays away from the surface. However, in the absence of upper crustal refraction arrivals west of the Taranaki fault, it is not possible to assess whether such a velocity inversion exists.

The upper crustal velocities determined in Wanganui Basin are $\sim 5$ $\%$ higher than those determined within the Rakaia terrane in the South Island, were Vp values are reported between $\sim 5.7-6.3 \mathrm{kms}^{-1}$ (e.g. Scherwath et al., 2003; Brikke, 2010). An interpretation of these anomalously high velocities is discussed below in Section 6.6. 
6. Synthesis

\subsection{Lower crust}

Lower crustal Vp values are poorly constrained within Wanganui Basin due to the absence of lower crustal refractions and the inherent velocity vs thickness trade-off that exists when using wide-angle reflections to constrain Vp values. Nevertheless, resolution testing indicates that the Vp values used to model PmP arrivals provide the best fit for the wide-angle reflections. Furthermore, a comparison between the SAHKE03 multi-channel-seismic reflection stack and the Moho determined in the SAHKE03-M wide-angle reflection/refraction model (converted to two way travel-time) (Fig. 4.20), confirms that the velocities used in this model are reasonable, as the wide-angle Moho fits well with the Moho interpreted on the reflection stack (see section 4.11).

Lower crustal $\mathrm{Vp}$ values in the SAHKE03-M model are between 6.5 $6.85 \mathrm{kms}^{-1}$. These are higher than those determined in central South Island wh ere values are reported as $\sim 6-6.3 \mathrm{kms}^{-1}$ at depths of up to $\sim 25 \mathrm{~km}$ (e.g. Scherwath et al., 2003; Brikke, 2010). Interestingly, on the west coast of South Island, within the Western Province, Takaka and Buller Terranes (Fig. 1.6), Melhuish et al. (2005) resolved velocities of $\sim 6.5-7 \mathrm{kms}^{-1}$ for the lower crust, closer to what is observed in Wanganui Basin.

In the SAHKE02-M model, lower crustal velocities range between 6.5 - $6.65 \mathrm{kms}^{-1}$. These $\mathrm{Vp}$ values are slightly lower than those determined in the SAHKE03-M model. It is noted however, that a similarly good fit for SAHKE02-M PmP reflection travel-times can be achieved using velocities equal to those of the SAHKE03-M model, provided the Moho is deepened from $35 \mathrm{~km}$ to $37.5 \mathrm{~km}$. A Moho depth of $37.5 \mathrm{~km}$ along the SAHKE02-M transect is, however, inconsistent with the both the results of three-dimensional gravity modelling (Ewig, 2009) and the SAHKE02 multi-channel-seismic reflection stack (Section 5.5). The velocities used in the final models (Figs. 6.1 and 6.2) are therefore the preferred velocity 
structure. Thus, there is an apparent difference in lower crustal Vp values between the two models. This is suggestive of a $\mathrm{P}$-wave azimuthal anisotropy of up to $3 \%$ in the lower crust of Wanganui Basin.

Given the orientations of each model transect relative to the Australian/Pacific plate boundary, there are several possible reasons for the apparent Hikurangi margin parallel $\mathrm{P}$-wave fast direction are (1) this is a preexisting fabric inherited from deformation prior to the inception of the Hikurangi subduction system (2) the preferential alignment of mineral fabrics in the direction of relative transpressive plate motion during the last $\sim 23 \mathrm{Ma}$ (see Fig. 1.2), or (3) structural anisotropy owing to the Hikurangi Margin sub-parallel strike of both (a) the Taranaki Fault Zone and other thrust faults predicted within the Wanganui Basin region during the Miocene and (b) the contemporary Kapiti-Manawatu Fault System, within which, major faults are postulated to extend to the plate interface (Lamarche et al., 2005).

\subsection{Interpretation of High $\mathrm{Vp}$ values}

Given the variability in P-wave velocity exhibited in high pressure laboratory experiments of similar grade rocks as those of the New Zealand Eastern Province basement terranes (Christensen and Mooney, 1995), it is unclear whether the upper crustal Vp difference of $\sim 5 \%$ compared to the Rakaia terrane of central South Island represents any significant tectonic or petrological signal. However Vp values between $6.5-7.0 \mathrm{kms}^{-1}$ (as are inferred for the lower crust) are usually indicative of mafic rocks (Christensen and Mooney, 1995).

Three possible contributing factors that may account for the anomalously high $\mathrm{Vp}$ values determined in this thesis are: 
6. Synthesis

1. Exhumation during the Miocene:

Prior to the development of Wanganui Basin, $\sim 70+/-30 \mathrm{~km}$ of shortening is predicted to have occurred within Central and Western North Island during the Miocene (Stern et al., 2006). Presumably, this shortening would have resulted in crustal thickening and potentially exhumation within the Wanganui Basin area. For example, Kamp (2000) showed using fission track thermochronology, that in the Wellington region, at least $4 \mathrm{~km}$ of exhumation occurred during the late Miocene. Such exhumation may explain the fast upper crustal Vp values observed in Wanganui Basin due to the removal upper and mid crustal rocks and the emplacement of underlying higher Vp rocks at shallow depths. Similar interpretations of anomalously high Vp values have been reported in areas such as southeastern Alaska and Western British Columbia (e.g. Morozov et al., 2001).

2. Western Province lower crust:

The Vp values of $6.5-6.85 \mathrm{kms}^{-1}$ inferred for the lower crust in Wanganui Basin are far in excess of continental crust Vp values determined for Eastern Province basement rocks in central South Island. These are, however, similar to lower continental crustal velocities interpreted by Melhuish et al., (2005) on the east coast of South Island. These high velocities may provide evidence for deposition of basement terranes upon high Vp, Australian plate lower crust, that may extend from eastern South Island northward through to the Wanganui Basin.

3. Low crustal temperatures:

Surface heat flow is low in Wanganui Basin (Funnell et al., 1996) and in the absence of a magmatic arc, the dominate thermal feature will be 
the subducting oceanic slab. It is well documented that P-wave velocity increases with decreasing temperature (e.g. Lin and Wang, 1980; Kern and Tubia, 1993; Christensen and Mooney, 1995) and that cold subducting slabs can act as a refrigerator of the overlying crust (e.g. Molnar and England, 1990; Dumitru et al., 1991). Hence, cooling from the underlying Pacific slab, emplaced $\sim 5$ - 10 Ma beneath the Wanganui Basin area may further increase lower crustal Vp values within Wanganui Basin. It is unclear, however, whether $\sim 5-10 \mathrm{Ma}$ is a sufficient length of time for cooling to have any significant effect on $\mathrm{Vp}$.

\subsection{Plate interface structure}

The Australian/Pacific plate interface geometry is constrained by wide angle reflections on both the SAHKE03-M and SAHKE02-M transects. The SAHKE03-M transect is orientated at an oblique angle to the strike of the subducting plate and hence this interface displays an increasingly steep apparent dip from south to north of $2.3-9.5^{\circ}$, deepening from $28.15-35.6$ $\mathrm{km}$ between the latitudes of Paekakariki and Foxton.

The SAHKE02-M model is orientated perpendicular to the Hikurangi margin and represents a dip-section through the subduction zone. In the SAHKE02-M model, the dip of the plate interface increases from $5.4-19^{\circ}$ between Martinborough and central Wanganui Basin at depths of 10 $33 \mathrm{~km}$. On both transects, the plate interface is modelled as a relatively smooth surface, with the exception of a dome-like body that appears to protrude from the interface between Featherston and the west coast on the SAHKE02-M transect. This body is estimated as up to $\sim 3.5 \mathrm{~km}$, based on modelling of $P i P$ and $P p P_{1}$ reflections analysed in this study (e.g. Figs. 2.20 and 5.8). The $\mathrm{Vp}$ is constrained as $\sim 5-5.2 \mathrm{kms}^{-1}$ by first arrival tomography analysis of the entire SAHKE transect dataset conducted by 
6. Synthesis

Henrys et al. (in prep). This feature is also prominent on a low-fold reflection stack constructed along this transect using both onshore/offshore and onshore data (Henrys et al., in prep).

The apparent low Vp of this feature suggests that this may represent the pooling of subducted sediment material. Accreation of subducted sediment material into the overlying crust is evident in the Northern Hikurangi margin (e,.g. Sutherland et al., 2009; Bassett et al., 2010; Scherwath et al., 2010) where active source seismic imaging reveal a $\sim 7$ - $12 \mathrm{~km}$ low velocity hump beneath East Cape ridge and the Raukumara Ranges. At this locality, it is proposed that the down-dip extent of the underplating material is controlled by the Australian plate Moho, as the density contrast between the Moho and sediments of $\triangle \rho=0.8-1.1 \mathrm{~kg} / \mathrm{m}^{3}$ should prevent further subduction and result in the accretion of the sediment into the overlying Australian plate crust (Bassett et al., 2010). In contrast the subducted sedimentary body appears most prominent updip of the Moho/plate interface intersection on the SAHKE02 transect (Fig. 6.2). Evidence for subducted sedimentary material downdip of this prominent feature is provided by a single onshore-offshore wide-angle reflection phase and refractions that turn within the oceanic crust. However, this layer is far thinner $(1.5 \mathrm{~km})$ than the prominent bulge. The location of the sedimentary body may be related to the forces acting to drive Wanganui Basin subsidence. The Moho within Wanganui Basin is $\sim 15 \mathrm{~km}$ deeper than within Raukumara Basin and the lower crust is likely much denser. In this case, the neutral buoyancy level (i.e. where the density contrast between the subducted sedimentary material and adjacent material is sufficient to prevent further subduction) should be expected to reside updip of the plate interface/Moho intersection, closer to the position of the underplated sediment body.

One consequence of the accretion of subducted sedimentary material into the overlying crust is the application of equal and opposite forces above 
and below the accreted body (Fig. 6.3). The upwardly directed force, caused by the relative buoyancy of the accreted material, would be expected to drive rock uplift at the surface. Walcott (1987) was the first to propose such a force acting within the Hikurangi margin, in order to explain the broad regional warp-like uplift of the Axial Ranges, in light of minimal evidence for internal deformation. Results of both this study and those surrounding the Raukumara Basin (e.g. Sutherland., 2009; Bassett et al., 2010; Scherwarth et al., 2010) provide compelling evidence in support of this hypothesis. Given the similarity between the SAHKE02-M transect and those within Raukumara Basin, in addition to the pervasive nature of the Axial Ranges, it is proposed that this process may be characteristic of the entire Hikurangi margin.

For example, analogous to creating elevation by crustal thickening of the Moho, we can calculate the buoyancy due to the injection of low-density sediment into the mid-crustal region. Assuming local isostatic compensation, the uplift, $x$, expected from the accretion of an underlying sediment body of thickness $h$ can be calculated as

$$
h\left(\rho_{s}-\rho_{c}\right)=x \rho_{c}
$$

where $\rho_{s}$ is the density of the accreted sediment body and $\rho_{c}$ is the density of the crust in the region of the accreted body. Setting $h$ as 3.5 $\mathrm{km}$ and using standard values of $\rho_{s}$ and $\rho_{c}$ of $2.4 \mathrm{~kg} / \mathrm{m}^{3}$ and $2.8 \mathrm{~kg} / \mathrm{m}^{3}$ respectively, $x$ is calculated as $500 \mathrm{~m}$. This is about the average height of the Axial Ranges where maximum peaks reach $\sim 1500 \mathrm{~m}$.

Furthermore, the position of this body also appears to coincide with a "halo" of high microseismic activity within the underlying Pacific plate crust. Some of this seismicity is most plausibly caused by bending stresses related to the subduction process and dehydration reactions (e.g. Peacock and Wang, 1999). However, given this spatial relationship between these 
hypocenters and the accreted sedimentary material, it may be that loading stresses, applied in the opposite direction as that causing the rock uplift, are responsible for some of the earthquakes observed. A useful avenue for future research regarding this spatial correlation would be a detailed study of the focal mechanisms from these earthquakes. For the purpose of this analysis the original un-relocated GeoNet earthquake catalogue was used, as these lcoations are most consistent with the SAHKE02 velocity model, as discussed in section 6.10 .

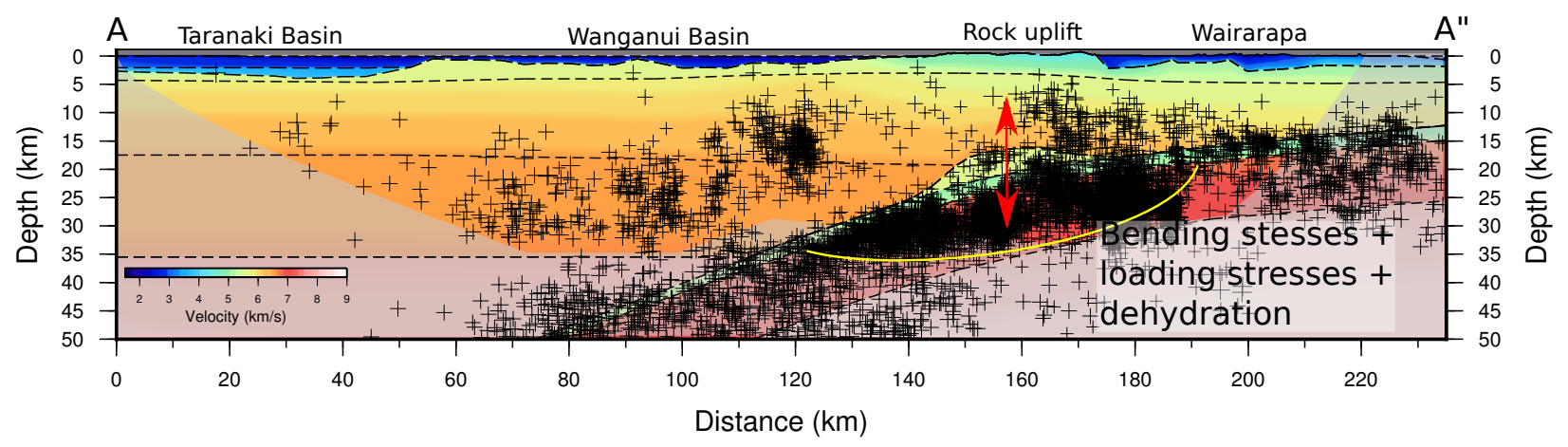

Figure 6.3: SAHKE02-M model overlain by swath of earthquakes projected from $25 \mathrm{~km}$ either side of the model line from the GeoNet earthquake catalogue (black crosses). Red arrows indicate the application of equal and opposite directed forces applied by the propsed underplated sediment body. These forces are postulated as partly responsible for the rock uplift of the Axial Ranges and the increased seismicity beneath the body, indicated by the yellow "halo" . A - A" shown on figure 5.1. The grey shaded area indicates the unconstrained region with no ray coverage.

\subsection{Pacific plate velocity structure}

The crust of the Pacific plate is modelled as two layers. The upper layer is sampled by reflections only. Following the results of previous studies (Chadwick, 1997; Bourne and Stuart, 2000; Savage et al., 2007; Ewig, 2009; Plaza Faverola et al., 2012 in review) this layer is modelled as a low velocity zone $\left(5-5.20 \mathrm{kms}^{-1}\right)$ interpreted as a subducted sediment channel. This layer is modelled as $\sim 3.5 \mathrm{~km}$ thick beneath the Tararua Ranges where the subducted sedimentary material is interpreted to be pooling. Even though 
reflections from the base of this layer are absent both up and downdip of the pooling material, travel-times of oceanic crust refractions indicate that the sediment channel is $\sim 2 \mathrm{~km}$ thick updip and $<1.5 \mathrm{~km}$ thick downdip. On the SAHKE03-M transect, a reflection recorded at station KIW is also modelled to be from the base of the sediment channel. The thickness derived from this phase, using equivalent velocities of $5-5.2 \mathrm{kms}^{-1}$ is $\sim 3 \mathrm{~km}$. This is twice as thick as on the SAHKE02-M transect, and this discrepancy may in part be due to travel-time pick error and/or variation in the thickness of this subducted sedimentary sheet along strike.

The underlying oceanic crust is sampled by uni-directional turning waves and Moho reflections. The turning waves bottom out within the first $\sim 3 \mathrm{~km}$ of this layer and constrain $\mathrm{Vp}$ as $6.7-6.8 \mathrm{kms}^{-1}$. Given the upper $\mathrm{Vp}$ constraint provided by refractions, resolution testing of the Moho reflection travel-times reveals that $\mathrm{Vp}$ gradients of $6.7-7.1 \mathrm{kms}^{-1}$ and $6.8-7.2 \mathrm{kms}^{-1}$ with a layer thickness of $\sim 10 \mathrm{~km}$ produce the best fit to the data. These velocities are consistent with those determined for the subducting oceanic crust in central and northern Hikurangi margin (e.g. Henrys et al., 2006; Scherwarth et al., 2009; Bassett et al., 2010). A thickness of $\sim 12-13 \mathrm{~km}$ for the crust of the subducting slab supports the idea that the anomalously thick crust of the Hikurangi Plateau has been subducted at least as far east as the Tararua Ranges. Thus, in contrast to the thick (18 - $23 \mathrm{~km}$ ) Hikurangi Plateau jamming at the Chatham Rise Gondwana suduction zone at $\sim 100$ Ma Davy et al., (2008) the present day subduction of the Hikurangi Plateau may not yet have choked the Hikurangi subduction zone.

\subsection{Taranaki-Ruapehu Line}

The onshore-offshore wide-angle reflection and refraction data collected at stations north of Taranaki-Ruapehu Line (TR-Line) (see Section 1.3.1.1) on 
6. Synthesis

the SAHKE03-M transect, place new constraints on the structure of this abrupt $(\sim 7-8 \mathrm{~km})$ step in Moho depth.

\subsubsection{Interpretation of seismic phase arrivals}

Receiver gathers recorded at stations S-KAI and TWVZ, north of the TRLine, both exhibit coherent, high amplitude arrivals at offsets up to $\sim 140$ and $135 \mathrm{~km}$ respectively, beyond which amplitudes decrease markedly (Figs. 6.4a and 6.5a). Viewed as instantaneous amplitude plots (Yilmaz, 2001), it is seen that the amplitudes of the high amplitude arrivals are at least twice as high as those of the adjacent low amplitude arrivals (Figs. 6.4b and 6.5b). 

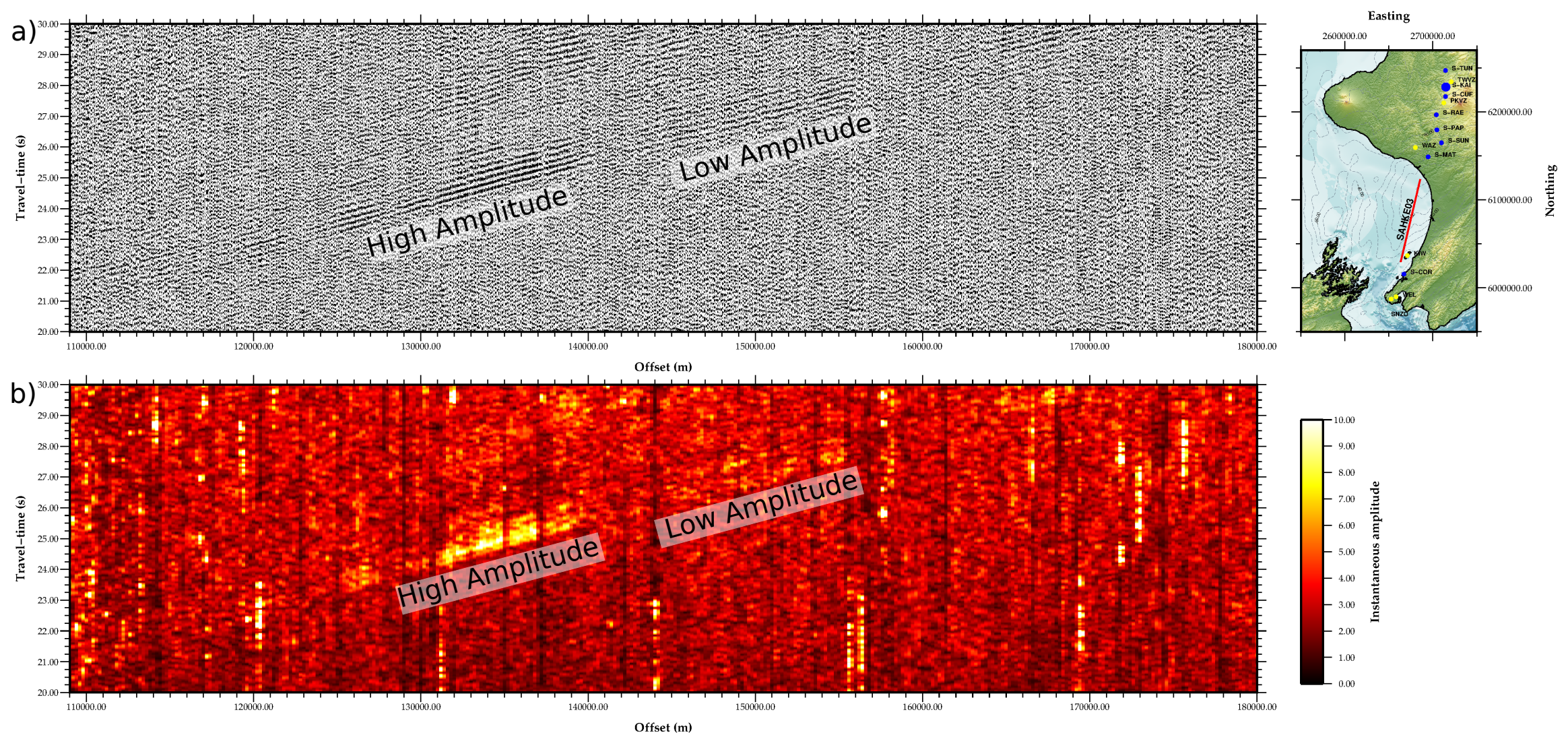

Figure 6.4: SAHKE03 receiver gather gather S-KAI (a) Receiver gather plotted in total travel-time and processed using a full trace length debias, [1 3 8 12] $\mathrm{Hz}$ bandpass filter and $3000 \mathrm{~ms}$ window length automatic gain control. (b) Same as in (a) however displayed as instantaneous amplitude. 
a)
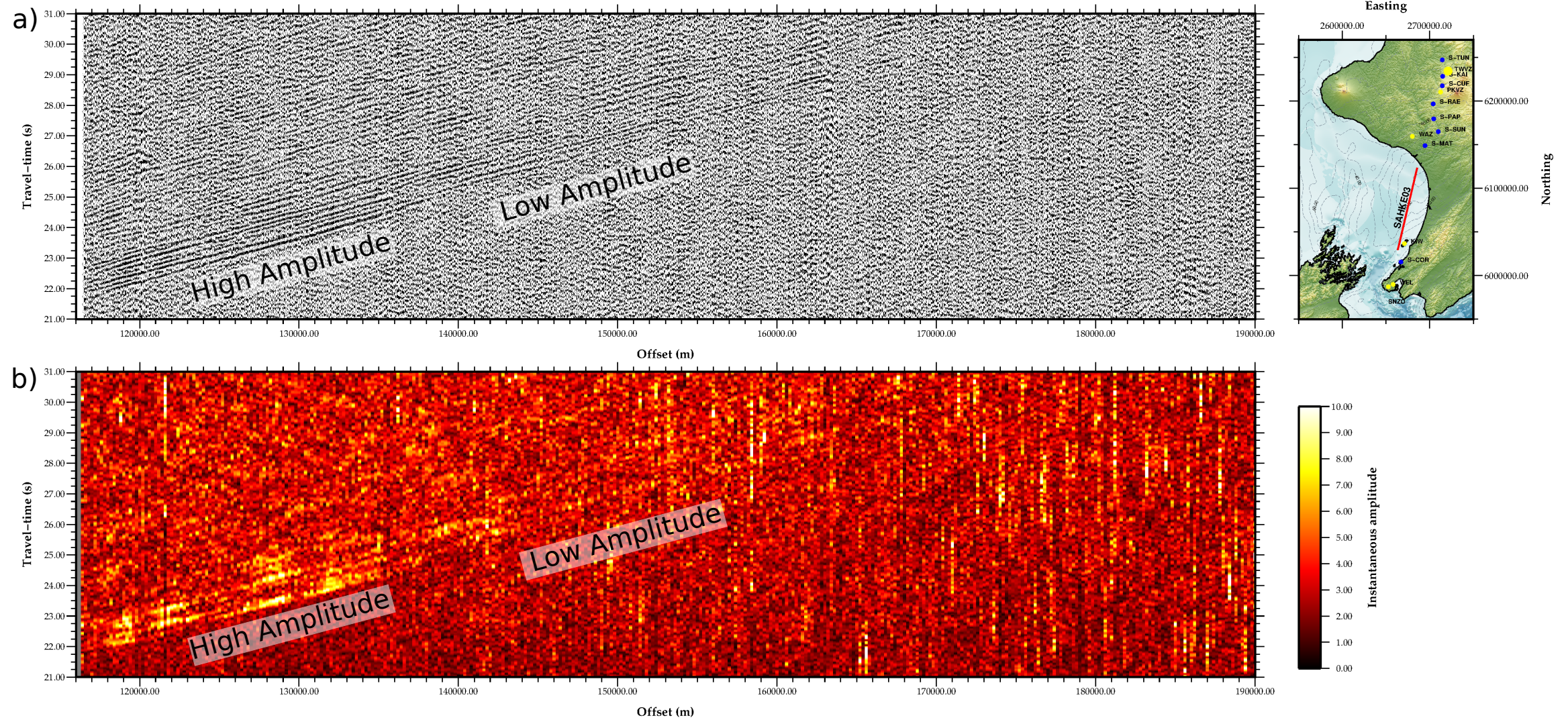

Figure 6.5: SAHKE03 receiver gather gather TWVZ (a) Receiver gather plotted in total travel-time and processed using a full trace length debias, [1 3 8 12] $\mathrm{Hz}$ bandpass filter and $3000 \mathrm{~ms}$ window length automatic gain control. (b) Same as in (a) however displayed as instantaneous amplitude. 
Given these stations are located $\sim 40 \mathrm{~km}$ north of the proposed position of the Taranaki-Ruapehu Line, one interpretation for these gathers is that the high amplitude arrivals are reflections from the Moho on the northern side of the Taranaki-Ruapehu Line, while the low amplitude arrivals are reflections from the Moho within Wanganui Basin. Analysis of upper mantle wave speeds, receiver functions and electric resistivity across the TRL suggest the mantle-lid is thinned or completely absent to the north (e.g. Horspool et al., 2006; Seward et al., 2009; Salmon et al., 2011). Receiver functions in particular, exhibit high amplitude conversions that may indicate a smooth interface and high velocity contrast in comparison to the more standard crust/mantle-lid boundary further to the south (Salmon et al., 2011). In this case, we may expect reflections from the Moho north of the TRL to also exhibit high amplitudes, compared to those to the south.

An alternative interpretation is that the low amplitude arrivals are diffractions from the edge of the proposed step in the Moho. When viewed at far offsets, diffraction arrivals from similar structures have been shown to display remarkably similar travel-time moveout to reflections (e.g. Stratford, 2006). Furthermore, the maximum amplitude of diffractions are half that of the reflected waves and these will also decrease with increasing offset (Sheriff and Geldart, 1995). If there arrivals were diffractions, they would also indicate a short lateral length for the TR-Line as diffractions only occur when the radius of curvature of the edge of the step is less than a few wavelengths of the incident wave (Lay and Wallace, 1995). Given the dominate frequency of these arrivals is $4-10 \mathrm{~Hz}$ and taking an average $\mathrm{Vp}$ of $6 \mathrm{kms}^{-1}$, wavelengths of $0.6-1.5 \mathrm{~km}$ are derived. Hence, a step with a lateral extent of no greater than $\sim 5 \mathrm{~km}$ would be required.

Assuming a vertical step is the diffractor, the travel-times expected for a diffraction from the edge of the step can be calculated using equation 6.2 . 
6. Synthesis

$$
\frac{1}{V_{r m s}} \times\left(\sqrt{h^{2}+a^{2}}+\sqrt{(x-a)^{2}+h^{2}}\right)
$$

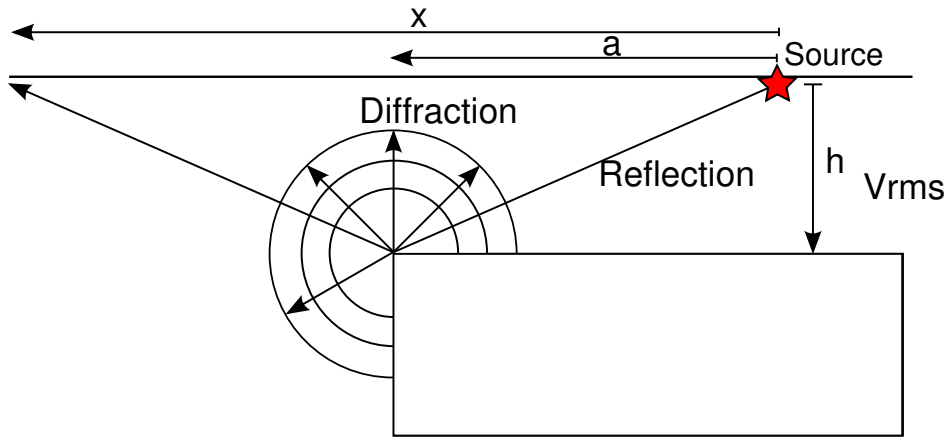

Figure 6.6: Cartoon illustrating the parameters of equation 6.2 (modified after Stratford, 2006).

where Vrms is the average velocity, $\mathrm{h}$ is the depth to the diffractor, a is the horizontal distance from source to diffractor and $\mathrm{x}$ is offset between source and receiver. Using Vrms of $6 \mathrm{kms}^{-1}$, and $\mathrm{h}$ of $25 \mathrm{~km}$, figure 6.7 shows the calculated travel-times for a diffraction from the TR-line at stations S-KAI and TWVZ respectively. At offsets where the proposed diffractions first appear, the calculated arrivals are virtually identical to those observed for station TWVZ. However, for station S-KAI and further offsets for TWVZ, diffractions clearly display a markedly different moveout velocity to the observed arrivals. It therefore seems unlikely that these arrivals are diffractions at station S-KAI. It is possible, however, that the arrivals between offsets of $140-150 \mathrm{~km}$ observed at TWVZ are diffractions.

One further interpretation for the high amplitude reflections is that they are from the Moho within Wanganui Basin, and the high amplitudes occur because the angle of incidence is close to the critical angle where the reflection coefficient reaches maximum (Kearey et al., 2002). However, ray tracing clearly shows that the travel-times of these events on station S-KAI cannot be reflections from the Moho within Wanganui Basin, ruling out this 

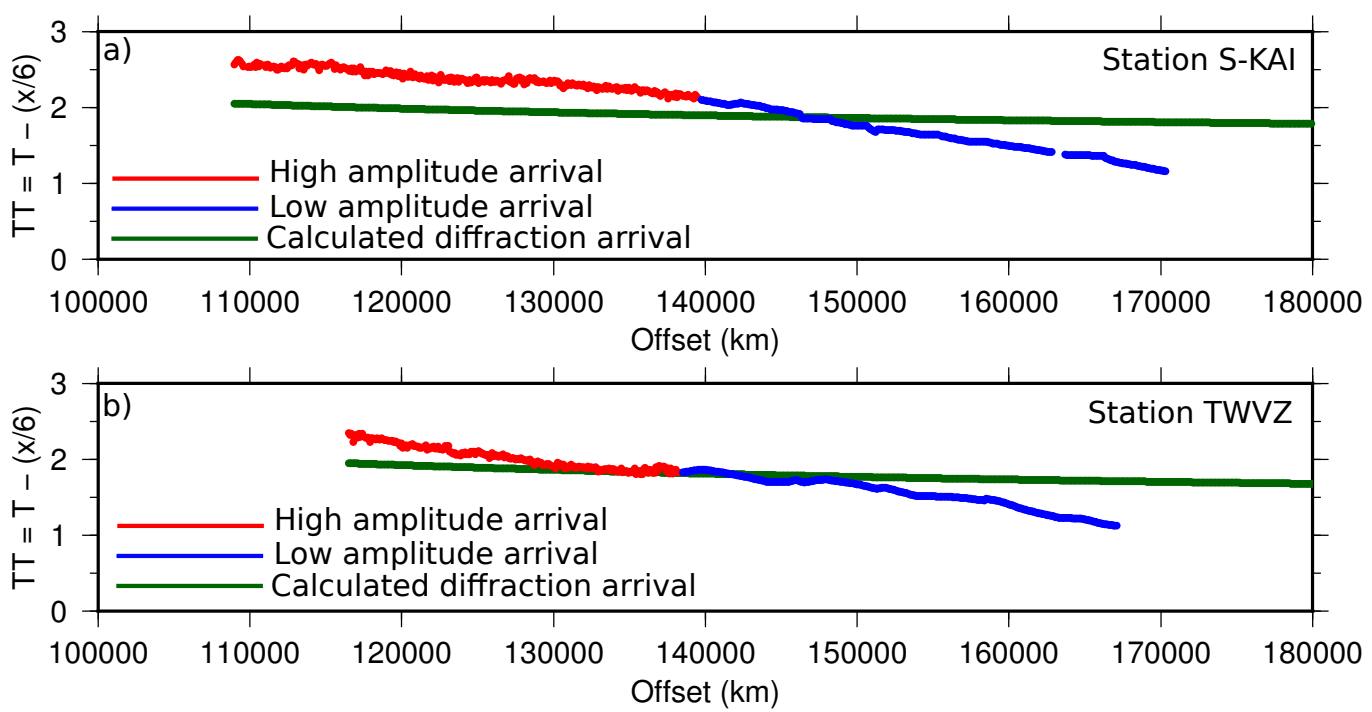

Figure 6.7: Calculated travel-times for a diffraction from an edge. a) Travel-time arrivals (as labelled) for station S-KAI. b) same as in (a) but for station TWVZ.

interpretation.

Thus, the preferred interpretation is that the high amplitude arrivals are reflections from the Moho north of the Taranaki-Ruapehu Line, while the low amplitude arrivals are from the Moho within Wanganui Basin, and may also be diffractions on gather TWVZ. In this case, the model developed in this thesis places new constraints on the geometry and location of the proposed TR-line Moho step as the step must occur over a lateral distance of $<30 \mathrm{~km}$, with a step of $7 \pm 3 \mathrm{~km}$. Furthermore the step must be located at the southern limit of seismicity associated with the TR-Line (at $\sim 220$ km Fig. 6.1).

\subsubsection{Seismicity related to the Taranaki-Ruapehu Line}

The final SAHKE03-M model clearly locates the Taranaki-Ruapehu Line Moho step near an area of increased microseismicity that spans a lateral distance $\sim 40 \mathrm{~km}$, where hypocenters reach depths as great as $45 \mathrm{~km}$ (Fig. 6.1). This relationship has been noted by several previous authors (e.g. 
6. Synthesis

Hatherton, 1970; Reyners, 1980; Stern et al., 1987; 2006; 2010; Sherburn and White, 2005; Salmon et al., 2011). Sherburn and White (2005) argued that the step in the Moho is positioned north of this seismicity, allowing all of the earthquakes to be constrained within thicker crust on the southern side of the step. In contrast, the model developed in this study requires the step to be located at the southern limit of seismicity. This supports the interpretation of Salmon et al., (2011) that earthquakes are located within both the lower crust and upper mantle. Earthquakes in the lower crust and upper mantle are rare in non-cratonic regions of continental crust and when deep seismicity has been detected, there has been a debate about whether these are really in the uppermost mantle rather than the lower crust (e.g. Chen and Molnar 1983; Maggi et al., 2000; Burov and Watts, 2006; Jackson et al., 2008). This is because it is unclear whether the deep seismicity is an indication that the strength of the continental lithosphere resides mainly in the seismogenic crust or extends into the mantle (Jackson et al., 2008). It is clear the the microseismicity in the vicinity of the TR-Line occurs through the entire lower crust as well as in the upper $20 \mathrm{~km}$ of the mantle.

The occurrence of earthquakes in the upper mantle north of the TR-Line is very surprising given that is has been proposed, based on magnetotelluric data, that the mantle-lid has been replaced by hot $\left(\sim 900^{\circ} \mathrm{C}\right)$ and buoyant asthenosphere (Salmon et al., 2011). At this temperature, experimental rock mechanics suggest these rocks should be well into the ductile creep regime. One explanation for these earthquakes (see Stern et al., 2012, in review) is that strain rates are sufficiently high for brittle failure to occur even at temperatures above $900^{\circ} \mathrm{C}$, similar to what has been observed at some rift margins (e.g. Keir et al., 2009; Lindenfeld and Rümpker, 2011). For example, figure 6.8 shows different yields strengths predicted for continental lithosphere based on high and low strain rates of $10^{-10}$ and $10^{-18} \mathrm{~s}^{-1}$ (after Watts, 2001). This shows that even at depths of $>80 \mathrm{~km}$ brittle failure is possible given a high strain rate (Fig.6.8). Strain rates as great as $10^{-13}$ 
$s^{-1}$ are one consequence predicted from the convective removal of mantle lithosphere in western North Island and hence this process may offer an explanation for these earthquakes (Stern et al., 2012 in review).

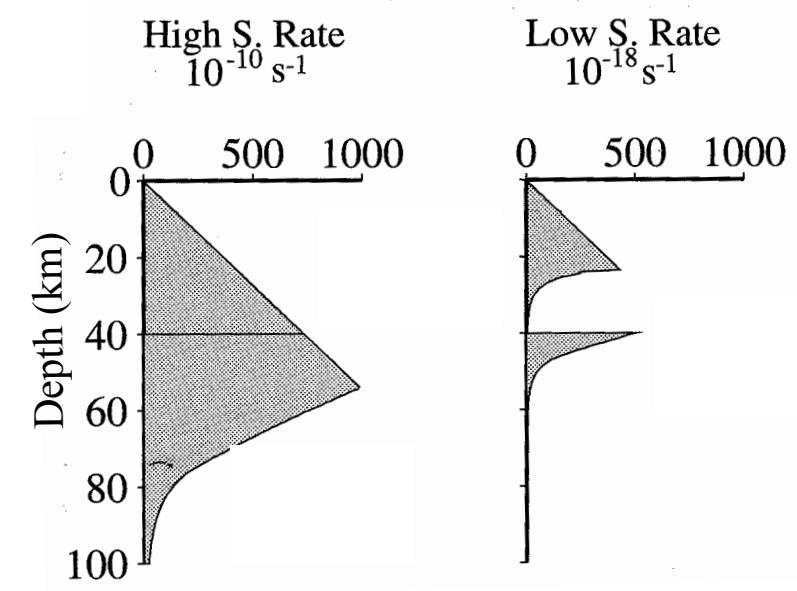

Figure 6.8: Yield strength envelopes for a standard continental crust (anorthosite crust and olivine mantle) when subject to high and low strain rates (after Watts, 2001).

However, global positioning system measurements indicate that strain rates are an order of magnitude lower in this area, with a maximum shear strain rate of 10aaaaa citebeavanhaines2001.

\subsubsection{Geological evolution of the Taranaki-Ruapehu Line}

Two fundamental questions regarding the TR-Line are when and how did this step develop? In this section three alternative ideas regarding the evolution of the TR-Line are discussed, although at this stage it is not possible to draw any definitive conclusions.

The TR-Line approximately coincides with the onshore extension of the southern edge of New Caledonia Trough (Fig. 1.1). Given this spatial correlation, one possibility is that this step is a remnant feature from the 
6. Synthesis

formation of the New Caledonia Trough. The New Caledonia Trough is thought to be a failed rift basin that developed in the Cretaceous during the final stages of Gondwana breakup (Uruski and Wood, 1991). However, it has been recently proposed that Eocene-Oligocene lithospheric delamination, related to the initiation of the Australian-Pacific plate boundary, played a major role in forming the New Caledonia Trough (Hackney et al., 2012; Sutherland et al., 2010). Paleomagnetic data (Lamb, 2011) indicate significant clockwise vertical axis rotation of western North Island of up to $30 \circ$ in the Oligocene. So the precise timing of the formation of the New Caledonia trough is critical in determining whether any potential extension within western North Island (i.e. the TR-Line) would have undergone any rotation. If the TR-Line is a remnant of New Caledonia trough extension, this suggests no rotation has occurred. Thus, this physiographic relationship remains an intriguing prospect that deserves further investigation in the future.

Another avenue for assessing potential origins of the TR-Line is by comparison with similar features elsewhere in the world. Steps in the Moho are rare, but have been observed in cratonic regions such as Australia (e.g. Lambeck and Burgess, 1992) where the strength of the continental crust is thought to be strong enough to support steps on Gyr timescales. Where steps have been observed within non-cratonic regions, they are normally associated with strike-slip/transcurrent faults where crust of contrasting thickness has been juxtaposed (e.g. Wittlinger et al., 2004). Kusznir and Matthews (1988) suggest that over time we may expect sharp vertical steps created by strike-slip faulting to be smoothed out given the expected strength of the lower crust, such that a longer wavelength structure is achieved. This will occur presumably by both ductile flow and brittle failure as a result of large horizontal deviatoric stresses that would develop due to different gravitational potential energy between the two contrasting lithospheric blocks (e.g. Platt and England, 1993). For example, Stern and McBride (1998) note that there is evidence for localised crustal thickening 
preserved in ancient ( > $100 \mathrm{Ma}$ ) old strike-slip zones, though the amplitude is much reduced compared to contemporary strike-slip zones such as in southern California. It is indeed possible that the earthquakes surrounding the TR-Line are caused by this process of Moho "relaxation". There is no direct evidence, however, that a strike-slip fault system trending at the orientation of the TR-Line has ever existed, and hence a different explanation is required for the TR-Line.

Given the spatial correlation between the TR-Line and the boundary between extension to the north and compression to the south in western North Island (see Chapter One), it has long been thought that these phenomena may be interrelated. One hypothesis linking these phenomena is that the TR-Line is a dynamic feature related to the convective removal of mantle lithosphere within Western North Island (Stern et al., 2012 in review). These authors argue that in the mid to late Miocene the rapid migration of the Hikurangi Margin and resulting transtensional motion through central North Island (e.g. Lamb, 2011), would have resulted in the juxtaposition of lithosphere of varying thickness, with thick lithosphere west of the boundary and thin lithosphere to the east. When an initial lithospheric edge-instability such as this is present, it has been shown that the convective removal of the mantle lithosphere can be achieved providing mantle viscosities are of the order of $5 \times 10^{20} \mathrm{~Pa}$ s. In this case, the Taranaki-Ruapehu Line represents the current position of such an edge instability, that has migrated southward from its initial location and approximately north-south orientation adjacent to the plate boundary in the mid Miocene. This involves a complex three-dimensional evolution for the convective removal of the lithosphere and the position of the Taranaki-Ruapehu Line. Further research into the both the kinematics and mechanics of the TR-Lines evolution is required in order to further explain and test this hypothesis. 
6. Synthesis

\subsection{Comparison of $\mathrm{P}$-wave velocity models and earthquake catalogues}

Modelling of the forces and geodynamic processes that operate within subduction zones and back-arc basins usually requires detailed knowledge of the structure and geometry of the subducting oceanic plate. In the absence of constraints from seismic imaging or other geophysical surveys, the top of the WadatiBenioff zone - the zone of seismicity associated with the subducting plate, henceforth referred to as the Benioff zone - is often used as a proxy for the plate interface. This assumes that earthquakes that define the top of this zone, occur at or near the plate interface. However, errors in the depth to the plate interface of as little as $<2 \mathrm{~km}$ can have large effects on model results. Furthermore, observations in other subduction zones suggest the top of the Benioff zone can be either above or below the plate interface and can also vary downdip within a single subduction zone (e.g. Abers et al., 2006; MacKenzie et al., 2010). The two Vp models developed in this study allow the relationship between the "seismically-defined" plate interface and Benioff zone in the southern Hikurangi margin to be closely examined.

The geometry of the plate interface beneath Wanganui Basin places initial constraints on geodynamic models of basin subsidence. For example, Stern et al., (1992) correlated the area of highest loading, obtained using flexural modelling, with the longest and most laterally continuous section of the plate interface defined by an earthquake inversion scheme (Smith et al., 1989). These authors used this correlation to propose a causal relationship between fictional coupling at the plate interface and the downwarpping of the Wanganui Basin. Similarly, Ewig (2009) used the plate interface geometry determined by Ansell and Bannister (1996) using microseismicity hypocenters for three dimensional modelling of the Wanganui Basin gravity field. The gravity field can be severely perturbed by variations 
6.10. Comparison of P-wave velocity models and earthquake catalogues

in the strike and dip of the plate interface as well as the thickness of the subducting oceanic crust. Furthermore, force balance calculations of the shear stress across the plate interface (Lamb, 2006) and geodetically derived frictional coupling at the plate interface (Darby and Beavan, 2001) have both relied on the geometry of the plate interface defined by the Benioff zone.

The crustal scale velocity models developed in this thesis provide the first active source seismic constraints on the geometry and depth of the plate interface within Wanganui Basin. These models therefore provide the best constraints available to assess whether the Benioff zone is a viable proxy for the geometry of the plate interface in this area. Figures 6.9 and 6.10 show comparisons for the Benioff zone defined using; (a) seismicity from the freely available GeoNet earthquake catalogue for the time period January 2001 March 2010 (b) a relocated earthquake catalogue for the same time period as in (a) using the nationwide tomography model of Eberhart-Phillips et al., (2010) supplied by Martin Reyners (pers. Comms. 2011) (c) the same earthquake catalogue is in (b) however with a static shift of $-5 \mathrm{~km}$ applied (d) the same earthquake catalogue is in (b) however with a static shift of -7 $\mathrm{km}$ applied. Each profile contains swath of earthquakes from $25 \mathrm{~km}$ either side of the model transects. 


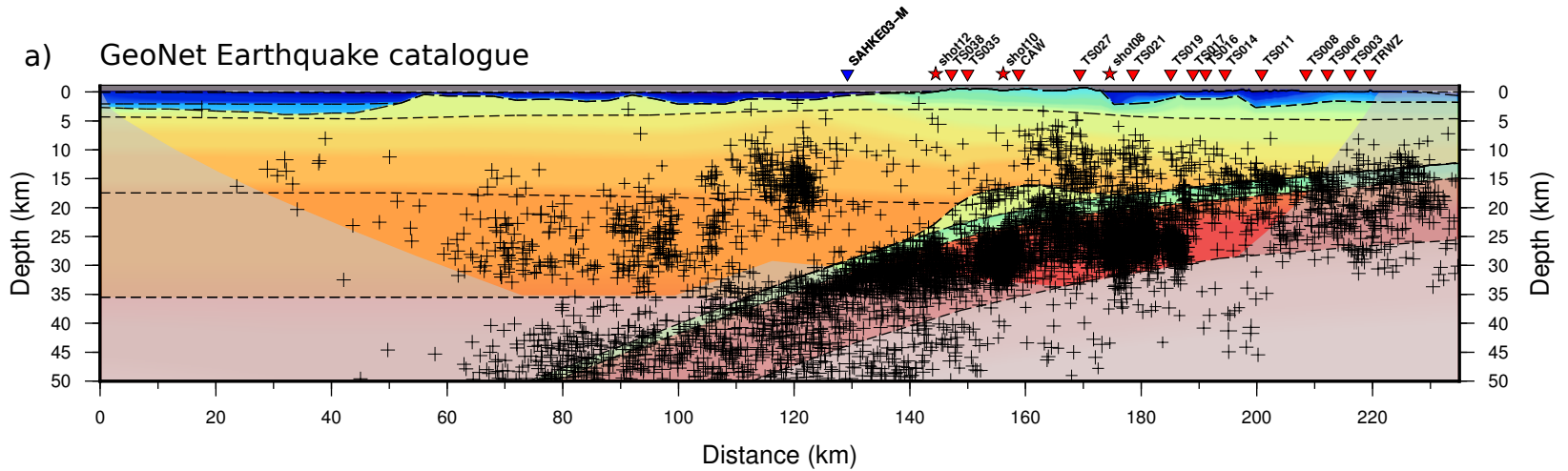

b) Relocated seismicity using Eberhart

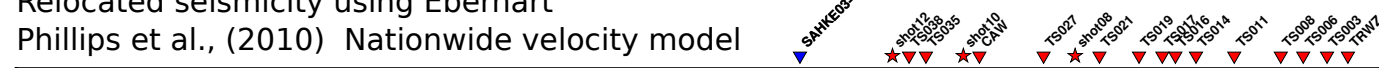

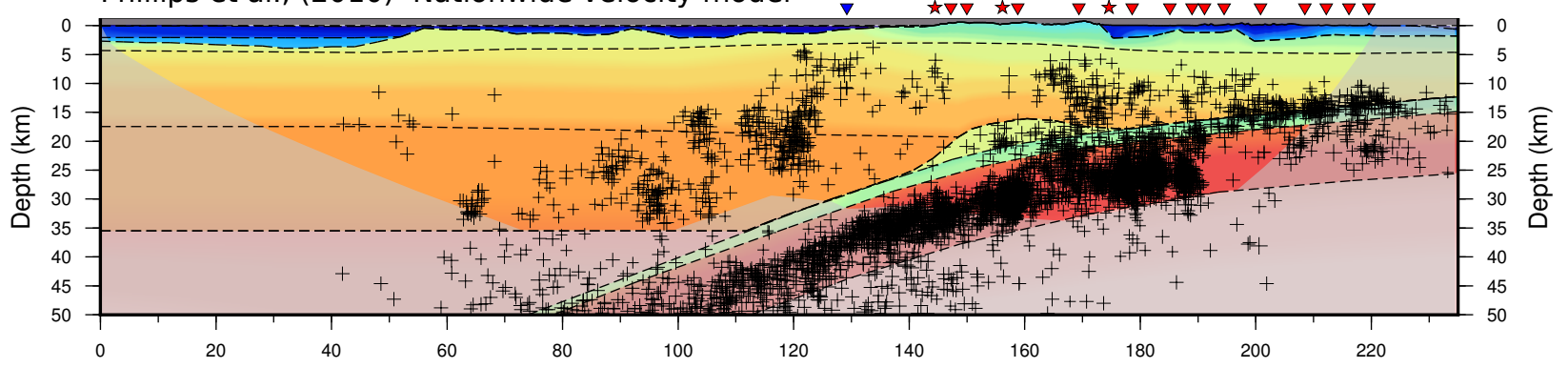

c) Relocated seismicity - $5 \mathrm{~km}$ static shift Distance $(\mathrm{km})$
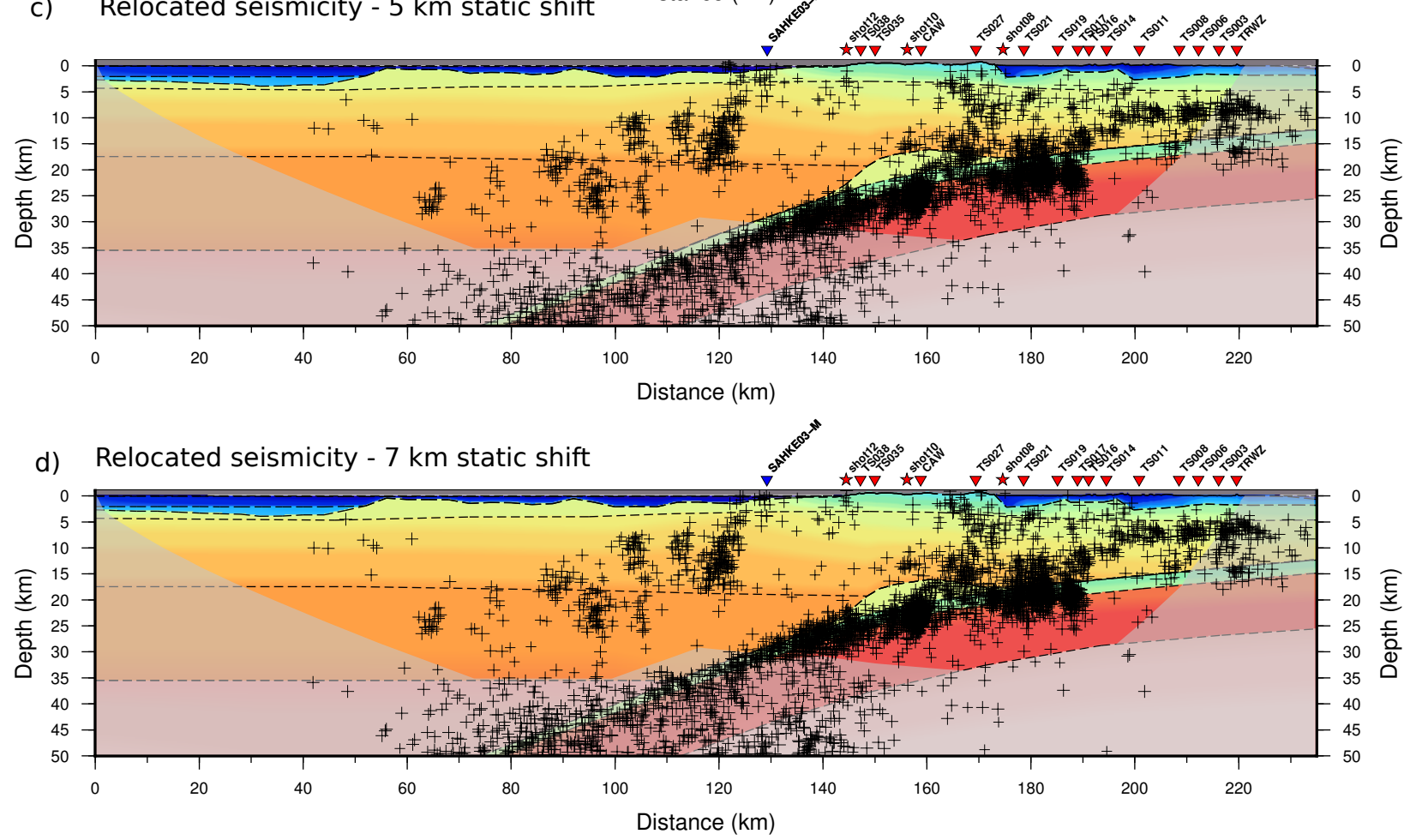

Figure 6.9: a) SAHKE02-M P-wave velocity model overlain by earthquakes from $25 \mathrm{~km}$ either side of the model line recorded between January 2001 and March 2011, sourced from the freely available GeoNet earthquake catalogue (black crosses). b) Same as in (a) but with earthquake hypocenters relocated using the nation wide 3D velocity model of Eberhart-Phillips et al. (2010), supplied by Martin Reyners.(M. Reyners, personal communication, 21 November 2011) c) Same as in (b) but with a - $5 \mathrm{~km}$ static shift applied to hypocenters. d) Same as in (b) but with a $-7 \mathrm{~km}$ static shift applied to hypocenters. A - A" shown on figure 5.1. The grey shaded area indicates the unconstrained region with no ray coverage. 
a) GeoNet Earthquake catalogue

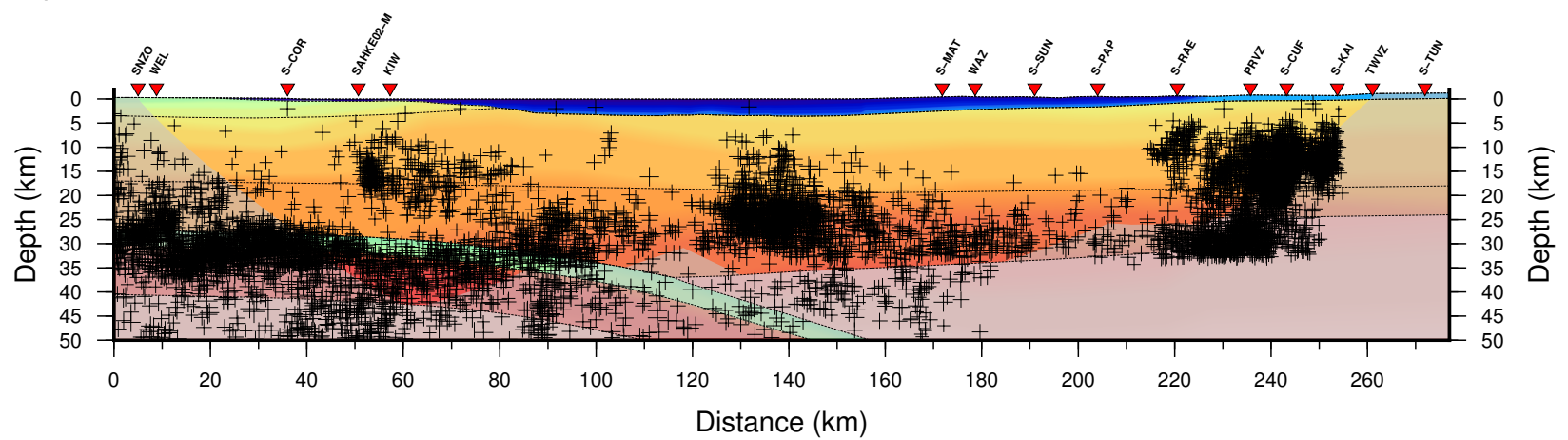

b) Relocated seismicity using Eberhart

Phillips et al., (2010) Nationwide velocity model

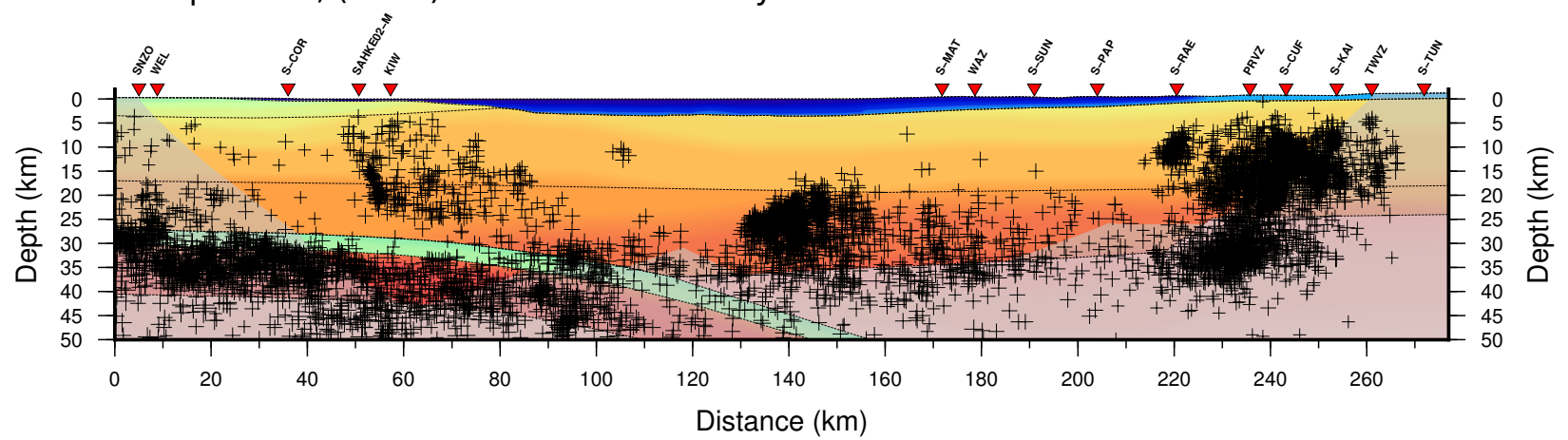

c) Relocated seismicity - $5 \mathrm{~km}$ static shift

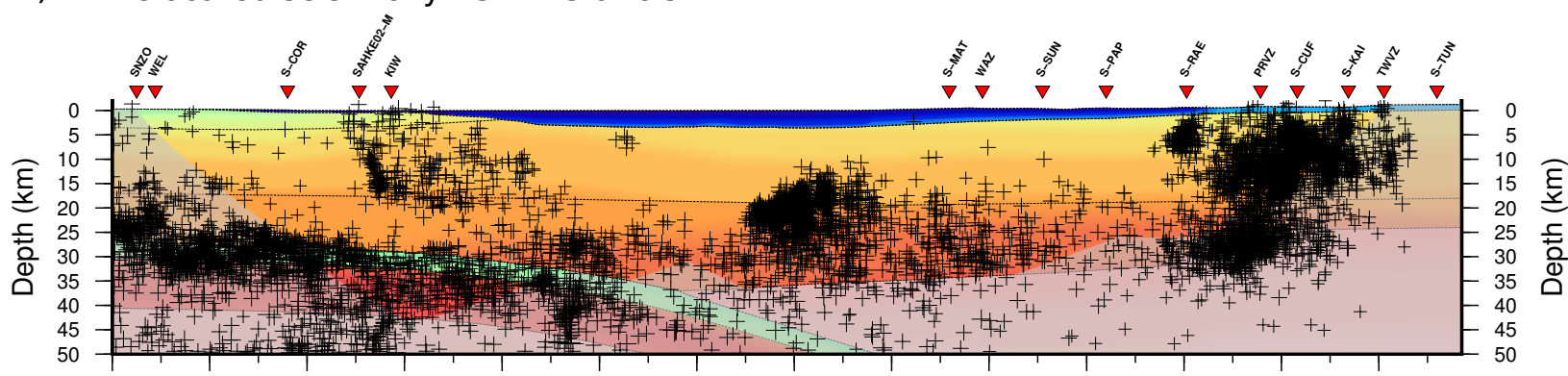

d) Relocated seismicity - $7 \mathrm{~km}$ static shift

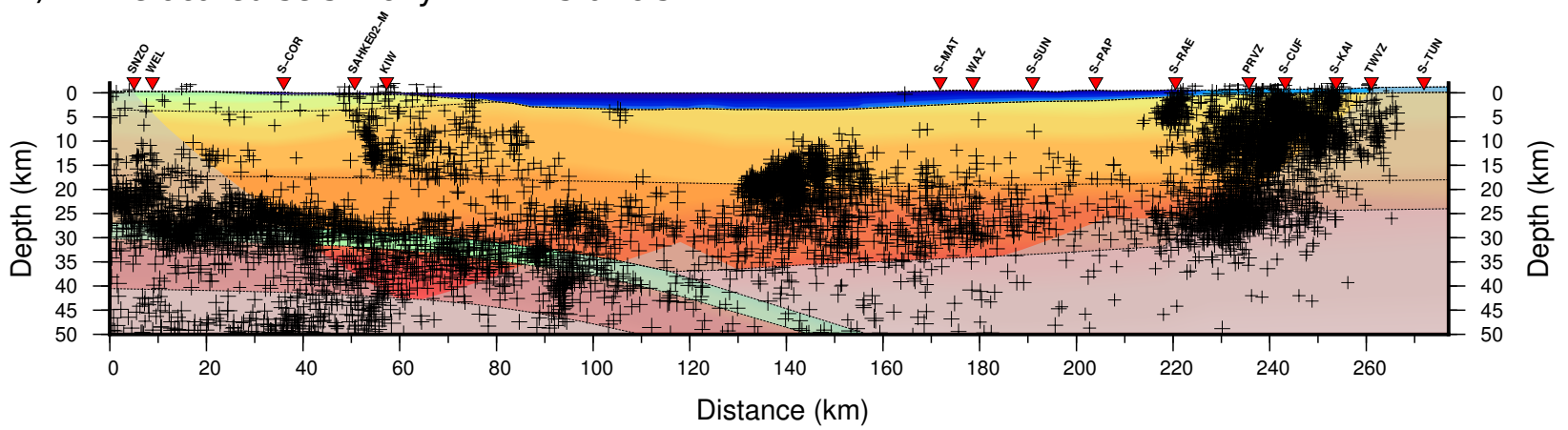

Figure 6.10: a) SAHKE03-M P-wave velocity model overlain by earthquakes from $25 \mathrm{~km}$ either side of the model line recorded between January 2001 and March 2011, sourced from the freely available GeoNet earthquake catalogue (black crosses). b) Same as in (a) but with earthquake hypocenters relocated using the nation wide 3D velocity model of Eberhart-Phillips et al. (2010), supplied by Martin Reyners.(M. Reyners, personal communication, 21 November 2011) c) Same as in (b) but with a - $5 \mathrm{~km}$ static shift applied to hypocenters. d) Same as in (b) but with a - $7 \mathrm{~km}$ static shift applied to hypocenters. A - A shown on figure 4.1. The grey shaded area indicates the unconstrained region with no ray coverage. 
6. Synthesis

These figures demonstrate that the Benioff zone from the GeoNet earthquake catalogue (Figs. $6.9 \mathrm{a}$ and 6.10a) defines a plate interface that is in good agreement with the models developed in this thesis. This validates the use of this earthquake catalogue as a viable proxy for the three-dimensional structure of the plate interface within Wanganui Basin.

Interestingly, the relocated GeoNet earthquake catalogue $(6.9 \mathrm{~b}$ and 6.10b) exhibits a less scattered Benioff zone compared to the original (Figs. 6.9a and 6.10a) that parallels the plate interface defined in this model with an offset of $\sim-4--5 \mathrm{~km}$. Figures $6.9 \mathrm{c}, \mathrm{d}$ and $6.10 \mathrm{c}, \mathrm{d}$ show the same relocated earthquake catalogue, with a static shift of -5 and $-7 \mathrm{~km}$ applied to hypocenter depths respectively. The catalogue with a $-5 \mathrm{~km}$ static shift applied is in good agreement with the Vp models, particularity the SAHKE02-M dip-section (Fig 6.9). Assuming the plate interface determined in this study is accurate, there are two possibilities for this static shift. The first is that seismicity within the subducting plate is confined to a region $\sim 5 \mathrm{~km}$ below the plate interface. This seems unlikely given that geodetic analysis suggests the plate interface is partially locked in southern North Island (e.g. Walcott 1987; Wallace et al., 2004, 2009, 2010, 2012), in which case we would expect microseismicity at the plate interface. The second is that this static shift is a result of a systematic offset in hypocenter locations caused by a systematic error in the velocity model used for locating the earthquakes. As discussed in Sections 4.9 and 5.7, the $\mathrm{Vp}$ values in the upper $5 \mathrm{~km}$ of the models developed in this thesis $\left(\sim 1.7-5.5 \mathrm{kms}^{-1}\right)$ are significantly lower than those of coincident slices through the Eberhart-Phillips et al., (2010) tomography model $\left(\sim 4.5-5.5 \mathrm{kms}^{-1}\right)$ where sedimentary fill is present. One obvious effect of high near surface velocities when determining crust structure is the over estimation of interface depths, as discussed in Section 3.8. The same relationship holds true for earthquake hypocenter locations, and hence the high near surface velocities in the Eberhart-Phillips et al., (2010) tomography model are likely to be a significant contributing factor 
6.11. Application of $\mathrm{Vp}$ model for elastic dislocation modelling of continuous GPS data

to the mismatch between earthquake hypocenters and the slipping plate interface.

The high near surface velocities in the Eberhart-Phillips et al., (2010) model are probably due to the coarse node spacing $(\sim 8 \mathrm{~km})$ and the smoothing of faster, deeper velocities over the near surface velocities. Therefore, fixing a near surface low velocity zone, perhaps $3 \mathrm{~km}$ thick with a Vp of $2.5 \mathrm{kms}^{-1}$ may improve the velocity model for future earthquake location analysis. Furthermore, although the relocated catalogue undoubtedly reduces the smear of seismicity in the Benioff zone compared to the GeoNet catalogue, it seems the GeoNet catalogue better defines the Benioff zone and plate interface.

\subsection{Application of $\mathrm{Vp}$ model for elastic dis- location modelling of continuous GPS data}

Using the geometry of the subduction interface derived in this thesis, standard elastic dislocation theory has been used to model the elastic deformation signal recorded during the last 5 - 10 years at nine continuous Global Positioning System (cGPS) stations located in the vicinity of the SAHKE02-M transect (Simon Lamb, personal communication 02/07/2011).

This work shows that by defining a single "locking point" (i.e. the plate interface is assumed freely slipping downdip and fully coupled updip), the predicted elastic velocity field demonstrates an extremely good fit of all three cGPS components along the SAHKE02-M line (i.e. marginal-normal shear, marginal-parallel shortening and vertical motion) (Simon Lamb, personal communication $02 / 07 / 2011$ ). The locking point that provides the best fit is located $\sim 1 \mathrm{~km}$ offshore of the west coast of North Island at $\sim$ 
$25 \mathrm{~km}$ depth (Fig. 6.11). Thus, this provides independent corroborating evidence that the geometry of the plate interface determined in this thesis is a reasonable representation of this surface.

It is noted, however, that in order to fit the vertical component recorded at station KIW, located on Kapiti Island, the addition of an artificial slow-slip-earthquake (SSE) with a coupling factor of 0.4 is required offshore of the west coast (Fig. 6.11). The coupling factor describes a portion of relative plate convergence, where a value of 0 implies the plates are freely slipping and a value of 1 implies they are fully locked. SSEs have been documented in this area in the recent past (Wallace and Beavan, 2010), and this result suggests we may except to see a similar event in the near future.

Two spatial relationships are evident from figure 6.11. The first is that the locking point coincides with the downdip limit of the pooling underplated sedimentary material constrained by PiP reflections. The second is that the landward extent of displacement predicted for SSEs coincides with the intersection between the Moho and subducting plate. These spatial correlations suggest that the rheological changes at these points may be important in modulating both mega-thrust and the extent of SSEs within the southern Hikurangi margin. Investigation into the implications of these spatial relationships provides an exciting avenue for future study. 


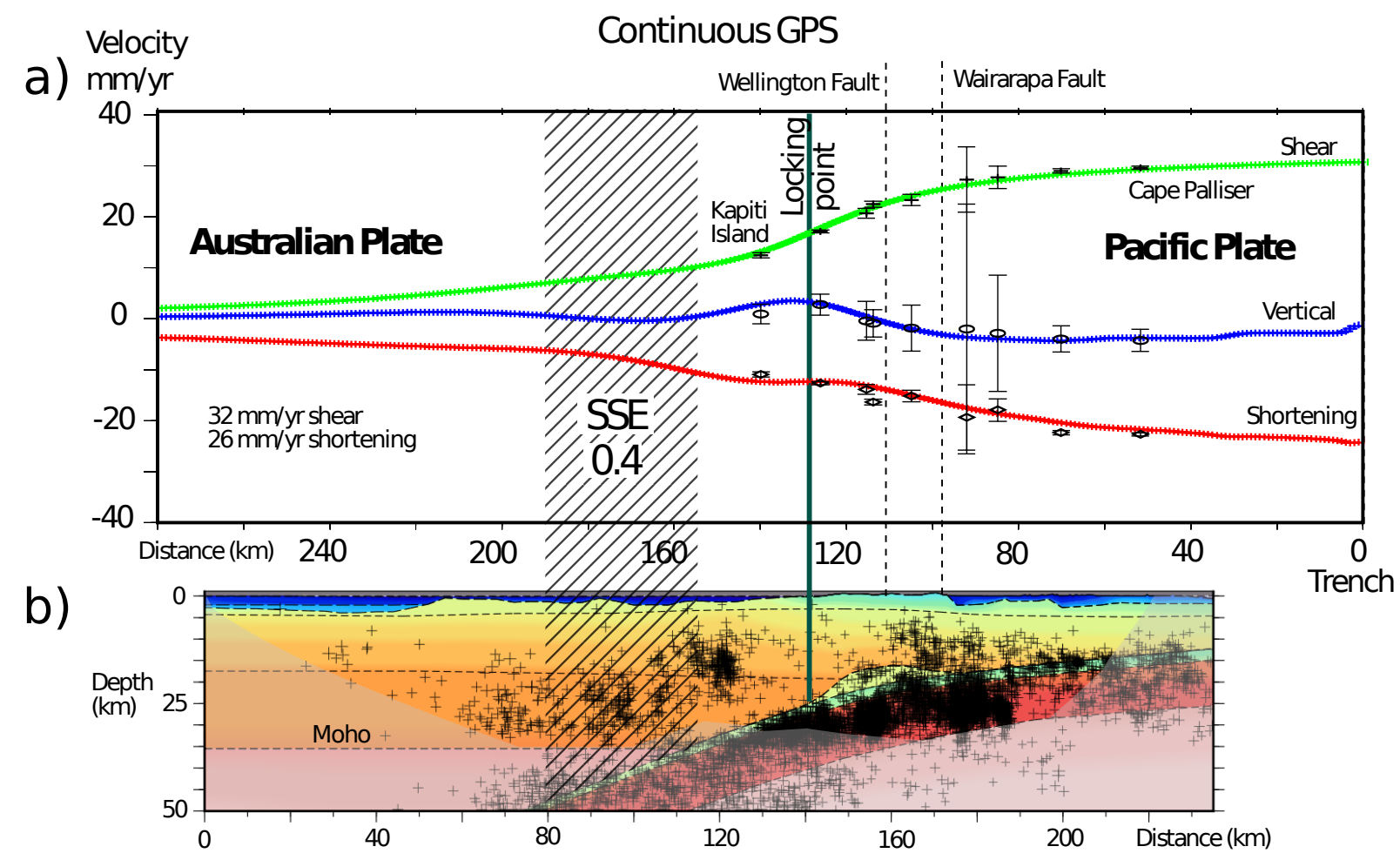

Figure 6.11: a) Elastic dislocation modelling solution along the SAHKE02-M transect assuming the geometry of the plate interface determined for the P-wave velocity model shown in (b) and a locking position at the point labelled. Updip of this point the plate interface is considered completely locked while downdip is considered freely slipping. b) Final SAHKE02-M P-wave velocity model developed in Chapter 5. Black crosses are earthqaukes from $25 \mathrm{~km}$ either side of the model line recorded between January 2001 and March 2011, sourced from the freely available GeoNet earthquake catalogue. The hatched black area defines the region where a future SSE with a coupling factor of 0.4 is required in order to fir the vertical cGPS component at station KIW.

\subsection{Conclusions}

- Modelling of wide-angle refraction and reflection seismic data confirms that the crust within Wanganui Basin is anomalously thick, with the Australian plate Moho reaching a maximum thickness of $\sim 36.5 \pm 1.5$ $\mathrm{km}$ in center of the basin.

- The Australian plate Moho interpreted on a multi-channel-seismic re- 
6. Synthesis

flection stack is up to $\sim 5 \mathrm{~km}$ deeper than that determined using wideangle data. In this case, the Moho may be considered to extend to a depth of $41.5 \mathrm{~km}$.

- The presence of a step in the Moho at the Taranaki-Ruapehu Line is confirmed. The vertical offset at the step is resolved as $7 \pm 3 \mathrm{~km}$ over a lateral distance $<30 \mathrm{~km}$.

- The interpretation of two deep reflection phases, with a small traveltime differential, that are visible on both onshore-offshore and onshore gathers, supports the presence of a subducted low velocity sedimentary layer within the southern Hikurangi margin.

- The thickness of the subducting Oceanic crust is constrained as 12 - 13 $\mathrm{km}$. This suggests that the anomalously thick Hikurangi Plateau crust has been subducted at least as far east as the Tararua Ranges.

- The Australian/Pacific plate interface is modelled as a relatively smooth surface, with the exception of a low velocity sediment body, located between between Featherston and Kapiti Island. This body reaches a maximum thickness of $\sim 3.5 \mathrm{~km}$ (with an additional $2 \mathrm{~km}$ of subducting sedimentary material beneath) and is capable of driving at least $500 \mathrm{~m}$ of rock uplift at the surface.

- Modelling of the elastic deformation signal recorded at cGPS stations in the vicinity of the SAHKE02-M transect suggests that (1) The downdip limit of accreted sedimentary material beneath the Wellington region coincides with the eastward limit of plate locking and (2) the downdip limit of plate locking coincides with the plate interface/Australian plate Moho intersection. 


\subsection{Future research}

The Vp models developed in this thesis place new constraints on the crustal structure within Wanganui Basin and southern Hikurangi margin. The interaction between the subducting Pacific plate, the thickened crust (and lithosphere) and TR-Line Moho step, does, however, present a complex three-dimensional problem. Many avenues for future research exist in this area and further geophysical investigation will be required to better our understanding of the tectonic processes operating here.

Furthermore, the interpretation of seismic data in this thesis has been limited to $\mathrm{P}$-wave travel-time analysis and this dataset presents the potential for many future studies.

\section{S-wave arrivals}

Several of the receiver gathers analysed in this thesis exhibit seismic phases interpreted as S-wave refractions ( $\mathrm{Sg}$ ) and Moho reflections ( $\mathrm{SmS}$ or $\mathrm{PmS}$ ). Although these data are limited in offset range, modelling of these phases, coupled with the P-wave analysis conducted in this thesis, will allow for the first controlled source $\mathrm{Vp} / \mathrm{Vs}$ analysis in this area. $\mathrm{Vp} / \mathrm{Vs}$ ratios provide more insight into the physical properties and petrology of rocks than $\mathrm{Vp}$ alone and may be useful for assessing the presence of fluids as predicted in the lower crust of Wanganui Basin (e.g. Reyners et al., 2006; Ewig, 2009).

\section{Seismic reflection processing of multi-channel-seismic data}

The multi-channel-seismic brute stacks that were interpreted in this study (Figs. 4.20 and 5.12) exhibit coherent reflectivity at depths as great as $\sim$ $14.5 \mathrm{~s}$ two-way travel-time. Targeted processing that attempts to accentuate this deep reflectivity may provide important constraints on both the structure of the Australian plate Moho and subducting Pacific plate interface. 
6. Synthesis

\section{Gravity modelling of the Wanganui Basin gravity anomaly}

Constraints placed on the crustal and lithospheric structure within Wanganui Basin by the Vp models developed in this thesis, will facilitate the re-modelling of the Wanganui Basin gravity field. Limiting the allowable thickness of both the Australian plate crust and subducting Pacific plate crust will allow for a more robust assessment of other variables that effect the isostatic/freeair gravity anomaly e.g. the depth of the eclogite transition in the subduction slab.

\section{Waveform Modelling}

Full waveform modelling of seismic phases interpreted in this thesis will facilitate a greater understanding of the physical properties of interfaces such as the Australian/Pacific plate interface and will also provide a robust assessment for the presence of a low velocity sedimentary sheet at the top of the subducting Pacific plate.

\section{Future surveys - the Taranaki-Ruapehu Line}

The origin of the TR-Line remains an intriguing question and a better understanding of this feature is fundamental for determining the tectonic processes operating in western North Island. The deployment of a dense seismic network surrounding the TR-Line would provide complimentary data for improving the resolution of the receiver function analysis conducted by Salmon et al., (2011) across the TR-Line. This would also enable the analysis of focal mechanisms from earthquakes surrounding the TR-Line and provided a means of testing for phenomena such as seismic tremor and deep ( $>600$ $\mathrm{km})$ earthquakes. 


\section{Bibliography}

Abers, G. a., van Keken, P. E., Kneller, E. a., Ferris, A., and Stachnik, J. C. (2006). The thermal structure of subduction zones constrained by seismic imaging: Implications for slab dehydration and wedge flow. Earth and Planetary Science Letters, 241(3-4):387-397.

Adams, C. and Mortimer, N. (2009). Age and isotopic characterisation of metasedimentary rocks from the Torlesse Supergroup and Waipapa Group in the central North Island, New Zealand. New Zealand Journal of ..., $52(2): 149-170$.

Adams, R. and Ferris, B. G. (1976). A further earthquake at exceptional depth beneath New Zealand (Note). New Zealand Journal of Geology and Geophysics, 19(2):269-273.

Adams, R. and Ware, D. (1977). Subcrustal earthquakes beneath New Zealand; locations determined with a laterally inhomogeneous velocity model. New Zealand Journal of Geology and Geophysics, 20(1):37-41.

Anderson, H. and Webb, T. (1994). New Zealand seismicity: patterns revealed by the upgraded National Seismograph Network. New Zealand journal of geology and geophysics, 37(4):477-493.

Anderton, P. (1981). Structure and evolution of the south Wanganui Basin, New Zealand. New Zealand journal of geology and geophysics, 24:39-63. 
Ansell, J. and Bannister, S. (1996). Shallow morphology of the subducted Pacific plate along the Hikurangi margin, New Zealand. Physics of the Earth and Planetary Interiors, 93(1-2):3-20.

Audoine, E. (2004). Anisotropic structure under a back arc spreading region, the Taupo Volcanic Zone, New Zealand. Journal of Geophysical Research, 109(B11):1-22.

Babel Working Group (1993). Deep Seismic Reflection/Refraction Interpretation of Crustal Structure Along Babel Profiles A and B In the Southern Baltic Sea. Geophysical Journal International, 112(3):325-343.

Baldock, G. (2004). High resolution crustal structure adjacent to a continental transform, South Island, New Zealand. PhD thesis, Victoria University of Wellington, baldock2004.

Ballance, P. (1976). Evolution of the upper Cenozoic magmatic arc and plate boundary in northern New Zealand. Earth and planetary science letters, 28:356-370.

Barazangi, M., Isacks, B., Oliver, J., Dubois, J., and Pascal, G. (1973). Descent of lithosphere beneath New Hebrides, Tonga-Fiji and New Zealand: evidence for detached slabs. Nature, 242:98-101.

Bassett, D. G. (2009). 3-D Velocity structure of the northern Hikurangi margin: implications for crustal growth. Master's thesis, Victoria University of Wellington.

Bassett, D. G., Sutherland, R., Henrys, S., Stern, T. a., Scherwath, M., Benson, A., Toulmin, S., and Henderson, M. (2010). Three-dimensional velocity structure of the northern Hikurangi margin, Raukumara, New Zealand: Implications for the growth of continental crust by subduction erosion and tectonic underplating. Geochemistry Geophysics Geosystems, 11(10):Q10013. 
Beanland, S. (1995). The North Island dextral fault belt, Hikurangi subduction margin, New Zealand. PhD thesis, Victoria University of Wellington.

Beavan, J. (2002). Motion and rigidity of the Pacific Plate and implications for plate boundary deformation. Journal of Geophysical Research, 107(B10):2261.

Begg, J. G., Johnston, M. R., and (compliers) (2000). Geology of the Wellington area: scale 1:250,000. Lower Hutt: Institute of Geological \& Nuclear Sciences. Institute of Geological \&5 Nuclear Sciences 1:250,000 geological map 10., pages 64 p. +1 folded map.

Behr, Y. (2011). Imaging new zealand's crustal structure using ambient seismic noise recordings from permanent and temporary Instruments. $\mathrm{PhD}$ thesis, Victoria University of Wellington.

Bird, P. (1979). Continental delamination and the Colorado Plateau. J. geophys. Res, 84(B13):7561-7571.

Bott, M. H. P., Stein, S., Wortel, R., Kusznir, N., Fleitout, L., Zoback, M. L., and J.Cartwright (1991). Sublithospheric Loading and Plate-Boundary Forces. Philosophical Transactions: Physical Sciences and Engineering, 337(1645):83-93.

Bourne, M. and Stuart, G. (2000). ScSp observed on North Island, New Zealand: implications for subducting plate structure. Geophysical Journal International, 142(3):925-932.

Brikke, N. E. A. (2010). 3D Seismic Traveltime Tomography of the Central South Island, New Zealand. Master's thesis, Victoria University of Wellington.

Burov, E. and Watts, A. (2006). The long-term strength of continental lithosphere: jelly sandwich or crème brûlée? GSA TODAY, 16(1):4-10. 
Carter, R. M. and Naish, T. R. (1998). A review of Wanganui Basin, New Zealand: global reference section for shallow marine, PlioPleistocene (2.50 Ma) cyclostratigraphy. Sedimentary Geology, 122(1-4):37-52.

Cerveny, V. and Ravindra, R. (1971). Theory of seismic head waves. University of Toronto Press, Toronto.

Chadwick, M. (1997). The 1991 Hikurangi margin seismic refraction experiment. PhD thesis, Victoria University of Wellington.

Charter Around New Zealand (2008). Published Chart: Charting Around New Zealand. New Zealand Region Bathymetry', 1:4,000,000 scale at 46S on Mercator projection NIWA Chart, Miscellaneous, Series No.

Chen, W. and Molnar, P. (1983). Focal depths of intracontinental and intraplate earthquakes and their implications for the thermal and mechanical properties of the lithosphere. J. geophys. Res, 88(B5):4183-4214.

Christensen, N. I. and Mooney, W. D. (1995). Seismic velocity structure and composition of the continental crust: A global view. Journal of Geophysical Research, 100(B6):9761.

Christoffel, D. and Calhaem, I. (1973). Upper mantle viscosity determined from Stokes's law. Nature, 243:51-52.

Cloos, M. (1993). Lithospheric buoyancy and collisional orogenesis: Subduction of oceanic plateaus, continental margins, island arcs, spreading ridges, and seamounts. Geological Society of America Bulletin, 105(6):715.

Conrad, C. P. (2000). Convective instability of thickening mantle lithosphere. Geophysical Journal International, 143(1):52-70.

Cook, F. a. (2002). Fine structure of the continental reflection Moho. Geological Society of America Bulletin, 114(1):64-79. 
Craw, D. and Waters, J. (2007). Geological and biological evidence for regional drainage reversal during lateral tectonic transport, Marlborough, New Zealand. Journal of the Geological Society, 164:785-793.

Darby, D. and Beavan, J. (2001). Evidence from GPS measurements for contemporary interplate coupling on the southern Hikurangi subduction thrust and for partitioning of strain in the upper plate. Journal of geophysical research, 106(12):30881-30891.

Davey, F. and Smith, E. G. C. (1983a). A crustal seismic reflection-refraction experiment across the subducted Pacific plate under Wellington, New Zealand. Physics of the Earth and Planetary Interiors, 31(4):327-333.

Davey, F. J. and Smith, E. G. C. (1983b). A crustal seismic reflectionrefraction experiment across the subducted Pacific plate under Wellington, New Zealand. Physics of the Earth and Planetary Interiors, 31:327-333.

Davies, G. F. and Richards, M. A. (1992). Mantle Convection. The Journal of Geology, 100(2):151-206.

Davy, B., Hoernle, K., and Werner, R. (2008). Hikurangi Plateau: Crustal structure, rifted formation, and Gondwana subduction history. Geochemistry Geophysics Geosystems, 9(7):Q07004.

Davy, B. and Wood, R. (1994). Gravity and magnetic modelling of the Hikurangi Plateau. Marine Geology, 118(2):139-151.

Dumitru, T., Gans, P., Foster, D., and Miller, E. (1991). Refrigeration of the western Cordilleran lithosphere during Laramide shallow-angle subduction. Geology, 19:1145-1148.

Eberhart-Phillips, D., Reyners, M., Bannister, S., Chadwick, M., and Ellis, S. (2010). Establishing a versatile 3-D seismic velocity model for New Zealand. Seismological Research Letters, 81(6):992. 
Eberhart-Phillips, D., Reyners, M., Chadwick, M., and Chiu, J.-M. (2005). Crustal heterogeneity and subduction processes: 3-D Vp, Vp/Vs and Q in the southern North Island, New Zealand. Geophysical Journal International, 162(1):270-288.

Elkins-Tanton, L. (2005). Continental magmatism caused by lithospheric delamination. Foulger, G.R., Natland, J.H., Presnall, D.C., and Anderson, D.L., eds., Plates, plumes, and paradigms: Geological Society of America Special Paper 388, pages 449-461.

England, P. and Molnar, P. (1991). Inferences of deviatoric stress in actively deforming belts from simple physical models. Physical Sciences and Engineering, 337(1645):151-164.

Ewig, E. (2009). Lithospheric shortening and ductile deformation in a backarc setting: South Wanganui Basin, New Zealand. PhD thesis, Victoria University of Wellnigton.

Forsyth, D. and Uyeda, S. (1975). On the Relative Importance of the Driving Forces of Plate Motion*. Geophysical Journal of the Royal Astronomical Society, 43:163-200.

Funnell, R., Chapman, D., Allis, R., and Armstrong, P. (1996). Thermal state of the Taranaki Basin, New Zealand. Journal of Geophysical Research, 101(B11):25197-25215.

Furlong, K. P. and Kamp, P. J. (2009). The lithospheric geodynamics of plate boundary transpression in New Zealand: Initiating and emplacing subduction along the Hikurangi margin, and the tectonic evolution of the Alpine Fault system. Tectonophysics, 474(3-4):449-462.

Garrick, R. A. (1968). Letter to the editor : A reinterpretation of the Wellington Crustal refraction profile. New Zealand Journal of Geology and Geophysics, 11(5):1280-1294. 
Garrick, R. a. and Gibowicz, S. J. (1983). Continuous swarm-like seismicity: the Wanganui, New Zealand, earthquakes. Geophysical Journal of the Royal Astronomical Society, 75(2):493-512.

Gerrard, M. (1971). Tupapakurua-1. ANZPAC Petroleum Corp Petroleum Report Series.

Greve, S. M., Savage, M. K., and Hofmann, S. D. (2008). Strong variations in seismic anisotropy across the Hikurangi subduction zone, North Island, New Zealand. Tectonophysics, 462(1-4):7-21.

Hackney, R., Sutherland, R., and Collot, J. (2012). Rifting and subduction initiation history of the New Caledonia Trough, southwest Pacific, constrained by process-oriented gravity models. Geophysical Journal International, 189(3):1293-1305.

Haines, A. J. (1979). Seismic wave velocities in the uppermost mantle beneath New Zealand. New Zealand Journal of Geology and Geophysics, $22(2): 245-257$.

Hatherton, T. (1969). Geophysical anomalies over the eu-and miogeosynclinal systems of California and New Zealand. Geological Society of America Bulletin, 80:213-230.

Hatherton, T. (1970). Upper mantle inhomogeneity beneath New Zealand: surface manifestations. Journal of Geophysical Research, 75(2):269-284.

Hawkesworth, C. A., Dhuim, B., Pietranik, A., Cawood, P., and Kemp, A. (2010). The generation and evolution of the continental crust. Journal of the Geological Society, London, 167:229-248.

Henrys, S., Reyners, M., and Bibby, H. (2003). Exploring the plate boundary structure of the North Island, New Zealand. Eos, Transactions American Geophysical Union, 84(31):289,294-295. 
Henrys, S., Reyners, M., Pecher, I., Bannister, S., Nishimura, Y., and Maslen, G. (2006). Kinking of the subducting slab by escalator normal faulting beneath the North Island of New Zealand. Geology, 34(9):777.

Hochstein, M. P. and Ballance, P. F. (1993). Hauraki Rift: Ayoung active intra-continental rift in a back-arc setting. South Pacific Sedimentary Basins, pages 295-308.

Hole, J. (1992). Nonlinear high-resolution three-dimensional seismic travel time tomography. Journal of Geophysical Research, 97(B5):6553-6562.

Holt, W. E. and Stern, T. a. (1994). Subduction, platform subsidence, and foreland thrust loading: The late Tertiary development of Taranaki Basin, New Zealand. Tectonics, 13(5):1068-1092.

Hoogenboom, T. and Houseman, G. a. (2006). RayleighTaylor instability as a mechanism for corona formation on Venus. Icarus, 180(2):292-307.

Horspool, N. a., Savage, M. K., and Bannister, S. (2006). Implications for intraplate volcanism and back-arc deformation in northwestern New Zealand, from joint inversion of receiver functions and surface waves. Geophysical Journal International, 166(3):1466-1483.

Houseman, G., McKenzie, D., and Molnar, P. (1981). Convective instability of a thickened boundary layer and its relevance for the thermal evolution of continental convergent belts. Journal of Geophysical Research, 86:61156132.

Hunt, T. (1980). Basement structure of the Wanganui Basin, onshore, interpreted from gravity data. New Zealand journal of geology and geophysics, 23(1):1-16.

Issac, M. J., R. Herzer, Brook, F. J., and Hayward, B. (1994). Cretaceous and Cenozoic geology of Northland, New Zealand. Monogr. 8, Inst. of Geol. and Nucl. Sci., Lower Hutt, New Zealand. 
Jackson, J., McKENZIE, D., Priestley, K., and Emmerson, B. (2008). New views on the structure and rheology of the lithosphere. Journal of the Geological Society, 165(2):453-465.

Jarrard, R. D. (1986). Relations among subduction parameters. Reviews of Geophysics, 24(2):217.

Kamp, P. J., Vonk, A., Bland, K., and Griffin, A. (2002). Megasequence architecture of Taranaki, Wanganui, and King Country basins and Neogene progradation of two continental margin wedges across western New. New Zealand Petroleum Conference Proceedings, February:464-481.

Karig, D. (1970). Kermadec arcNew Zealand tectonic confluence. New Zealand journal of geology and geophysics, 13(1):21-29.

Katz, H. and Leask, B. L. (1990). The south Wanganui basin - A neglected hydrocarbon prospect. Petroleum exploration in New Zealand News, Wellington, New Zealand, pages 19-25.

Kay, R. and Mahlburg Kay, S. (1993). Delamination and delamination magmatism. Tectonophysics, 219(1-3):177-189.

Kearey, P., Brooks, M., and Hall, I. (2002). An Introduction to Geophysical Exploration. Blackwell Publishing, third edition.

Keir, D., Bastow, I. D., Whaler, K. a., Daly, E., Cornwell, D. G., and Hautot, S. (2009). Lower crustal earthquakes near the Ethiopian rift induced by magmatic processes. Geochemistry Geophysics Geosystems, 10(8031):1-10.

King, P. R. (2000). Tectonic reconstructions of New Zealand: 40 Ma to the present. New Zealand Journal of Geology and Geophysics, 43(4):611-638.

King, P. R. and Thrasher, G. P. (1992). Post-Eocene development of the Taranaki Basin, New Zealand: convergent overprint of a passive margin. Watkins, J. S.; Zhiqiang, F.; McMillen, K. J. ed. Geology and geophysics of 
continental margins. American Association of Petroleum Geologists Memoir, 53:93-118.

King, P. R. and Thrasher, G. P. (1996). Cretaceous-Cenozoic geology and petroleum systems of the Taranaki Basin, New Zealand. Institute of Geological \&5 Nuclear Sciences Monograph 13. 6 enclosures, 243 p. Lower Hutt, Institute of Geological \& Nuclear Sciences.

Knopoff, L. and Gangi, A. (1959). Seismic reciprocity. Geophysics, 24:681.

Kusznir, N. and D., M. (1988). Deep reflections and the deformational mechanics of the continental lithosphere. Journal of Petrology, Special $\mathrm{Vo}(1): 63-87$.

Lamarche, G., Proust, J.-N., and Nodder, S. D. (2005). Long-term slip rates and fault interactions under low contractional strain, Wanganui Basin, New Zealand. Tectonics, 24(4).

Lamb, S. (2006). Shear stresses on megathrusts: Implications for mountain building behind subduction zones. Journal of Geophysical Research, 111(B7):7401.

Lamb, S. (2011). Cenozoic tectonic evolution of the New Zealand plateboundary zone: A paleomagnetic perspective. Tectonophysics, 509(34):135-164.

Lamb, S. and Bibby, H. (1989). The last 25 Ma of rotational deformation in part of the New Zealand plate-boundary zone. Journal of structural geology, 11(4):473-492.

Lamb, S. and Vella, P. (1987). The last million years of deformation in part of the New Zealand plate-boundary zone. Journal of Structural Geology, $9(7): 877-891$.

Lambeck, K. and Burgess, G. (1992). Deep crustal structure of the Musgrave Block, central Australia: Results from teleseismic travelâtime anomalies. 
Australian Journal of Earth Sciences: An International Geoscience Journal of the Geological Society of Australia, 31(1):1-19.

Lay, T. and Wallace, T. (1995). Modern Global Seismology. Acedemic Press, San Diego.

Lee, J., Begg, J., and (compilers) (2002). Geology of the Wairarapa area: scale 1:250,000. Lower Hutt:. Institute of Geological \& Nuclear Sciences Limited. Institute of Geological \&3 Nuclear Sciences 1:250,000 geological map 11., pages 66 p. +1 folded map.

Lin, F.-C., Ritzwoller, M. H., Townend, J., Bannister, S., and Savage, M. K. (2007). Ambient noise Rayleigh wave tomography of New Zealand. Geophysical Journal International, 170(2):649-666.

Lindenfeld, M. and Rümpker, G. (2011). Detection of mantle earthquakes beneath the East African Rift. Geophysical Journal International, 186(1):1-5.

Long, R. E., Matthews, P. a., and Graham, D. P. (1994). The nature of crustal boundaries: combined interpretation of wide-angle and normalincidence seismic data. Tectonophysics, 232(1-4):309-318.

Luetgert, J. (1992). MacRay: Interactive two-dimensional seismic raytracing for the Macintosh. US Geological Survey Open File Report, 92(356):1-2.

Luo, X. (1992). Subduction interface and crustal structure in the Cape Palliser region, North Island, New Zealand, from observations of Cape Palliser earthquakes. New Zealand journal of geology and geophysics, 35(4):37-41.

MacKenzie, L. S., Abers, G. a., Rondenay, S., and Fischer, K. M. (2010). Imaging a steeply dipping subducting slab in Southern Central America. Earth and Planetary Science Letters, 296(3-4):459-468.

Maggi, A., Jackson, J., Mckenzie, D., and Priestley, K. (2000). Earthquake focal depths, effective elastic thickness, and the strength of the continental lithosphere. Geology, 28:495-498. 
Marty, B. and Tolstikhin, I. N. (1998). CO2 fluxes from mid-ocean ridges, arcs and plumes. Chemical Geology, 145(3-4):233-248.

Melhuish, A. (1990). along the Pacific-Australian Plate margin ,. PhD thesis, Victoria University of Wellington.

Melhuish, A., Holbrook, W. S., Davey, F., Okaya, D., and Stern, T. a. (2005). Crustal and upper mantle seismic structure of the Australian Plate, South Island, New Zealand. Tectonophysics, 395(1-2):113-135.

Molnar, P. and England, P. (1990). Late Cenozoic uplift of mountain ranges and global climate change: chicken or egg? Nature, 346(6279):29-34.

Mooney, D., Brocher, M., Survey, U. S. G., and Park, M. (1987). Seismic Reflection / Refraction Studies of the Continental Lithosphere' A Global Review. Reviews of Geophysics, 25(4):723-742.

Mooney, H. (1970). Upper mantle inhomogeneity beneath New Zealand: seismic evidence. Journal of geophysical research, 75(2):285-309.

Morozov, I., Smithson, S., Chen, J., and Hollister, L. (2001). new continental crust and terrane accretion in southeastern Alaska and western British Columbia: Constraints from P-and S-wave wide-angle seismic data (ACCRETE. Tectonophysics, 341(1-4):49-67.

Mortimer, N. (2004). New Zealand's Geological Foundations. Gondwana Research, 7(1):261-272.

Mortimer, N. and Parkinson, D. (1996). Hikurangi Plateau: a Cretaceous large igneous province in the southwest Pacific Ocean. Journal of geophysical research, 101:687-696.

Mumme, T. and Walcott, R. (1985). Paleomagnetic studies at Geophysics Division 1980-1983. Geophys. Div. Rep. N.Z. Dept. Sci. Ind. Res, 204. 
Nelson, K. (1992). Are crustal thickness variations in old mountain belts like the Appalachians a consequence of lithospheric delamination? Geology, 20:598-502.

Nicol, A. (2003). Shortening of an overriding plate and its implications for slip on a subduction thrust, central Hikurangi Margin, New Zealand. Tectonics, $22(6): 1-14$.

Nicol, A., Mazengarb, C., Chanier, F., Rait, G., Uruski, C., and Wallace, L. M. (2007). Tectonic evolution of the active Hikurangi subduction margin, New Zealand, since the Oligocene. Tectonics, 26(4):1-24.

Nicol, A., VanDissen, R., Vella, P., Alloway, B., and Melhuish, A. (2002). Growth of contractional structures during the last 10 my at the southern end of the emergent Hikurangi forearc basin, New Zealand. New Zealand Journal, 43(3):37-41.

Nicol, A. and Wallace, L. M. (2007). Temporal stability of deformation rates: Comparison of geological and geodetic observations, Hikurangi subduction margin, New Zealand. Earth and Planetary Science Letters, 258(3-4):397413.

Okaya, D., Henrys, S., and Stern, T. a. (2002). Double-sided onshore-offshore seismic imaging of a plate boundary: "super-gathers" across South Island, New Zealand. Tectonophysics, 355:247-263.

Okaya, D., Stern, T. a., and Holbrook, W. S. (2003). Imaging a plate boundar using double-sided onshore-offshore seismic profiling. The Leading.

Oueity, J. and Clowes, R. M. (2010). Nature of the Moho transition in NW Canada from combined near-vertical and wide-angle seismic-reflection studies. Lithosphere, 2(5):377-396.

Peacock, S. and Wang, K. (1999). Seismic consequences of warm versus cool subduction metamorphism: examples from southwest and northeast japan. Science (New York, N.Y.), 286(5441):937-9. 
Platt, J. and England, P. (1993). Convective removal of lithosphere beneath mountain belts: thermal and mechanical consequences. American Journal of Science, 293:307-336.

Plaza Faverola, A., Klaeschen, D., Barnes, P. M., Pecher, I., Henrys, S., and Mountjoy, J. J. (2012). Evolution of fluid expulsion and concentrated hydrate zones across the southern Hikurangi subduction margin, New Zealand: an analysis from depth migrated seismic data. Geochemistry Geophysics Geosystems.

Proust, J.-N., Lamarche, G., Nodder, S. D., and Kamp, P. J. (2005). Sedimentary architecture of a Plio-Pleistocene proto-back-arc basin: Wanganui Basin, New Zealand. Sedimentary Geology, 181(3-4):107-145.

Pulford, A. and Stern, T. a. (2004). Pliocene exhumation and landscape evolution of central North Island, New Zealand: The role of the upper mantle. Journal of Geophysical Research, 109:F01016.

Rait, G., Chanier, F., and Waters, D. (1991). Landward-and seawarddirected thrusting accompanying the onset of subduction beneath New Zealand. Geology, 19:230-233.

Ravens, J. (1999). Globe Claritas seismic processing dictionary. Institute of Geological and Nuclear Sciences Limited, Institute.

Rawlinson, N. (2005). fast marching tomography package: Instruction manual. Tech. rep., Research School of Earth Sciences, Australian National University.

Rawlinson, N., Pozgay, S., and Fishwick, S. (2010). Seismic tomography: A window into deep Earth. Physics of the Earth and Planetary Interiors, 178(3-4):101-135.

Reading, A. M., Gubbins, D., and Mao, W. (2001). A multiphase seismic investigation of the shallow subduction zone, southern North Island, New Zealand. Geophysical Journal International, 147(1):215-226. 
Reyners, M. (1980). A microearthquake study of the plate boundary, North Island, New Zealand. Geophysical Journal of the Royal Astronomical Society, 63:1-22.

Reyners, M. (1989). New Zealand seismicity 196487: an interpretation. New Zealand journal of geology and geophysics, 32(3):307-315.

Reyners, M. and Eberhart-Phillips, D. (2009). Small earthquakes provide insight into plate coupling and fluid distribution in the Hikurangi subduction zone, New Zealand. Earth and Planetary Science Letters, 282(1-4):299 305.

Reyners, M., Eberhart-Phillips, D., Stuart, G., and Nishimura, Y. (2006). Imaging subduction from the trench to $300 \mathrm{~km}$ depth beneath the central North Island, New Zealand, with Vp and Vp/Vs. Geophysical Journal International, 165(2):565-583.

Robinson, R. (1986). Seismicity, structure and tectonics of the Wellington region, New Zealand. Geophysical Journal International, 87(2):379-409.

Salmon, M. L., Stern, T. a., and Savage, M. K. (2011). A major step in the continental Moho and its geodynamic consequences: the TaranakiRuapehu line, New Zealand. Geophysical Journal International, 186(1):3244 .

Sandwell, D. T. and Smith, W. H. F. (2009). Global marine gravity from retracked Geosat and ERS-1 altimetry: Ridge segmentation versus spreading rate. Journal of Geophysical Research, 114(B1):1-18.

Savage, M. K., Park, J., and Todd, H. (2007). Velocity and anisotropy structure at the Hikurangi subduction margin, New Zealand from receiver functions. Geophysical Journal International, 168(3):1034-1050.

Scherwath, M. (2002). Lithospheric structure and deformation in an oblique continental collision zone, South Island, New Zealand. PhD thesis, Victoria University of Wellington. 
Scherwath, M., Kopp, H., Flueh, E. R., Henrys, S., Sutherland, R., Stagpoole, V. M., Barker, D. H. N., Reyners, M., Bassett, D. G., Planert, L., and Others (2010). Fore-arc deformation and underplating at the northern Hikurangi margin, New Zealand. Journal of Geophysical Research, 115(B6):B06408.

Scherwath, M., Stern, T. a., Davey, F., Okaya, D., Holbrook, W. S., and Kleffmann, S. (2003). Lithospheric structure across oblique continental collision in New Zealand from wide-angle $\mathrm{P}$ wave modeling. J. geophys. Res, 108(12):2566.

Scholz, C. and Campos, J. (1995). On the mechanism of seismic decoupling and back arc spreading at subduction zones. Journal of Geophysical Research, 100(B11):22103-22115.

Seward, A., Henrys, S., Henderson, M., Stern, T. a., Savage, M. K., Mochizuki, K., Sato, H., Iwasaki, T., Kennedy, C., and Bassett, D. G. (2010). Seismic Array HiKurangi Experiment (SAHKE); Field Acquisition Report . GNS Science Report 2010/48.

Seward, A. M., Henderson, C. M., and Smith, E. G. C. (2009). Models of the upper mantle beneath the central North Island, New Zealand, from speeds and anisotropy of subhorizontal $\mathrm{P}$ waves $(\mathrm{Pn})$. Journal of Geophysical Research, 114(B1):B01301.

Seward, A. M., Henrys, S., Okaya, D., Stern, T. a., Savage, M. K., Sato, H., Iwasaki, T., Sutherland, R., and Henderson, C. M. (2011). Seismic Array HiKurangi Experiment ll (SAHKE 1l); Onshore Active Source Acquisition Report . GNS Science Report 2011/50.

Sherburn, S. and White, R. S. (2005). Crustal seismicity in Taranaki, New Zealand using accurate hypocentres from a dense network. Geophysical Journal International, 162(2):494-506. 
Sheriff, R. and Geldart, L. (1995). Exploration seismology. Cambridge University Press.

Smith, E. G. C. (1981). Calculation of poles of instantaneous rotation from poles of finite rotation. Geophysical Journal of the Royal Astronomical ..., $65: 223-227$.

Smith, E. G. C., Stern, T. a., and Reyners, M. (1989). Subduction and backarc activity at the Hikurangi convergent Margin, New Zealand. Pure and Applied Geophysics, 129(1-2):203-231.

St John, D. (1964). Parikino-1 Exploration Well Resume. Shell BP and Todd Oil Services Ltd Petroleum Report Series.

Stein, S. and Wysession, M. (2003). An Introduction to Seismology, Earthquakes, and Earth Structure. Blackwell Publishing Ltd.

Stern, R. J. (2002). Subduction zones. Reviews of Geophysics, 40(4):1012.

Stern, T. a. (1985). A back-arc basin formed within continental lithosphere: the Central Volcanic Region of New Zealand. Tectonophysics, 112:385-409.

Stern, T. a. and Davey, F. (1990). Deep seismic expression of a foreland basin: Taranaki Basin, New Zealand. Geology, 18:979-982.

Stern, T. A. and Davy, F. A. (1989). Crustal structure and origin for basins formed behind the Hikurangi subduction zone of New Zeland. Prince, R.A., ed., Origin and evolution of sedimentary basins and their energy and mineral resources: American Geophysical Union Monograph 48,, pages $73-86$.

Stern, T. A., Houseman, G., Salmon, M. L., and Evans, L. (2012). Instability of a lithospheric step beneath western North Island, New Zealand (in review). in prep., pages --. 
Stern, T. a. and McBride, J. (1998). Seismic exploration of continental strikeslip zones. Tectonophysics, 286:63-78.

Stern, T. A., Quinlan, G., and Holt, W. (1992). Basin formation behind an active subduction zone: threedimensional flexural modelling of Wanganui Basin, New Zealand. Basin research, 4:197-214.

Stern, T. a., Smith, E. G. C., Davey, F. J., and Muirhead, K. J. (1987). Crustal and upper mantle structure of the northwestern North Island, New Zealand, from seismic refraction data. Geophysical Journal International, 91(3):913-936.

Stern, T. A., Stratford, W. R., and Salmon, M. L. (2006). Subduction evolution and mantle dynamics at a continental margin: Central North Island, New Zealand. Review of geophyics, 44:RG4002.

Stern, T. a., Stratford, W. R., Seward, A. M., Henderson, C. M., Savage, M. K., Smith, E. G. C., Benson, A., Greve, S., and Salmon, M. L. (2010). Crust-mantle structure of the central North Island, New Zealand, based on seismological observations. Journal of Volcanology and Geothermal Research, 190(1-2):58-74.

Stock, J. and Molnar, P. (1982). Uncertainties in the relative positions of the Australia, Antarctica, Lord Howe, and Pacific plates since the Late Cretaceous. Journal of geophysical research, 87:4697-4714.

Stratford, W. R. (2006). Lithosheric structure of a continental back-arc: Central volcanic region, New Zeland. PhD thesis, Victoria University of Wellington.

Sutherland, R. (1995). The Australia-Pacific in the SW Pacific : boundary and Cenozoic plate motions. Tectonics, 14(4):819-831.

Sutherland, R., Collot, J., Lafoy, Y., Logan, G. a., Hackney, R., Stagpoole, V., Uruski, C., Hashimoto, T., Higgins, K., Herzer, R. H., Wood, R., Mortimer, N., and Rollet, N. (2010). Lithosphere delamination with foundering 
of lower crust and mantle caused permanent subsidence of New Caledonia Trough and transient uplift of Lord Howe Rise during Eocene and Oligocene initiation of Tonga-Kermadec subduction, western Pacific. Tectonics, 29(2):1-16.

Sutherland, R., Davey, F., and Beavan, J. (2000). Plate boundary deformation in South Island, New Zealand, is related to inherited lithospheric structure. Earth and Planetary Science Letters, 177(3-4):141-151.

Sutherland, R., Stagpoole, V., Uruski, C., Kennedy, C., Bassett, D., Henrys, S., Scherwath, M., Kopp, H., Field, B., Toulmin, S., Barker, D., Bannister, S., Davey, F., Stern, T. a., and Flueh, E. R. (2009). Reactivation of tectonics, crustal underplating, and uplift after $60 \mathrm{Myr}$ of passive subsidence, Raukumara Basin, Hikurangi-Kermadec fore arc, New Zealand: Implications for global growth and recycling of continents. Tectonics, 28(5):1-23.

Taylor, B. (2006). The single largest oceanic plateau: Ontong Java-ManihikiHikurangi. Earth and Planetary Science Letters, 241(3-4):372-380.

Te Punga, M. (1957). Live anticline in western Wellington. N. Z. J. Sci. Technol., Sect. B, 38:433-446.

Townsend, D., Vonk, A., Kamp, P. J., and (compilers) (2008). Geology of the Taranaki area: scale 1:250,000. Lower Hutt: GNS Science. Institute of Geological \&3 Nuclear Sciences 1:250,000 geological map 7., pages 77 p. + 1 folded map.

Townsend, T. (1998). Paleoseismology of the Waverley Fault Zone and implications for earthquake hazard in South Taranaki, New Zealand. New Zealand Journal of Geology and Geophysics, 41(4):467-474.

Uruski, C. and Wood, R. (1991). A new look at the New Caledonia Basin, an extension of the Taranaki Basin, offshore North Island, New Zealand. Marine and Petroleum Geology, 8(4):379-391. 
Uyeda, S. and Kanamori, H. (1979). Back-Arc Opening and the Mode of Subduction. Journal of Geophysical Research, 84(B3):1049-1061.

Van Dissen, R. and Berryman, K. R. (1996). Surface rupture earthquakes over the last 1000 years in the Wellington region, New Zealand, and implications for ground shaking hazard. Journal of Geophysical Research, 101(B3):5999-6019.

Walcott, R. (1987). Geodetic strain and the deformational history of the North Island of New Zealand during the late Cainozoic. Philosophical Transactions of the Royal Society of London. Series A., 321:163-181.

Walcott, R. (1998). Modes of oblique compression: Late Cenozoic tectonics of the South Island New Zealand. Reviews of Geophysics, 36(1):97RG03084.

Walcott, R., Christoffel, D., and Mumme, T. (1981). Bending within the axial tectonic belt of New Zeland in the last 9 Myr from Paleomagnetic data. Earth and Planetary Science Letters, 52:427-434.

Walcott, R. and Mumme, T. (1982). Palaeomagnetic study of the Tertiary sedimentary rocks from the East Coast of the North Island, New Zealand. Department of Scientific and Industrial Research, Geophysics Division Report 189.

Wallace, L. M., Barnes, P. M., Beavan, J., Van Dissen, R., Litchfield, N., Mountjoy, J., Langridge, R., Lamarche, G., and Pondard, N. (2012). The kinematics of a transition from subduction to strike-slip: An example from the central New Zealand plate boundary. Journal of Geophysical Research, 117:B02405.

Wallace, L. M. and Beavan, J. (2004). Subduction zone coupling and tectonic block rotations in the North Island, New Zealand. Journal of Geophysical Research, 109(B12):1-21. 
Wallace, L. M. and Beavan, J. (2010). Diverse slow slip behavior at the Hikurangi subduction margin, New Zealand. Journal of Geophysical Research, 115(B12):1-20.

Wallace, L. M., Reyners, M., Cochran, U., Bannister, S., Barnes, P. M., Berryman, K., Downes, G., Eberhart-Phillips, D., Fagereng, A., Ellis, S., Nicol, A., McCaffrey, R., Beavan, J., Henrys, S., Sutherland, R., Barker, D. H. N., Litchfield, N., Townend, J., Robinson, R., Bell, R., Wilson, K., and Power, W. (2009). Characterizing the seismogenic zone of a major plate boundary subduction thrust: Hikurangi Margin, New Zealand. Geochemistry Geophysics Geosystems, 10:Q10006.

Watson, J. and Allen, D. (1964). Compilation of Seismic Results in Wanganui Basin. Petroleum Report Series, Shell BP and Todd Oil Services Ltd.

Watts, A. (2001). Isostasy and Flexure of the Lithosphere. Cambridge University Press.

Weissel, J., Hayes, D., and Herron, E. (1977). Plate tectonics synthesis: the displacements between Australia, New Zealand, and Antarctica since the Late Cretaceous. Marine geology, 25(2561).

Wessel, P. and Smith, W. H. F. (1991). Free software helps map and display data. Eos, Transactions American Geophysical Union, 72:441-446.

West, J. D., Fouch, M. J., Roth, J. B., and Elkins-Tanton, L. T. (2009). Vertical mantle flow associated with a lithospheric drip beneath the Great Basin. Nature Geoscience, 2(6):439-444.

Whittaker, a., Bott, M., and Waghorn, G. (1992). Stresses and plate boundary forces associated with subduction plate margins. Journal of Geophysical Research, 97(B8):11933-11944.

Wilson, G. S. and McGuire, D. M. (1995). Distributed deformation due to coupling across a subduction thrust: Mechanism of young tectonic rotation within the south Wanganui basin, New Zealand. Geology, 23(7):645. 
Wittlinger, G., Vergne, J., Tapponnier, P., Farra, V., Poupinet, G., Jiang, M., Su, H., Herquel, G., and Paul, A. (2004). Teleseismic imaging of subducting lithosphere and Moho offsets beneath western Tibet. Earth and Planetary Science Letters, 221(1-4):117-130.

Wright, I. (1993). Pre-spread rifting and heterogeneous volcanism in the southern Havre Trough back-arc basin. Marine Geology, 113(3-4):179-200.

Yilmaz, O. (2001). Seismic Data Analysis. Soc. Explor. Geophys.,, Tulsa, Okla., 2nd edition.

Zandt, G., Gilbert, H., Owens, T. J., Ducea, M., Saleeby, J., and Jones, C. H. (2004). Active foundering of a continental arc root beneath the southern Sierra Nevada in California. Nature, 431(7004):41-6.

Zelt, C. A. (1999). Modelling strategies and model assessment for wide-angle seismic traveltime data. Geophysical Journal International, 139(1):183204.

Zelt, C. A. and Smith, R. B. (1992). Seismic traveltime inversion for 2-D crustal velocity structure. Geophysical journal international, 108(1):16-34. 


\section{Appendix A}

\section{Survey geometry and data processing}

\section{A.1 Introduction}

This appendix outlines (1) the survey geometry and instrumentation details of both phase one and two of the "Seismic Array HiKurangi Experiment" (SAHKE I and SAHKE II), (2) the procedure by which a sub-set of onshore-offshore wide angle reflection/refraction data acquired during SAHKE I, were converted into a 'common-receiver' gather travel-time dataset, (3) details of the seismic processing operations applied to each receiver gather (SAHKE I) and shot gather (SAHKE II) and (4) the strategy by which individual phase arrivals from each receiver and shot gather were interpreted and picked.

SAHKE occurred in two phases. SHAKE I involved the acquisition of three offshore two-dimensional (2-D) multi-channel-seismic (MCS) reflection profiles. These were located on both the eastern (SAHKE01) and western (SAHKE02 and 03) sides of lower North Island, New Zealand (Fig. A.1). Contemporaneous to this survey, two temporary seismometer arrays were deployed as onshore extensions of each profile. These seismometers were used to record seismic energy emanating from the offshore MCS air-gun blasts. 
A. Survey parameters and data processing

The continuous time series data recorded at these seismometers during the shooting of each MCS profile, were extracted from each seismometer and used to construct a suite of 'common-receiver' gathers using IRIS Passcal utility codes [www.passcal.nmt.edu]. This study focuses on the analysis of receiver gathers collected on the western side of North Island within Wanganui Basin, during the shooting of SAHKE lines 02 and 03. A total of the 44 receiver gathers and 12 shot gathers were create created, from which picks were made on 41 receiver gathers and all shot gathers, with 142 individual phases interpreted and $\sim 45,000$ travel-time picks made.

SAHKE II involved the detonation of twelve onshore dynamite blasts along a profile coincident to that of the SAHKE I TRANSECT deployment (Fig's. A.1 and A.2). The seismic energy produced by each shot was recorded by 558 single-component and 277 three-component seismometers deployed at $\sim 100$ $\mathrm{m}$ spacing (narrowed to $\sim 50 \mathrm{~m}$ spacing between Kaitoke and Featherston). These data were used to construct a suite of twelve shot gathers that compliment the onshore-offshore receiver gather dataset.

These data were processed and interpreted using Globe Claritas seismic processing software and used to constrain the two 2-D crustal velocity models developed in Chapters 4 and 5 .

Scripts used to conduct these procedures are included on the accompanying compact disc (CD) in the directory "scripts" . These scripts were developed entirely within this thesis or modified from those supplied by Daniel Bassett (formally of GNS, now at the University of Oxford).

\section{A.2 Data}

SAHKE I involved the acquisition of three 2-D offshore MCS reflection profiles on board the M/V Bergen Resolution (later renamed M/V Reflect Resolution) during March 2010 (Fig. A.1). SAHKE01 and 02 were ori- 
A.2. Data

entated SE - NW perpendicular to the Hikurangi margin on either side of North Island, and collectively create a single profile. SAHKE03 was orientated SSW-NNE sub-parallel to SAHKE02, approximately through the axis of the Wanganui Basin gravity anomaly on the western side of North Island (Fig. ). Three seismometer deployments were active during the acquisition of these reflection profiles and were used to record seismic energy emanating from the offshore shots. Data acquired on the temporarily deployed TRANSECT (section A.2.2), WANGANUI (section A.2.3) and permanent GeoNet (section A.2.4) networks during the shooting of SAHKE lines 02 and 03 are analysed in this study.

SAHKE II involved the acquisition of twelve onshore shot gathers along a profile stretching from coast to coast across lower North Island during May 2012 (Fig. A.2). This profile was coincident to that of the SAHKE01/02 profile and consisted of 558 single-component and 277 three-component seismometers deployed at $\sim 100 \mathrm{~m}$ spacing (narrowed to $\sim 50 \mathrm{~m}$ spacing between Kaitoke and Featherston) between Glendhu Rocks in the east and Paekakariki in the west. A three component station was employed at every third site.

Details regarding the locations and instrumentation of each of these deployments are discussed by Seward et al. (2010) and Seward et al. (2011) and summarized below.

\section{A.2.1 Multi-channel-seismic acquisition parameters}

During SAHKE 480 line km's of MCS reflection data were acquired along three transects (SAHKE01 02 and 03) (Fig. 2.1). These data were processed by Geotrace $\AA$ as contracted by New Zealand Petroleum and Minerals (NZMP) (see NZ Petroleum Report 4279). These were supplied as both brute and post-migration time stacks courtesy of NZPM for use in this thesis. 
A. Survey parameters and data processing

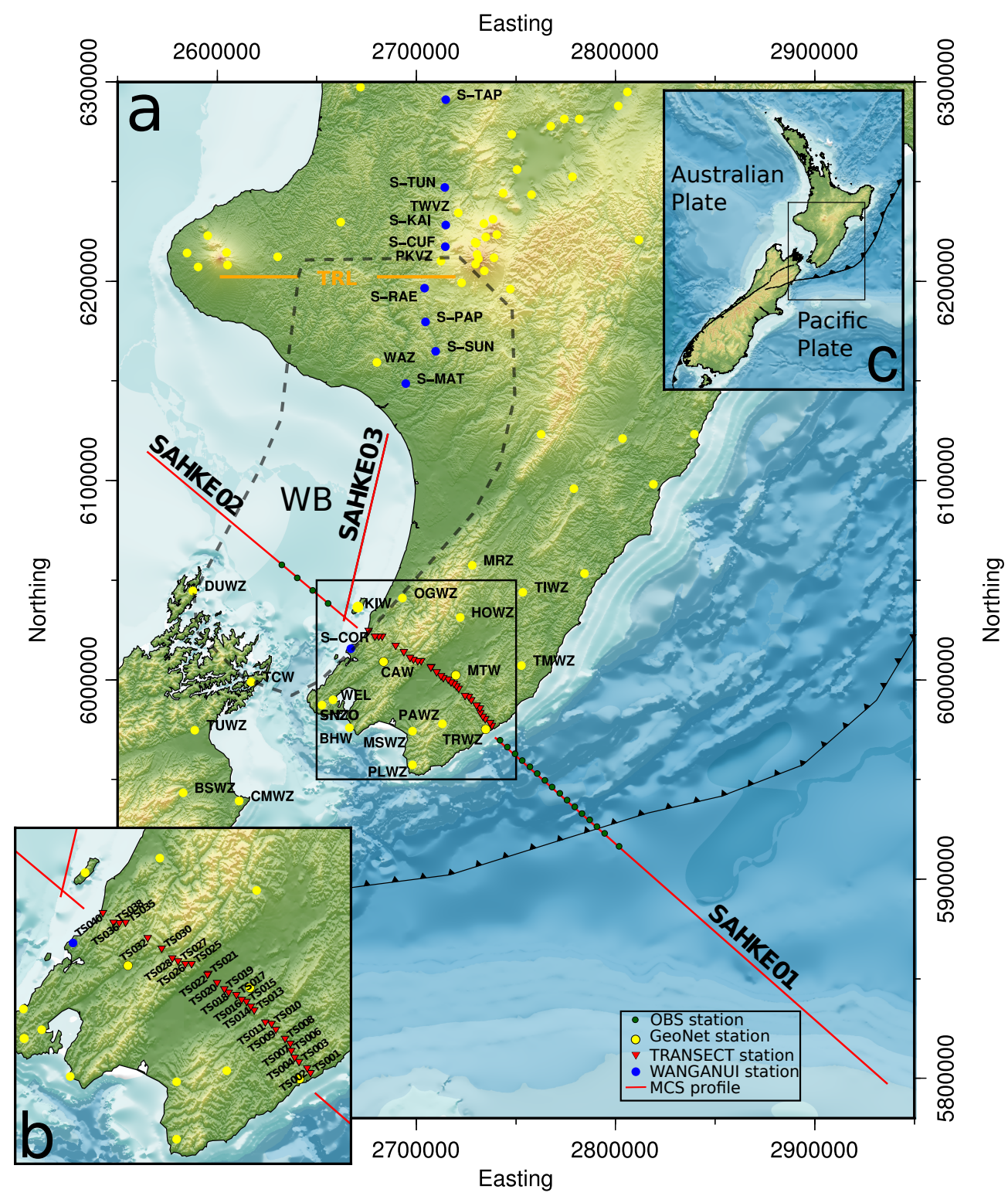

Figure A.1: (a) Regional location map displaying the survey geometry of the onshore/offshore section of the "Seismic Array HiKurangi Experiment"(SAHKE). Red lines are MCS profile tracks, red triangles and blue circles are temporary short period seismometers belonging to the TRANSECT and WANGANUI deployments respectively. Yellow circles are permanent GeoNet seismometers. The dashed grey line outlines the extend of Wanganui Basin. The orange line indicates the position of the proposed Taranaki-Ruapehu Line (TRL). (b) Inset map showing the locations of short period temporary seismometers belonging to the TRASECT deployment. (c) Inset showing the location of (a) (black box). Bathymetry data are sourced from the National Institute Water and Atmospheric Research (NIWA) chart No. 85 (CANZ, 2008). 
A.2. Data

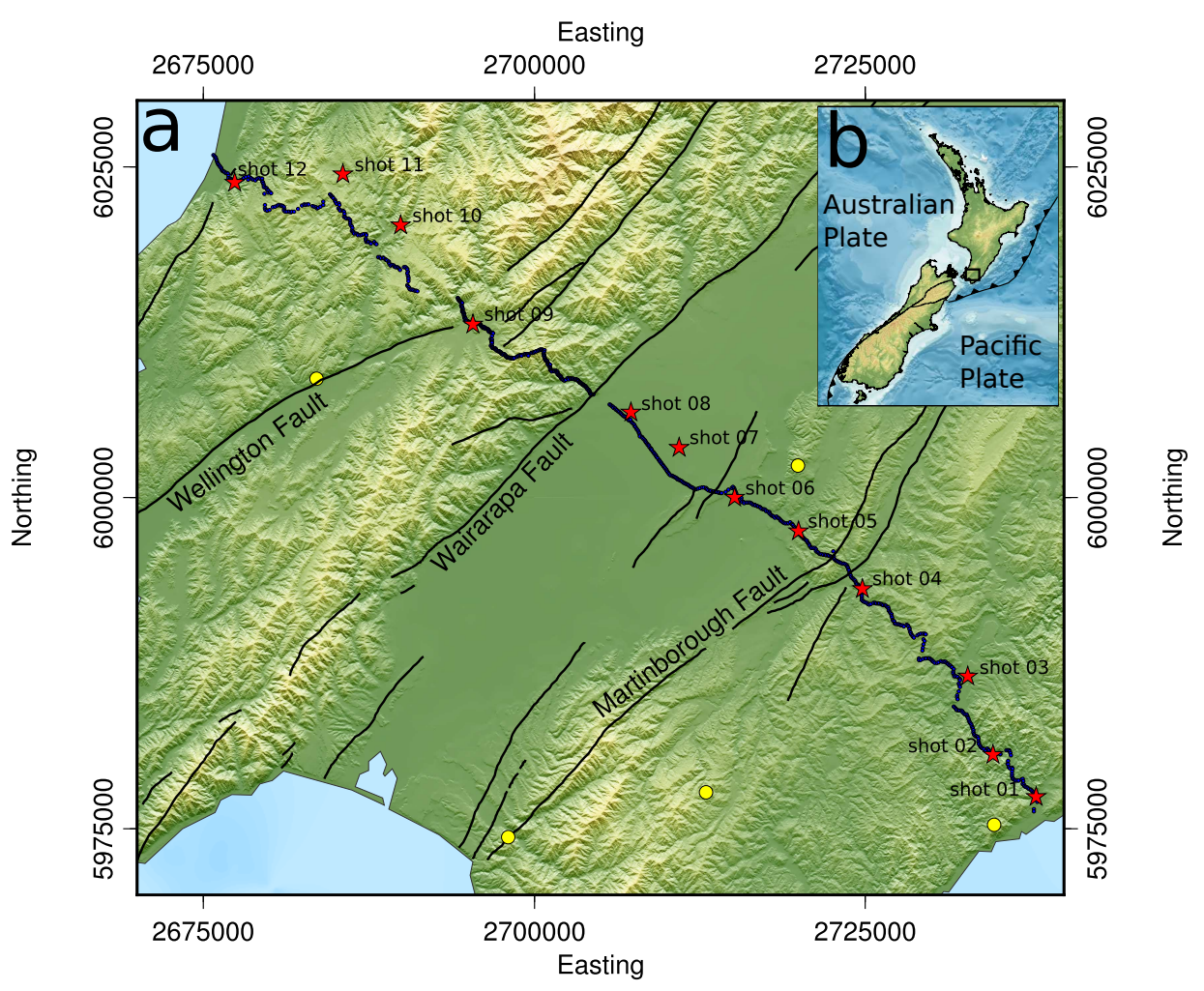

Figure A.2: (a) Regional location map displaying the geometry of the onshore SAHKE II survey. Red stars are shot locations, blue circles are temporary short period seismometers sites and yellow circles are permanent GeoNet seismometers. Solid black lines are major mapped faults. (b) Inset showing the location of (a) (black box). Bathymetry data are sourced from the National Institute Water and Atmospheric Research (NIWA) chart No. 85 (CANZ, 2008).

The SAHKE03 post-migration time stack was used to constrain the thickness and p-wave velocity structure of the sedimentary sequence within the SAHKE03 crustal scale Vp model developed in Chapter 4 (see section 4.2.1.2). Furthermore, both the SAHKE02 and SAHKE03 brute stacks preserve deep (> $10 \mathrm{~s}$ two way travel-time) reflectors. These stacks are interpreted and compared to the velocity models developed using wide-angle refraction and wide-angle reflection data by time-converting each of the the velocity models developed in this study (see sections 4.5 and 5.5).

Acquisition parameters used during the SAHKE MCS survey are described in table A.1. Of particular importance are streamer length (10000 
A. Survey parameters and data processing

$\mathrm{m})$ and record length (15 s/ $17 \mathrm{~s})$. The long streamer and record lengths enabled the recording of coherent seismic reflections at depths as great as $13.5 \mathrm{~s}$ two-way travel time. These are interpreted as Moho (see section 6.9) reflections and of significant importance to the analysis conducted in this thesis.

\begin{tabular}{|l|l|}
\hline Vessel: M/V Bergen Resolution & group int. $[\mathbf{m}]: 12.5 \mathrm{~m}$ \\
\hline Date: March 2010 & Streamer depth: $9 \mathrm{~m}+/-1 \mathrm{~m}$ \\
\hline $\begin{array}{l}\text { Source: Air Guns }- \text { Annular Port } \\
\text { Gun linear }\end{array}$ & Streamer length: $10000 \mathrm{~m}$ \\
\hline Gun Depth: $6 \mathrm{~m}+/-1 \mathrm{~m}$ & Record length [ms]: $15 \mathrm{~s} / 17 \mathrm{~s}$ \\
\hline Volume: $5400 \mathrm{cu}$ in & Sample rate: $2 \mathrm{~ms}$ \\
\hline Array Pressure: $2200 \mathrm{psi}$ & SODD: $200 \mathrm{~ms}$ \\
\hline Shot point int. $[\mathbf{m}]: 100 \mathrm{~m}$ & Low cut: $2 \mathrm{~Hz}$ @ 6 dB/Oct \\
\hline Streamer: 1 & High Cut: $206 \mathrm{~Hz} @ 264 \mathrm{~dB} /$ Oct \\
\hline Near Offset: 133 & Format: SEG-D 8058 \\
\hline Number of Groups: 800 & \\
\hline
\end{tabular}

Table A.1: Acquisition parameters used during the multi-channel-seismic SAHKE survey (after, PR4279).

\section{A.2.2 TRANSECT deployment}

Contemporaneous to the acquisition of MCS lines SAHKE01 and 02, three temporary seismometer deployments were active. Collectively these are termed the TRANSECT deployment and consisted of

(1) a shot-period array active for the month of March 2010, monitored and deployed by GNS Science (GNS) and Victoria University of Wellington (VUW).

(2) an Ocean Bottom Seismometer (OBS) array active during March and April 2010, monitored and deployed by University of Tokyo Earthquake Reserach Institute (ERI) and GNS; and

(3) a long term ten station broadband deployment, deployed between 
A.2. Data

November 2009 and March 2010, collected during December 2010, principally monitored and deployed by VUW.

Data obtained from the short period array (1) are employed in this thesis and used to constrain the velocity model SAHKE02-M presented in Chapter 5. Table A.2 outlines site location and instrumentation details from each of the TRANSECT stations.

\section{A.2.2.1 Short period array}

This array consisted of thirty seven seismometers deployed along the TRANSECT profile running $80 \mathrm{~km}$ northwest-southeast across lower North Island (red triangles Fig. A.1). Seismometer sites were deployed at an average spacing of $\sim 2 \mathrm{~km}$. Each site consisted of an L28 sensor (section A.3.1) and Reftek-130 logging system (section A.3.5) set to record on high gain at $100 \mathrm{~Hz}$. Sites were installed between March $5^{\text {th }}$ and March $12^{\text {st }}$ and were collected between March $29-31^{\text {st }} 2010$.

For details concerning the broadband array and ocean bottom seismometers see Seward et al. (2010).

\section{A.2.3 WANGANUI deployment}

During the acquisition of the SAHKE03 MCS line, nine short-period seismometers were deployed along a profile running SSW-NNE within Wanganui Basin (Fig. A.1). Of these nine seismometers, one was deployed to the south of the MCS profile, while the remaining eight were deployed north along the flanks of State Highway 4, between Wanganui city and $\sim 35 \mathrm{~km}$ north of Taumarunui. The two northern most sties used L4 sensors (section A.3.2), while the remaining sites used L28 sensors (section A.3.1). In addition, all sites used Reftek-130 logging systems (section A.3.5). These stations were only in place for three or four days spanning the acquisition of the SAHKE3 MCS 
A. Survey parameters and data processing

line (March $16-18^{t h}$ ). Table A.3 outlines site location and instrumentation details from each of the WANGANUI stations.

\section{A.2.4 GeoNet deployment}

In addition to the temporary seismometers deployed on the TRANSECT and WANGANUI profiles, data were also recorded at permanent National Seismometer Network (GeoNet) seismic sites during SAHKE I (Fig. A.1). All of the 25 GeoNet stations in this region consist of either an L4 or CMG-3ESP sensor (sections A.3.2 and A.3.3) and Reftek-130 data logger (section A.3.5). In addition to the GeoNet network, station SNZO (see section A.3.4) located in the suburb of Karori, Wellington (Fig. A.1) also recorded coherent seismic phases during SAHKE I. This station belongs to the Global Seismograph Network (GSN) deployed by IRIS and the United States Geological Survey (IRIS/USGS). Table A.4 outlines site location and instrumentation details of each of the GeoNet stations from which data was analysed during this study.

\section{A.2.5 SAHKE II borehole shot sources}

SAHKE II involved the detonation of 12 dynamite shots across lower North Island. This required the drilling of twelve bore holes for dynamite emplacement. Drilling of these was conducted between January 25th and March 20th 2011, following the granting of consent from each governing district council (Kapiti Coast District Council, Upper Hutt City Council and South Wairarapa district Council), in addition to the Greater Wellington Regional Council and local Iwi. Each borehole was $200 \mathrm{~mm}$ in diameter and drilled to a total vertical depth of $50 \mathrm{~m}$. These were filled with $500 \mathrm{~kg}$ of Centra ${ }^{\mathrm{TM}}$ Gold explosive emulsion with the exception of shots 7 and 8 where $350 \mathrm{~kg}$ was used. The boreholes were loaded between the 3rd and 5th of May 2011 and detonation of the explosives was completed by Orica during the nights of the $10-11^{\text {th }}$ and $12-13^{\text {th }}$ of May 2011. Table A.5 summarises details of each shot location. 
A.2. Data

\section{A.2.6 SAHKE II deployment}

The temporary SAHKE II seismometer deployment was installed along an $80 \mathrm{~km}$ profile from coast to coast across the lower North Island between Glendhu Rocks in the east and Paekakariki in the west (Fig. A.2). This profile was coincident to that of the SAHKE01/02 profile and consisted of 558 single-component and 277 three-component seismometers deployed at $\sim 100$ $\mathrm{m}$ spacing (narrowed to $\sim 50 \mathrm{~m}$ spacing between Kaitoke and Featherston). The transect followed established tracks/roads when possible with some areas in the west only accessible by foot. A gap of $\sim 2 \mathrm{~km}$ exists between shot 09 and 10 (Fig. A.2) where access was restricted by dense bush and a thick peat floor (up to $\sim 2 \mathrm{~m}$ thick). Installation of seismometers in this terrain would have resulted in poor instrument coupling and therefore data quality. Hence, it was deemed unproductive to attempt to deploy stations in this area.

Of the 558 single component seismometers deployed, 281 were "Texan "seismometers (REFTEK RT125) supplied by IRIS/PASSCAL and 277 were "Lunchbox "seismometers (HAKUSAN LS8200SD) provided by Earthquake research institute, University of Tokyo (ERI). All three component seismometers were comprised of three Texan instruments connected to a $3 \mathrm{C}$ sensor. 


\begin{tabular}{|c|c|c|c|c|c|c|c|c|c|c|}
\hline site & Lat & Lon & $\begin{array}{l}\text { Approx. } \\
\text { Elv (m) }\end{array}$ & Northing & Easting & $\begin{array}{c}\text { Logger type } \\
\text { type }\end{array}$ & $\begin{array}{c}\text { Logger } \\
\text { number }\end{array}$ & $\begin{array}{c}\text { Sensor } \\
\text { type }\end{array}$ & Sensor \# & $\begin{array}{c}\text { Sensor } \\
\text { orientation }\end{array}$ \\
\hline OBS16 & -41.9087 & 176.5221 & -2763 & 5916125 & 2802181 & HDDR-5 & - & $4.5 \mathrm{~Hz}$ & & \\
\hline OBS15 & -41.8516 & 176.4289 & -2755 & 5922777 & 2794697 & HDDR-5 & - & $4.5 \mathrm{~Hz}$ & - & - \\
\hline OBS14 & -41.8231 & 176.3817 & -2766 & 5926094 & 2790900 & HDDR-5 & - & $4.5 \mathrm{~Hz}$ & - & - \\
\hline OBS13 & -41.7944 & 176.3359 & -2759 & 5929429 & 2787217 & HDDR-5 & - & $4.5 \mathrm{~Hz}$ & - & - \\
\hline OBS12 & -41.7658 & 176.2889 & -2689 & 5932752 & 2783435 & HDDR-5 & - & $4.5 \mathrm{~Hz}$ & - & - \\
\hline OBS11 & -41.737 & 176.2431 & -2455 & 5936093 & 2779748 & HDDR-5 & - & $4.5 \mathrm{~Hz}$ & - & - \\
\hline OBS10 & -41.7083 & 176.1961 & -2057 & 5939418 & 2775853 & HDDR-5 & - & $4.5 \mathrm{~Hz}$ & - & - \\
\hline OBS9 & -41.6799 & 176.1499 & -2121 & 5942711 & 2772219 & HDDR-5 & - & $4.5 \mathrm{~Hz}$ & - & - \\
\hline OBS8 & -41.651 & 176.1029 & -2988 & 5946061 & 2768425 & HDDR-5 & - & $4.5 \mathrm{~Hz}$ & - & - \\
\hline OBS7 & -41.6225 & 176.0568 & -1893 & 5949363 & 2764699 & HDDR-5 & - & $4.5 \mathrm{~Hz}$ & - & - \\
\hline OBS6 & -41.5938 & 176.0112 & -1714 & 5952686 & 2761006 & HDDR-5 & - & $4.5 \mathrm{~Hz}$ & - & - \\
\hline OBS5 & -41.5647 & 175.965 & -1493 & 5956043 & 2757266 & HDDR-5 & - & $4.5 \mathrm{~Hz}$ & - & - \\
\hline OBS4 & -41.536 & 175.9182 & -1126 & 5959361 & 2753473 & HDDR-5 & - & $4.5 \mathrm{~Hz}$ & - & - \\
\hline OBS3 & -41.5075 & 175.8721 & -1113 & 5962657 & 2749727 & HDDR-5 & - & $4.5 \mathrm{~Hz}$ & - & - \\
\hline OBS2 & -41.4785 & 175.8261 & -731 & 5965997 & 2745989 & DTC 6110 & - & $2.0 \mathrm{~Hz}$ & - & - \\
\hline OBS1 & -41.4495 & 175.7809 & -123 & 5969346 & 2742318 & DTC 6110 & - & $2.0 \mathrm{~Hz}$ & - & - \\
\hline TS001 & -41.3807 & 175.7257 & 25 & 5977129 & 2737946 & Reftek & 9200 & $\mathrm{~L} 28$ & G998 & 0 \\
\hline TS002 & -41.3686 & 175.7126 & 36 & 5978500 & 2736895 & Reftek & $92 \mathrm{~B} 5$ & $\mathrm{~L} 28$ & G58B & 0 \\
\hline TS003 & -41.3518 & 175.6838 & 38 & 5980437 & 2734546 & Reftek & 9490 & $\mathrm{~L} 28$ & $\mathrm{~K} 143$ & 0 \\
\hline LE4 & -41.3579 & 175.6919 & 197 & 5979745 & 2735203 & Reftek & 9298 & $40 \mathrm{~T}$ & T4433 & - \\
\hline TSLE4 & -41.3579 & 175.6919 & 197 & 5979745 & 2735203 & Reftek & $944 \mathrm{~B}$ & $\mathrm{~L} 28$ & $\mathrm{~K} 7$ & 0 \\
\hline
\end{tabular}




\begin{tabular}{|c|c|c|c|c|c|c|c|c|c|c|}
\hline T004 & -41.3403 & 175.6688 & 47 & 5981762 & 2733330 & Reftek & $\mathrm{AC} 13$ & $3 \mathrm{ESP}$ & T34733 & - \\
\hline TS004 & -41.2603 & 175.6684 & 43 & 5981759 & 2733294 & Reftek & $995 \mathrm{~A}$ & $\mathrm{~L} 28$ & G103 & 0 \\
\hline TS006 & -41.3229 & 175.6546 & 78 & 5983722 & 2732199 & Reftek & $924 \mathrm{~F}$ & L28 & G361 & 0 \\
\hline T007 & -41.3041 & 175.6513 & 48 & 5985816 & 2731986 & AUS & AUS & $40 \mathrm{~T}$ & T4148 & - \\
\hline TS007 & -41.3041 & 175.6513 & 48 & 5985816 & 2731986 & Reftek & $930 \mathrm{~A}$ & L28 & G332 & 0 \\
\hline TS008 & -41.2916 & 175.6308 & 64 & 5987260 & 2730313 & Reftek & 9142 & $\mathrm{~L} 28$ & G117 & 0 \\
\hline TSLE3 & -41.2763 & 175.617 & 300 & 5988995 & 2728208 & Reftek & $951 \mathrm{~A}$ & $\mathrm{~L} 28$ & G061 & 12 \\
\hline TS009 & -41.2669 & 175.598 & 218 & 5990088 & 2727648 & Reftek & 9795 & L28 & G338 & 5 \\
\hline T010 & \begin{tabular}{|l|}
-41.252 \\
\end{tabular} & 175.5825 & 111 & 5991775 & 2726385 & AUS & $40 \mathrm{~T}$ & T4673 & - & - \\
\hline TS010 & \begin{tabular}{|l|}
-41.252 \\
\end{tabular} & 175.5825 & 111 & 5991775 & 2726385 & Reftek & $92 \mathrm{~B} 2$ & L28 & K47 & 0 \\
\hline TS011 & -41.2489 & 175.5591 & 143 & 5992183 & 2724446 & Reftek & 9290 & $\mathrm{~L} 28$ & 5060 & 0 \\
\hline TSLE2 & -41.234 & 175.5396 & 91 & 5993884 & 2722858 & Reftek & 9891 & $\mathrm{~L} 28$ & G383 & -0 \\
\hline TS013 & -41.2171 & 175.5193 & 170 & 5995802 & 2721213 & Reftek & $978 \mathrm{~A}$ & L28 & G159 & 5 \\
\hline T014 & -41.2075 & 175.5063 & 145 & 5996902 & 2720154 & AUS & $40 \mathrm{~T}$ & T4664 & - & - \\
\hline TS014 & -41.2076 & 175.5063 & 145 & 5996897 & 2720157 & Reftek & 9446 & L28 & G207 & 0 \\
\hline TS015 & -41.1951 & 175.4908 & 57 & 5998315 & 2718894 & Reftek & 9860 & L28 & 5052 & 0 \\
\hline T016 & -41.1893 & 175.4737 & 39 & 5999003 & 2717475 & Reftek & $\mathrm{AC} 40$ & $40 \mathrm{~T}$ & T4430 & - \\
\hline TS016 & -41.1893 & 175.4737 & 39 & 5999003 & 2717475 & Reftek & 9487 & L28 & R001 & 14 \\
\hline TS017 & -41.1773 & 175.4536 & 30 & 6000381 & 2715831 & Reftek & 9864 & L28 & G401 & 0 \\
\hline T018 & -41.1715 & 175.4257 & 56 & 6001092 & 2713504 & AUS & $40 \mathrm{~T}$ & - & - & - \\
\hline TS018 & -41.1715 & 175.4257 & 56 & 6001092 & 2713504 & Reftek & 9258 & L28 & 9402 & 0 \\
\hline TS019 & -41.1626 & 175.4101 & 36 & 6002111 & 2712225 & Reftek & 9440 & L28 & K145 & 0 \\
\hline T020 & -41.1461 & 175.385 & 23 & 6004001 & 2710165 & Reftek & 9F96 & $40 \mathrm{~T}$ & - & - \\
\hline
\end{tabular}




\begin{tabular}{|c|c|c|c|c|c|c|c|c|c|c|}
\hline TS020 & -41.1461 & 175.385 & 23 & 6004001 & 2710165 & Reftek & $914 \mathrm{~A}$ & L28 & G167 & 0 \\
\hline TS021 & -41.1231 & 175.3522 & 36 & 6006632 & 2707485 & Reftek & A973 & L28 & G230 & -6 \\
\hline T022 & -41.1251 & 175.3497 & 31 & 6006417 & 2707268 & AUS & 40 T & T4336 & - & - \\
\hline TS022 & -41.1251 & 175.3497 & 31 & 6006417 & 2707268 & Reftek & 9560 & L28 & G122 & 10 \\
\hline LTN6 & -41.1033 & 175.3238 & 103 & 6008891 & 2705159 & Reftek & 9926 & 3 ESP & - & - \\
\hline TSLTN6 & -41.1033 & 175.3238 & 103 & 6008891 & 2705159 & Reftek & $933 \mathrm{~d}$ & L28 & G011 & 0 \\
\hline TS025 & -41.0975 & 175.292 & 345 & 6009603 & 2702509 & Reftek & 9478 & L28 & G178 & -8 \\
\hline TS026 & -41.0978 & 175.2705 & 527 & 6009618 & 2700697 & Reftek & $943 \mathrm{~F}$ & L28 & 5089 & 0 \\
\hline TS027 & -41.0914 & 175.245 & 681 & 6010388 & 2698572 & Reftek & $984 \mathrm{D}$ & L28 & G175 & 0 \\
\hline TS028 & -41.0841 & 175.2232 & 350 & 6011240 & 2696764 & Reftek & 9917 & L28 & NW001 & 0 \\
\hline TSLTW3 & -41.0662 & 175.1996 & 199 & 6013278 & 2694833 & Reftek & $92 \mathrm{AB}$ & L28 & G373 & 0 \\
\hline TS030 & -41.0587 & 175.1858 & 184 & 6014145 & 2693696 & Reftek & $956 \mathrm{~F}$ & L28 & G084 & -8 \\
\hline TS032 & -41.0311 & 175.135 & 464 & 6017317 & 2689502 & Reftek & $92 \mathrm{FA}$ & L28 & K8 & 0 \\
\hline TS035 & -40.991 & 175.0552 & 515 & 6021923 & 2682892 & Reftek & $92 \mathrm{E} 4$ & L28 & G372 & 0 \\
\hline TS036 & -40.9924 & 175.0331 & 568 & 6021817 & 2681036 & Reftek & 9283 & L28 & G377 & 0 \\
\hline TS038 & -40.9917 & 175.0121 & 389 & 6021931 & 2679266 & Reftek & 9241 & L28 & G34 & 0 \\
\hline TSLTW1 & -40.965 & 175.0191 & 176 & 6024885 & 2679922 & Reftek & $949 \mathrm{~A}$ & L28 & G118 & 0 \\
\hline TS040 & -40.9671 & 174.9732 & 1 & 6024709 & 2676054 & Reftek & $92 \mathrm{AB}$ & L28 & 5064 & 0 \\
\hline OBS17 & -40.8502 & 174.7302 & 141 & 6038148 & 2655864 & DTC & 6110 & $2.0 \mathrm{~Hz}$ & - & - \\
\hline OBS18 & -40.7935 & 174.6372 & 138 & 6044599 & 2648144 & DTC & 6110 & $2.0 \mathrm{~Hz}$ & - & - \\
\hline OBS19 & -40.7374 & 174.5451 & 137 & 6050965 & 2640484 & DTC & 6110 & $2.0 \mathrm{~Hz}$ & - & - \\
\hline OBS20 & -40.6809 & 174.4529 & 131 & 6057371 & 2632804 & DTC & 6110 & $2.0 \mathrm{~Hz}$ & - & - \\
\hline
\end{tabular}




\begin{tabular}{|c|c|c|c|c|c|c|c|c|c|c|}
\hline site & Lat & Lon & $\begin{array}{l}\text { Approx. } \\
\text { Elv (m) }\end{array}$ & Northing & Easting & $\begin{array}{c}\text { Logger type } \\
\text { type }\end{array}$ & $\begin{array}{l}\text { Logger } \\
\text { number }\end{array}$ & $\begin{array}{c}\text { Sensor } \\
\text { type }\end{array}$ & Sensor \# & \begin{tabular}{|c|} 
Sensor \\
orientation
\end{tabular} \\
\hline S-COR & -41.0506 & 174.8700 & 74 & 6015658 & 2667175 & Reftek & $92 \mathrm{~B} 1$ & L28 & G077 & 0 \\
\hline S-MAT & -39.8462 & 175.1570 & 10 & 6148783 & 2694577 & Reftek & 9236 & L28 & 5018 & 0 \\
\hline S-SUN & -39.6986 & 175.3274 & 160 & 6164787 & 2709762 & Reftek & 9299 & L28 & G200 & 0 \\
\hline S-PAP & $\mid-39.5672$ & 175.2638 & 246 & 6179519 & 2704509 & Reftek & $92 \mathrm{~A} 5$ & L28 & K57 & 0 \\
\hline S-RAE & $\mid-39.4134$ & 175.2529 & 560 & 6196613 & 2704010 & Reftek & 9471 & L28 & G301 & 0 \\
\hline S-CUF & $\mid-39.2232$ & 175.3673 & 764 & 6217454 & 2714422 & Reftek & 9514 & L28 & G082 & 0 \\
\hline S-KAI & $\mid-39.1262$ & 175.3671 & 671 & 6228220 & 2714697 & Reftek & $945 \mathrm{C}$ & L28 & G517 & 0 \\
\hline S-TUN & -38.957 & 175.3575 & 389 & 6247014 & 2714365 & Reftek & $\mathrm{AC} 08$ & L4 & 601 & 0 \\
\hline S-TAP & -38.5606 & 175.3472 & 478 & 6291025 & 2714647 & Reftek & AC09 & L4 & 835 & 0 \\
\hline
\end{tabular}

Table A.3: WANGANUI Deployment station details 


\begin{tabular}{|c|c|c|c|c|c|c|c|c|c|c|}
\hline Site & Lat & Long & $\begin{array}{c}\text { Approx. } \\
\text { Elv (m) }\end{array}$ & Easting & Northing & $\begin{array}{c}\text { Logger } \\
\text { Type }\end{array}$ & $\begin{array}{c}\text { Sensor } \\
\text { brand }\end{array}$ & $\begin{array}{c}\text { Sensor } \\
\text { type }\end{array}$ & Sensor \# & $\begin{array}{c}\text { Sensor } \\
\text { orientation }\end{array}$ \\
\hline SNZO* & 174.7041 & -41.3105 & 110 & 2652683 & 5987279 & - & Geotech & KS-54000 & - & - \\
\hline WEL & 174.7680 & -41.2858 & 138 & 2658093 & 5989915 & - & Guralp & CMG-3ESP & T3Q00 & 0 \\
\hline KIW & 174.9096 & -40.8626 & 381 & 2670973 & 6036647 & - & Sercel & L4C-3D & 2911 & 0 \\
\hline WAZ & 174.9853 & -39.7564 & 382 & 2680139 & 6159293 & - & Guralp & CMG-3ESP & T3B64 & 0 \\
\hline PRVZ & 175.3462 & -39.2910 & 770 & 2712422 & 6210171 & - & Sercel & L4C-3D & 795 & 0 \\
\hline TWVZ & 175.4375 & -39.0725 & 1084 & 2720964 & 6234206 & - & Sercel & L4C-3D & 2822 & 0 \\
\hline CAW & 175.0663 & -41.1089 & 283 & 2683536 & 6009002 & - & Sercel & L4C-3D & 1119 & 0 \\
\hline MTW & 175.5014 & -41.1596 & 311 & 2719914 & 6002417 & - & Sercel & L4C-3D & 2995 & 0 \\
\hline TRWZ & 175.6877 & -41.3998 & 379 & 2734728 & 5975297 & - & Sercel & L4C-3D & 2905 & 0 \\
\hline
\end{tabular}

Table A.4: GeoNet deployment station details. * Station SNZO belongs to Global Seismic Network (GSN). 


\begin{tabular}{|c|c|c|c|c|c|c|c|c|c|c|}
\hline Borehole & Latitude & Longitude & $\begin{array}{c}\mathbf{N Z T M} \\
(\mathrm{N})\end{array}$ & $\begin{array}{c}\text { NZTM } \\
(\mathrm{E})\end{array}$ & $\begin{array}{l}\text { Elevation } \\
(\mathbf{m})\end{array}$ & $\begin{array}{c}\text { Shot time } \\
\text { (UTC) }\end{array}$ & $\begin{array}{c}\text { Borehole } \\
\text { depth }(\mathrm{m})\end{array}$ & $\begin{array}{l}\text { Charge } \\
\text { size }(\mathrm{kg})\end{array}$ & \begin{tabular}{|c|} 
Type of \\
explosive
\end{tabular} & \begin{tabular}{|c|} 
Date borehole \\
loaded
\end{tabular} \\
\hline 1 & 175.72479 & -41.37981 & 5415496 & 1827849 & 24 & 2011:132:15:23:00 & \begin{tabular}{|l|}
48.3 \\
\end{tabular} & 500 & Centra $^{t m}$ Gold & 4-May \\
\hline 2 & 175.6848 & -41.35205 & 5418683 & 1824601 & 33 & 2011:132:14:43:00 & 48 & 500 & Centra $^{t m}$ Gold & 4-May \\
\hline 3 & 175.65999 & -41.2993 & 5424604 & 1822705 & 70 & 2011:132:13:57:00 & 50.4 & 500 & Centra $^{t m}$ Gold & 4-May \\
\hline 4 & 175.56282 & -41.24227 & 5431191 & 1814755 & 92 & 2011:132:13:00:00 & 50 & 500 & Centra $^{t m}$ Gold & 5-May \\
\hline 5 & 175.50369 & -41.20403 & 5435571 & 1809922 & 100 & 2011:132:12:14:00 & 50 & 500 & Centra $^{t m}$ Gold & 4-May \\
\hline 6 & 175.44523 & -41.18247 & 5438104 & 1805088 & 26 & 2011:132:11:13:00 & 50 & 500 & Senatel $^{\text {tm }}$ & 5-May \\
\hline 7 & 175.39397 & -41.14971 & 5441861 & 1800888 & 28 & 2011:132:10:24:00 & 50 & 350 & Centra $^{t m}$ Gold & 4-May \\
\hline 8 & 175.35007 & -41.12631 & 5444559 & 1797274 & 35 & 2011:132:09:03:00 & 50 & 350 & Centra $^{t m}$ Gold & 4-May \\
\hline 9 & 175.20571 & -41.06937 & 5451198 & 1785315 & 219 & 2011:130:11:14:00 & 50.4 & 500 & Centra $^{t m}$ Gold & 3-May \\
\hline 10 & 175.13882 & -41.00309 & 5458697 & 1779876 & 355 & 2011:130:13:22:00 & 50 & 500 & Senatel $^{t m}$ & 5-May \\
\hline 11 & 175.08568 & -40.96936 & 5462549 & 1775496 & 395 & 2011:130:15:13:00 & 50 & 500 & Centra $^{t m}$ Gold & 3-May \\
\hline 12 & 174.98897 & -40.97708 & 5461882 & 1767333 & 54 & 2011:130:16:46:00 & 50 & 500 & Centra $^{t m}$ Gold & 3-May \\
\hline
\end{tabular}

Table A.5: SAHKE II onshore shot summary information (Seward et al., 2011). 
A. Survey parameters and data processing

\section{A.3 Instrumentation and data extraction}

Several different instrument types were used to record both passive and active source seismic data during the SAHKE. Active source data used in this thesis were recorded by two types of short period instruments. Almost all temporary sites were equipped with L28 sensors supplied by IRIS/PASSCAL, the only exceptions being the two most northern sites on the WANGANUI deployment. These two sites (S-TUN and S-TAP) were equipped with L4 sensors provided by Victoria University of Wellington (VUW). Each short period site was also equipped with a Reftek RT130 data logger and a power source. Two types of power sources were used, consisting of either a single battery and solar panel or two $78 \mathrm{~A} / \mathrm{h}$ sealed lead-acid batteries. Most of the permanent GeoNet sites in this area are equipped with L4 sensors, while a few CMG sensors are used (section A.3.3). All geonet sites are powered by a single battery and solar panel.

\section{A.3.1 L28 sensors - Sercal L28-3D}

These are high frequency shot period sensors with natural frequencies of 4.5 Hz. Data recorded by sensors of this type on the TRANSECT deployment were processed and cut into receiver gathers at Geological and Nuclear Sciences (GNS). Data from the WANGANUI deployment were converted from raw reftek format to SEG-Y format and cut into receiver gathers using the scripts ref2segy.sh (CD) and create_gather.sh (CD).

\section{A.3.2 L4 sensors - Sercal L4C-3D}

These are shot period sensors with natural frequencies of $1 \mathrm{~Hz}$. Data recorded by sensors of this type on the WANGANUI deployment were supplied as raw reftek files. These were converted to SEG-Y format and cut into receiver gathers using the same method as for data from L28 sensors, as discussed above in section A.3.1. 
A.3. Instrumentation and data extraction

Data recorded by sensors of this type on the GeoNet network were acquired in Mini-SEED format (see http : //www.iris.washington.edu/manuals/SEEDappG.htm) by querying the online GNS Common Waveform Buffer data repository (http://www.geonet.org.nz/resources/basic-data/waveform-data/). This process was automated using script download_geonet_data.sh (CD). This script was also used to convert these data into SEG-Y format. Once in SEG-Y format, the script create_gather.sh (CD) was then used to cut these data into receiver gathers. Both scripts download_geonet_data.sh and create_gather.sh were modified from scripts supplied by Daniel Bassett.

\section{A.3.3 CMG sensors - Guralp CMG-3ESP}

These are broadband sensors with corner frequencies of $0.333 \mathrm{~Hz}$, making these sensors more suited to recording passive seismic data. GeoNet sites WEL and WAZ (Fig. A.1) are equipped with this type of sensor. Although these senors are not specifically designed for recording active source data, receiver gathers cut from these sites exhibit clear refraction and reflection phase arrivals. Data for these stations were downloaded and processed into receiver gathers using the same method as discussed above for GeoNet L4 sensors in section A.3.2.

\section{A.3.4 SNZO sensor - Geotech KS-54000}

Station SNZO (Fig. A.1), belongs to the IRIS Global Seismic Network and is a equipped with a Geotech KS-54000 borehole seismometer, designed for ultra low-noise monitoring for frequencies from 0.003 to $5 \mathrm{~Hz}$.

Data recorded at this station during the shooting of MCS line SAHKE03 are amongst the most coherent in the dataset and this receiver gather was supplied by Stuart Henrys (GNS). This data can also be acquired from ISIS using a standard IRIS batch request form. A batch request form informs 
A. Survey parameters and data processing

IRIS from which station the user wishes to retrieve data from, in addition to the time duration and data channel(s) required. The resulting data is posted to an FTP server for retrieval in SEED format. These data can then be processed into receiver gathers using the same method as discussed above for GeoNet data in section A.3.2.

\section{A.3.5 Reftek-130 data logger}

Reftek-130 data loggers were used to record all data recorded at short period sensors deployed during SAHKE I. These are also capable of recording broadband data and hence are ideal for both active and passive experiments. Each device can record two channels, and are equipped with a GPS receiver connector. They also have a serial connector for setup and control, and a Net connector that combines serial PPP and ethernet for network access.

\section{A.4 Receiver gather preparation}

Analysis of the onshore-offshore wide-angle reflection/reflection data collected during SAHKE I was achieved by creating and interpreting a suite of receiver gathers. The creation of receiver gather datasets is widely regarded as the best method for interpreting these data (e.g. Babel Working Group, 1993; Okaya et al., 2003; Bassett et al., 2010; Scherwath et al., 2010).

The creation of a common-receiver gather requires the extraction of set lengths of data from a waveform time-series continuously recorded at a particular seismometer, during the acquisition of a corresponding MCS profile. Each portion of data extracted represents a single trace on the final gather. The start time of each trace is determined by the timing of a corresponding MCS shot. In this study, the conversion of raw data into a common receiver gather involved several processing steps that varied 
A.4. Receiver gather preparation

depending on whether data was recorded at a temporary seismograph or permanent GeoNet seismograph. Construction of these gathers was achieved using IRIS/PASSCAL utility codes as explained below.

\section{A.4.1 WANGANUI data}

Data recorded by sensors on the WANGANUI deployment were stored by reftek-130 data loggers as hour long data packets. In order to convert these data from raw reftek format to SEG-Y format, the raw data packets from each site were first merged into single files using the PASSCAL command rt130cut. By default the reftek data were stored in separate directories that are defined and named according to the Julian day of recording. Executing the command rt130cut from the top level data directory (while including the argument flag -r) results in the merging of all raw reftek data from subdirectories recursively. This step was necessary in order to simplify data management and allow the execution of the command ref2segy for conversion from reftek format to SEG-Y format. The command ref2segy requires the provision of the reftek channel (flag -c) and stream (flag -s) from which to source data, in addition to a text file that provides station information (DAS name, sample rate, format and preamp gain) for each stream and channel pair (flag -1). Table A.6 demonstrates the formatting required for this text file. This process was automated using script ref2segy.sh (CD).

$\begin{array}{lllllll}\text { \#st_das } & \text { end_das } & \text { DS } & \text { s_rate } & \text { format } & \text { chan } & \text { preamp_gain } \\ 921 \mathrm{~B} & 921 \mathrm{~B} & 1 & 100 & \text { co } & 1 & 1 \\ 921 \mathrm{~B} & 921 \mathrm{~B} & 1 & 100 & \text { co } & 2 & 1 \\ 921 \mathrm{~B} & 921 \mathrm{~B} & 1 & 100 & \text { co } & 3 & 1 \\ 9236 & 9236 & 1 & 100 & \text { co } & 1 & 1 \\ 9236 & 9236 & 1 & 100 & \text { co } & 2 & 1 \\ 9236 & 9236 & 1 & 100 & \text { co } & 3 & 1\end{array}$

Table A.6: Example file demonstrating the format of a typical DAS.list text file for provision to the command ref2segy. 
A. Survey parameters and data processing

\section{A.4.2 GeoNet data}

Data recorded at permanent GeoNet sites were acquired in Mini-SEED format (Standard Earthquake Exchange Data; see http : //www.iris.washington.edu/manuals/SEEDappG.htm) by querying the online GNS Common Waveform Buffer data repository (http://www.geonet.org.nz/resources/basic-data/waveform-data/). This process was automated using script download_geonet_data.sh (CD). These data were converted from Mini-SEED format to SEG-Y format using the PASSCAL command rdseed. This command requires the specification of two important input parameters. The first parameter is the output format, this is set using flags - $d$ and -o. The -o flag is provided with the argument "7" as this specifies PASSCAL SEG-Y as the output format. The second parameter sets the SEED volume from where Mini-SEED metadata is sourced. This is set using the -g flag, the New Zealand dataless seed volume, supplied by Daniel Bassett was used for converting GeoNet data.

\section{A.4.3 Global Seismographic Network data}

Data from station SNZO (Fig. A.1) was supplied by Stuart Henrys (GNS), however can also be acquired using a standard GSN batch request form email. Table A.7 displays the request form that can be used to acquire these data. This form specifies the station, time range and data type required. The resulting data are posted to an FTP server for retrieval in SEED format. These data can then be cut into a common receiver gather using the same method as for the GeoNet data.

\section{A.4.4 Constructing receiver gathers}

Once converted to SEG-Y format, the PASCCAL command segygather was used to construct each receiver gather. This process was automated using the script create_gather.sh (CD). The command segygather requires the provision of two important input files. The first is the corresponding MCS line 


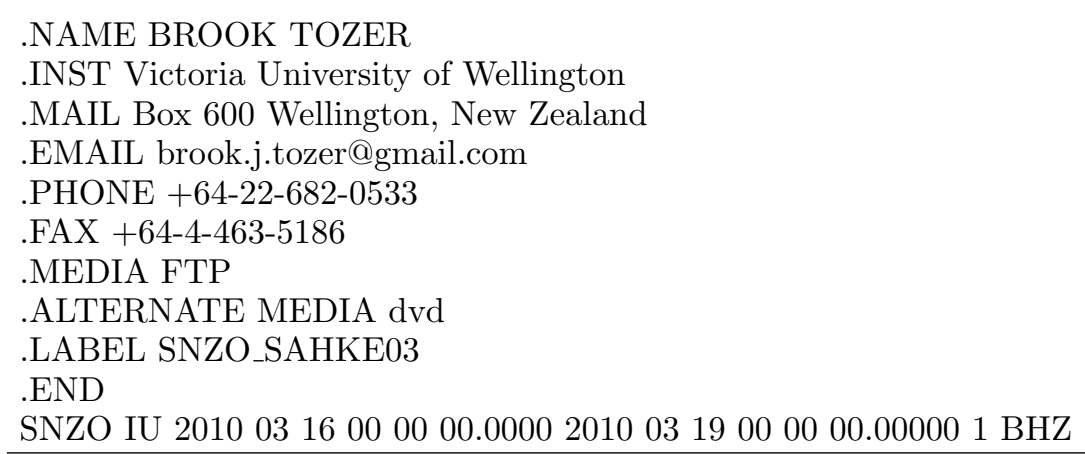

Table A.7: Example table demonstrating the format of a typical GSN batch request form. The final line of this form specifies the station, time range and data type required.

shot-time record (-l flag). The second is a list file that contains the full directory paths to the suite of SEG-Y files containing the continuous wave form data, from which discrete sections are extracted to construct each trace (-i flag). Text files containing shot-time records of MCS lines SAHKE02 and SAHKE03, were pre-formatted as required by segygather and supplied by Daniel Bassett. Table A.8 provides an example of the formatting required for this text file.

\begin{tabular}{llllllll} 
shot & time & delay & lon & lat & elevation depth wdepth \\
33001001 & $10: 075: 14: 10: 42.163$ & 0 & 174.8220991 & -40.9293796 & 0 & 6 & 2000 \\
33001002 & $10: 075: 14: 11: 41.978$ & 0 & 174.8223704 & -40.9284974 & 0 & 6 & 2000 \\
33001003 & $10: 075: 14: 12: 40.736$ & 0 & 174.8226376 & -40.9276297 & 0 & 6 & 2000 \\
33001004 & $10: 075: 14: 13: 39.566$ & 0 & 174.8229079 & -40.9267403 & 0 & 6 & 2000 \\
& \multicolumn{5}{c}{ Table A.8: M }
\end{tabular}

CS shot time text file exampleExample demonstrating the format required for a MCS shot time text file for provision to the command segygather.

The trace length for each gather must also be provided to segygather (-n flag). A trace length of $60 \mathrm{~s}$ was used when constructing all receiver gathers created during this project. This length was chosen to ensure all potential $\mathrm{p}$ and s-wave arrivals would be included in each record. 
A. Survey parameters and data processing

\section{A.4.5 Geometry}

The addition of geometry information (i.e. source-receiver offset of each trace) to each receiver gather was performed subsequent to the construction of each gather. This was achieved using the Geometry application within Claritas. The Geometry application creates a geometry database (.geom) file for given shot and receiver pairs. In the case of receiver gathers this application requires the provision of two text files. The first contains coordinates of the seismic station from which the receiver gather was created and the second contains the coordinates of the corresponding MCS shot locations. Unfortunately, this process was unable to be automated and hence a geometry database was created for each seismograph individually.

The offset information contained within each geometry database file was written into the corresponding receiver gather trace header "offset" using a Claritas job flow. This process was automated using the job control system (JCS) function within Claritas.

\section{A.4.6 SAHKE II shot gather data}

These data were processed into shot gathers by IRIS passcal technicians. Subsequently, trace headers were prepared and added to these data by David Okaya at the University of South California. These were supplied by David Okaya for use in this study.

\section{A.5 Sesimic processing}

Processing and interpretation of receiver gathers was achieved using the Seismic Viewer (SV) application within Claritas. A variety of seismic processing techniques were applied to each receiver gather in order to increase signalto-noise ratio in an attempt to 'illuminate' phase arrivals. The majority of these processing techniques were able to be applied on-the-fly within the SV 
A.5. Sesimic processing

application, and were varied throughout the interpretation process in order to enhance the coherency of individual phase arrivals. However, two processing techniques, Deconvolution and Runmix trace summing, are not available within SV and therefore required the creation of separate SEG-Y files. In addition to the application of processing techniques, manipulation of both the aspect ratio and data display type of each gather proved extremely useful.

\section{A.5.1 Debias}

A debias was used to remove the DC bias of each seismic trace. A debias operates by subtracting the mean of the live sample values from each of the sample values in the given window (Ravens, 1999). Window length was set equal to record length to ensure the mean value of the entire record was used for calculating debias values.

\section{A.5.2 Trace balance}

A constant trace balance was applied to average the amplitude of all traces within a given gather. The balance window length was set equal to record length to ensure traces were balanced according to the average amplitude of the entire record.

\section{A.5.3 Frequency filtering}

Bandpass frequency filters were applied to remove frequency content considered to be noise within each gather. Bandpass filters were designed on a gather-by-gather basis, with initial ramp and cut values determined using the SV analysis tool Frequency spectrum graph, subsequent to the application of a debias and trace balance. This tool displays an amplitude vs frequency plot, on which peaks in amplitude occur at dominate frequencies. An amplitude peak at a $\sim 5.2 \mathrm{~Hz}$ occurs in most gathers, consistent with the frequency content expected for refracted and wide-angle reflected seismic phases. Hence, filters were designed to pass freqencies in the range of 
A. Survey parameters and data processing

$5.2 \mathrm{~Hz}$. Filters were further modified for optimum effect using a fixed and anchor method, whereby three filter values are kept constant while the other is varied. Filter values ranged from [1 $\left.2 \begin{array}{llll}1 & 6 & 8 & \mathrm{~Hz}\end{array}\right]$ to $\left[\begin{array}{lllll}2 & 4 & 10 & 14 \mathrm{~Hz}\end{array}\right]$ with the majority of gathers filtered using a $\left[\begin{array}{llllll}1 & 3 & 8 & 12 & \mathrm{~Hz}\end{array}\right]$ bandbass filter.

\section{A.5.4 Automatic gain control}

An automatic gain control (AGC) was applied to gathers to normalise trace amplitudes down (in time) and horizontally (spatially) within each gather. An AGC operates by multiplying each trace sample by a scaling factor that is calculated so that the average amplitude within a specified time window is constant down the trace (Ravens, 1999). The AGC window length was varied during processing with a length of $\sim 3000 \mathrm{~ms}$ usually most effective.

\section{A.5.5 Linear moveout}

Receiver gathers were plotted using a reduced travel time scale (see section 2.4.1.3) by applying a linear moveout correction within SV. This has the effect of progressively reducing travel travel-time as a function of offset, resulting in the rotation of travel-time curves, such that, wave phases with apparent velocities equal to a given reduction velocity plot as horizontal arrivals. Reduction velocities were varied throughout interpretation, as the flattening of different phase arrivals enabled the delineation between first arrivals and reverberations.

\section{A.5.6 Runmix trace summing}

A runmix trace summing function was applied to all receiver gathers in an attempt to increase the amplitude of coherent phase arrivals while decreasing the amplitude of random noise. This function operates by multiplying a specific number of adjacent traces (which must be odd), after they are multiplied by specified weighting values. The resulting trace values are summed 
A.5. Sesimic processing

to produce the output trace (Ravens, 1999). The function moves across the gather such that the operation is centred on each trace once. This process has an advantage over other trace summing methods, in that it preserves the number of input traces on the output gather. Weighting values are stored in a vector that specifies the value by which the current trace is to be multiplied.

Several runmix operators were tested, with the final operator set to sum three traces with weightings of $0.1-0.8-0.1$. Maintaining a weighting vector sum of 1 preserves relative amplitudes between traces.

\section{A.5.7 Predictive deconvolution}

Predictive deconvolution was used to remove seismic noise that occurs within the frequency spectrum of refracted and reflected phase arrivals. Particularly, deconvolution filters were designed to suppress reverberations (ringing of the seismic data) and ghosts (short path multiples) that disrupt and/or mask first arrival wave trains.

In an analytical sense, deconvolution is the process of removing a filter operation (convolution) that is applied to a seismic waveform as it propagates through the ground or within a recording system (Kearey et al., 2002). This process is demonstrated by equation A.5.7

$$
\gamma(t)=g(t) \star f(t)
$$

where $\gamma(t)$ is the filtered output of the input waveform $g(t)$ convolved by the impulse response of the Earth filter $f(t)$. Unfortunately, the input waveform $g(t)$ and Earth filter $f(t)$ are unknown and hence were estimated using a predictive approach. This was achieved using the Cliritas processing $D E$ $C O N W$. This requires the provision of filter and gap operators. These were determined by using the autocorrelation function in SV. The gap length is estimated by the length of the first wavelet while the filter length is estimated 
A. Survey parameters and data processing

as the length of the correlated wavelets.

\section{A.5.8 Visual display}

The ability to easily manipulate both the visual display type and aspect ratio of the data display in SV proved very useful for interpreting phase arrivals. Plotting gathers with a small trace spacing improved identification of coherent wave trains, while increasing trace spacing to very large values enabled the accurate picking of arrival times on individual traces. Gathers were interpreted using both reduced and total travel-time, and displayed using both variable density (VD) and variable area and wiggle trace (VAWG) display types. VD plotting enabled the assessment of phase coherency were signal-to-noise ratio was low, while VAWG display was useful for accurately picking phase inflections on single traces.

\section{A.6 Interpretation}

Gathers were interpreted using the Globe Claritas ${ }^{T M} \mathrm{SV}$ application. Picks were limited to $\mathrm{P}$-wave arrivals and of the 44 receiver gathers and 12 shot gathers created, from which picks were made on 41 receiver gathers and all shot gathers, with 142 individual phases interpreted and $\sim 45,000$ travel-time picks made.

Phase arrivals were identified by eye and picked manually or by using a cross-correlation function to semi-automate this process when appropriate. Initial picks were limited to those phases that were easily identified, namely first arrivals and some later arriving wide-angle reflections. These were used to develop preliminary $\mathrm{Vp}$ models, from which synthetic travel-time arrivals where calculated and overlaid upon each gather, in order to aid in the identification of weakly coherent phases and test the reproducibility of original travel-time picks.

In this way, picks were made concurrently to the development of each model. 
An advantage to this approach is that it allowed for the systematic adjustment or removal of picks that were evidently erroneous when considered in relation to the fit of travel-time picks from proximal stations.

Individual pick (*.pic) files were output from SV for each individual phase interpretation. Pick uncertainties were assigned by inspection, taking consideration of signal-to-noise ratio and coherency of each phase. Uncertainty values ranged from $70 \mathrm{~ms}$ to $200 \mathrm{~ms}$ with the vast majority $\sim 100 \mathrm{~ms}$. Uncertainties were assigned to each pick during the execution of script claritas2invr.sh (CD). This script was constructed to convert the output .pic files from SV into the input format required by the velocity modelling code RayINVR used to developed the velocity models presented in Chapters 4 and 5 .

\section{A.7 Summary}

Figure A.3 displays a summary flow chart outlining the procedure by which the subset of onshore/offshore receiver gather data and onshore shot gather data used in this thesis were extracted, processed and interpreted. These steps are coloured according to the input (orange), processing method (blue/green) and output (red). 
A. Survey parameters and data processing

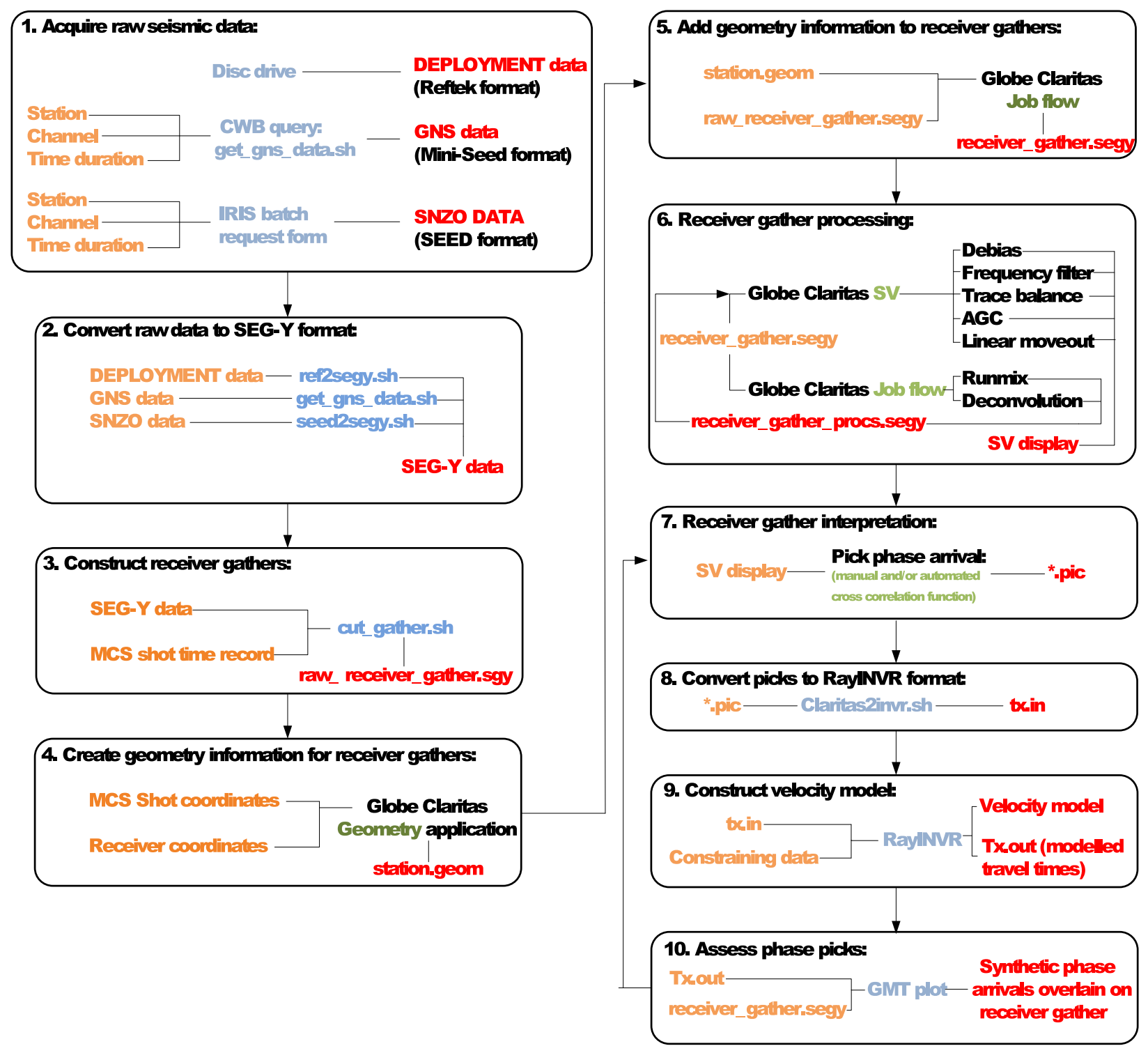

Figure A.3: Flowchart outlining the procedure by which the subset of onshore/offshore receiver gather data and onshore shot gather data used in this thesis were extracted, processed and interpreted. The steps are coloured according to the input (orange), processing method (blue/green) and output (red)

\section{A.8 Receiver and shot gather interpretations}

All receiver gathers and shot gathers interpreted during this study are available for viewing on the attached CD within the directory "gathers". Travel- 
times of phase arrivals interpreted on these gathers were used to constrain the two 2-D velocity models developed in Chapter 4. Each gather is displayed with a reduced travel-time of $6 \mathrm{kms}^{-1}$. Plain gathers are displayed first, with interpretations of phase arrivals overlain below. 
A. Survey parameters and data processing 
Appendix B

Multi-channel-seismic shot gathers 

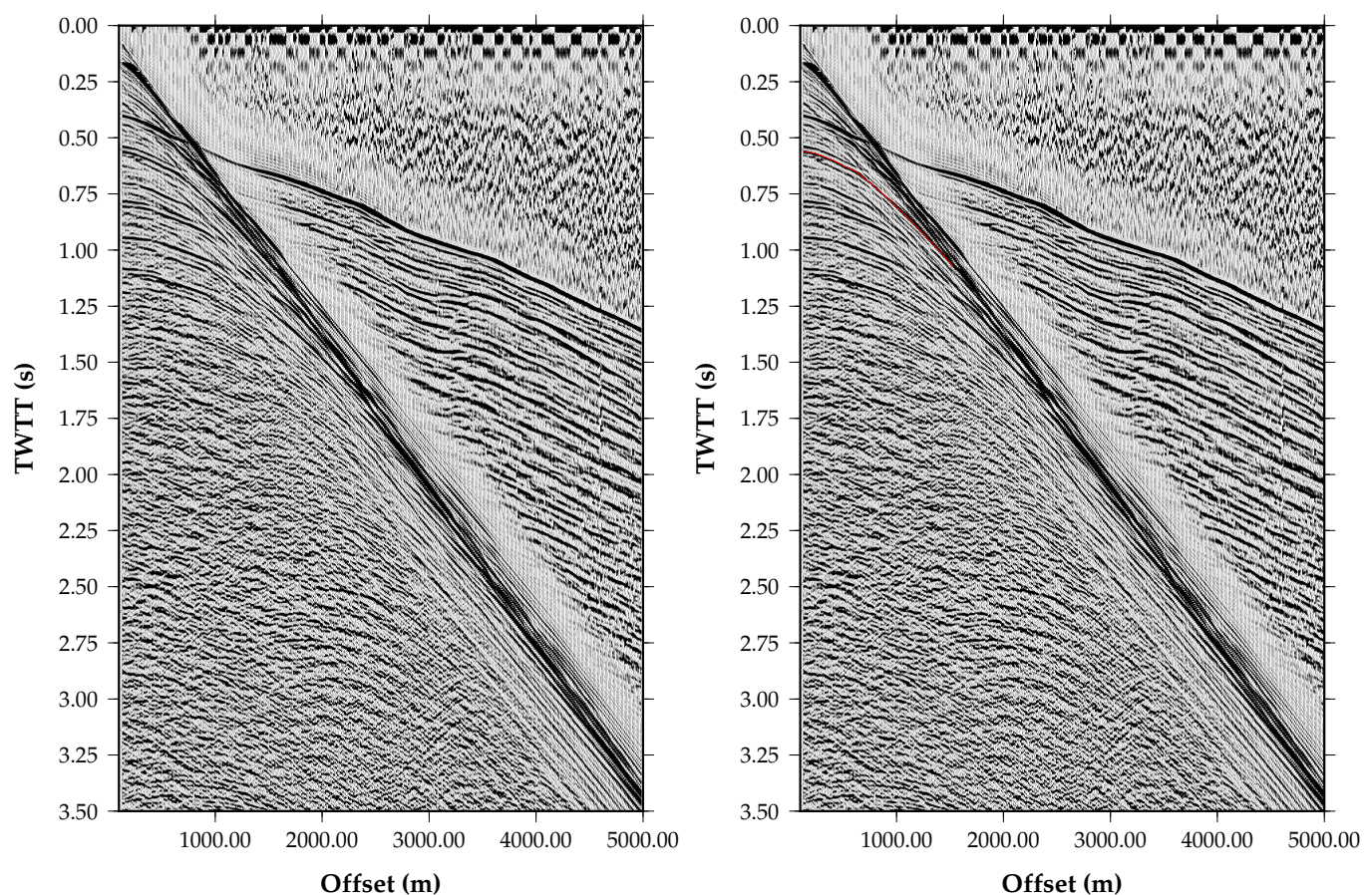

Figure B.1: Left: Multi-channel-seismic shot gather 54 from seismic reflection line SAHKE03. Right: Interpreted basement reflection overlain. Each gather has had a debias (9999 ms window length), bandpass frequency filter [10 $204060 \mathrm{~Hz}]$ and automatic gain control (500 ms window length) applied. 

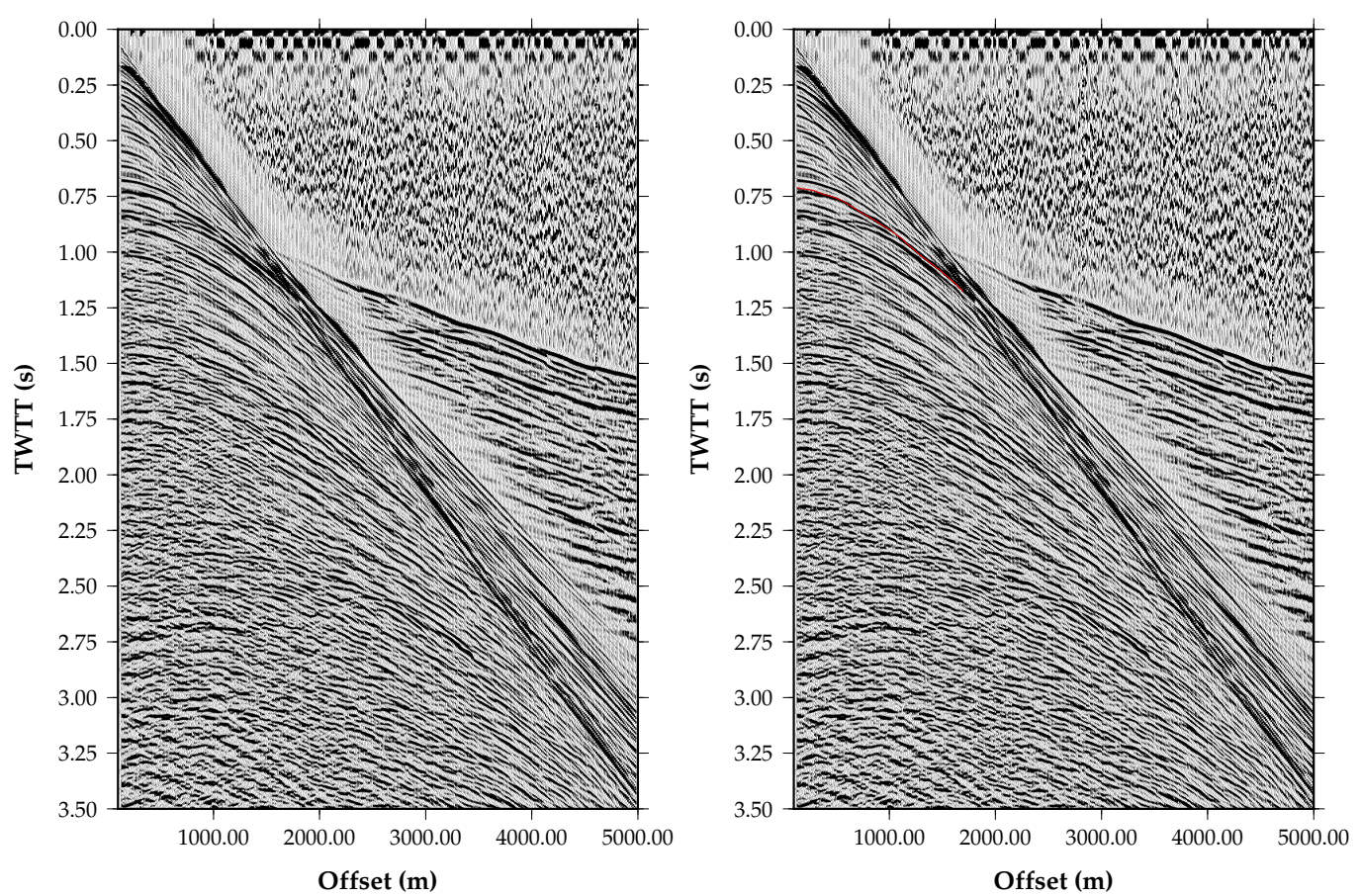

Figure B.2: Left: Multi-channel-seismic shot gather 104 from seismic reflection line SAHKE03. Right: Interpreted basement reflection overlain. Each gather has had a debias (9999 ms window length), bandpass frequency filter [10 $204060 \mathrm{~Hz}]$ and automatic gain control (500 ms window length) applied. 

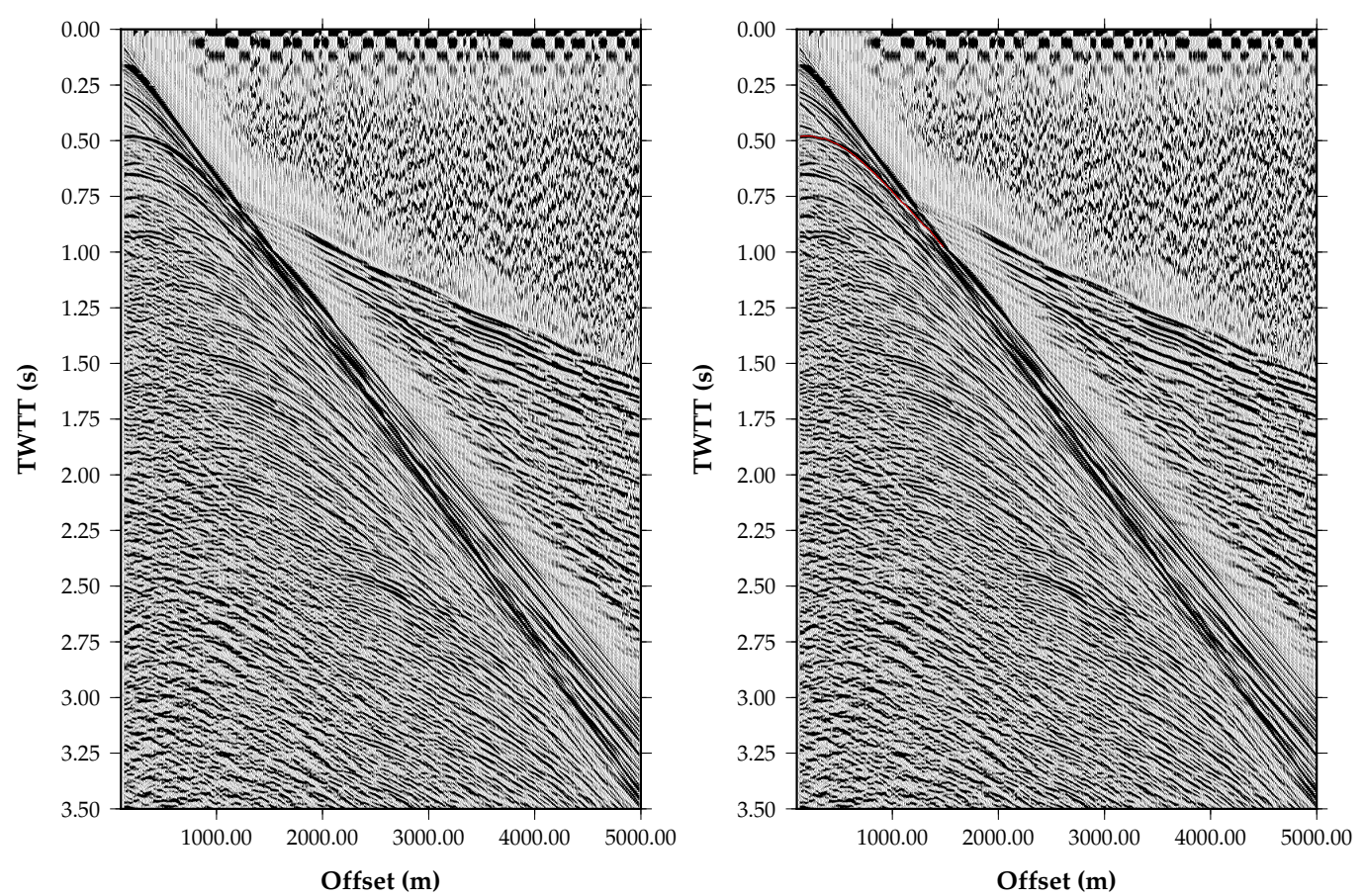

Figure B.3: Left: Multi-channel-seismic shot gather 154 from seismic reflection line SAHKE03. Right: Interpreted basement reflection overlain. Each gather has had a debias (9999 ms window length), bandpass frequency filter [10 $204060 \mathrm{~Hz}]$ and automatic gain control (500 ms window length) applied. 

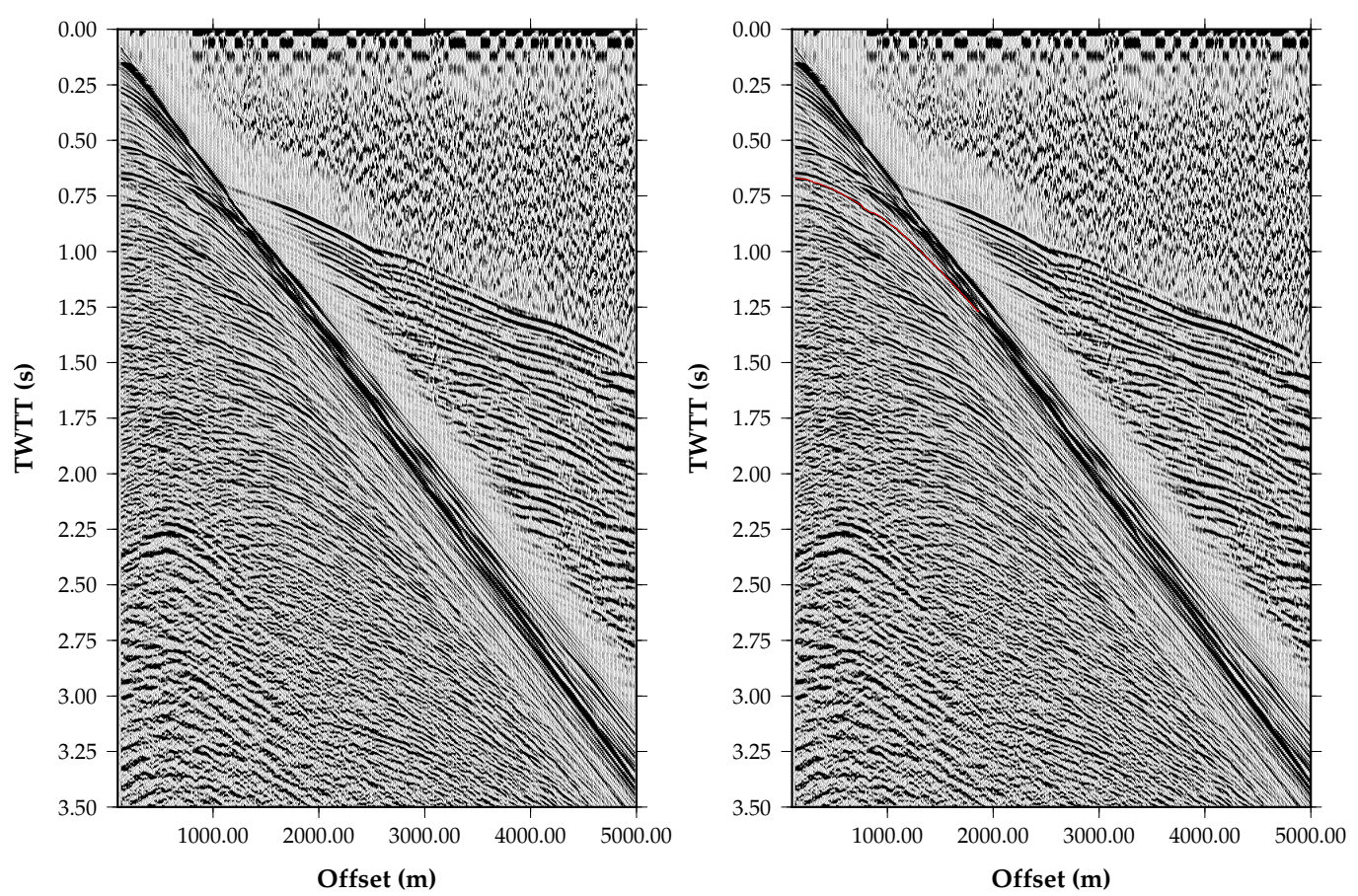

Figure B.4: Left: Multi-channel-seismic shot gather 204 from seismic reflection line SAHKE03. Right: Interpreted basement reflection overlain. Each gather has had a debias (9999 ms window length), bandpass frequency filter [10 $204060 \mathrm{~Hz}]$ and automatic gain control (500 ms window length) applied. 

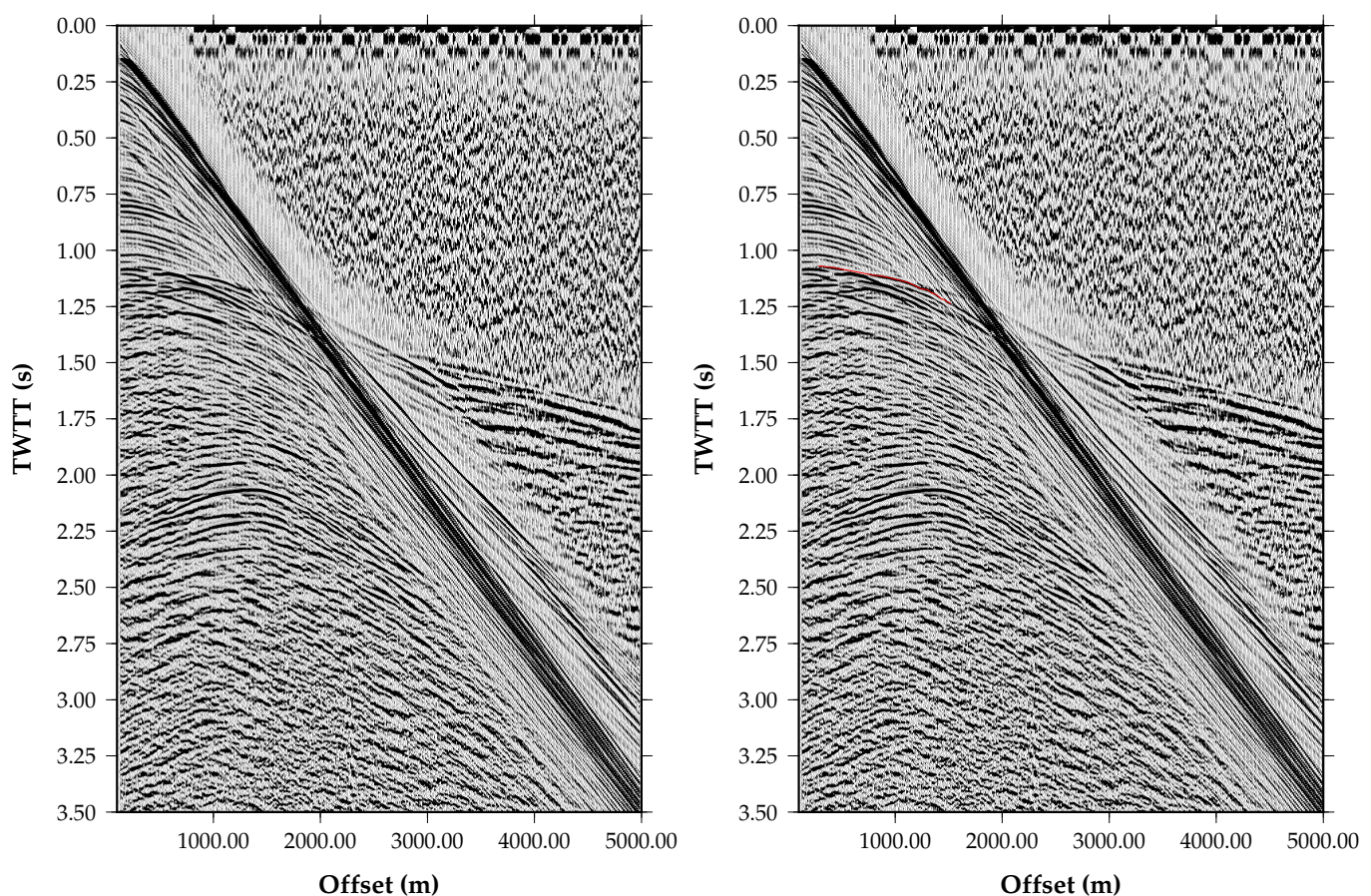

Figure B.5: Left: Multi-channel-seismic shot gather 254 from seismic reflection line SAHKE03. Right: Interpreted basement reflection overlain. Each gather has had a debias (9999 ms window length), bandpass frequency filter [10 $204060 \mathrm{~Hz}]$ and automatic gain control (500 ms window length) applied. 

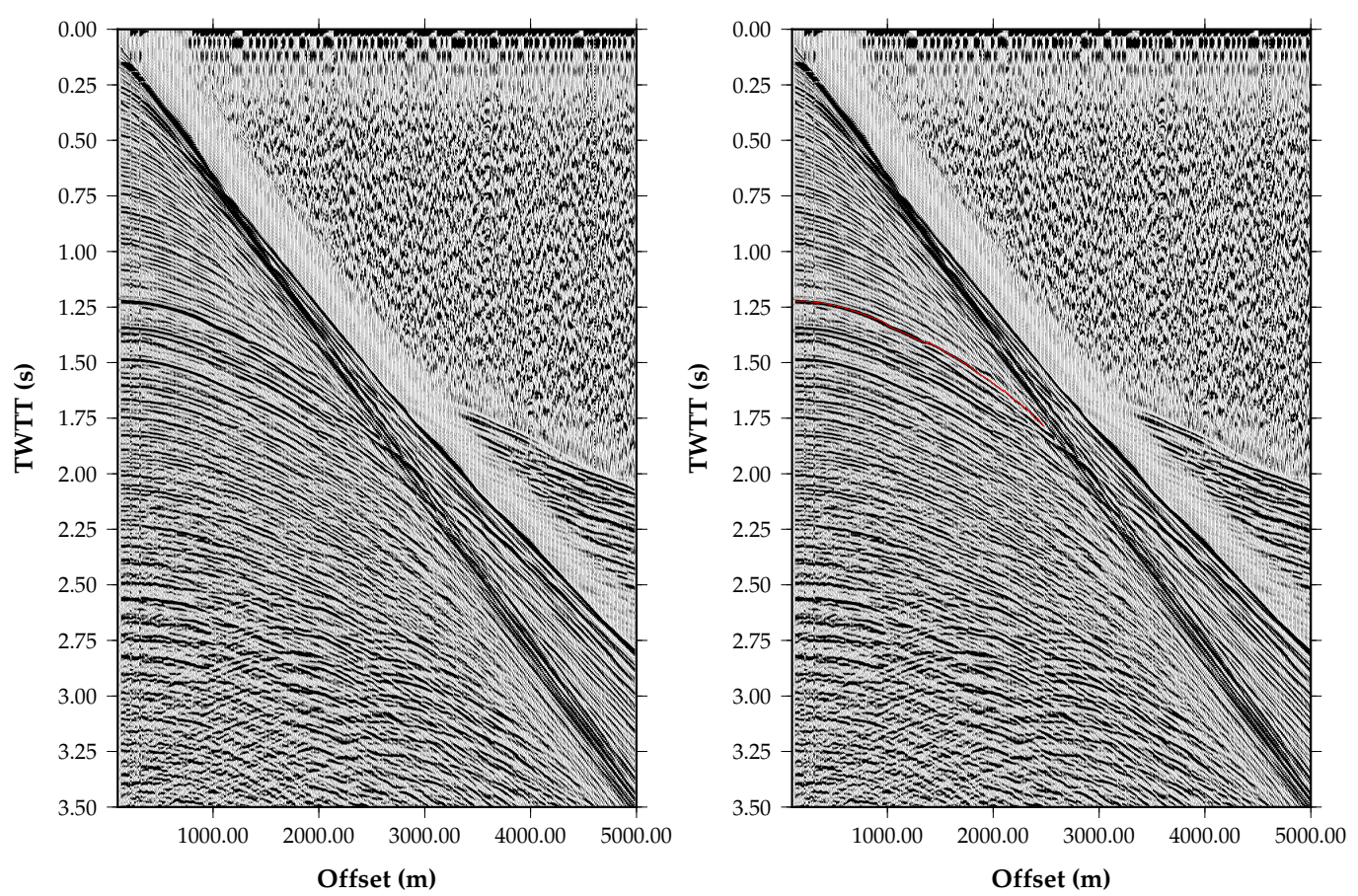

Figure B.6: Left: Multi-channel-seismic shot gather 304 from seismic reflection line SAHKE03. Right: Interpreted basement reflection overlain. Each gather has had a debias (9999 ms window length), bandpass frequency filter [10 $204060 \mathrm{~Hz}]$ and automatic gain control (500 ms window length) applied. 

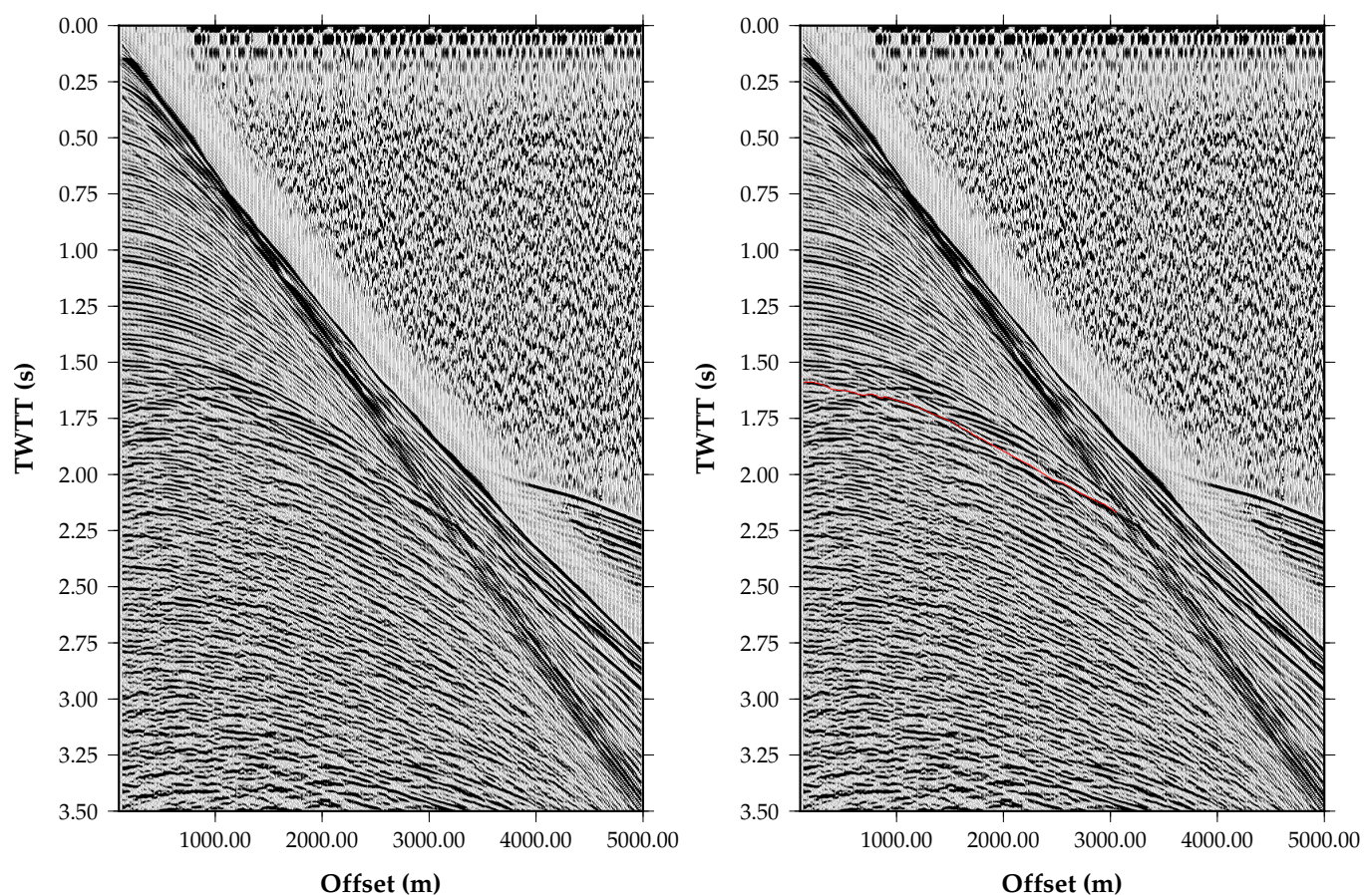

Figure B.7: Left: Multi-channel-seismic shot gather 354 from seismic reflection line SAHKE03. Right: Interpreted basement reflection overlain. Each gather has had a debias (9999 ms window length), bandpass frequency filter [10 $204060 \mathrm{~Hz}]$ and automatic gain control (500 ms window length) applied. 

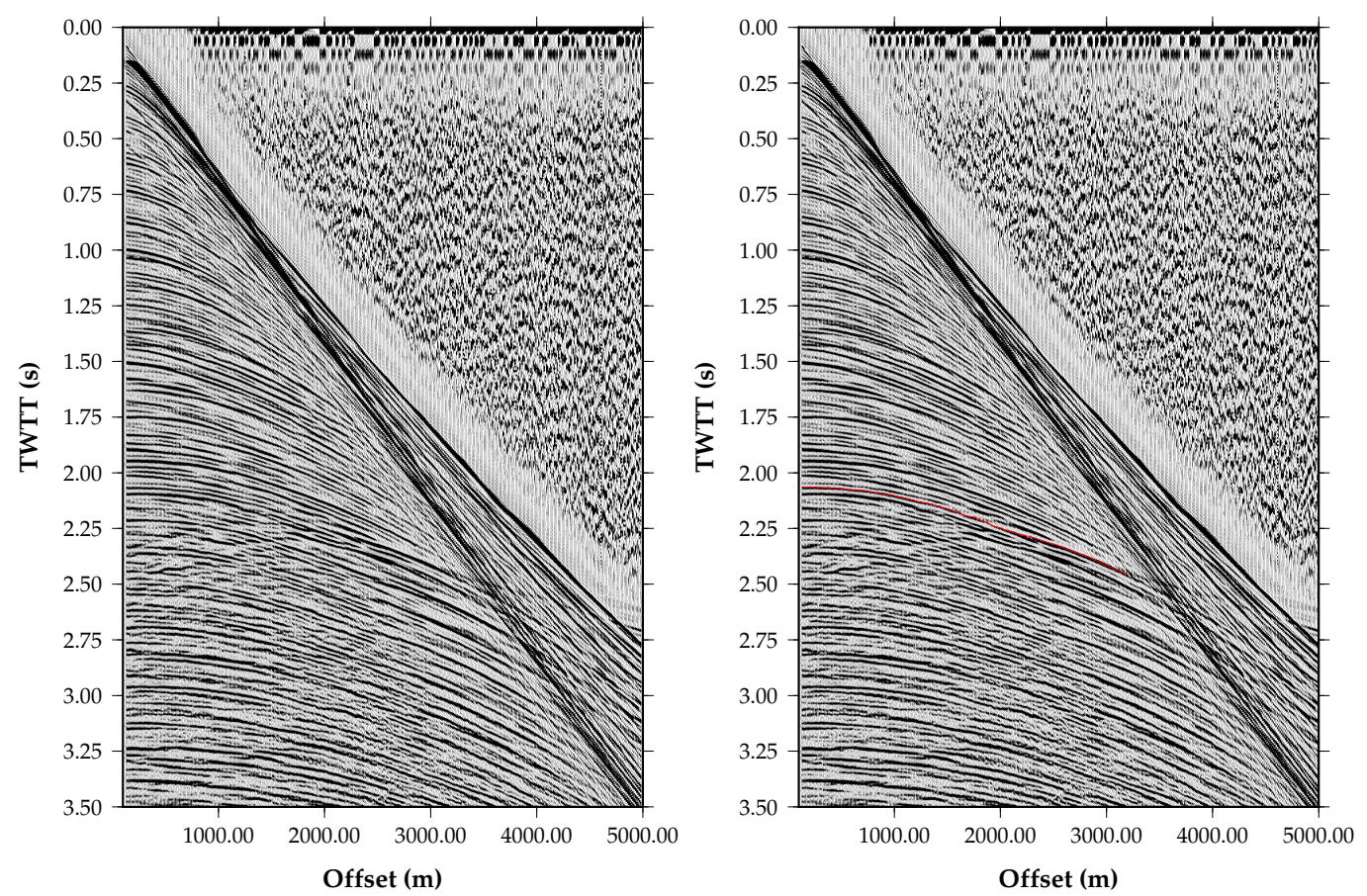

Figure B.8: Left: Multi-channel-seismic shot gather 404 from seismic reflection line SAHKE03. Right: Interpreted basement reflection overlain. Each gather has had a debias (9999 ms window length), bandpass frequency filter [10 $204060 \mathrm{~Hz}]$ and automatic gain control (500 ms window length) applied. 

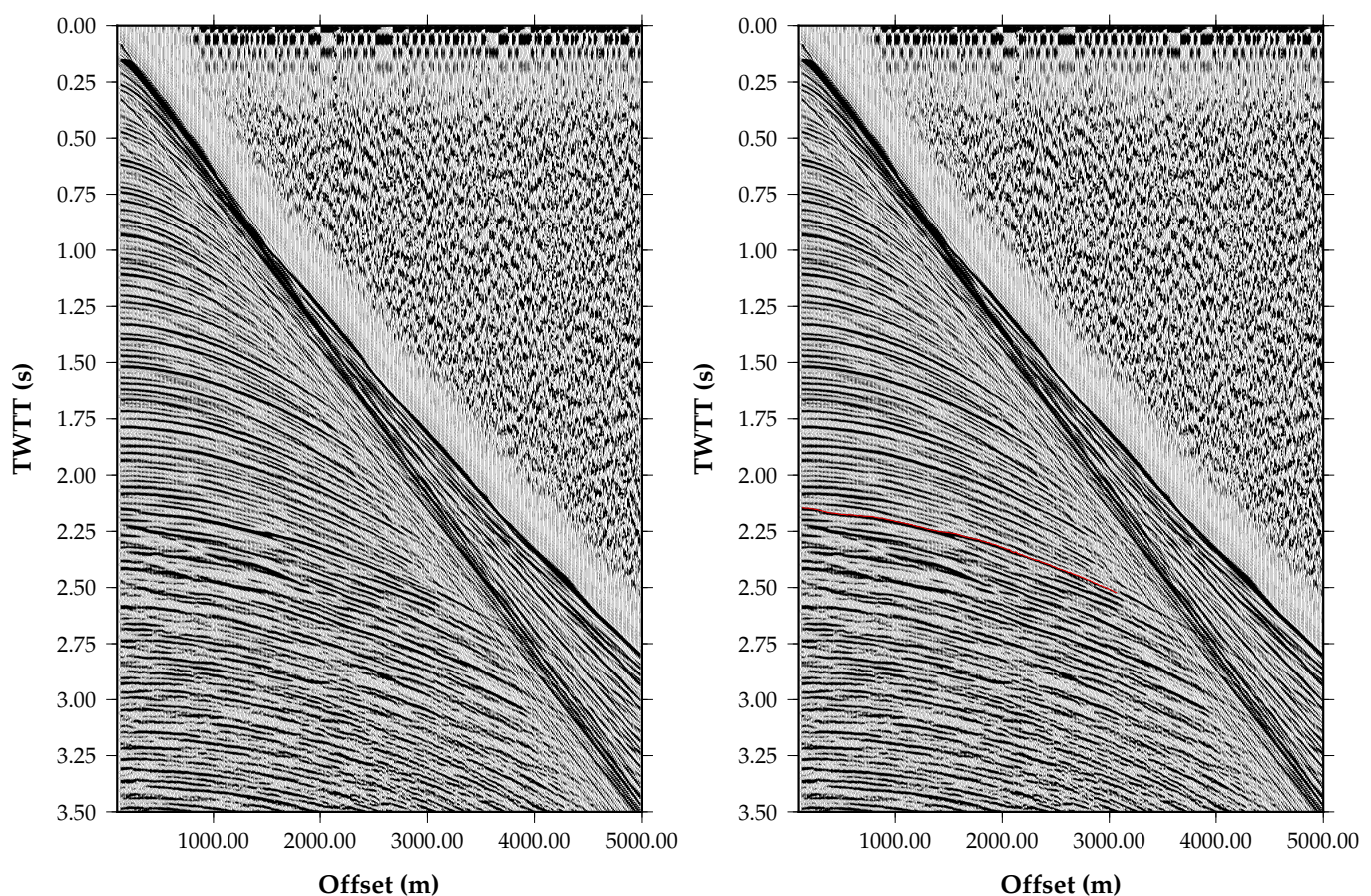

Figure B.9: Left: Multi-channel-seismic shot gather 444 from seismic reflection line SAHKE03. Right: Interpreted basement reflection overlain. Each gather has had a debias (9999 ms window length), bandpass frequency filter [10 $204060 \mathrm{~Hz}]$ and automatic gain control (500 ms window length) applied. 

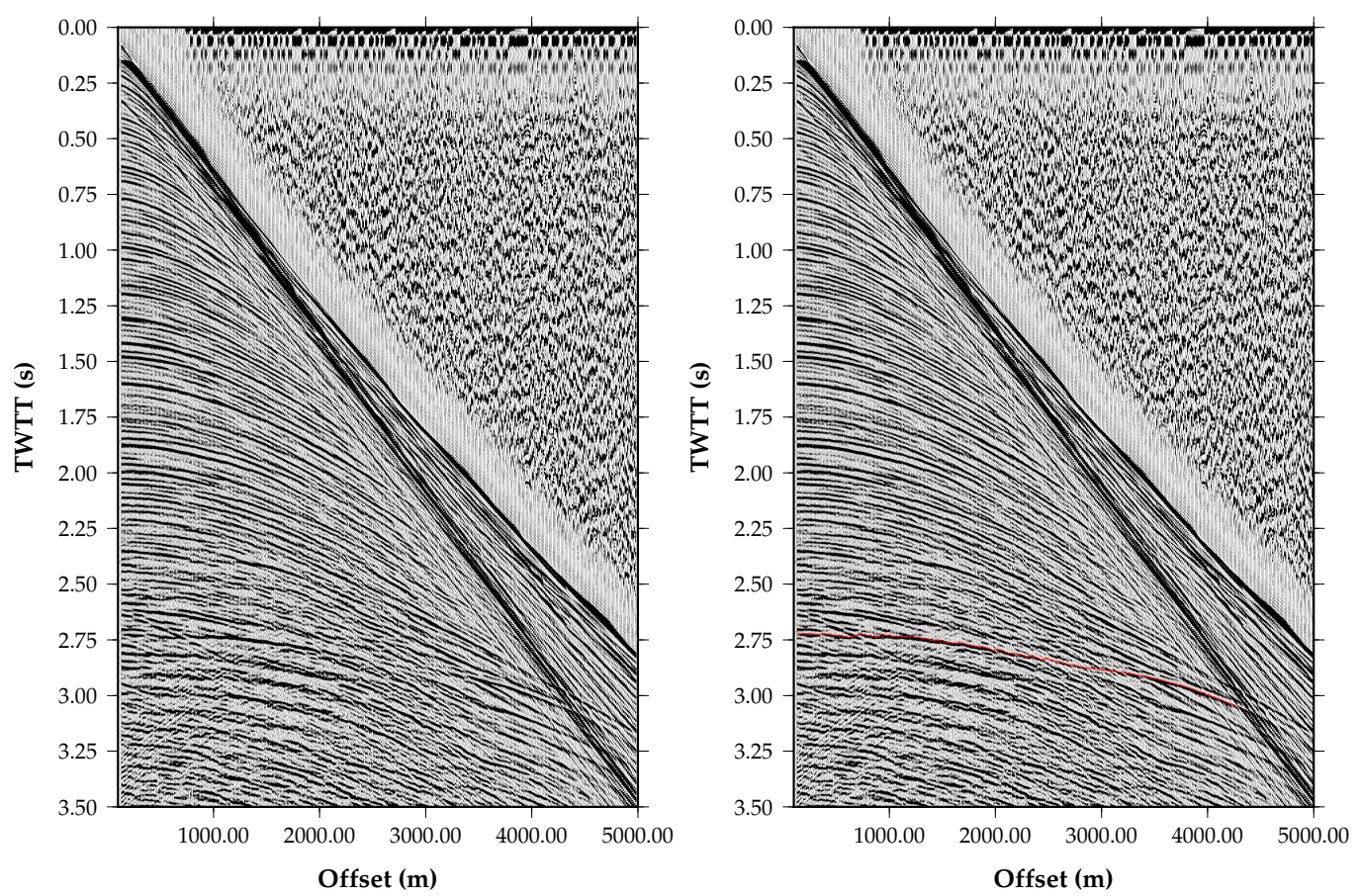

Figure B.10: Left: Multi-channel-seismic shot gather 504 from seismic reflection line SAHKE03. Right: Interpreted basement reflection overlain. Each gather has had a debias (9999 ms window length), bandpass frequency filter [10 $204060 \mathrm{~Hz}]$ and automatic gain control (500 ms window length) applied. 

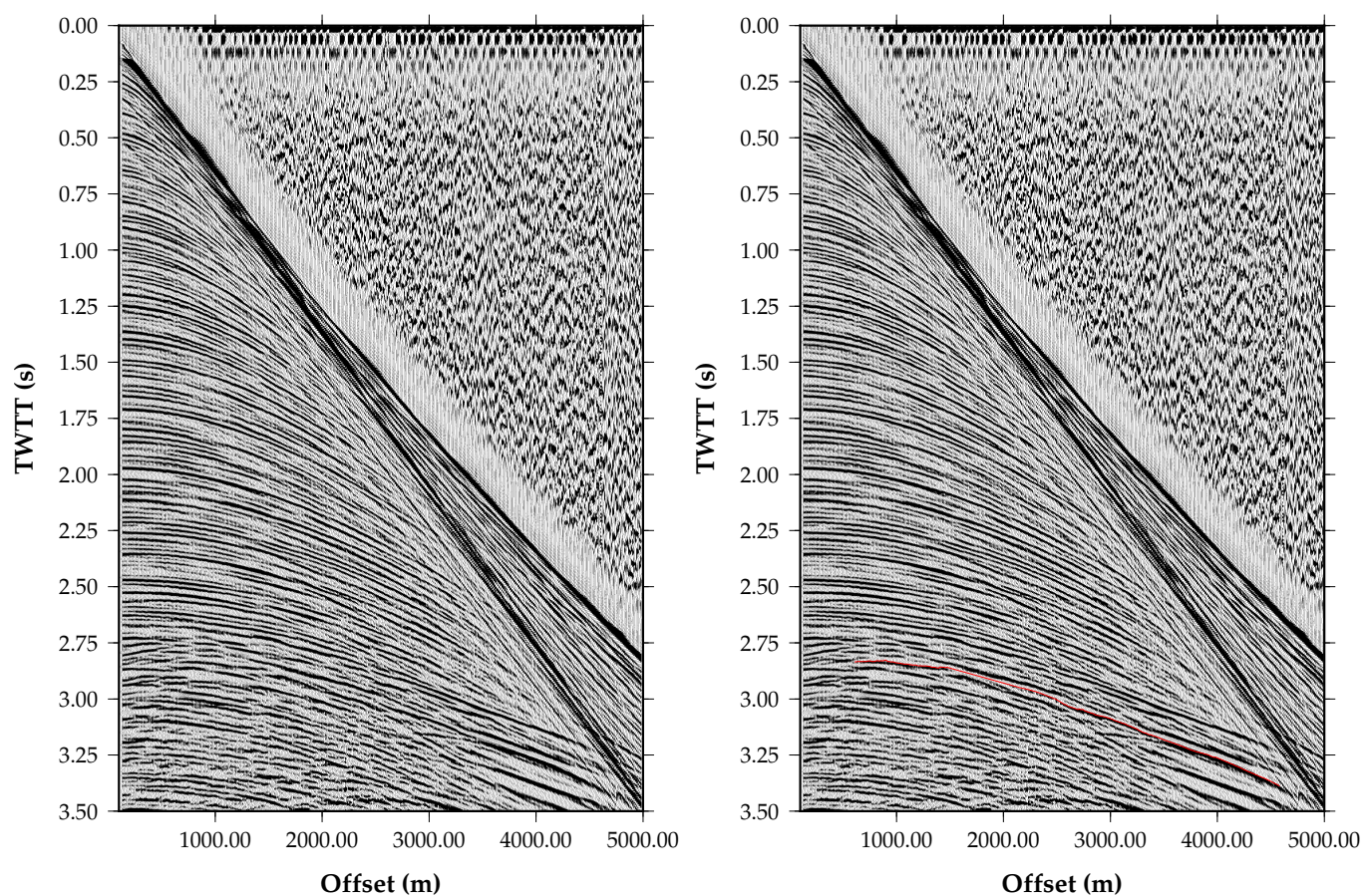

Figure B.11: Left: Multi-channel-seismic shot gather 554 from seismic reflection line SAHKE03. Right: Interpreted basement reflection overlain. Each gather has had a debias (9999 ms window length), bandpass frequency filter [10 $204060 \mathrm{~Hz}]$ and automatic gain control (500 ms window length) applied. 

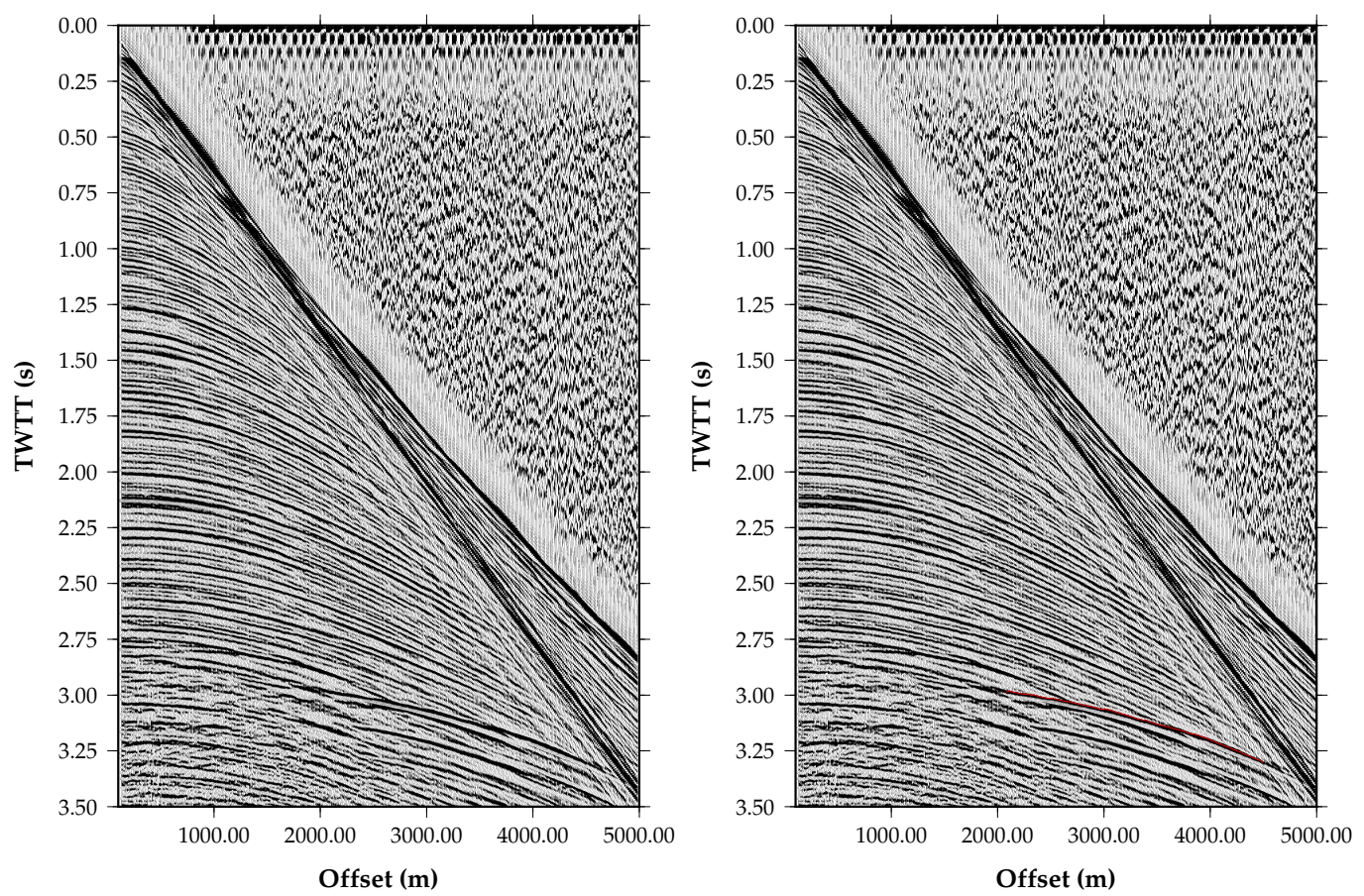

Figure B.12: Left: Multi-channel-seismic shot gather 604 from seismic reflection line SAHKE03. Right: Interpreted basement reflection overlain. Each gather has had a debias (9999 ms window length), bandpass frequency filter [10 $204060 \mathrm{~Hz}]$ and automatic gain control (500 ms window length) applied. 

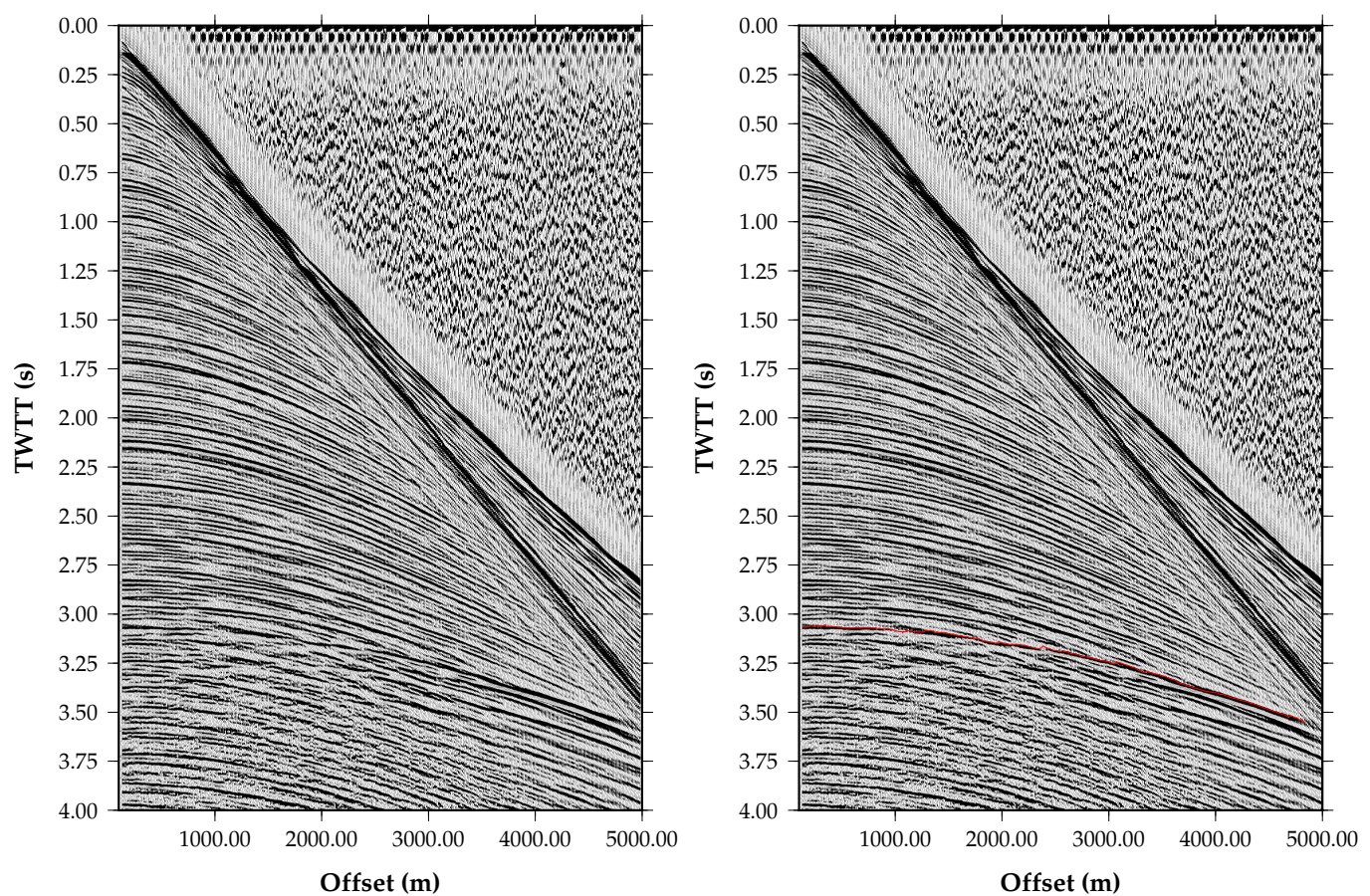

Figure B.13: Left: Multi-channel-seismic shot gather 664 from seismic reflection line SAHKE03. Right: Interpreted basement reflection overlain. Each gather has had a debias (9999 ms window length), bandpass frequency filter [10 $204060 \mathrm{~Hz}]$ and automatic gain control (500 ms window length) applied. 

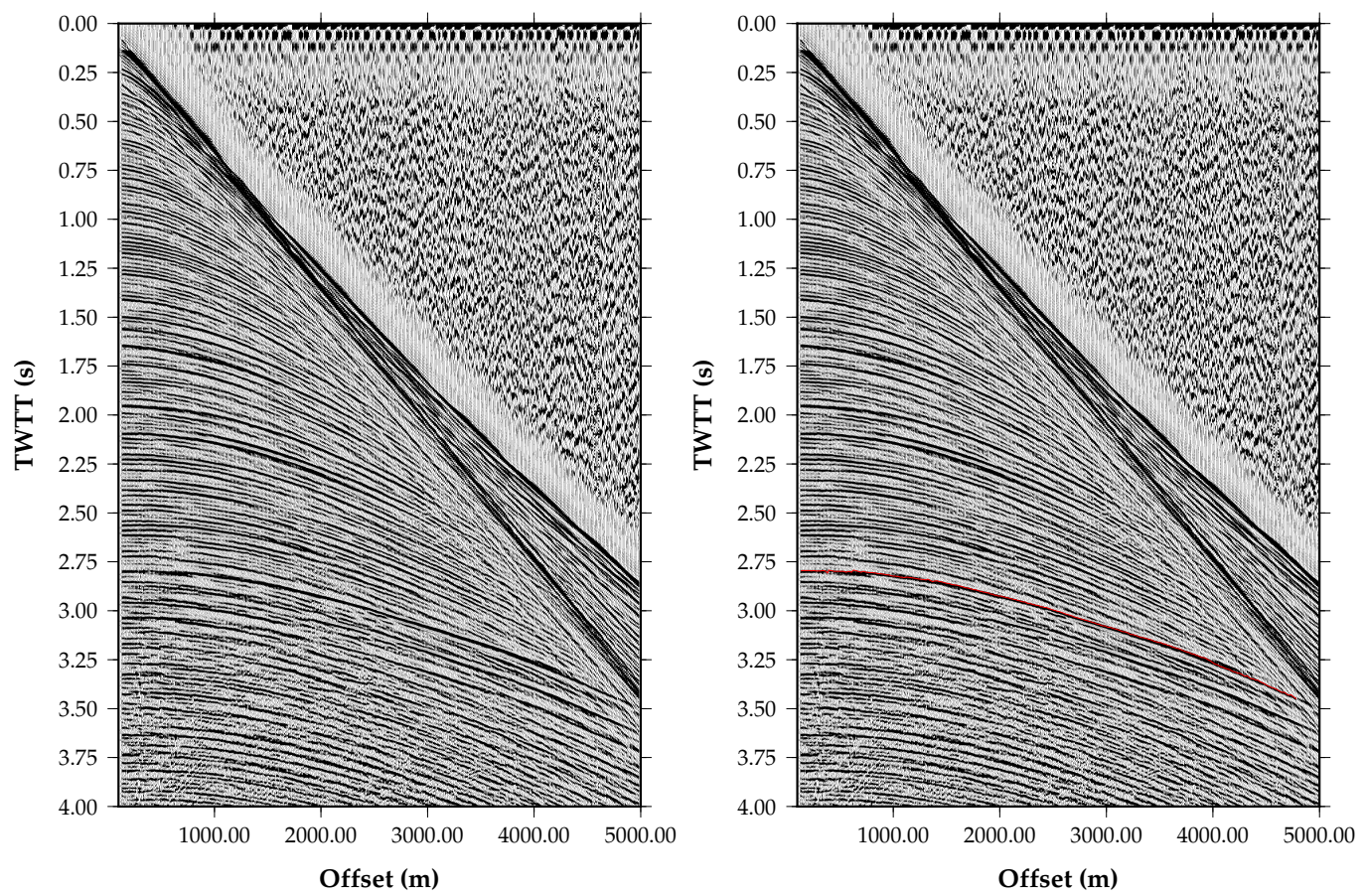

Figure B.14: Left: Multi-channel-seismic shot gather 704 from seismic reflection line SAHKE03. Right: Interpreted basement reflection overlain. Each gather has had a debias (9999 ms window length), bandpass frequency filter [10 $204060 \mathrm{~Hz}]$ and automatic gain control (500 ms window length) applied. 

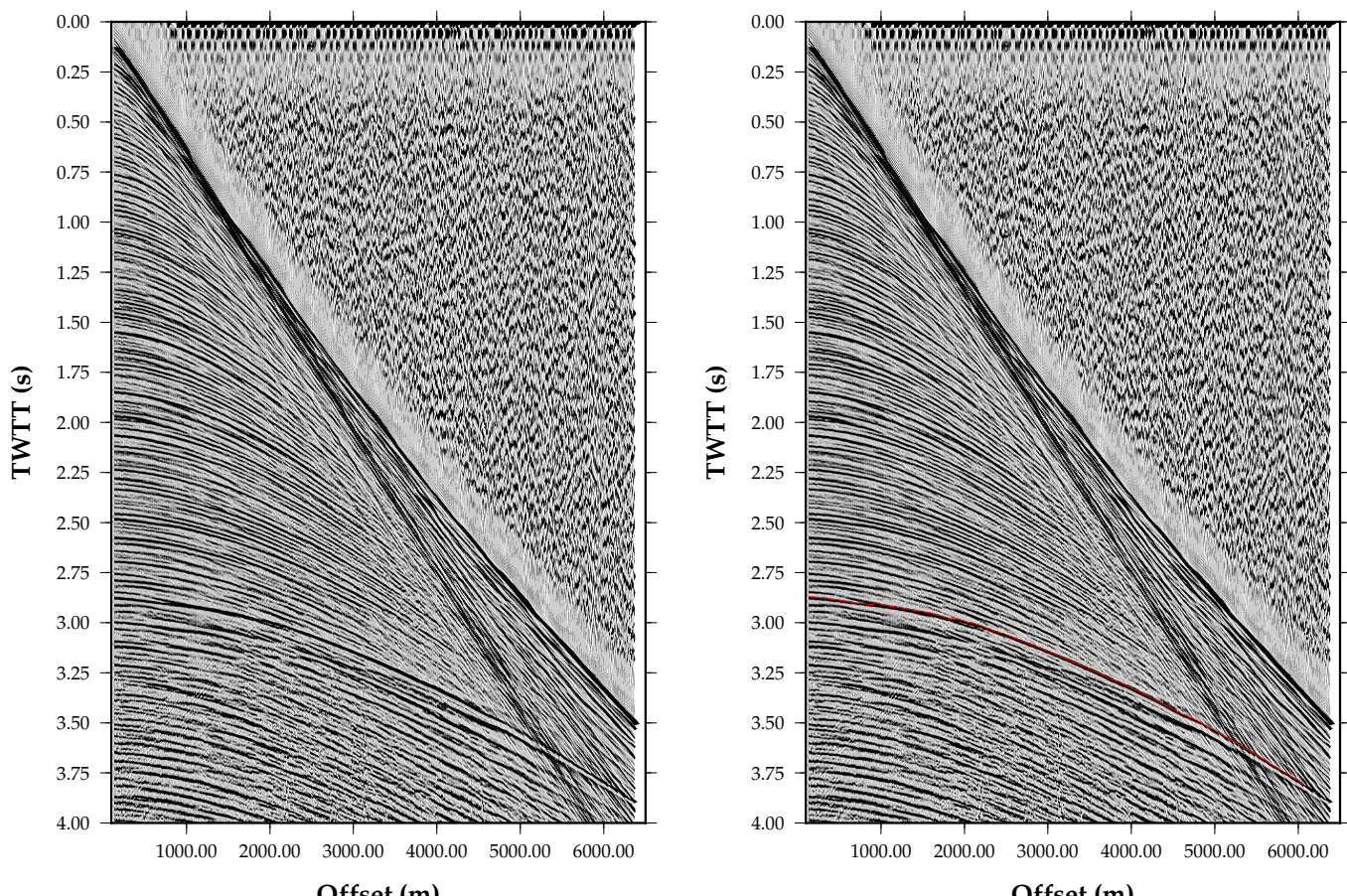

Figure B.15: Left: Multi-channel-seismic shot gather 754 from seismic reflection line SAHKE03. Right: Interpreted basement reflection overlain. Each gather has had a debias (9999 ms window length), bandpass frequency filter [10 $204060 \mathrm{~Hz}]$ and automatic gain control (500 ms window length) applied. 

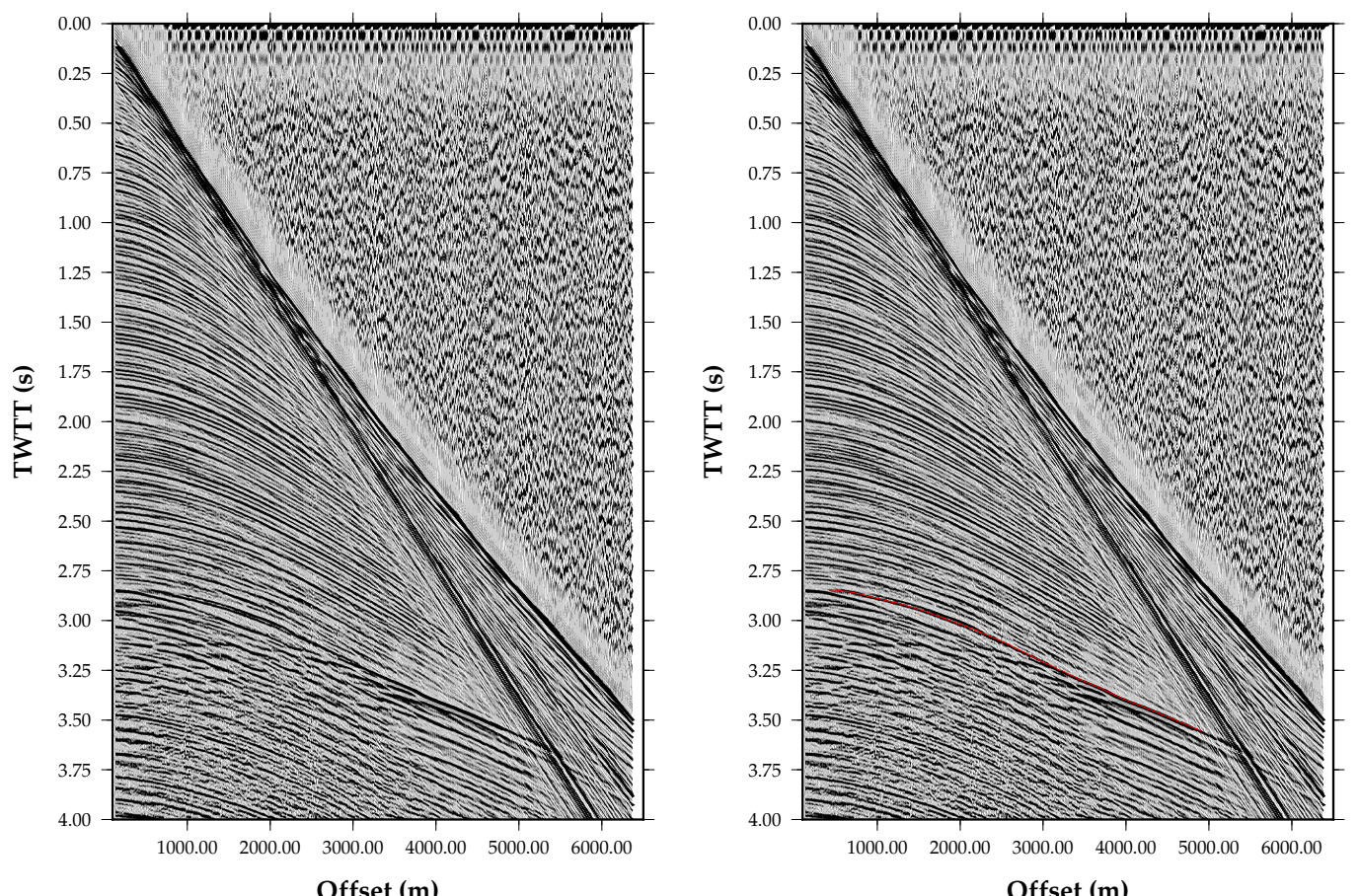

Figure B.16: Left: Multi-channel-seismic shot gather 804 from seismic reflection line SAHKE03. Right: Interpreted basement reflection overlain. Each gather has had a debias (9999 ms window length), bandpass frequency filter [10 $204060 \mathrm{~Hz}]$ and automatic gain control (500 ms window length) applied. 


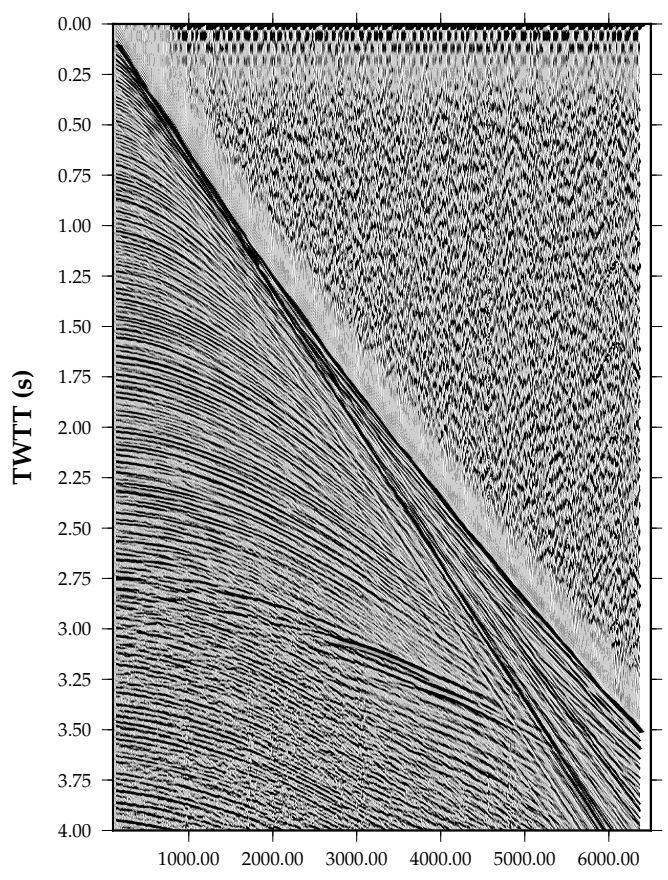

Offset (m)

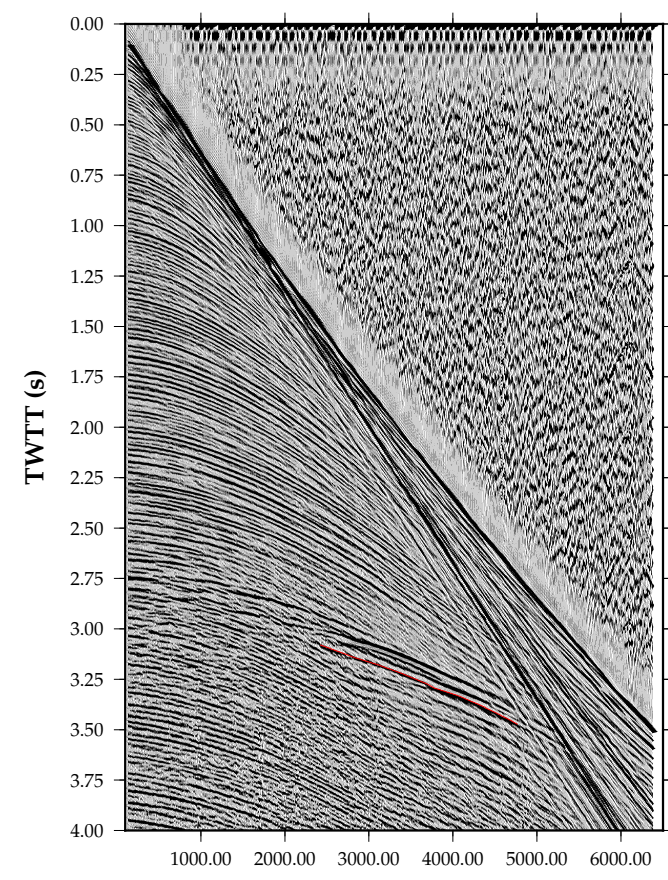

Offset (m)

Figure B.1\%: Left: Multi-channel-seismic shot gather 854 from seismic reflection line SAHKE03 Right: Interpreted basement reflection overlain. Each gather has had a full trace length debias, bandpass frequency filter [10 2040 60] Hz and automatic gain control (500 ms window length) applied. 

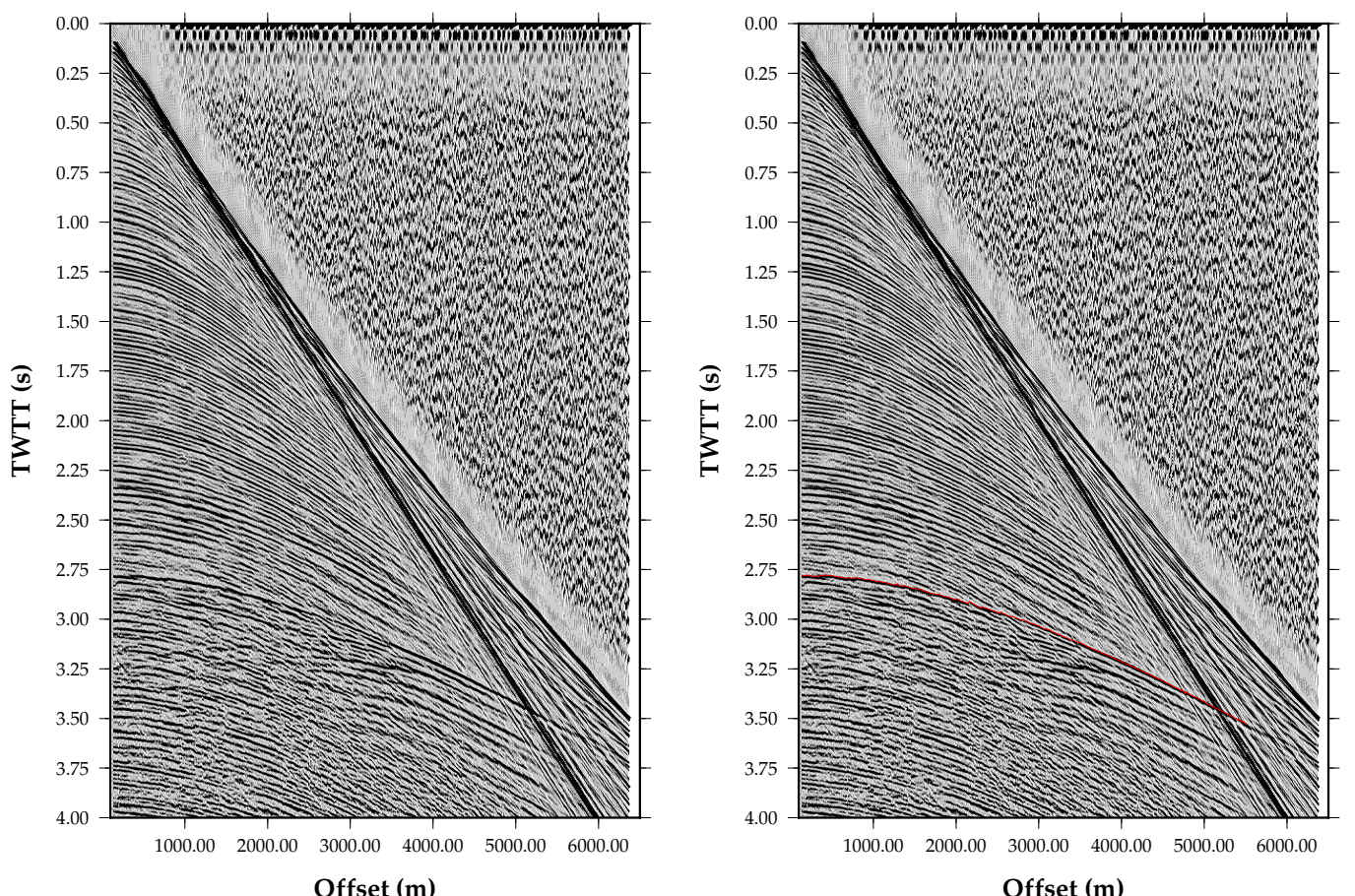

Figure B.18: Left: Multi-channel-seismic shot gather 904 from seismic reflection line SAHKE03. Right: Interpreted basement reflection overlain. Each gather has had a debias (9999 ms window length), bandpass frequency filter [10 $204060 \mathrm{~Hz}]$ and automatic gain control (500 ms window length) applied. 
B. Multi-channel-seismic shot gathers 


\section{Appendix C}

\section{Kapiti Island Static Correction}

\section{C.1 Introduction}

The southern end of the SAHKE03 MCS line passes the western side of Kapiti Island (Fig. 4.1), where the GeoNet seismometer KIW, is located at an elevation of $381 \mathrm{~m}$. Due to the proximity of KIW to the SAHKE03 MCS line, the seismic phases recorded at this station are amongst the most coherent within the SAHKE03 receiver gather dataset (Fig. 2.10). In order to include phases recorded at KIW in the SAHKE03-M model developed in Chapter 4, the location of KIW was perpendicularly projected onto the model transect, as were all other shot locations (see Section 3.7.1). The topographic elevation from each shot location was also projected onto the model transect, in order to honour raypath lengths.

However, the projection of topography from KIW onto the model transect results in a discrepancy in the ray lengths for phases emanating from all other shot points, as the projected location of KIW overlaps with receiver locations (The SAHKE03 MCS profile). It is therefore necessary that receivers at this location are fixed at sea level in order to remain consistent with the lengths of seismic rays emanating from all other shot points. This results in a discrepancy in ray length for phases recorded at KIW.

This appendix explores the magnitude of this discrepancy in terms of phase 
C. Kapiti Island Static Correction

travel-time, by estimating a static correction that accounts for both the elevation and medium velocity discrepancies that exist at KIW in model SAHKE03-M (Fig. C.2d).

\section{C.2 Static correction assumptions}

In order to develop a static correction value for each seismic phase recorded at KIW, several assumptions were made to simplify the geometric problem as described below.

\section{C.2.1 Geometric ray theory}

Seismic wave propagation is modelled using raypaths opposed to a ray front. Although this method does not fully describe some important aspects of wave propagation, it greatly simplifies analysis when using travel-time data and provides a reasonable approximation of seismic wave behavior (Stein and Wysession, 2003).

\section{C.2.2 Ray incidence angle}

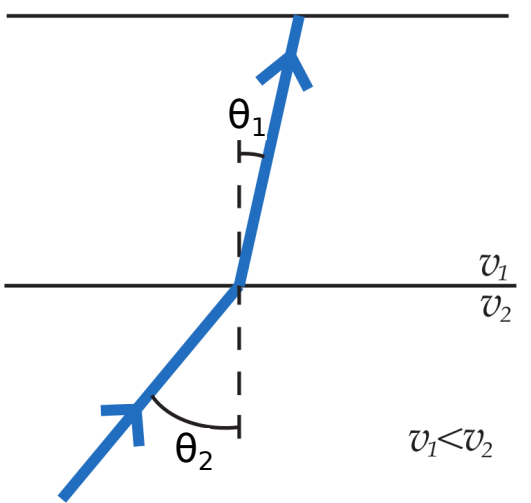

Figure C.1: Schematic sketch illustrating Snell's Law. $\theta_{1}=$ angle of incidence, $\theta_{2}=$ angle of refraction, $v_{1}=$ medium velocity in layer one and $v_{2}=$ medium velocity in layer two (after Brikke, 2010). 
The use of geometric ray theory to describe seismic wave propagation, is dependent on Snell's Law (Eq. C.1; Fig. C.1), which states that the ratio of the sines of the angles of incidence $\theta_{1}$ and refraction $\theta_{2}$ across a boundary between two media, is equivalent to the ratio of phase velocities $v_{1}$ and $v_{2}$ within the two media.

$$
\begin{array}{r}
\frac{\sin \theta_{1}}{\sin \theta_{2}}=\frac{V_{1}}{V_{2}} \\
\theta_{1}=\sin ^{-1}\left(\frac{V_{1} \cdot \sin \theta_{2}}{V_{2}}\right)
\end{array}
$$

\section{C.2.3 Kapiti Island static correction}

Static corrections are often applied to onshore seismic data in order to normalise seismic traces by removing the effect of irregular topography and sedimentary fill thickness variations on phase arrive time.

In crustal scale surveys, this usually involves applying equation C.1 to a scenario in which seismic waves emerge from the upper crust and refract into overlying sedimentary fill. In this case, the large velocity contrast between $v_{1}$ (sedimentary fill $V_{p}$ e.g. $2.5 \mathrm{kms}^{-1}$ ) and $v_{2}$ (upper crustal $V_{p}$ e.g. $6 \mathrm{kms}^{-1}$ ), results in small refraction angle $\theta_{1}$, such that, waves emerge near vertical. Hence, to good approximation it can assumed that both crustal scale wideangle reflections and refractions travel vertically through sedimentary fill. This simplifies the geometric problem as ray lengths become equal to unit thickness.

However, this assumption is invalid at station KIW, which is located on Mesozoic greywacke basement rock. Thus, waves are not refracted to near vertical incidence near the surface (Fig. C.2). For this reason, the length over which each static correction is calculated is dependent on ray takeoff angle, as measured by raytracing of each phase (see section C.3.1). 
C. Kapiti Island Static Correction

\section{C.3 Correction strategy}

This section describes the strategy used to calculate each static correction. Numerically the application of a static correction can be described as:

$$
T_{c o r r}=T_{o b s}+T_{c f}
$$

Where $T_{\text {corr }}$ is the corrected travel time, $T_{\text {obs }}$ is the observed travel time and $T_{c f}$ is a static correction factor. In this case, $T_{c f}$ comprises of two components, an elevation correction $T_{c f_{e l v}}$ and a medium velocity correction $T_{c f_{v e l}}$. The value of each correction is dependent on the thickness and velocity of the mediums each ray samples beneath KIW. $T_{c f_{e l v}}$ and $T_{c f_{v e l}}$ were determined by creating a crustal velocity model using SAHKE03 MCS data and upper crustal refraction arrivals (Pg) recorded at KIW (Fig. C.2). Simple geometric equations were then applied to determine a solution for each individual ray, as described below.

\section{C.3.1 Forward model of KIW}

In order to estimate the upper crustal velocity structure sampled by wave phases recorded at KIW, an upper crustal velocity model was developed by forward modelling the onshore/offshore upper crustal refraction phase (Pg) recorded at KIW (Fig. C.2). This model incorporated the sedimentary basin velocity model developed using MCS data in Section 4.2.1.2. From figure C.2, a Vp gradient of $5.2-5.28 \mathrm{kms}^{-1}$ is estimated between the surface and sea level for greywacke basement rock that outcrops on Kapiti Island. Below this datum, a second Vp gradient of $5.28-5.36 \mathrm{kms}^{-1}$ to a depth of $0.42 \mathrm{~km}$ (the depth to basement determined using MCS data in the SAHKE03-M) is derived. From these velocity gradients, constant velocities of $5.24 \mathrm{kms}^{-1}$ and $5.32 \mathrm{kms}^{-1}$ are used for calculating the elevation and medium velocity static corrections discussed below. 

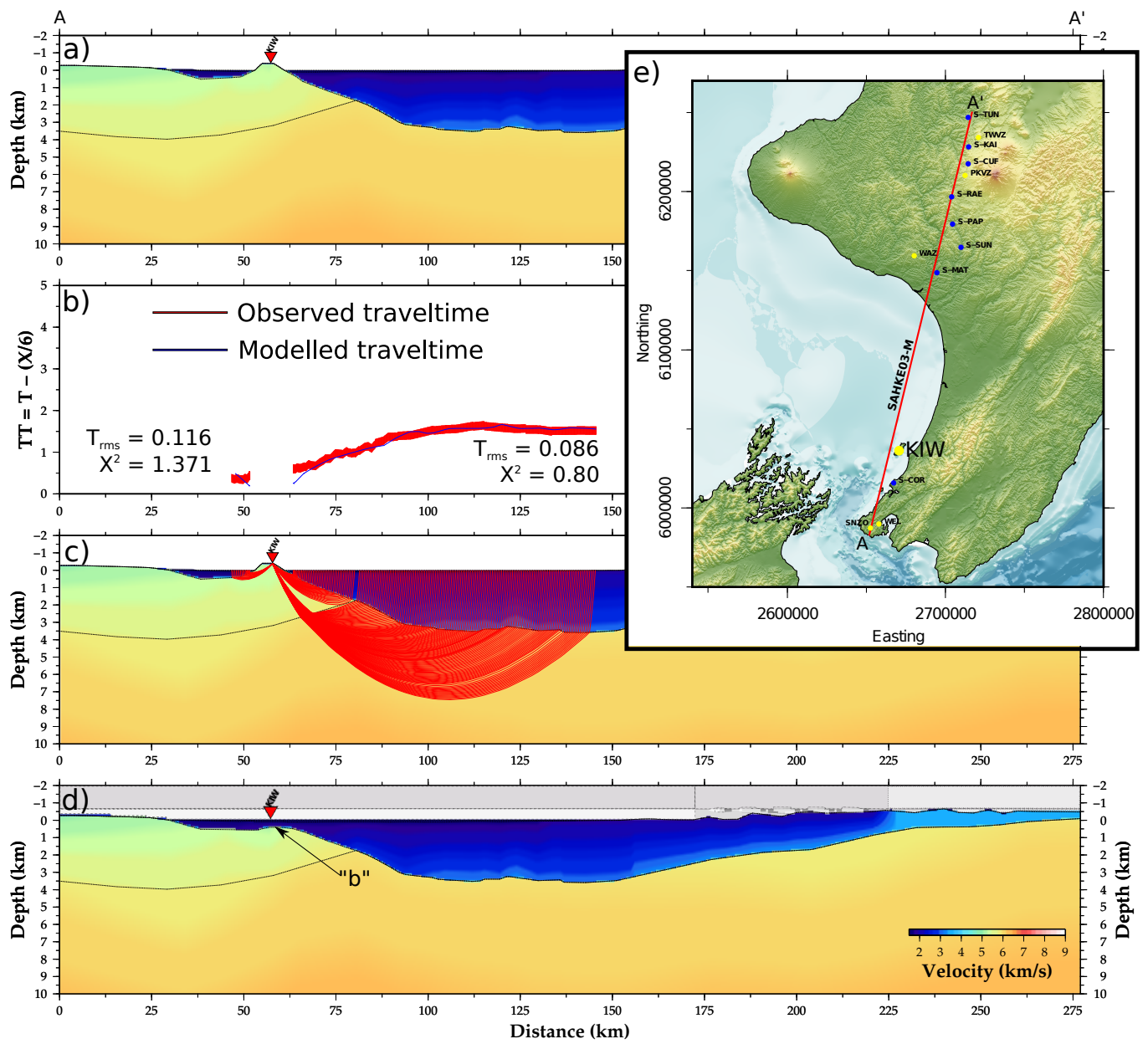

Figure C.2: (a) $V_{p}$ Model KIW01. This model was constructed using the SAHKE03 sedimentary velocity model developed in Section 4.2.1.2 and by forward modelling onshore/offshore upper crustal refractions recorded at station KIW, from the shooting of SAHKE03 MCS line. (b) Travel-time plot showing observed (red) and model (blue) travel-times. Travel time pick errors are $100 \mathrm{~ms}$. (c) Model KIW01 showing a selection of modelled raypaths (red) (Note the non-vertical ray geometry near KIW compared to rays travelling through the sedimentary section. (d) $V_{p}$ Model SAHKE03-M as developed in Chapter 4 using all SAHKE03 receiver gathers. Note the variation in velocity structure between this model and KIW01 (a), also note "b" the depth to basement below KIW, as described in the text. (e) Location map showing the spatial relationship between station KIW (labelled) and the SAHKE03 MCS transect (dashed red line) and SAHKE03-M model transect (solid red line).

\section{C.3.2 Elevation traveltime correction}

The elevation discrepancy between the true location of KIW and its location once projected onto the SAHKE03 $V_{p}$ model is - $381 \mathrm{~m}$, a static correction that accounts for this discrepancy was calculated using a layer-stripping ap- 
C. Kapiti Island Static Correction

proach. Essentially, the travel time of each wave recorded at KIW is adjusted by factor equal to the transit travel time of a ray passing through the top $381 \mathrm{~m}$ of model KIW01 (Fig. C.2) at a constant velocity of $5.24 \mathrm{kms}^{-1}$. The length $L$ of each ray through the top $381 \mathrm{~m}$ of model KIW01 was determined using ray takeoff angle $\theta$, and is calculated by:

$$
L=\frac{381}{\cos \theta}
$$

Takeoff angles calculated for refracted rays traveling north and south of KIW range from $13.4-19.9^{\circ}$ and $16.4-17.5^{\circ}$ from the vertical respectively. It assumed that these bending waves can be approximated as straight line rays over the $381 \mathrm{~m}$ required to reach the elevation static horizon.

Equation C.3 yields $L$ values of 391.7 - $405.2 \mathrm{~m}$ and 398 - $399.5 \mathrm{~m}$ for rays traveling north and south of KIW respectively. The elevation correction factor $T_{c f_{e l v}}$ for each ray is then given by:

$$
T_{c f_{e l v}}=L / 5240 \mathrm{~ms}^{-1}
$$

This yields elevation correction values of $74.75-77.32 \mathrm{~ms}$ and $75.95-76.24$ ms for rays travelling north and south of KIW respectively.

\section{C.3.3 Medium velocity traveltime correction}

A discrepancy between the true velocity field immediately below KIW and the velocity field required by model SAHKE03-M also exists. This is because rays from all other shots are required to sample sediment and ocean velocities, opposed to basement rock, at the projected location of KIW. To account for this discrepancy, a correction was developed that accounts for the difference in medium velocities within models KIW01 and SAHKE03-M to depth "b" (the depth to basement rock below KIW in model SAHKE03-M 
(Fig. C.2d)).

Within model SAHKE03-M, basement rock occurs at a depth of $420 \mathrm{~m}$ beneath the projected location of KIW, consistent with the SAHKE03 MCS reflection data (Fig. C.2d). Above this interface, the model consists of a $340 \mathrm{~m}$ sedimentary layer with an average $V_{p}$ of $1.85 \mathrm{kms}^{-1}$ overlain by an $80 \mathrm{~m}$ ocean water column of $V_{p}$ of $1.5 \mathrm{kms}^{-1}$. Hence, an additional travel-time segment $T_{c f_{v e l}}$ exists in model SAHKE03-M due the difference in velocity between ray travel-time through the sediment and ocean water layers $T_{\text {sed }}+T_{\text {ocean }}$ and through the basement rock $T_{\text {basement }}$.

$V_{p}$ of basement rock at these depths was derived from model KIW01, and yield an average of $5.32 \mathrm{kms}^{-1}$ down to depth "b" . Following section C.3.2, the lengths of each ray through the ocean, sediment and basement layers are given by:

$$
\begin{gathered}
L_{\text {sed }}=\frac{360}{\cos \theta} \\
L_{\text {ocean }}=\frac{80}{\cos \theta} \\
L_{\text {basement }}=\frac{420}{\cos \theta}
\end{gathered}
$$

It follows that the transit travel-time of each ray through each layer is equal to:

$$
\begin{gathered}
T_{\text {sed }}=\frac{L_{\text {sed }}}{1850 \mathrm{~ms}^{-1}} \\
T_{\text {ocean }}=\frac{L_{\text {ocean }}}{1500 \mathrm{~ms}^{-1}} \\
T_{\text {basement }}=\frac{L_{\text {basement }}}{5320 \mathrm{~ms}^{-1}}
\end{gathered}
$$

The total medium velocity static correction $T_{c f_{v e l}}$ is then given by:

$$
T_{c f_{\text {vel }}}=\left(T_{\text {sed }}+T_{\text {ocean }}\right)-T_{\text {basement }}
$$

Using the range of takeoff angles discussed above in section C.2.2, equation C.11 yields $T_{c f_{v e l}}$ values of $173.66-179.68 \mathrm{~ms}$ and $175.31-177.12 \mathrm{~ms}$ for 
C. Kapiti Island Static Correction

rays travelling north and south of KIW respectively.

\section{C.3.4 Application of corrections}

The total correction factor to to be applied to each rays traveltime is given by:

$$
T_{c f}=T_{c f_{v e l}}-T_{c f_{e l v}}
$$

Since $T_{c f_{v e l}}$ adds an additional travel-time segment, while $T_{c f_{e l v}}$ removes a travel-time segment. Using the results from sections C.3.2 and C.3.3, equation C.12 yields total static correction values of $98.91-102.36 \mathrm{~ms}$ and 99.36 - $100.88 \mathrm{~ms}$ for rays travelling north and south of KIW respectively. Finally, each travel-time pick is adjusted according to equation C.13:

$$
T_{\text {corr }}=T_{o b s}-T_{c f}
$$

For near offset $(5.6-20 \mathrm{~km})$ arrivals north of KIW, with travel-times of 1.422 $\mathrm{s}-4.239 \mathrm{~s}$, the correction factor $T_{c f}$ adds an additional travel- time of 2.33 $6.71 \%$ to ray travel-time. For the near offset arrivals $(5.6-10 \mathrm{~km})$ recorded south of KIW with travel-times of $(1.46-2.10 \mathrm{~s})$ correction factor $T_{c f}$ adds an additional travel-time of $4.7-6.9 \%$. For further offsets and later arriving phases the additional travel-time added by $T_{c f}$ becomes an increasingly smaller fraction of total travel-time. Nonetheless, these correction values are on the order of average wavelet pick error $(100 \mathrm{~ms})$. Therefore, without the application of these static corrections, fitting arrivals recorded at KIW would require perturbation of the SAHKE03-M model, and result in error of model parameters along these ray paths. 